Pós-Graduação em

Desenvolvimento Sustentável

\title{
A Estratégia do Programa Áreas Protegidas da Amazônia para avaliar a Efetividade das Unidades de Conservação
}

Daniela de Oliveira e Silva

Tese de Doutorado

Brasília - DF, setembro/2016

Universidade de Brasília

Centro de Desenvolvimento Sustentável 


\section{A Estratégia do Programa Áreas Protegidas da Amazônia para avaliar a Efetividade das Unidades de Conservação}

Daniela de Oliveira e Silva

Matrícula: 12/0001373

Orientador: José Luiz de Andrade Franco

Co-orientador: Fernando Paiva Scardua

Brasília, Setembro de 2016 
OLIVEIRA, DANIELA

A Estratégia do Programa Áreas Protegidas da Amazônia para avaliar a Efetividade das Unidades de Conservação, 212p., (UnB

- CDS, Doutora, Política e Gestão Ambiental, 2016).

Tese de Doutorado - Universidade de Brasília. Centro de Desenvolvimento Sustentável.

1. Unidades de Conservação

2. Efetividade de Gestão

3. Programa Arpa

4. Biodiversidade

5. Conservação

6. Áreas Protegidas

I. UnB-CDS

II. Título (série)

É concedida à Universidade de Brasília permissão para reproduzir cópias desta dissertação e emprestar ou vender tais cópias somente para propósitos acadêmicos e científicos. O autor reserva outros direitos de publicação e nenhuma parte desta dissertação de mestrado pode ser reproduzida sem a autorização por escrito do autor.

Daniela de Oliveira 


\section{UNIVERSIDADE DE BRASÍLIA \\ CENTRO DE DESENVOLVIMENTO SUSTENTÁVEL}

\section{A Estratégia do Programa Áreas Protegidas da Amazônia para avaliar a Efetividade das Unidades de Conservação \\ Daniela de Oliveira e Silva}

Tese de doutorado submetida ao Centro de Desenvolvimento Sustentável da Universidade de Brasília, como parte dos requisitos necessários para a obtenção do Grau de Doutor em Desenvolvimento Sustentável, área de concentração em Política e Gestão Ambiental.

Aprovado por:

José Luiz de Andrade Franco, Doutor (UnB)

(Orientador)

Fernando Paiva Scardua, Doutor (UnB)

(Co-orientador)

Cristiane Gomes Barreto, Doutora (UnB/CDS)

(Examinador Interno)

Vivian da Silva Braz, Doutora (UnB/CDS)

(Examinador Interno)

Roseli Senna Ganem, Doutora (Câmara dos Deputados)

(Examinador Externo)

Carlos Christian Della Giustina, Doutor (Uni Evangélica)

(Examinador Externo)

Brasília, Setembro de 2016 
O esforço empreendido no processo de busca e absorção do conhecimento para a conclusão desta dissertação não foi um processo solitário. Várias pessoas, amigos, parentes, colegas de trabalho e de curso me ajudaram, direta e indiretamente, a tornar este trabalho uma realidade. Quero agradecer aqui a todos e em especial:

Ao amigo, professor, e orientador José Luiz Franco pelo incentivo, confiança, conselho, orientação e, sobretudo, por insistir diariamente que essa etapa chegasse ao fim, me impedindo de desistir. Zé muito obrigado, essa caminhada que começou em 2010, ainda no mestrado, só seria possível sob a sua orientação.

Ao amigo, professor, e co-orientador Fernando Scardua pelo incentivo, confiança, franqueza e pelos conselhos para reorientação desta Tese.

Aos professores do Centro de Desenvolvimento Sustentável da UnB pelas ricas discussões e por demonstrar sempre grande entusiasmo com a área acadêmica, em especial a professora Doris Sayago e ao professor Fabiano Toni pelo incentivo para conclusão desta etapa.

Aos colegas de trabalho do WWF-Brasil, em espacial a Mariana Napolitano Ferreira, pela supervisão e orientação profissional que me permitiu participar da equipe técnica que acompanhou as discussões e os estudos para elaboração do novo protocolo de monitoramento da efetividade de gestão, concebido pelo ICMBio, sob a orientação do Felipe Rezende, a quem também agradeço a generosidade por compartilhar informações preciosas durante todo o processo.

Ao Carlos Scaramuzza, Mauro Armelin e Marco Lentini, meus chefes em diferentes momentos da minha passagem pelo WWF-Brasil, pela oportunidade de acompanhar, como parte da equipe, a Iniciativa Arpa para Vida responsável pela estruturação da terceira fase do Programa Arpa.

Aos membros da banca avaliadora pela paciência, compreensão e orientações para a reorganização desta Tese

A amiga, comadre e eterna chefe, Therese Hofmann Gatti, pelo carinho, amizade e por ser sempre grande incentivadora da caminhada acadêmica.

À minha família, pelo carinho e apoio constantes.

Ao Garcia, Amor Meu, pelo carinho, compreensão pelos momentos de ausência e pela enorme paciência sempre. 
As áreas protegidas cobrem, no mundo todo, $15,4 \%$ da superfície terrestre e das ilhas marinhas, e são de longe a maior estratégia de conservação da biodiversidade. No Brasil, as unidades de conservação (UCs) são a principal estratégia de conservação e, nas últimas duas décadas, foram desenvolvidos marcos legais que orientam e disciplinam a implementação dessas áreas: a ratificação da CDB, a instituição da Lei do Sistema Nacional de Unidades de Conservação da Natureza/SNUC (Lei 9.985, de 18 de julho de 2000), a adesão ao Plano de Trabalho sobre Áreas Protegidas da CDB (Decisão V/28) e o processo de elaboração do Plano Estratégico Nacional de Áreas Protegidas/PNAP (Decreto 5.758/06). Estes marcos contribuíram para que o governo brasileiro se compromete-se em ampliar o esforço de monitoramento da conservação, de forma a demonstrar que as UCs são geridas de maneira efetiva, equitativa, ecologicamente representativas e satisfatoriamente interligadas. O SNUC é representado por uma área de 155 milhões de hectares que corresponde a 17,2\% do território nacional, com forte desequilíbrio entre as proporções das áreas das UCs de uso sustentável (102.318.900 hectares) e as áreas das UCs de proteção integral (52.800,700 hectares). Em relação à representatividade dos biomas, só o bioma Amazônia representa 72 \% do total de UCs do SNUC e o Programa Áreas Protegidas da Amazônia (Arpa) - maior programa de conservação de florestas tropicais sob a forma de UCs - abrange $88 \%$ da área total das UCs de proteção integral do bioma. Para avaliar o sucesso da estratégia de conservação por meio de UCs, o Brasil tem utilizado diferentes abordagens, com foco na extensão e localização das áreas das UCs, em função da representatividade por bioma; na manutenção da integridade da paisagem; na efetividade de gestão e contribuição para a conservação da biodiversidade. A presente tese trata da estratégia de avaliação da efetividade de gestão do Programa Arpa, e demonstra que boa parte das avaliações de efetividade de gestão implementadas no Brasil, e sobretudo no Arpa, são avaliações de eficácia de gestão, pois tem por objetivo avaliar os processos (os meios) e os resultados em relação a performance de gestão, sem priorizar a avaliação de impactos. Foram identificadas como avaliações de efetividade aquelas cujo objetivo e o instrumental analítico permite avaliar as evidencias de conservação e do uso sustentável dos recursos naturais. O Arpa, ao logo da sua execução molda e é moldado por uma estratégia de avaliação que tem como foco os resultados gerenciais e de performance do Programa. Embora em sua fase atual, a Fase III, o Arpa tenha evoluído para a separação clara entre os instrumentos de avaliação da performance de gestão (eficácia) e os instrumentos de avaliação de efetividade (impacto de conservação e usos dos recursos naturais), com a institucionalização do Rappam e a adoção do Sistema de Análise e Monitoramento da Gestão (SAMGe), a avaliação de impacto de conservação tem como foco o levantamento de dados no âmbito da paisagem e o estabelecimento de protocolos para o monitoramento de alvos de conservação das UCs. Não são estabelecidas, no entanto, formas de aferição para todos os indicadores, no nível das UCs ou no nível do sistema. Isto reforça a necessidade de se discutir, elaborar e implementar estratégias que, de fato, avaliem a efetividade de gestão das UCs e do sistema como um todo.

Palavras Chave: Unidades de Conservação, Efetividade de Gestão, Programa Áreas Protegidas da Amazônia (Arpa) 
Protected areas cover, worldwide, $15.4 \%$ of the land surface and sea islands, and are by far the largest biodiversity conservation strategy. In Brazil, protected areas, as known as "Unidades de Conservação (UCs)", are the main conservation strategy and in the last two decades, legal frameworks have been developed to guide and regulate the implementation of these areas: CDB ratification, National System of Units Law Nature Conservation/SNUC (Law 9985/2000) institution, Work Plan of the CBD Protected Areas (Decision V/28) adherence and the process of preparation of the National Strategic Plan for Protected Areas/PNAP (Decree 5,758/06). These milestones have contributed to the Brazilian government is committed to expanding the monitoring efforts of conservation, in order to demonstrate that protected areas are managed effectively, equitably, ecologically representative and well connected. The SNUC is represented by an area of 155 million hectares corresponding to $17.2 \%$ of the country, with a strong imbalance between the proportions of the areas of sustainable use (102,318,900 hectares) and the areas of strict protection $(52,800,700$ hectares). Regarding the representation of biomes, only the Amazon region represents $72 \%$ of total protected areas of SNUC and the Amazon Region Protected Areas Program (Arpa) - largest tropical forest conservation program in the form of protected areas - covering $88 \%$ of the total area the strict protection protected areas in the region. To evaluate the success of the conservation strategy through protected areas, Brazil has used different approaches, focusing on the extent and location of the protected areas, on the basis of representation by biome; in landscape integrity maintenance; the effectiveness of management and contribution to biodiversity conservation. This thesis deals with the evaluation strategy of the effectiveness of management of the Arpa, and demonstrates that much of the management effectiveness assessments implemented in Brazil, and especially in Arpa are management effectiveness evaluations, it has to evaluate the processes (the media) and the results in relation to performance management, without prioritizing the impact assessment. They were identified as effectiveness assessments those whose objective and analytical tools allows us to evaluate the evidence for the conservation and sustainable use of natural resources. Arpa, the logo of its implementation shapes and is shaped by an evaluation strategy that focuses on the management results and program performance. Although in its current phase, Phase III, Arpa evolved into the clear separation between the management of performance assessment tools (efficacy) and the effectiveness of assessment instruments (conservation impact and uses of natural resources), with the institutionalization of Rappam and the adoption of the Analysis and Monitoring Management System (SAMGe), the evaluation of conservation impact is focused on data collection in the context of the landscape and the establishment of protocols for the monitoring of protected areas conservation targets. are not established, however, forms of measurement for all indicators at the level of protected areas or at the system level. This reinforces the need to discuss, develop and implement strategies that, in fact, evaluate the effectiveness of management of protected areas and the system as a whole.

Keywords: Protected Areas, Conservation Units, Management Effectiveness, Amazon Region Protected Areas Program (Arpa) 


\section{RESUMÉ}

Les aires protégées couvrent, dans le monde, $15,4 \%$ de la surface terrestre et des îles marines, et sont la plus importante stratégie pour salvaguardé la biodiversité. Au Brésil, ces sites naturels, qui s'appellent "unidades de conservação - unités de conservation (UC)", constituent la pierre angulaire pour l'atteinte des objectifs de maintien et d'utilisation durable de la biodiversité. Face à la nécessité d'améliorer la situation des aires protégées, le gouvernement, dans les deux dernières décennies, a développés d'un ensemble de príncipes, d'orientations et de cadres juridiques pour guider et réguler cette matiére: la ratification de la Convention sur la Diversité Biologique (CDB), l'institution du Système nationale de conservation de la Nature/ SNUC (creé par le Loi 9985/2000), l' adoption du programme de travail sur les aires protégées de la CDB (Décision V/28) et l'élaboration du plan nationale stratégique pour ces sites naturels/PNAP (creé par Décret 5758/06). Ces engagements ont contribué por maintenir et accroître les efforts de surveillance de la conservation, du governement brésilienne, afin de démontrer que les aires protegeés sont gérées de manière efficace, équitable, écologiquement représentatifs et bien reliés. $\mathrm{Au}$ Brésil possède le plus grand système d'aires protégées terrestres au monde et le SNUC représente une superfície de 155 millions d'hectares correspondant à 17,2\% du pays, mais avec un fort déséquilibre entre les proportions des sites administrée aux fins d'utilisation durable des écosystèmes naturels - sur la catégorie "Uso Sustentável" - (102.318.900 hectares) et les sites administrée principalement pour la protection et salvaguarde de la nature - sur la catégorie "Proteção Integral" (52.800.700 hectares). En ce qui concerne la représentation des biomes, seul le biome amazonien représente $72 \%$ des sites totales de SNUC, et cette region possede um programme especifique, le Programme des Aires Protégées da Amazonienne (Arpa) - le plus grand programme pour la conservation des forêts tropicales sur la forme de aires protégées et couvre environ $88 \%$ de la superficie totale des sites de "Proteção Integral" au bioma Amazonie. Pour évaluer le succès de la stratégie de conservation à travers des aires protégées, le Brésil a utilisé des approches différentes, en se concentrant sur l'étendue et l'emplacement des cettes sites, sur la base de la représentation par biome; dans l'entretien de l'intégrité du paysage; l'efficacité de la gestion et de la contribution à la conservation de la biodiversité. Cette thèse traite de la stratégie pour l'évaluation de l'efficacité de la gestion de l'Arpa, et démontre que la plupart des évaluations de l'efficacité de gestion mises en œuvre au Brésil, et en particulier dans au programme Arpa sont évaluations de la gestion de l'efficacité, il doit évaluer les processus (aux moyens) et les résultats en matière de gestion de la performance, sans fixer les priorités pour l'évaluation de l'impact. Cette évaluations ont été identifiés comme des évaluations de l'efficacité dont l'objectif et les outils d'analyse nous permet d'évaluer les éléments de preuve pour la conservation et l'utilisation durable des ressources naturelles. L'Arpa tout aulong de ses formes de mise en œuvre et est façonnée par une stratégie d'évaluation qui se concentre sur les résultats de la gestion et de l'exécution du programme. Bien que dans sa phase actuelle, Phase III, l'Arpa a évolué dans la séparation claire entre des outils d'évaluation la gestion de la performance (efficacité) et des instruments d'évaluation de l'efficacité (impact sur la conservation et utilise des ressources naturelles), avec le institutionnalisation de Rappam et l'adoption du système d'analyse et de suivi de gestion (SAMGe), l'évaluation de l'impact de la conservation se concentre sur la collecte des données dans le contexte du paysage et de la mise en place de protocoles pour le suivi des objectifs de conservation des aires protégées, mais ne sont pas mis en place, cependant, des formes de mesure et analyse des données pour tous les indicateurs au niveau des aires protégées ou au niveau du système. Cela renforce la nécessité de discuter, d'élaborer et de mettre en œuvre des stratégies qui, en fait, d'évaluer l'efficacité de la gestion des aires protégées et le système dans son ensemble.

Mots-clés: Aires protégées, efficacité de la gestion, Programme Aires Protégées d'Amazonie Arpa 


\section{LISTA DE ACRÔNIMOS}

APP - Áreas de Preservação Permanente

Arpa - Programa Áreas Protegidas da Amazônia

ASMUBIP - Associação Regional Mulheres Trabalhadoras Rurais Bico do Papagaio

AWF - African Wildlife Foundation

BID - Banco Interamericano de Desenvolvimento

BMU - Ministério Federal do Meio Ambiente, Proteção da Natureza, Construção e

Segurança Nuclear da República Federal da Alemanha

BMZ - Ministério para a Cooperação e Desenvolvimento Alemão

BNDES - Banco Nacional de Desenvolvimento Econômico e Social

CATIE - Centro Agronómico Tropical de Investigación y Enseñanza

CDB - Convenção sobre Diversidade Biológica

CFT - Comitê do Fundo de Transição

CI - Conservation Internacional (em português Conservação Internacional)

CMC - Conservation Monitoring Centre

CMP - The Conservation Measures Partnership (em português Aliança para as Medidas de Conservação)

CNPPA - Commission on National Parks and Protected Areas (em português-Comissão dos Parques Nacionais e Áreas Protegidas)

CNS - Conselho Nacional dos Seringueiros

CNUC - Cadastro Nacional de Unidades de Conservação

COIAB - Coordenação das Organizações Indígenas da Amazônia Brasileira

COMAG - Coordenação de Monitoramento e Avaliação da Gestão de Unidades de Conservação

CONABIO - Comissão Nacional de Biodiversidade

CONAMA - Conselho Nacional do Meio Ambiente

CONTAG - Confederação Nacional dos Trabalhadores Na Agricultura

COP - Convention of the Parties (em português Conferência das Partes) 
CP - Comitê do Programa

DAP - Diretoria de Áreas Protegidas

DEGRAD - Mapeamento Da Degradação Florestal Na Amazônia Brasileira

DETER - Sistema de Detecção do Desmatamento na Amazônia Legal em Tempo Real

EBIMAZ - Estudo Biográfico das Populações Amazônicas

EBVS - Essential Biodiversity Variables

ECI - Estratégia de Conservação e Investimento

ESEC - Estação Ecológica

EUA - Estados Unidos da América

FAP - Fundo de Áreas Protegidas

FAUC - Ferramenta de Avaliação da Efetividade do Programa Áreas Protegidas da Amazônia

FT - Fundo de Transição

GEF - Global Environmental Facility (em português Fundo para o Meio Ambiente Global)

GF - Gestor do Fundo

GTA - Grupo de Trabalho Amazônico

GTZ - German Technical Cooperation Agency (em português Agencia de Cooperação Técnica Alemã)

IBAMA - Instituto Brasileiro do Meio Ambiente e dos Recursos Naturais Renováveis

IBDF - Instituto Brasileiro do Desenvolvimento Florestal

IBRA - Instituto Brasileiro de Reforma Agrária

ICMBio - Instituto Chico Mendes para Conservação da Biodiversidade

IKI - Iniciativa Internacional de Proteção ao Clima

IMAZON - Instituto do Homem e Meio Ambiente da Amazônia

INCRA - Instituto Nacional de Colonização e Reforma Agrária

INPA - Instituto Nacional de Pesquisas da Amazônia

INPE - Instituto Nacional de Pesquisas Espaciais

ISA - Instituto Socioambiental 
ISPN - Instituto Sociedade, População e Natureza

IUCN - International Union for Conservation of Nature and Natural Resources (em português União Internacional para a Conservação da Natureza)

MEGP - Modelo de Excelência em Gestão Pública

METT/TT - Management Effectiveness Tracking Tool

MMA - Ministério do Meio Ambiente

MOP - Manual Operacional do Programa Arpa

MOU - Memorando de Entendimento

MPOG - Ministério do Planejamento, Orçamento e Gestão

MRs - Marcos referencias

NSOP - New South Wales State of Our Parks

OG - Órgão Gestor

ONGs - Organização Não Governamental

PAD - Project Appraisal Document

PADU - Protected Areas Data Unit (em português Unidade de Dados de Áreas Protegidas)

PainelBio - Painel Brasileiro de Biodiversidade

PAME - Protected Area Management Effectiveness

PANBIO - Plano Estratégico de Biodiversidade

PARNA - Parque Nacional

PCA - Painel Científico de Aconselhamento

PEP - Planejamento Plurianual

PGR - Programa de treinamento Gestão por Resultados/

PNAP - Plano Estratégico Nacional de Áreas Protegidas

PNUD - Programa das Nações Unidas para o Desenvolvimento

PNUMA - Programa das Nações Unidas para o Meio Ambiente

POA - Plano Operacional Anual

PPG7 - Programa Piloto para Conservação das Florestas Tropicais 
PROBIO - Projeto de Conservação e Utilização Sustentável da Diversidade Biológica Brasileira

PROBUC - Programa de Monitoramento da Biodiversidade e do Uso de Recursos Naturais em Unidades de Conservação Estaduais do Amazonas

PRODES - Projeto de Monitoramento Da Floresta Amazônica Brasileira Por Satélite PSC - Planejamento Sistemático da Conservação

PT - Plano de Trabalho

RAPPAM - Rapid Assessment and Prioritization of Protected Area Management

RDS - Reserva de Desenvolvimento Sustentável

REBIO - Reserva Biológica

RESEX - Reserva Extrativista

RFT - Fundo Fiduciário para Florestas Tropicais do PPG7

RL - Reservas Legais

RPPN - Reserva Particular do Patrimônio Natural

SAMGe - Sistema de Análise e Monitoramento de Gestão

SBF - Secretaria de Biodiversidade e Florestas

SEAIN - Secretaria de Assuntos Internacionais do Ministério do Planejamento, Orçamento e Gestão

SEMA - Secretaria Especial do Meio Ambiente (Ministério do Interior)

SIG - Sistemas de Informação Geográfica

SIMBIO - Sistema de Monitoramento de Biodiversidade

SISArpa - Sistema Integrado de Coordenação e Gerenciamento do Programa Áreas Protegidas da Amazônia

SIVAM - Sistema de Vigilância da Amazônia

SNUC - Sistema Nacional de Unidades de Conservação da Natureza

TerraClass - O projeto do INPE para a qualificação do desflorestamento da Amazônia legal, tendo por base as áreas desflorestadas mapeadas e publicadas pelo Projeto PRODES (Monitoramento da Floresta Amazônica Brasileira por Satélite) e imagens de satélite

TI - Terras Indígenas 
TNC - The Nature Conservancy

TT - Tracking Tool

UC - Unidades de Conservação

UCP - Unidade Coordenadora do Programa Arpa

UNEP - United Nations Environment Programme (em português Programa das Nações Unidas para o Meio Ambiente/PNUMA)

USAID - United States Agency for International Development (em português Agência dos Estados Unidos para o Desenvolvimento Internacional)

WCMC - World Conservation Monitoring Centre (em português Centro Mundial de Monitoramento da Conservação)

WCPA - World Commission on Protected Areas (em português Comissão Mundial para Áreas Protegidas)

WCS - Wildlife Conservation Society

WDPA - World Database on Protected Areas

WWF - World Wide Fund For Nature, but also known as World Wildlife Fund (em português Fundo Mundial para a Natureza)

ZEE - zoneamento econômico-ecológico 


\section{LISTA DE FIGURAS, QUADROS E TABELAS}

\section{Figuras}

Figura 1 - Arranjo organizacional do Programa Arpa

\section{Quadros}

Quadro 1 - Roteiro sobre a situação dos Parques Nacionais ......................................................... 26

Quadro 2 - Exemplo de um questionário de auto avaliação......................................................... 34

Quadro 3 - Bloco de perguntas do primeiro modelo de formulário de avaliação de efetividade

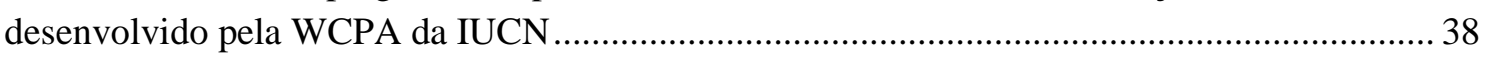

Quadro 4 - Marco conceitual de avaliação da efetividade da gestão ......................................... 46

Quadro 5 - Conceitos de Efetividade, Eficiência e Eficácia ..................................................... 49

Quadro 6 - Metodologias de avaliação da efetividade utilizadas nas unidades de conservação

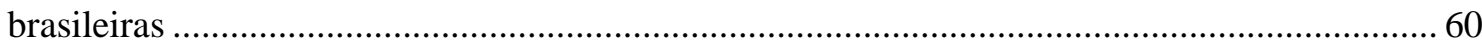

Quadro 7 - Evidências de sucesso nas UCs Brasileiras x Abordagens de avaliação propostas por

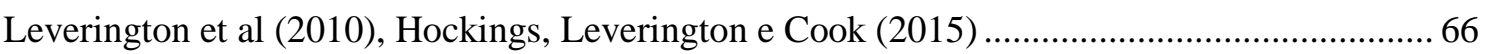

Quadro 8 - Área coberta por unidades de conservação por Biomas............................................. 72

Quadro 9 - Ferramentas que incorporam a avaliação do impacto ou efeito de conservação ...... 91

Quadro 10 - Metas de Aichi X Indicadores de monitoramento.................................................. 94

Quadro 11 - Área máxima e mínima das UCs criadas na década de 1980-1989 ...................... 112

Quadro 12 - Áreas de Unidades de Conservação criadas por grupo de manejo, por década (19301999)

Quadro 13 -. Áreas de Unidades de Conservação criadas por grupo de manejo, na década de 2000-2009

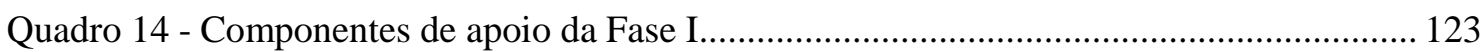

Quadro 15 - Metas do Programa Arpa para Fase I e Fase II ...................................................... 124

Quadro 16 - Metas previstas X Metas Alcançadas relacionadas ao FAP................................. 126

Quadro 17 - Resumo do histórico de criação de UCs nas Fases I, II e III ................................ 128

Quadro 18 - Marcos Referenciais do Programa Arpa X Padrões de alcance .............................. 131

Quadro 19 - Metas previstas X metas alcançadas para consolidação de UCs ........................... 133

Quadro 20 - Questão 16 do Tracking Tool........................................................................... 140

Quadro 21 - Questão 10 -FAUC Consolidação. Subprojeto Participação e Integração com o

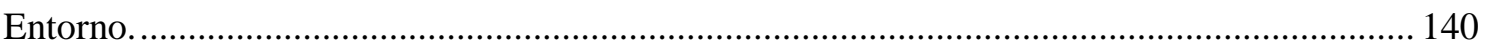

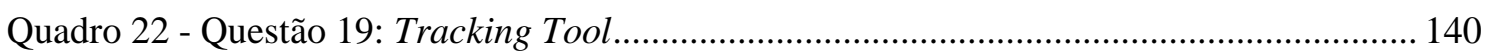

Quadro 23 - Questão 8: FAUC Estabelecimento. Subprojeto Participação e Integração com o

Entorno. Marco Referencial: Formação do conselho consultivo ou deliberativo da UC. .......... 141

Quadro 24 - Questão 13: FAUC Consolidação. Subprojeto Participação e Integração com o

Entorno. Marco Referencial: Funcionamento do conselho consultivo ou deliberativo da UC. 141

Quadro 25 - Dimensões de monitoramento do Programa Arpa na Fase I................................. 148

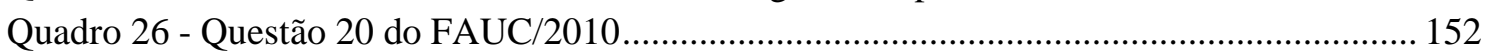

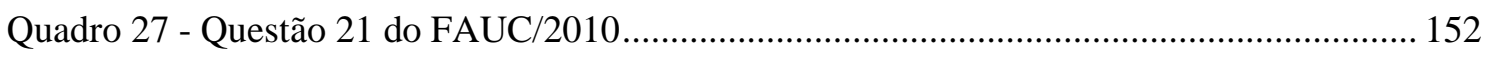

Quadro 28 - -Dimensões de monitoramento do Programa Arpa na Fase II ............................... 153

Quadro 29 -- -Dimensões de monitoramento do Programa Rapa na Fase III............................ 158

Quadro 30 - Estudos nas dimensões do impacto na Conservação e dos Benefícios

socioeconômicos do Programa Arpa 
Quadro 31 - Temas investigados no estudo sobre os Benefícios Sociais das UCs do Programa Arpa

Tabelas

Tabela 1 - Áreas de Unidades de Conservação apoiadas pelo Programa Arpa por categoria de manejo e esfera administrativa.... 120

Tabela 2 - Áreas de Unidades de Conservação do Bioma Amazônia e apoiadas pelo Programa Arpa por categoria de manejo 120

Tabela 3 - UCs apoiadas pelo Programa Arpa nas Fases I, II e III por grau de consolidação . 130 


\section{A ESTRATÉgIA DO PROGRAMA ÁREAS PROTEGIDAS DA AMAZÔNIA PARA AVALIAR A EFETIVIDADE DAS UNIDADES DE CONSERVAÇÃO}

Daniela de Oliveira e Silva

\section{Sumário}

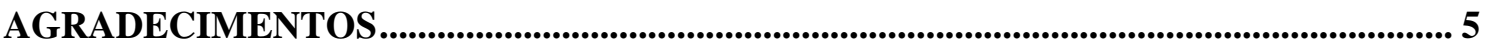

RESUMO ........................................................................................................................................................... 6

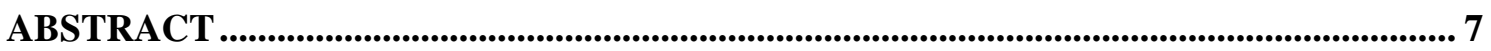

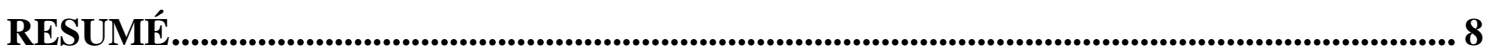

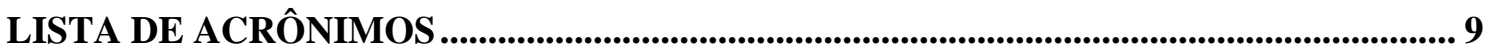

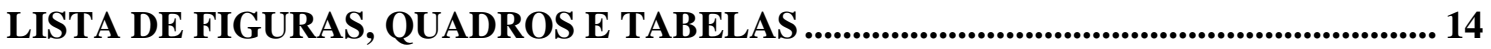

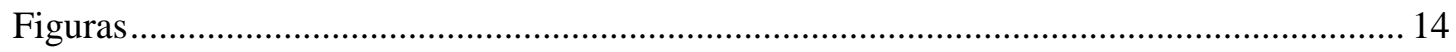

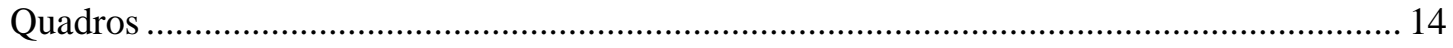

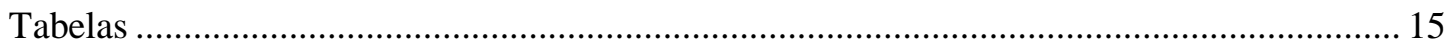

Introdução................................................................................................................................................................. 18

Capitulo 1 - História do conceito de efetividade aplicado às áreas protegidas ...................... 25

1.1.Motivações e recomendações para avaliação de efetividade ............................................ 25

1.2.Marco conceitual para avaliação da efetividade de gestão................................................. 43

1.3.A Institucionalização das avaliações de efetividade ........................................................... 49

Capitulo 2 - Metodologias e ferramentas de avaliação do sucesso de áreas protegidas ..... 56

2.1.Avaliação da extensão e localização das áreas protegidas, incluindo a sua representatividade biológica.

2.2.Avaliação da efetividade das áreas protegidas como um mecanismo de conservação na

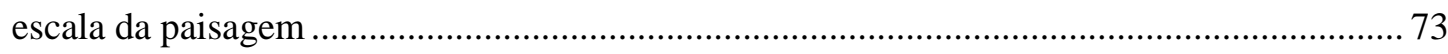

2.3.Avaliação da efetividade de gestão de áreas protegidas (PAME) …………....................... 81

2.4.Avaliação da contribuição das áreas protegidas para a conservação de seus valores de

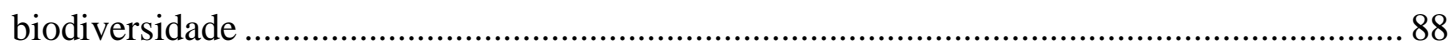

Capitulo 3 - O Programa Áreas Protegidas da Amazônia (Arpa) ......................................... 109

3.1.Primeiras iniciativas e motivações para criação de UCs no Bioma Amazônia e do

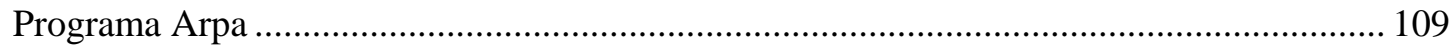

3.2. Arranjo Institucional e de implementação do Programa Arpa ......................................... 120

3.3.O Programa Arpa e o apoio a criação de UCs................................................................ 126

3.4. O Programa Arpa e o apoio a consolidação e a manutenção de UCs.............................. 129

Capitulo 4 - A estratégia do Programa Áreas Protegidas da Amazônia para avaliar o sucesso das UCs na conservação da Biodiversidade e na sustentabilidade do uso dos recursos naturais. 
4.1.Fase I: Uma estratégia de avaliação para mostrar o sucesso de execução do Programa Arpa

4.2.Fase II: O resgate das orientações iniciais para avaliação e monitoramento do Programa Arpa

4.3.Fase III: Avaliação da Gestão e Impacto do impacto de conservação das UCs apoiadas pelo Programa Arpa

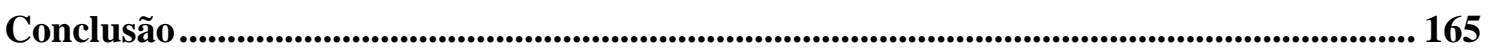

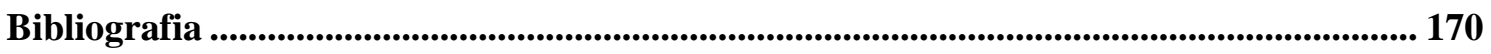

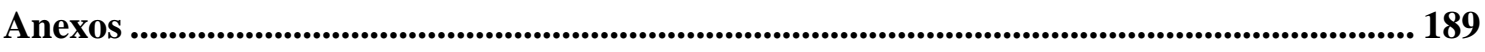

Anexo 1 - Formulário para avaliação da efetividade das áreas protegidas proposto por MacKinnon e MakKinnon, 1986, e MacKinnon e MakKinnon,1990_................................. 189

Anexo 2 - Metodologias de Avaliação da Efetividade de Gestão (Estudo Global)............... 193

Anexo 3 - Lista de Unidade de Conservação apoiadas pelo Programa Arpa ........................ 195

Anexo 4 - Decretos de criação do Programa Áreas Protegidas da Amazônia - Programa Arpa

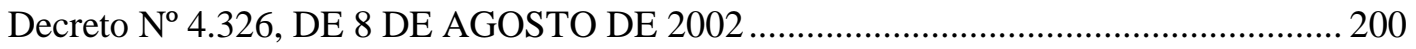

Portaria MMA N ${ }^{\circ}$ 187, DE 22 DE MAIO DE 2014 ......................................................... 201

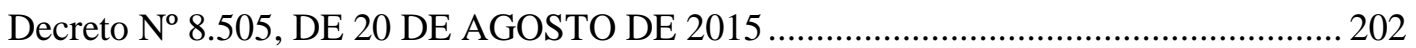

Anexo 5 - Formulário aplicado ao estudo sobre os Benefícios Sociais das UCs do Programa Arpa e lista das UCs consultadas 205 


\section{Introdução}

As áreas protegidas cobrem, no mundo todo, 15,4\% da superfície terrestre e das ilhas marinhas, 3,4\% da área dos oceanos, $8,4 \%$ de todas as zonas marinhas, e 10,9\% de todas as águas costeiras. Segundo a World Database on Protected Areas (WDPA), responsável pelo banco de dados global sobre áreas protegidas, existem 197.368 áreas terrestre e 12.076 áreas marinhas protegidas, que juntas somam mais de 209.000 áreas distribuídas por 193 países (JUFFE-BIGNOLI et al. 2014; FRANKS and SCHRECKENBERG 2016).

No contexto mundial são várias as formas de proteção territorial com fins conservacionistas e as áreas protegidas diferenciam-se entre si em relação à finalidade, ao nível de intervenção do homem na natureza e à esfera de gestão (governamental ou privada). A União Internacional para a Conservação da Natureza/IUCN e, mais tarde, a Convenção sobre Diversidade Biológica/ $\mathrm{CDB}^{1}$ têm orientado o processo de criação e gestão de áreas protegidas no mundo. A IUCN definiu área protegida como "uma área de terra e/ou mar especialmente dedicada à proteção e manutenção da diversidade biológica, assim como dos recursos naturais e patrimônio cultural associados, e gerida através de meios jurídicos, ou outros meios eficazes". A CDB reforçou o papel das áreas protegidas como instrumento para conservação, uso sustentável e compartilhamento justo e equitativo dos benefícios da diversidade biológica, ao conceituar área protegida como "uma área definida geograficamente que é destinada, ou regulamentada, e administrada para alcançar objetivos específicos de conservação” (IUCN 1993; MMA, 2000).

No Brasil, estabeleceu-se uma distinção entre Unidades de Conservação (UCs), um termo que é restrito ao Brasil, e outros tipos de áreas protegidas, tais como Áreas de Preservação Permanente (APPs) e Reservas Legais (RLs), Terras Indígenas e Terras de Quilombo. A sistematização, a criação e o gerenciamento das UCs foram estabelecidos após longo trâmite, durante toda a década de 1990 - pela chamada Lei 9885/2000, que institui o Sistema Nacional de Unidades de Conservação da Natureza/SNUC ${ }^{2}$. A Lei do SNUC define as UCs como "espaço territorial e seus recursos ambientais, incluindo as águas jurisdicionais, com características naturais relevantes, legalmente instituído pelo

\footnotetext{
${ }^{1}$ Decreto Legislativo no. 2, de 5 de junho de 1992 (MMA, 2000)

${ }^{2}$ Lei $n^{\circ} 9.985 / 2000$ - SNUC, regulamentada pelo Decreto ${ }^{\circ}$. 4.340, de 22 de agosto de 2002
} 
Poder Público, com objetivos de conservação e limites definidos, sob regime especial de administração, ao qual se aplicam garantias adequadas de proteção" (SNUC, 2000; MERCADANTE, 2001; DRUMMOND at al, 2006; DRUMMOND at al, 2010).

O SNUC tem uma área de 155.119.600,00 de hectares, distribuída em 1940 UCs enquadradas em 12 categorias: 954 federais (76.384.500,00 hectares), 781 estaduais (76.084.800,00 hectares) e 205 municipais (2.650.300,00 hectares). A área protegida sob a forma de UCs representa 17,2\% do território nacional, com forte desequilíbrio entre as proporções das áreas das UCs de uso sustentável (102.318.900 hectares) e as áreas das UC de proteção integral (52.800,700 hectares). Entre os anos de 2003 e 2008, o Brasil foi responsável por $74 \%$ das áreas protegidas criadas no mundo, resultado da expansão ocorrida, particularmente, no Bioma Amazônia entre os anos 2000 e 2009, quando foram criadas 121 UCs, que correspondem a cerca de 66 milhões de hectares. Ou seja, durante esses anos, foi protegida, por meio da criação de UCs, mais área na Amazônia do que em todo o período anterior. Atualmente, o bioma Amazônia está protegido por 322 UCs, que ocupam uma área de 113.630.400 hectares, e que correspondem a 27,1\% da área total do bioma - descontadas as sobreposições chega-se a uma área de 111.750 .900 hectares, o que corresponde a $26,4 \%$ da área total do bioma. Destes, 40.207 .100 hectares $(9,6 \%$ da área total do bioma) estão protegidos por UCs de proteção integral e 70.182 .000 hectares (16,7\% da área total do bioma) por UCs de uso sustentável (CNUC, 2015).

Esse cenário reforça o esforço empreendido pelo Brasil, pelo menos no bioma Amazônia, para o cumprimento da meta nacional de conservação da biodiversidade, estabelecida em função do compromisso do Brasil com as Metas CDB para 2010 no âmbito da Sétima Conferência das Partes ${ }^{3}$ da Convenção sobre Diversidade Biológica COP7/CDB, realizada em 2004, em Kuala Lumpur, na Malásia, para a conservação dos ecossistemas terrestres e marinhos por meio de UCs, e representada pelas metas de $30 \%$ do bioma Amazônia e 10\% dos demais biomas e na zona costeira e marinha. Este compromisso foi reafirmado e ampliado, pelo Brasil e outros 192 signatários da CDB, na $10^{\text {a }}$ Conferência das Partes da CDB (COP-10), realizada em dezembro de 2010, em Nagoya, no Japão. As metas, denominadas agora Metas CDB 2020, aumentaram, de 10\% de todas as regiões ecológicas do planeta para $17 \%$.

\footnotetext{
${ }^{3}$ A CDB é governada pela Convenção das Partes (ou Convention of the Parties - COP).
} 
A discussão brasileira em torno das novas metas do Plano Estratégico de Biodiversidade 2011-2020 da $\mathrm{CDB}^{4}$ para 2020 - "Metas de Aichi" - resultou em um compromisso formal do governo Brasileiro (Resolução CONABIO 06/2013) para melhorar a situação da biodiversidade, dispondo em sua Meta Nacional 11 que:

Até 2020, serão conservadas, por meio de unidades de conservação previstas na Lei do SNUC e outras categorias de áreas oficialmente protegidas, como APPs, reservas legais e terras indígenas com vegetação nativa, pelo menos $30 \%$ da Amazônia, $17 \%$ de cada um dos demais biomas terrestres e $10 \%$ de áreas marinhas e costeiras, principalmente áreas de especial importância para biodiversidade e serviços ecossistêmicos, assegurada e respeitada a demarcação, regularização e a gestão efetiva e equitativa, visando garantir a interligação, integração e representação ecológica em paisagens terrestres e marinhas mais amplas (CONABIO 06/2013).

Ao se comprometer em ampliar o esforço de conservação da biodiversidade, o governo Brasileiro se comprometeu também em ampliar o esforço de monitoramento para demonstrar que tais áreas são geridas de maneira efetiva e equitativa, que são ecologicamente representativas e estão satisfatoriamente interligadas. Neste contexto, e como desdobramento da definição das Metas Nacionais, novos indicadores de monitoramento devem ser incorporados, pois além da extensão representativa de cada bioma, espera-se que o Brasil possa informar sobre aspectos como efetividade de gestão, conectividade e representatividade ecológica dessas áreas. Soma-se aos desafios já apresentados para a Meta 11, o desafio de também demonstrar quanto equitativo e justo é o sistema de UCs e como as UCs contribuem para a conservação da biodiversidade, para introduzir ou manter a sustentabilidade no uso dos recursos naturais e para a promoção do desenvolvimento sustentável. Por outro lado, e motivado por constantes debates, nas esferas acadêmica e governamental, encontra-se o questionamento sobre se a grande extensão territorial sob proteção na forma de áreas protegidas garante a conservação da biodiversidade. Neste contexto, embora as UCs sejam para o Brasil a principal e mais disseminada estratégia de conservação da natureza, até agora apenas o bioma Amazônia foi contemplado com uma estratégia específica para atingir metas ousadas para criação e consolidação de UCs em quantidade suficiente para garantir a representatividade ecológica da proteção. Trata-se do Programa Áreas Protegidas da

\footnotetext{
${ }^{4}$ A CDB é governada pela Convenção das Partes (ou Convention of the Parties - COP) e durante a sua $10^{\mathrm{a}}$ Convenção, em Nagoya, no Japão, as "partes" concordaram em trabalhar juntas para implementar 20 metas até 2020 .
} 
Amazônia - Arpa - criado em 2002 e considerado a maior e a mais importante iniciativa para o estabelecimento de UCs. Atualmente, o Programa Arpa abrange cerca de 59 milhões de hectares distribuídos em 114 UCs, 69 federais com 36.904.030,2 hectares, 45 estaduais com 22.274.953,8 hectares. No caso do Arpa, há um certo equilíbrio entre as proporções das áreas das UCs de proteção integral, com 60\% (35.421.434,89 hectares), e a das UCs de uso sustentável, com 40\% (23.757.549,13 hectares). O programa traz contribuições significativas que devem ser observadas na implementação do SNUC para os demais biomas e para reportar o alcance das Metas Nacionais do Plano Estratégico de Biodiversidade 2011-2020 da CDB (WEIGAND JR, CALANDINO, e OLIVEIRA, 2011; WEIGAND JR, OLIVEIRA, e WEIGAND 2014; IUCN, WWF-Brasil, and IPÊ, 2011; CNUC, 2015 e MMA/ARPA, 2015).

De modo geral, e mesmo no Programa Arpa, as ações para avaliar o sucesso da estratégia de conservação da biodiversidade baseada em UCs, ou pelo menos para avaliar o impacto da gestão de UCs no que diz respeito ao estado de conservação da biodiversidade, foram pouco priorizadas quando comparadas ao esforço em demonstrar o sucesso o Programa na criação e na instrumentalização para gestão das UCs apoiadas por ele. Embora as diferentes dimensões avaliadas possam ser um meio para se observar os efeitos e sucessos das UCs, tais avaliações dão poucos subsídios para aferir de forma conjunta a conservação da biodiversidade e a sustentabilidade do uso dos recursos naturais com base nos conceitos e premissas do SNUC e nos seus objetivos de conservação.

As ferramentas e metodologias, sobretudo, as de avalição da performance ou eficácia das UCs, não dispõem de indicadores para avaliar se a gestão está sendo integrada, se contribui para a melhoria da capacidade operacional do conjunto das UCs (recursos, infraestrutura, ações, etc..); se garante o alcance dos objetivos individuais de acordo com a categoria da UC; se amplia a escala de conservação da biodiversidade (o objetivo do conjunto deve ser maior que a soma dos objetivos das áreas envolvidas); se promove a conectividade funcional e física; se garante a manutenção das funções ecossistêmicas, se contribui para o ordenamento territorial e para o desenvolvimento territorial com base conservacionista; se estabelece espaços de articulação institucional e se fortalece a identidade territorial (OLIVEIRA, 2012).

Geldmann et al. 2013, ao avaliarem 2.599 publicações científicas, concluíram que há boas evidências de que as áreas protegidas conservaram o habitat florestal, mas 
que essas evidências permanecem inconclusivas quando tratamos da sua contribuição para a manutenção de populações de espécies. Nesse contexto, outra lacuna de evidência é a relação entre a situação ou progressão do esforço de gestão das UCs e a conservação da biodiversidade ou a adequada utilização dos recursos e seus benefícios.

No Brasil, alguns métodos foram, são ou estão sendo desenvolvidos para avaliar as evidências de sucesso das UCs, pois a busca por respostas é constante. Busca, por vezes, carregada de vieses e visões que atendem objetivos e dimensões especificas, e que priorizam o diálogo entre os objetivos das UCs e as questões de ordem social, utilitária, produtiva, em detrimento de ferramentas mais específicas para a conservação da biodiversidade. Mas considerando-se o conjunto de iniciativas existentes para a avaliação dos sucessos das UCs e das áreas protegidas podemos organizá-las segundo as quatro abordagens de avaliação de Leverington et al. (2010) e Hockings, Leverington, and Cook (2015): (i) avaliação da extensão e localização das áreas protegidas, incluindo a sua representatividade biológica; (ii) avaliação da efetividade das áreas protegidas como um mecanismo de conservação na escala da paisagem; (iii) avaliação da efetividade de gestão de áreas protegidas (PAME5); e (iv) avaliação da contribuição das áreas protegidas para a conservação de seus valores de biodiversidade. Essa organização ajuda a entender, no contexto brasileiro, o propósito e a complementariedade dos instrumentos existentes, bem como refletir sobre como eles podem ser utilizados para avaliar a efetividade das UCs.

No âmbito desta tese as avaliações de efetividade de gestão de UCs e áreas protegidas serão enquadras como avaliações de eficácia de gestão, quando o objetivo for avaliar processos, e como avaliações de efetividade quando o objetivo e o instrumental analítico permitir avaliar os impactos (as evidências de conservação e do uso sustentável dos recursos naturais). Em termos de efetividade de conservação, as UCs terão alcançado seus objetivos quando a manutenção da integridade, resiliência e funcionamento dos ecossistemas estiver assegurada, de modo a garantir a representatividade e viabilidade de todos os níveis de organização da biodiversidade (ecossistemas, espécies e variedade genética). Nas áreas terrestres essa verificação tem sido realizada por meio do monitoramento da manutenção da cobertura vegetal nativa. Este tem sido o indicador mais utilizado, como vimos na segunda abordagem, admitindo-se a partir daí uma relação direta de status de conservação para os demais níveis da biodiversidade. A efetividade de gestão, que na verdade é a eficácia, tem sido vista como a medida em que a UC, tendo os

\footnotetext{
${ }^{5}$ Abreviação em inglês para Protected Area Management Effectiveness
} 
meios, executa as ações relacionadas com o seu papel de promotora da conservação. A eficácia tem sido medida pela implementação de um kit básico de gestão, que envolve uma equipe mínima, equipamentos e infraestrutura, recursos e instrumentos de gestão, como o plano de manejo e o conselho gestor ${ }^{6}$ (STOLTON et al., 2008 e WEIGAND JR et al, 2014). No âmbito das UCs, tais efeitos podem ser de ordem social (impactos positivos para comunidade e seus meios de vida) e ambiental (impacto positivo para biodiversidade), mas uma pergunta precisa ser respondida: Como a contribuição das UCs para conservação da biodiversidade e para a sustentabilidade do uso dos recursos estão sendo avaliadas? Este é o desafio da presente tese, que acolhe como ponto de partida os princípios que orientam a criação, a consolidação e a implementação das estratégias de avaliação da efetividade de gestão UCs do Programa Áreas Protegidas da Amazônia (Arpa ou Programa Arpa).

A Tese está estruturada em quatro capítulos, além da introdução, das referências bibliográficas e dos anexos. O Capítulo 1 apresenta o referencial teórico utilizado para discutir a efetividade da conservação da biodiversidade e da sustentabilidade no uso dos recursos naturais, abordando a história do conceito de efetividade aplicado às áreas protegidas e as orientações para avaliação de efetividade de áreas protegidas sugeridas no âmbito global. O Capitulo 2 apresenta as metodologias e ferramentas de avaliação do sucesso de áreas protegidas, organizados em função das quatro abordagens de Leverington et al (2010), Hockings, Leverington e Cook (2015), cuja reflexão e discussão contribuem para a implementação do Sistema Nacional de Unidades de Conservação da Natureza. O Capítulo 3 apresenta o Programa Arpa, cuja estratégia para atingir em quantidade e representatividade a proteção e a conservação da biodiversidade no Brasil é única e específica. Este capítulo ainda detalha o histórico de criação do programa e sua forma de funcionamento. O Capitulo 4 apresenta e discute a metodologia adotada pelo Arpa para avaliar as evidências de conservação da biodiversidade e da sustentabilidade no uso dos recursos naturais nas UCs por ele apoiadas. A conclusão sinaliza as lacunas de conhecimento e os caminhos para aprofundar a discussão sobre evidências de conservação da biodiversidade e da sustentabilidade no uso dos recursos naturais.

A metodologia utilizada para a elaboração da tese levou em consideração a necessidade de acessar um conjunto significativo de dados sobre o estado da arte do tema

\footnotetext{
${ }^{6}$ O capítulo IV da Lei do SNUC, nos artigos 27 e 29, dispõe os instrumentos plano de manejo (Art. 27), conselho gestor (Art. 29)
} 
avaliação de efetividade em unidades de conservação e sobre a estratégia do Programa Arpa para avaliar a efetividade de suas UCs. Como etapas desse processo destacam-se: (i) levantamento das referências encontradas sobre o tema, prioritariamente, em artigos científicos (revistas, periódicos e jornais), livros, teses, dissertações, registros históricos, com destaque para relatórios governamentais sobre o Programa Arpa; (ii) mapeamento e organização desse levantamento em um gerenciador de bibliografias, o Mendeley ${ }^{7}$, permitindo identificar os principais autores sobre o tema, bem como priorizar as referências mais recentes; (iii) construção de uma contextualização para o tema e a elaboração do seu histórico; e (iv) análise das referências para a construção do referencial teórico e a sua implementação, tendo o Programa Arpa como objeto de um olhar mais fino, com o intuito de identificar as abordagens recorrentes e apontar novas perspectivas.

A minha proximidade com as ações de implementação do Programa Arpa, seja como técnica da Unidade Coordenadora do Programa (UCP) do Ministério do Meio Ambiente, entre os anos de 2006 e 2010, seja como Analista de Conservação Sênior do WWF-Brasil, no período de 2012 a 2015, e como membro do Painel Científico de Aconselhamento (PCA), desde 2016, permitiu o acesso aos documentos governamentais e técnicos, bem como a discussão dos mesmos com o corpo técnico e com as instâncias de implementação do Arpa. Essa proximidade foi fundamental para identificar a estratégia de avaliação da efetividade das UCs do Programa Arpa. Não foram utilizados métodos quantitativos ou estatísticos, com a finalidade de gerar uma avaliação de resultados da produção científica ou dos dados levantados.

\footnotetext{
${ }^{7}$ Software gratuito para gerenciar, compartilhar, ler, anotar e editar artigos científicos. Disponível para a plataforma Windows w Linus, o Mendeley, através de uma interface amigável permite filtrar artigos por autor, periódico, ano de publicação e as palavras chaves
} 


\section{Capitulo 1 - História do conceito de efetividade aplicado às áreas protegidas}

\subsection{Motivações e recomendações para avaliação de efetividade}

Motivações e recomendações para o manejo de áreas protegidas durante o período entre o I e o II Congresso Mundial de Parques, realizados em 1962 e 1972, nos Estados Unidos da América

A preocupação com a gestão das áreas protegidas tem se evidenciado desde que elas começaram a ser criadas nas mais diversas partes do mundo: Parque Nacional de Yellowstone, nos Estados Unidos da América (EUA), 1872; Parque Nacional Royal, na Austrália, 1879; Parque Nacional de Banff, no Canadá, 1883; Parque Nacional de El Chico, no México, 1884; Parque Nacional de Tongariro, na Nova Zelândia, 1894; Parque

Nacional Kruger, na África do Sul, em 1898; Parque Nacional Nahuel Huapi, na Argentina, 1903; Parque Nacional Vicente Pérez Rosales, no Chile, 1926; Parque Nacional de Kaiteur, na Guiana, em 1929; Parque Nacional de Galápagos, no Equador, 1936; Parque Nacional do Itatiaia, no Brasil, 1937; e Parque Nacional de Sajama, na Bolívia, 1939 (NASH, 2001; MCCORMICK, 1992; FRANCO, 2000; OLIVEIRA, 2012; PETROVA, 2014.

Não há registro, no entanto, de quando as primeiras discussões técnicas sobre efetividade de gestão de áreas protegidas aconteceram. Os dois primeiros congressos mundiais de parques nacionais e reservas realizados pela IUCN (International Union for Conservation of Nature and Natural Resources) - I Congresso Mundial de Parques, em Seattle, 1962, e II Congresso Mundial de Parques, em Yellowstone, 1972, ambos nos EUA - não trataram diretamente sobre a questão da efetividade de gestão, embora tenham chamado a atenção para a necessidade de se criar diretrizes globais de gestão e de se estabelecer um sistema de classificação internacional para áreas protegidas, além de alertar para a importância da incorporação do tema conservação nos programas de desenvolvimento e nas ações de planejamento (SOUZA, 2103; FRANCO et. al., 2015).

Nos EUA, a Força-Tarefa de Conservação do Sistema Nacional de Parques levantou, em 1972, a questão das pressões e ameaças ao sistema de parques nacionais e debateu sobre a capacidade do Serviço de Parques Nacionais para lidar com elas. A recomendação foi para que se adotasse um sistema anual de relatórios ambientais que 
garantisse o monitoramento contínuo dos fatores responsáveis pelas pressões e ameaças dentro e fora de cada parque, bem como a identificação das principais ações para remediálas. Os relatórios também deveriam ser compilados em um relatório ambiental de todo o sistema (HOCKINGS et al, 2000).

No mesmo período, no Brasil, foi publicado, pelo IBDF (Instituto Brasileiro do Desenvolvimento Florestal), Política e Diretrizes dos Parques Nacionais do Brasil (IBDF, 1970), documento que orientava sobre ações e atividades para implementação dos parques nacionais brasileiros e que resumia, tal qual um roteiro básico, a proposta de implementação do Serviço de Parques Nacionais dos EUA: Compilation of the Administrative Polices for the National Parks and National Monuments of SignificanceNatural área caterory, National Park Service, 1967, USA. Entretanto, dentre as diretrizes brasileiras nada havia sobre a necessidade de avaliação ou monitoramento dos parques nacionais. Dentre as ações destacadas encontravam-se: manejo de uso dos recursos, elaboração dos planos diretores (planos de manejo), visitação, proteção, pesquisa (com foco na coleta de material) e infraestrutura. Um ano antes, um relatório elaborado pelo IBRA (Instituto Brasileiro de Reforma Agrária) e pelo IBDF, com a finalidade de dar subsídios à revisão da política nacional para os parques nacionais e reservas equivalentes no Brasil (IBRA e IBDF, 1969) já havia destacado dois aspectos importantes: a) a necessidade de um roteiro para padronizar as informações sobre a situação dos parques nacionais, que inclui a informação sobre o estado de conservação no nível dos ecossistemas e de espécies da fauna e flora (Quadro 1); b) a pesquisa como ferramenta fundamental para o conhecimento dos recursos naturais e para o planejamento da sua conservação, especificando o levantamento ecológico, aliado ao inventário da fauna e flora, os estudos de sucessão e o estudo das biotas para conhecimento de seus ecossistemas.

Quadro 1 - Roteiro sobre a situação dos Parques Nacionais

\begin{tabular}{|c|c|}
\hline TÓPICOS & DETALHAMENTO DO TÓPICO \\
\hline $\begin{array}{l}\text { Identificação da } \\
\text { área }\end{array}$ & Nome, localização e Histórico da região \\
\hline $\begin{array}{l}\text { Caracterização } \\
\text { legal }\end{array}$ & $\begin{array}{l}\text { Documentação relativa à criação do Parque e eventuais ampliações } \\
\text { Plantas e mapas } \\
\text { Registro do patrimônio da União } \\
\text { Propriedades particulares existentes na área do Parque e sua } \\
\text { desapropriação } \\
\text { Utilização do Parque para TV, rádio e linhas de transmissão }\end{array}$ \\
\hline Administração & $\begin{array}{l}\text { Chefia, guarda e vigilância } \\
\text { Veículos }\end{array}$ \\
\hline
\end{tabular}




\begin{tabular}{|c|c|}
\hline & $\begin{array}{l}\text { Infraestrutura técnica científica (Biblioteca, museu e alojamentos) } \\
\text { Outras Infraestruturas ou instalações (rodovias, obras diversas) }\end{array}$ \\
\hline $\begin{array}{l}\text { Atendimento ao } \\
\text { público }\end{array}$ & $\begin{array}{l}\text { Facilidades de acesso } \\
\text { Instalações e serviço: alimentação, guias, pousadas, etc. } \\
\text { Cobrança } \\
\text { Problemas com o público } \\
\end{array}$ \\
\hline Pesquisa & $\begin{array}{l}\text { Geologia e geomorfologia } \\
\text { Botânica e fitogeografia } \\
\text { Zoologia e zoogeografia } \\
\text { Ecologia } \\
\text { Climatologia e Meteorologia } \\
\end{array}$ \\
\hline Conservacionismo & $\begin{array}{l}\text { Conservação da Flora } \\
\text { Conservação da Fauna } \\
\text { Conservação das paisagens } \\
\text { Conservação das águas }\end{array}$ \\
\hline
\end{tabular}

Fonte: IBRA e IBDF, 1969

\section{Motivações e recomendações para avaliação de efetividade no âmbito do III Congresso Mundial de Parques, realizado em 1982, em Bali na Indonésia}

O III Congresso Mundial de Parques, realizado em 1982, em Bali, na Indonésia, traz o registro da primeira discussão técnica sobre efetividade, e esta foi liderada por um grupo de membros da Comissão dos Parques Nacionais e Áreas Protegidas $\left(\mathrm{CNPPA}^{8}\right)$ da IUCN. Mais tarde, em 1996, no Congresso Mundial de Conservação, realizado pela IUCN em Montreal, no Canadá, a CNPPA se tornaria a Comissão Mundial para Áreas Protegidas $\left(\mathrm{WCPA}^{9}\right)$. Na ocasião do III Congresso Mundial de Parques, a CNPPA era presidida por Kenton R. Miller ${ }^{10}$, que abriu a segunda sessão do Congresso, cujo tema foi Cobertura Mundial de Áreas Protegidas.

Miller destacou o apoio da recém-criada Unidade de Dados de Áreas Protegidas $\left(\mathrm{PADU}^{11}\right)$, responsável por inventariar, monitorar e compartilhar os avanços das áreas protegidas em área e número. A criação da PADU foi possível graças ao apoio do Programa das Nações Unidas para o Meio Ambiente (PNUMA/UNEP), como parte de seu Programa Global de Monitoramento do Meio Ambiente. A PADU se transformou na Base de Dados Mundial de Áreas Protegidas (WDPA ${ }^{12}$ ), o conjunto de dados mais

\footnotetext{
${ }^{8}$ Nome original Commission on National Parks and Protected Areas - CNPPA

${ }^{9}$ Nome original World Commission on Protected Areas - WCPA. A WCPA também já foi chamada de Comitê dos Parques Nacionais na época da sua fundação em 1958 (Committee on National Parks) e Comissão para as Áreas Protegidas (Commisson on National Parks), em 1960, como divisão técnica da Assembleia Geral da IUCN (IUCN, 2009)

${ }^{10}$ A CNPPA foi presidida pelo Kenton Miler no período de 1976 a 1983.

${ }^{11}$ Nome original Protected Areas Data Unit - PADU

${ }^{12}$ Nome original World Database on Protected Areas - WDPA
} 
abrangente disponível sobre áreas protegidas globais marinhas e terrestres. O WDPA é um projeto conjunto do PNUMA/UNEP e da IUCN, produzido pelo Centro Mundial de Monitoramento da Conservação (WCMC ${ }^{13} / \mathrm{UNEP}$ ) e pela Comissão Mundial de Áreas Protegidas (WCPA/IUCN), com a colaboração de governos e ONGs (IUCN, 1991). Já o WCMC tem sua origem no Centro de Monitoramento da Conservação $\left(\mathrm{CMC}^{14}\right)$, criado pela IUCN em 1979. No final dos anos 1980, a IUCN, em conjunto com a WWF e o PNUMA/UNEP, criou o WCMC. Em 1998, a IUCN e o WWF deixaram de fazer parte do núcleo de financiamento do WCMC e, em 2000, ele se tornou um braço do PNUMA/UNEP, operando como WCMC/ UNEP.

Kenton Miller e outros especialistas da WCPA/IUCN chamaram a atenção, durante o congresso de Bali, para o fato de que não havia dados sobre a efetividade da conservação das áreas protegidas. Nessa época, a gestão das áreas protegidas emergia como uma das questões prioritárias para a WCPA, pois estava cada vez mais claro que o futuro das áreas protegidas dependia de uma compreensão mais ampla de como avaliálas e sobretudo de como melhorar a eficácia da sua gestão (IUCN, 1982; IUCN, 2009).

A efetividade foi discutida na sessão da WCPA sobre as Novas Direções para o Manejo de Áreas Protegidas (New Directions in Protected Areas Management), realizada no congresso de Bali, na qual Harvey Croze, do PNUMA/UNEP, defendeu a criação de meios para que cada nação desenvolvesse um sistema de monitoramento dentro e fora dos parques com o intuito de controlar e compreender as dinâmicas que envolvem o complexo e multidisciplinar contexto em que as áreas protegidas se inseriam (IUCN, 1982). O monitoramento ao qual Croze se referiu visava fornecer uma base de dados e tendências dos sistemas ecológicos. A importância de tais informações para a efetividade da gestão foi notada, mas o uso desta informação para avaliar e adaptar a gestão não foi abordada.

A questão da efetividade foi novamente debatida, no congresso de Bali, no workshop Preparing tolls for the man on the ground, que abordou três temas amplos: (i) Gestão de áreas protegidas nos trópicos; (ii) Gestão de áreas protegidas costeiras e marinhas; e (iii) Capacitação e treinamento de pessoal. Cada tema amplo se subdividiu em 12 sessões, que tratavam de temas específicos (IUCN, 1982). Os temas específicos escolhidos para a discussão da gestão de áreas protegidas nos trópicos e a ordem de

\footnotetext{
${ }^{13}$ Nome original World Conservation Monitoring Centre

${ }^{14}$ Nome original Conservation Monitoring Centre
} 
discussão deles sugerem uma reflexão sobre a avaliação da efetividade como uma sequência natural do processo de elaboração e implementação do plano de manejo:

1. Contribuição das áreas protegidas para o desenvolvimento económico e social: políticas para atender necessidades de expansão das áreas protegidas;

2. Categorias, critérios e objetivos para as áreas protegidas;

3. A base biogeográfica para sistemas de áreas protegidas;

4. A base jurídica e administrativa para a gestão: desenho organizacional;

5. As áreas protegidas e ordenamento do território;

6. Os fatores socioeconómicos na gestão de áreas protegidas;

7. O desenvolvimento de princípios de gestão de recursos;

8. Planejamento da gestão das áreas protegidas;

9. Implementação das áreas protegidas;

10. Determinar a gestão efetiva;

11. A cooperação internacional na gestão das áreas protegidas;

12. Comunicação: garantir que a mensagem certa atinge o público certo. ${ }^{15}$

A discussão da sessão 10, "Determinar a gestão efetiva", teve por objetivo discutir uma proposta de metodologia para que os gestores de áreas protegidas pudessem avaliar a efetividade das suas ações de manejo. Tal metodologia deveria abarcar as ações de gestão em relação aos objetivos, aos recursos (humanos e financeiros), ao monitoramento de impactos ecológicos na gestão do habitat, e muitos outros. Os princípios e diretrizes propostos para discussão foram:

- Refletir sobre um modelo de questionário que permitisse ao gestor da área determinar a efetividade da sua gestão, assim como permitisse ao diretor do sistema de áreas protegidas avaliar a gestão de diferentes áreas)

\footnotetext{
15 Texto original em IUCN, 1982: 1. Managing protected natural areas to contribute to social; nd economic development: Policies to meet expanding needs; 2. Categories, criteria and objectives for protected areas; 3. The biogeographical basis for protected areas systems; 4. The legal and administrative basis for management: organizational design; 5. Protected areas and regional planning; 6 . Socio-economic factors in managing protected areas; 7. Developing principles of resource management; 8. Management planning; 9. Implementing management; 10.Determining effective management; 11. International cooperation in management of protected areas; 12. Communication: Ensuring that the right message reaches the right audiences
} 
- Estabelecer de padrões e controle nos diferentes níveis ${ }^{16}$;

- Refletir sobre as ferramentas ou instrumentos de gestão para o adequado funcionamento da área: identificação de problemas e definição de prioridades; estabelecimento de metas; planejamento e implementação; controle e monitoramento, e elaboração de relatórios realização;

- Refletir em como usar cientistas e investigadores para ajudar a avaliação da efetividade da gestão (em particular no que diz respeito ao acompanhamento das mudanças de habitats, flutuando populações de espécies-chave animais selvagens, etc.);

- Estabelecer um sistema de monitoramento: princípios e orientações para sistemas de áreas protegidas;

- Identificar que lições foram aprendidas em países de clima temperado na avaliação da gestão efetiva e como podem essas lições ser aplicadas aos trópicos.

Os principais trabalhos que orientaram esta sessão plenária foram sobre o banco de dados das áreas protegidas (PADU/WDPA) e o monitoramento no nível internacional (Jeremy Harrison); o uso das áreas protegidas para o monitoramento ambiental (Harvey Croze); e os trabalhos de Willian O. Deshler - Uma abordagem sistemática para gestão efetiva de áreas protegidas, J. W. Thorsell - Avaliando a efetividade de gestão em áreas protegidas: uma aplicação para o Parque Nacional de Arusha, Tazmania, e Leslie F. Molloy - A gestão efetiva de áreas protegidas. Estes três últimos abordaram a questão da efetividade da gestão explicitamente (IUCN, 1982).

Deshler abordou o que constitui uma gestão efetiva, mas não chegou a discutir sobre um sistema de avaliação. Ele definiu a gestão efetiva como o uso eficiente e ordenado dos recursos humanos e materiais planejados com vistas ao alcance dos objetivos de gestão. Seu trabalho apresentou uma metodologia para a gestão de áreas protegidas que maximizava a probabilidade de que cada ação implementada, independentemente do escopo, fosse um passo para alcançar mais um dos objetivos de gestão. Recomendava que tal metodologia fosse utilizada pelo gestor da área ou seu superior para avaliar a eficácia da gestão e como uma ferramenta de treinamento valiosa para profissionais e técnicos, no escritório e no campo (IUCN, 1982).

\footnotetext{
${ }^{16} \mathrm{O}$ documento original não traz informações que permitam identificar a que se aplica os diferentes níveis: se diferentes níveis de gestão (do ponto de vista hierárquico) ou se a diferentes indicadores ou níveis de impacto, como por exemplo no nível da paisagem, de espécies ou de variabilidade genética.
} 
O trabalho de Thorsell além de defender o ponto de vista de que deveríamos envidar esforços para as avaliações das áreas protegidas, também apontava as limitações envolvidas nessas avaliações, e sugeria como elas deveriam ser realizadas. Ao testar um método no Parque Nacional de Arusha, ele identificou como um dos principais problemas o estabelecimento de objetivos. Ainda com relação a esta questão, ele chamou a atenção para o fato de que em 55 áreas protegidas na Tanzânia, por exemplo, apenas duas áreas tinham objetivos claros e formalmente declarados. Dentre as opções para avaliar a efetividade da gestão, Thorsell incluía respostas diretas de visitantes para a área, a auditoria realizada por um painel de especialistas, ou a aplicação periódica de questionários (check-list) (IUCN, 1982).

Leslie F. Molloy compartilhou algumas ideias sobre a implementação de áreas protegidas: elaboração e implementação dos planos e programas de gestão, qualidade e utilidade dos estoques de recursos, adequação do nível de vigilância, utilidade da avaliação de impacto ambiental na regulação do uso público (para minimizar o impacto sobre os recursos naturais), formação de pessoal, atitude dos usuários em relação ao parque público, e forte questionamento sobre se as metodologias aplicadas aos países temperados seriam absorvidas com sucesso pelos países tropicais (IUCN, 1982)

Não temos os registros das discussões que ocorreram no âmbito da sessão 10 , mas, parecem ter sido produtivas, pois esse tema foi incorporado ao Plano de Ação de Bali, elaborado pelos 450 delegados que participaram do III Congresso Mundial de Parques. O Plano de Ação destacou 10 pontos considerados a essência dos debates realizados nas sessões técnicas. Dentre eles destacava-se o desenvolvimento de ferramentas e diretrizes para avaliar a qualidade ecológica e de gestão das áreas protegidas existentes, e a implementação de um inventário e de um serviço de monitoramento para as áreas protegidas:

\section{Objective 8}

To implement an effective inventory and monitoring service for protected areas.

Activities:

8.1. Expand and develop the Protected Areas Data unit (PADU) and related components of IUCN Conservation Monitoring Centre (CMC) so as to:

a) Provide information on protected areas

b) Guide the determination of priorities, and 
c) Support national and international governmental agencies in relating the design of development projects to critical protected areas

8.2. Publish and distribute real-based directories and periodical reports to inform and support national and international organizations in their planning activities

8.3. Promote arrangements by international organizations, governments and regional associations of nations for the long-term development and use of data collection systems, such as satellite remote sensing, covering all protected areas (IUCN, 1987, páginas 6 e 7).

É importante destacar que o tema da efetividade da gestão emergiu em meio às discussões centrais do III congresso, que eram: a) conexão da conservação com o desenvolvimento social e econômico; e b) futuro das áreas protegidas, que passava pela maximização dos benefícios sociais e econômicos de tais territórios, dentro dos limites permitidos pelas categorias de manejo. Nesse contexto, o objetivo 7 do Plano de Ação de Bali também merece destaque, pois chamava a atenção para a necessidade de desenvolver ferramentas de apoio para as áreas protegidas, tais como ferramentas de análise dos valores tangíveis, não tangíveis, monetários e não-monetários das áreas protegidas; ferramentas e meios para divulgação e disseminação de informações que demonstrassem a relação entre conservação (papel das áreas protegidas) e o desenvolvimento, com destaque para a manutenção dos serviços ecossistêmicos (IUCN, 1982; IUCN, 1987).

Os resultados da discussão sobre Gestão de Áreas Protegidas nos Trópicos mais tarde foram compilados no livro Managing Protected Areas in the Tropics ${ }^{17}$, de MacKinnon e MakKinnon (1986), que contém um capítulo sobre avaliação da efetividade: Avaliando a Efetividade da Gestão. Segundo MacKinnon e MakKinnon (1986; 1990), a avaliação da efetividade da gestão deve ser um processo conscientemente orientado a avaliar o progresso alcançado em relação aos objetivos de manejo, no curto e no longo prazo, propostos para uma determinada área protegida ou para o sistema de áreas protegidas. Considerando a diversidade de variáveis ecológicas e socioeconômicas que podem influenciar os resultados do manejo, especialmente quando este se destina à proteção de sistemas naturais complexos, os autores destacam como é importante que as avaliações de efetividade possam proporcionar ao gestor uma diretriz que permita a ele adaptar o curso das suas ações. Este mecanismo de retroalimentação era essencial e aplicável aos diferentes níveis do processo de gestão, desde a identificação dos objetivos,

\footnotetext{
17 A versão em espanhol "Manejo de áreas protegidas em los trópicos", publicada também pela IUCN em 1990 conta com a participação de Graham Child e Jim Thorsell
} 
até o planejamento e instrumentalização das estratégias ou ações de manejo. Para MacKinnon e MakKinnon, o processo de avaliação promove a execução eficiente e, do ponto de vista deles, vários são os benefícios de uma avaliação consciente da efetividade de gestão:

- Verificar se os objetivos do plano de manejo estão sendo alcançados e se são realistas;

- Avaliar se os recursos humanos e financeiros são suficientes para alcançar o resultado esperado;

- Compartilhar os avanços e o sucesso no alcance dos objetivos com as autoridades e para sociedade;

- Dar visibilidade aos benefícios, nos níveis local, regional e nacional, das áreas protegidas;

- Auxiliar na elaboração de futuros planos ou programas de manejo;

- Avaliar a contribuição da área para o alce dos objetivos do sistema de áreas protegidas (objetivos nacionais) e internacionais de conservação;

- Contribuir para o aperfeiçoamento das estratégias de gestão e conservação.

A avaliação da efetividade não seria uma tarefa fácil, mas também não era impossível, e MacKinnon e MakKinnon (1986; 1990), Deshler (1982), e Thorsell (1982) recomendam algumas formas de avaliação:

- $\quad$ Autoavaliação: Realizada pela equipe gestora da área protegida, e com enfoque no cumprimento do planejamento ou plano de trabalho, bem como na eficácia e no êxito (efetividade) das atividades propostas e na adequação dos métodos utilizados. A descrição dessa forma de avaliação supõe que a mesma se adequa para a autoavaliação dos processos e dos impactos. Cabe aqui destacar a diferença entre eles, utilizando a abordagem proposta por Weigand Jr. et al (2014): a) Processos - avaliam em que medida as ações foram ou não realizadas, e em alguns casos, podem mostrar também a qualidade das ações; e b) Impacto: revelam as mudanças que estão acontecendo.

Um exemplo dos parâmetros sugeridos para a avaliação a ser realizada pelos gestores foi adaptado do trabalho de Deshler (1982) e encontra-se no Quadro 2, abaixo: 
Quadro 2 - Exemplo de um questionário de auto avaliação

\section{QUESTÕES UTILIZADAS PARA AVALIAR A EFETIVIDADE DO} GESTOR/ADMINISTRADO DA ÁREA PROTEGIDA

1. O gestor e a equipe da área protegida são suficientemente familiarizados com a área a ponto de perceber rapidamente mudanças significativas nos seus recursos naturais?

2. Foram identificadas as áreas problemáticas e existem ações para resolve-las ou minimiza-las?

3. Os impactos ambientais oriundos das ações de manejo são minimizados?

4. As atividades de uso público realizadas são compatíveis com os objetivos da área?

5. Foram identificados o existe um programa de monitoramento ou de pesquisa em andamento?

6. Um mapeamento da área (em grande escala) está disponível?

7. A equipe de manejo possui adequado material de campo para realização do seu trabalho?

8. A área possui um plano operacional anual para orientar a implementação?

9. As equipes desempenham suas atividades com vistas a garantir o alce dos objetivos estabelecidos no plano de trabalho?

10. Os procedimentos administrativos permitem adaptações para que as atividades de campo aconteçam de acordo com os planos e especificações estabelecidas?

11. A capacitação em segurança e prevenção é uma prioridade?

12. Os documentos que orientam o manejo da área estão arquivados?

13. A área possui um plano de manejo ou este está em processo de elaboração?

14. O gestor da área utiliza sua experiência e habilidades pessoais para resolver problemas e tomar decisões importantes?

15. O gestor da área delega sua autoridade a membros da equipe para dedicar mais tempo a demandas mais estratégicas?

16. O gestor da área é acessível e mantém boas relações com os membros da equipe em seus diferentes níveis hierárquicos?

17. O gestor da área é um exemplo de ética profissional, atitude e comportamento?

18. O gestor incentiva e permite a capacitação e treinamento da sua equipe?

19. As funções de cada posto de trabalho estão adequadamente descritas, de forma que cada profissional entenda quais são os seus deveres?

20. As tarefas a serem desempenhadas são compatíveis com o perfil da equipe técnica? 
21. As atividades são planejadas de forma a utilizar eficientemente a equipe disponível?

22. Os guardas-parques e vigilantes são bem treinados e disciplinados?

23. Os equipamentos e instalações da área encontram-se devidamente inventariado?

24. As equipes de campo contam com material básico necessário (equipamentos de proteção individual)

25. O gestor mantém bom relacionamento com seus superiores, funcionários do governo, líderes e representantes da comunidade?

Fonte: MacKinnon e MakKinnon, 1986; MacKinnon e MakKinnon, 1990.

- Avaliação pelos administradores do sistema de áreas protegidas: Onde cada órgão ou escritório será responsável pela elaboração de um modelo de avaliação que teria como suporte os comentários, opiniões e/ou relatos dos visitantes, as visitas de inspeção às áreas protegidas, e as auditorias em relação ao uso dos recursos. Da mesma maneira como proposto na autoavaliação, o progresso será avaliado em função das metas e atividades planejadas, além da possibilidade de se comparar áreas protegidas de um mesmo órgão ou sistema.

- Avaliações independentes: Nesta forma de avaliação a efetividade da administração de uma área protegida ou de um sistema de áreas protegidas pode ser determinada por uma equipe de especialistas externos, que não precisam estar diretamente envolvidos com a gestão da área ou com a implementação da política. Para esse tipo de avaliação seria estabelecido um conjunto de indicadores que pudesse quantificar os desempenhos individuais.

- Avaliações pelo comitê local: O papel do comitê local é semelhante ao papel dos conselhos de UC previsto no Capítulo V do Decreto 4340/2002 que regulamenta a Lei 9.985/2000 (Lei do SNUC):

Art. 17. As categorias de unidade de conservação poderão ter, conforme a Lei no 9.985, de 2000, conselho consultivo ou deliberativo, que serão presididos pelo chefe da unidade de conservação, o qual designará os demais conselheiros indicados pelos setores a serem representados.

$\S 1$ o A representação dos órgãos públicos deve contemplar, quando couber, os órgãos ambientais dos três níveis da Federação e órgãos de áreas afins, tais como pesquisa científica, educação, defesa nacional, cultura, turismo, paisagem, arquitetura, arqueologia e povos indígenas e assentamentos agrícolas.

§ 20 A representação da sociedade civil deve contemplar, quando couber, a comunidade científica e organizações não-governamentais ambientalistas 
com atuação comprovada na região da unidade, população residente e do entorno, população tradicional, proprietários de imóveis no interior da unidade, trabalhadores e setor privado atuantes na região e representantes dos Comitês de Bacia Hidrográfica.

§ 3o A representação dos órgãos públicos e da sociedade civil nos conselhos deve ser, sempre que possível, paritária, considerando as peculiaridades regionais.

$\S 4$ A A Organização da Sociedade Civil de Interesse Público - OSCIP com representação no conselho de unidade de conservação não pode se candidatar à gestão de que trata o Capítulo VI deste Decreto.

§ 5o O mandato do conselheiro é de dois anos, renovável por igual período, não remunerado e considerado atividade de relevante interesse público.

$\S 60$ No caso de unidade de conservação municipal, o Conselho Municipal de Defesa do Meio Ambiente, ou órgão equivalente, cuja composição obedeça ao disposto neste artigo, e com competências que incluam aquelas especificadas no art. 20 deste Decreto, pode ser designado como conselho da unidade de conservação.

Art. 18. A reunião do conselho da unidade de conservação deve ser pública, com pauta preestabelecida no ato da convocação e realizada em local de fácil acesso.

Art. 19. Compete ao órgão executor:

I - convocar o conselho com antecedência mínima de sete dias;

II - prestar apoio à participação dos conselheiros nas reuniões, sempre que solicitado e devidamente justificado.

Parágrafo único. O apoio do órgão executor indicado no inciso II não restringe aquele que possa ser prestado por outras organizações.

Art. 20. Compete ao conselho de unidade de conservação:

I - elaborar o seu regimento interno, no prazo de noventa dias, contados da sua instalação;

II - acompanhar a elaboração, implementação e revisão do Plano de Manejo da unidade de conservação, quando couber, garantindo o seu caráter participativo;

III - buscar a integração da unidade de conservação com as demais unidades e espaços territoriais especialmente protegidos e com o seu entorno;

IV - esforçar-se para compatibilizar os interesses dos diversos segmentos sociais relacionados com a unidade;

V - avaliar o orçamento da unidade e o relatório financeiro anual elaborado pelo órgão executor em relação aos objetivos da unidade de conservação;

VI - opinar, no caso de conselho consultivo, ou ratificar, no caso de conselho deliberativo, a contratação e os dispositivos do termo de parceria com OSCIP, na hipótese de gestão compartilhada da unidade;

VII - acompanhar a gestão por OSCIP e recomendar a rescisão do termo de parceria, quando constatada irregularidade;

VIII - manifestar-se sobre obra ou atividade potencialmente causadora de impacto na unidade de conservação, em sua zona de amortecimento, mosaicos ou corredores ecológicos; e

IX - propor diretrizes e ações para compatibilizar, integrar e otimizar a relação com a população do entorno ou do interior da unidade, conforme o caso (Lei 9.985/2000).

Uma instância semelhante deve ter também o papel de avaliar a efetividade de gestão, sobretudo em alguns países dos trópicos. Além de envolver um maior número de 
atores vinculados à gestão da área protegida, o funcionamento do comitê supõe que tais avaliações possam ser contínuas. Contudo, o decreto que regulamenta, no Brasil, a operacionalização dos conselhos das UCs não prevê dentre as suas atribuições (Art.20) acompanhar as avaliações de efetividade das UCs, sendo suas ações voltadas exclusivamente para as atividades de planejamento e implementação, não participando das atividades de avaliação. Mais adiante, perceberemos que, embora as primeiras discussões sobre efetividade tenham acontecido no âmbito do III Congresso Mundial de Parques, em 1982, esse tema só passou a ser debatido mais intensamente e com maior profundidade a partir dos anos 2000. Note-se que o decreto de regulamentação do SNUC é de 2002.

- Avaliação pelos usuários: Um tipo de avaliação menos rigorosa, baseada em relatos e opiniões dos usuários da área protegida, mas que pode ajudar a retroalimentação dos programas e planos de uso público.

- Avaliação do uso dos recursos: A efetividade da área também pode ser avaliada em relação à utilização eficiente dos recursos, avaliando os recursos disponíveis em relação às atividades realizadas. Entretanto, uma avaliação de custo-benefício estaria mais associada à eficiência do planejamento e execução das ações de manejo, e, portanto, associada à eficiência dos processos.

- Avaliação do planejamento: Cujo objetivo é avaliar as limitações administrativas (disponibilidade de pessoal) e de contexto (ambientais, socioeconômicas e politicas). Com este tipo de avaliação os autores pretendem identificar se as atividades planejadas foram executadas no tempo previsto, e quais foram os fatores determinantes para a adequada execução ou não.

- Avaliação do alcance das metas: Diretamente ligada à avaliação dos impactos esperados da gestão da área protegida, a avaliação do alcance das metas nem sempre conta com uma boa definição das mesmas: "conservar ecossistemas naturais", "salvar determinada espécie" ou "fomentar o uso público". Não são os melhores exemplos de metas, pois não ajudam na estimativa do êxito ou do sucesso no alcance delas. Para este tipo de avaliação são necessárias metas mais específicas com indicadores de êxito explícitos nos planos e programas de manejo, pois só dessa maneira será possível avaliar os impactos em relação às expectativas.

- Avaliação do custo-efetividade: Neste tipo de avaliação deve haver uma avaliação dos custos de implementação da área protegida em relação aos valores (tangíveis ou não) 
da área protegida, embora a recomendação seja priorizar as funções economicamente mensuráveis, como por exemplo as funções ecossistêmicas de manutenção dos regimes hídricos e de $\mathrm{CO}_{2}$. Quando estas estimativas não são possíveis, devem ser realizadas estimativas que demonstrem que as funções de proteção são maiores que as possibilidades de atividades produtivas.

- Formulários de avaliação: Para este tipo de avaliação, deve ser elaborado um modelo objetivo que tenha como ponto de partida os objetivos de manejo de cada categoria de área protegida, se relacionando com estratégias de implementação dos sistemas de áreas protegidas e com o plano de manejo da área em questão. Os parâmetros avaliados devem abranger todos os níveis de gestão em marcos temporais bem definidos (mensais, semestrais ou anuais). Este tipo de avaliação periódica serviria aos gestores, suas equipes e aos administradores dos sistemas de áreas protegidas de forma a permitir ações corretivas e o manejo adaptativo. Baseado no primeiro modelo desenvolvido pela WCPA/IUCN, foi desenvolvido um modelo inicial de formulário para avaliação da efetividade das áreas protegidas, modelo este dividido em 23 blocos de perguntas, que juntos ajudam a identificar a situação para cerca de 120 parâmetros (Quadro 3 e Anexo 1):

Quadro 3 - Bloco de perguntas do primeiro modelo de formulário de avaliação de efetividade desenvolvido pela WCPA da IUCN

\begin{tabular}{|c|c|c|c|}
\hline \multicolumn{4}{|c|}{$\begin{array}{l}\text { BLOCO DE PERGUNTAS DO FORMULÁRIO DE AVALIAÇÃO DE } \\
\text { EFETIVIDADE }\end{array}$} \\
\hline $\begin{array}{l}\text { 1. Objetivos } \\
\text { específicos }\end{array}$ & 2 Aspectos legais & $\begin{array}{l}3 \text { Alvos de } \\
\text { conservação }\end{array}$ & $\begin{array}{c}\text { Estudos ou } \\
\text { informações sobre } \\
\text { os alvos } \\
\end{array}$ \\
\hline $\begin{array}{l}5 \text { Manejo de } \\
\text { bacias }\end{array}$ & $\begin{array}{l}\text { 6. Recursos } \\
\text { genéticos }\end{array}$ & 7. Plano de manejo & 8. Zoneamento \\
\hline 9. Limite da área & 10 Desenho & $\begin{array}{l}\text { 11. Proteção dos } \\
\text { recursos naturais }\end{array}$ & 12. Pesquisa \\
\hline $\begin{array}{l}\text { 13, Educação } \\
\text { formal }\end{array}$ & $\begin{array}{l}\text { 14. Educação não } \\
\text { Formal } \\
\end{array}$ & 15. Turismo & $\begin{array}{l}16 \text { Apoio } \\
\text { institucional }\end{array}$ \\
\hline $\begin{array}{l}\text { 17. Participação } \\
\text { local }\end{array}$ & $\begin{array}{l}\text { 18. Benefícios } \\
\text { para população } \\
\text { local }\end{array}$ & 19. Orçamento & $\begin{array}{l}\text { 20. Recursos para } \\
\text { manutenção }\end{array}$ \\
\hline $\begin{array}{l}\text { 21. Equipe e } \\
\text { capacitaçãoo }\end{array}$ & 22 Equipamentos & 23. Apoio externo & \\
\hline
\end{tabular}

Fonte:MacKinnon e MakKinnon, 1986, e MacKinnon e MakKinnon,1990. 
Apesar da sistematização das discussões técnicas sobre efetividade de gestão realizadas no âmbito do III Congresso Mundial de Parques e compartilhadas por MacKinnon e MakKinnon (1986; 1990), Deshler (1982) e Thorsell (1982), nenhuma avaliação de efetividade ocorreu no Brasil durante o período entre o III e o IV Congresso Mundial de Parques, realizado em 1992, em Caracas na Venezuela. Contudo, o Brasil chegou à década de 1990 com uma pluralidade de categorias de áreas naturais protegidas a título ambiental. Além de parques, florestas e reservas biológicas, previstos pelo Código Florestal de 1965, Lei 4.771/1965, uma série de leis estabeleceu novas categorias de UCs: a Lei 6.902/1981 instituiu as estações ecológicas e as áreas de proteção ambiental; o Decreto 89.336/1984 criou duas categorias a mais, as reservas ecológicas e as áreas de relevante interesse ecológico ${ }^{18}$; as reservas extrativistas surgiram em 1987, com base na Portaria 627 do Instituto Nacional de Colonização e Reforma Agrária (Incra), mas só foram reconhecidas como UCs por intermédio do Decreto 98.897/1990; e a categoria reserva particular do patrimônio natural (RPPN) foi criada pelo Decreto 1.992/1996. Apesar dos diferentes tipos de UCs, faltavam leis e diretrizes de gerenciamento que garantissem eficácia a essa variedade de categorias (DRUMMOND, FRANCO e NINIS, 2006; DRUMMOND, FRANCO e OLIVEIRA, 2010).

\section{Motivações e recomendações para avaliação de efetividade no âmbito do IV Congresso Mundial de Parques, realizado em 1992, em Caracas na Venezuela}

Diferente do III Congresso, o IV Congresso Mundial de Parques não teve uma sessão ou um grupo de trabalho que tivesse as avaliações de efetividade de gestão como um tema gerador de discussão e recomendações. O tema do congresso foi Parks for Life e as discussões tiveram como pano de fundo temas amplos divididos em quatros grandes simpósios: I. Como as áreas protegidas podem atender as necessidades da sociedade: questões sociais, econômicas e políticas; II. As áreas protegidas e as mudanças globais: questões científicas; III. Planejamento regional e áreas protegidas; e IV. Os desafios para gestão das áreas protegidas. O tema avaliação de efetividade foi abordado no âmbito do Simpósio II, As áreas protegidas e as mudanças globais: questões científicas, nos workshops sobre Monitoramento de Áreas Protegidas, Pesquisa nas Áreas Protegidas, e Gestão de Áreas Costeiras (IUCN, 1993).

\footnotetext{
${ }^{18}$ Reconhecidas como UCs pela Resolução ${ }^{\circ}$ 12, de 14 de dezembro de 1987, do Conselho Nacional do Meio Ambiente (Conama)
} 
O primeiro workshop, Monitoramento de Áreas Protegidas, organizado pela IUCN, sob a responsabilidade de Jeff McNeely e coordenado por Francisco Dellmeier, teve o papel de propor orientações gerais para o monitoramento em áreas protegidas. Dentre as conclusões destacadas pelo grupo que participou do workshop encontramos a afirmação de que a efetiva conservação dos ecossistemas mundiais e das áreas protegidas passa pelo melhor entendimento dos processos e interações ecológicas, das questões socioeconômicas e de uso dos recursos, e de que os gestores e a comunidade científica deveriam avaliar a efetividade do monitoramento e das pesquisas para otimizar a utilidade das informações coletadas. As recomendações do grupo convergiam para o fortalecimento do Centro Mundial de Monitoramento da Conservação (WCMC) e dos governantes, como podemos ver abaixo:

- Reforçar o papel do WCMC como coordenação cientifica e como agência responsável pela base de dados. Cabe ao WCMC: orientar sobre os objetivos e prioridades de pesquisa e monitoramento que atendam às exigências de proteção dos ecossistemas mundiais e regionais, conforme apropriado; incentivar e apoiar iniciativas de pesquisa e monitoramento, por meio da assistência financeira, do intercâmbio de informações e conhecimentos, do desenvolvimento de sistemas de gestão de dados padronizados para assegurar a conformidade com as normas internacionais; e ampliar a sua capacidade educacional fomentando e produzindo materiais e manuais orientadores sobre o monitoramento em áreas protegidas.

- Cabe aos governos nacionais reforçar as suas infraestruturas de pesquisa e monitoramento de forma a garantir a gestão efetiva de suas áreas protegidas, assim como contribuir para a compreensão dos processos ecológicos e da gestão ambiental no nível global.

O segundo workshop, Pesquisa nas áreas Protegidas, como o primeiro, reforça a importância das informações (biológicas, econômicas, sociais e gerenciais) oriundas de diferentes níveis (comunidades locais e global) como instrumento para identificação dos problemas e das soluções que beneficiam a conservação. Organizado pela The George Wright Society e pela IUCN, sob a coordenação de Sarath Kotagama, teve como perguntas orientadoras do debate questões que reforçavam a relação entre a pesquisa e a adequada gestão das áreas protegidas: O que é necessário ser feito para facilitar a aplicação do conhecimento científico no manejo das áreas protegidas? O que os pesquisadores devem fazer pata incorporar a aplicação do manejo nas suas pesquisas? As conclusões do grupo 
indicavam as seguintes necessidades: a) de uma maior interface entre as ciências naturais e sociais; b) de que a pesquisa em áreas protegidas estivesse disponível e fizesse sentido para outros pesquisadores, para os gestores, agências de conservação e público em geral; c) de que toda pesquisa realizada em uma área protegida tivesse três formatos de comunicação: para os membros da comunidade científica, para os gestores e agências de conservação, e para o público e sociedade em geral.

O terceiro workshop, Gestão de áreas costeiras, tratou dos principais aspectos da ciência para a identificação, criação, planejamento, implementação e o efetivo monitoramento das áreas marinhas. Em relação ao monitoramento orientado para gestão efetiva, o grupo recomendou o monitoramento do estado e das mudanças nos ativos ou alvos de conservação; das ameaças às áreas protegidas; dos impactos das áreas protegidas nas economias locais e regionais; e da eficiência e do rumo/curso da gestão e das ações de manejo.

O tema monitoramento em áreas protegidas também foi transversalmente discutido no IV Congresso, em outros workshops, contribuindo para a reflexão sobre como medir ou mensurar a biodiversidade e os benefícios oriundos das áreas protegidas. Outro tema que chama a atenção no conjunto das discussões diz respeito às outras informações necessárias para a gestão (econômicas, sociais e gerenciais). Era preciso saber quais as informações mínimas e como mensurá-las. Dentre as ações listadas para implementação do plano de ação do IV Congresso de Parques, podemos destacar:

Objetivo 1. Integrar as áreas protegidas no planejamento regional; Ação 1.4. Desenvolver técnicas para avaliar e quantificar os benefícios das áreas protegidas

- Organizar os estudos existentes sobre os benefícios oriundos de áreas protegidas existentes, incluindo os benefícios que não podem ser expressos puramente em termos monetários;

- Divulgar informações sobre benefícios associados a diferentes categorias de manejo, e preparar orientações sobre a forma como esses benefícios podem ser determinados;

- Prepare inventários exaustivos dos ativos ou alvos de conservação de cada área protegida - paisagens, sítios históricos e culturais, os ecossistemas, espécies e recursos genéticos - e reconhecer esses recursos como bens de capital; 
- Desenvolver metodologias para avaliação econômica de áreas protegidas e usálas para determinar e defender as prioridades de utilização dos recursos.

Objetivo 3. Fortalecer a capacidade de gerir as áreas protegidas; Ação 3.3. Melhorar a gestão das áreas protegidas:

- O principal pré-requisito para garantir a gestão efetiva de uma área protegida é a elaboração do seu plano de manejo, que deve informar o que deve ser feito, por que, por quem, com quem e com quais recursos;

- Estabelecer o conjunto de requisitos profissionais que cada equipe das áreas protegidas deve apresentar;

- Melhorar a capacidade dos gestores no monitoramento da sua performance por meio de indicadores para o manejo efetivo;

- Desenvolver caminhos inovadores para realização das ações/tarefas de manejo em conjunto com outros atores (voluntários).

Objetivo 3. Fortalecer a capacidade de gerir as áreas protegidas; Ação 3.4. Melhorar a interface entre a gestão e a ciência:

- Incentivar a interface entre a gestão e a ciência básica, e que toda pesquisa desenvolvida em áreas protegidas deva contribuir para gestão efetiva da área;

- Quando possível, os resultados dessas pesquisas devem atender às demandas das comunidades do entorno e dos usuários dos recursos.

Tais ações tinham a finalidade de dar uma resposta para as questões mais urgentes identificadas no IV Congresso, mas o Comitê Organizador também compartilhou as recomendações, baseadas nos 49 workshops, em face dos principais desafios das áreas protegidas nos anos 1990. Algumas dessas recomendações tinham relações diretas com avaliações de efetividade de gestão, e outras com as discussões sobre a pesquisa e o monitoramento em áreas protegidas, reforçando o pensamento de que criar uma área protegida é um passo, mas garantir a sua boa gestão é outro igualmente importante. As recomendações da IUCN eram:

- Desenvolver ferramentas e estratégias para ajudar os gestores de áreas protegidas na avaliação e na melhoria da gestão das áreas protegidas;

- Desenvolver um sistema de monitoramento da efetividade de gestão e das ameaças para as áreas protegida, a ser aplicado pelas agências de conservação e seus gestores; 
- Que os envolvidos com a gestão das áreas protegidas compartilhassem tais informações com o WCMC.

\subsection{Marco conceitual para avaliação da efetividade de gestão}

Após o IV Congresso Mundial de Parques, que ocorreu em fevereiro de 1992, a Convenção sobre Diversidade Biológica (CDB), um dos principais documentos resultantes da Conferência das Nações Unidas para o Meio Ambiente $e$ Desenvolvimento ${ }^{19}$, também conhecida por Eco-92, Cúpula da Terra ou Rio 92, realizada no Brasil, na cidade do Rio de Janeiro, em junho de 1992, reforçou a importância da identificação e do monitoramento dos componentes da biodiversidade - Artigo 7 da CDB - e a importância das áreas protegidas como mecanismos para a conservação in situ Artigo 8 da CDB (MMA, 2000; BURSZTYN e BURSZTYN, 2012).

\section{Artigo 7: Identificação e Monitoramento}

Cada Parte Contratante deve, na medida do possível e conforme o caso, em especial para os propósitos dos arts. 8 a 10:

a) Identificar componentes da diversidade biológica importantes para sua conservação e sua utilização sustentável, levando em conta a lista indicativa de categorias;

b) Monitorar, por meio de levantamento de amostras e outras técnicas, os componentes da diversidade biológica identificados em conformidade com a alínea (a) acima, prestando especial atenção aos que requeiram urgentemente medidas de conservação e aos que ofereçam o maior potencial de utilização sustentável;

c) Identificar processos e categorias de atividades que tenham ou possam ter sensíveis efeitos negativos na conservação e na utilização sustentável da diversidade biológica, e monitorar seus efeitos por meio de levantamento de amostras e outras técnicas; e

d) Manter e organizar, por qualquer sistema, dados derivados de atividades de identificação e monitoramento em conformidade com as alíneas a, b e c acima.

\section{Artigo 8: Conservação in situ}

Cada Parte Contratante deve, na medida do possível e conforme o caso: a) Estabelecer um sistema de áreas protegidas ou áreas onde medidas especiais precisem ser tomadas para conservar a diversidade biológica; b) Desenvolver, se necessário, diretrizes para a seleção, estabelecimento e administração de áreas protegidas ou áreas onde medidas especiais precisem ser tomadas para conservar a diversidade biológica;

c) Regulamentar ou administrar recursos biológicos importantes para a conservação da diversidade biológica, dentro ou fora de áreas protegidas, a fim de assegurar sua conservação e utilização sustentável;

\footnotetext{
${ }^{19}$ Os principais documentos resultantes da Cúpula da Terra ou Rio 92 foram a Declaração das Nações Unidas sobre Meio Ambiente e Desenvolvimento, a Agenda 21, a Convenção-Quadro sobre a Mudança do Clima, a Convenção sobre a Diversidade Biológica e a Convenção sobre a Desertificação.
} 
d) Promover a proteção de ecossistemas, hábitats naturais e manutenção de populações viáveis de espécies em seu meio natural;

e) Promover o desenvolvimento sustentável e ambientalmente sadio em áreas adjacentes às áreas protegidas a fim de reforçar a proteção dessas áreas;

f) Recuperar e restaurar ecossistemas degradados e promover a recuperação de espécies ameaçadas, mediante, entre outros meios, a elaboração e implementação de planos e outras estratégias de gestão;

g) Estabelecer ou manter meios para regulamentar, administrar ou controlar os riscos associados à utilização e liberação de organismos vivos modificados resultantes da biotecnologia que provavelmente provoquem impacto ambiental negativo que possa afetar a conservação e a utilização sustentável da diversidade biológica, levando também em conta os riscos para a saúde humana;

h) Impedir que se introduzam, controlar ou erradicar espécies exóticas que ameacem os ecossistemas, hábitats ou espécies;

i) Procurar proporcionar as condições necessárias para compatibilizar as utilizações atuais com a conservação da diversidade biológica e a utilização sustentável de seus componentes;

j) Em conformidade com sua legislação nacional, respeitar, preservar e manter o conhecimento, inovações e práticas das comunidades locais e populações indígenas com estilo de vida tradicionais relevantes à conservação e à utilização sustentável da diversidade biológica e incentivar sua mais ampla aplicação com a aprovação e a participação dos detentores desse conhecimento, inovações e práticas; e encorajar a repartição eqùitativa dos benefícios oriundos da utilização desse conhecimento, inovações e práticas;

k) Elaborar ou manter em vigor a legislação necessária e/ou outras disposições regulamentares para a proteção de espécies e populações ameaçadas;

1) Quando se verifique um sensível efeito negativo à diversidade biológica, em conformidade com o art. 7, regulamentar ou administrar os processos e as categorias de atividades em causa; e m) Cooperar com o aporte de apoio financeiro e de outra natureza para a conservação in situ a que se referem as alíneas a a 1 acima, particularmente aos países em desenvolvimento(MMA, 2000, páginas 11 e 12).

O fato motivador para o estabelecimento da CDB foi a sensível redução da diversidade biológica causada por atividades humanas e a consciência do valor intrínseco da diversidade biológica, e também dos valores ecológico, genético, social, econômico, científico, educacional, cultural, recreativo e estético da diversidade biológica e de seus componentes.

A WCPA/IUCN preparou, em 1984, uma lista de áreas protegidas ameaçadas do mundo, e embora reconhecesse que a lista estava incompleta, considerou-a como indicativo de algumas das muitas ameaças enfrentadas pelas áreas protegidas em todo o mundo. Baseada em observações de membros da WCPA e do CMC, ambos da IUCN, as mais relatadas foram: gestão inadequada dos recusros naturais, invasão humana, mudança 
no regime hídrico, caça, e áreas urbanas no entorno. Uma nova inciativa foi empreendida para o IV Congresso Mundial de Parques Nacionais e Áreas Protegidas, ampliando o escopo do levantamento e incluindo informações sobre o estado e cobertura de áreas protegidas; sobre as modalidades de gestão, financiamento, pessoal, estruturas institucionais; e sobre as principais ameaças. Tal levantamento não fez uma análise comparativa entre as ameaças e as áreas protegidas, e tampouco uma comparação entre elas, já que para algumas perguntas as respostas eram subjetivas. Três das cinco ameaças mais comumente relatadas envolviam deficiências institucionais de gestão, incluindo legislação inadequada, práticas administrativas inadequadas, e escassez de financiamento e de pessoal, não sendo citado dentre estas impactos externos sobre as áreas protegidas (MCNEELY et al. 1994; HOCKINGS, 2003).

As iniciativas para avaliação da efetividade de áreas protegidas posteriores ao IV Congresso Mundial de Parques e à CDB ocorrem em sintonia com os estudos e discussões do Grupo de Trabalho de Efetividade de Gestão, criado em 1996-1997, no âmbito da WCPA. Nos anos que se seguiram, a WCPA começou a trabalhar em indicadores globais de efetividade de gestão, com a intenção de ajudar na visualização da forma como áreas bem protegidas eram geridas e administradas em todo o mundo. Até o momento do Congresso Mundial de Conservação da IUCN, realizado em 2000, em Amman, na Jordânia, a força-tarefa da WCPA, liderada pelo membro da WCPA - Marc Hockings, tinha desenvolvido e testado na prática um piloto para avaliação da efetividade de gestão. Nesse mesmo ano, a IUCN publicou o primeiro documento com o marco conceitual e as diretrizes para a avaliação da efetividade, Evaluating Effectiveness: A framework for assessing management effectiveness of protected áreas (HOCKINGs et al., 2000 ${ }^{20}$. Este documento destaca para a gestão efetiva três componentes principais de avaliação: 1) questões de design/desenho das áreas protegidas individuais e dos sistemas de áreas protegidas (conjunto); 2) adequação dos sistemas e processos de gestão; 3) alcance dos objetivos da área protegida. O grupo de trabalho, criado em 1997, passou a ser representado por um programa temático dentro da WCPA.

Baseado no ciclo de monitoramento e avaliação o marco conceitual da WCPA possui seis estágios ou elementos de avaliação: Contexto, Planejamento, Insumos, Processos, Produtos e Resultado/Impacto (Quadro 4). O quadro abaixo sugere que os

\footnotetext{
${ }^{20}$ A publicação teve sua segunda edição publicada em 2006
} 
sistemas de avaliação da eficácia da gestão devem incorporar componentes que cobrem cada um destes seis elementos, entendidos como complementares, ao invés de abordagens alternativas para a avaliação da efetividade de gestão. No entanto, uma vez que estes componentes constituem uma repartição conveniente de elementos de eficácia de gestão, cada um representa aspectos diferenciados. A avaliação conjunta dos elementos dá uma imagem detalhada de gestão, fornecendo informações que podem melhorar a eficácia das áreas protegidas individuais ou sistemas de áreas protegidas de conservação e gestão.

\begin{tabular}{|c|c|c|c|}
\hline $\begin{array}{l}\text { ELEMENTO DE } \\
\text { AVALIAÇÃO }\end{array}$ & DESCRIÇÃO & CRITÉRIO AVALIADO & $\begin{array}{c}\text { FOCO DA } \\
\text { AVALIAÇÃ }\end{array}$ \\
\hline Contexto & $\begin{array}{l}\text { Onde estamos } \\
\quad \text { agora? }\end{array}$ & $\begin{array}{l}\text { Importância, Ameaças, } \\
\text { Vulnerabilidade e Contexto } \\
\text { local }\end{array}$ & $\begin{array}{c}\text { Avaliação da } \\
\text { importância, das } \\
\text { ameaças e da política } \\
\text { ambiental } \\
\end{array}$ \\
\hline Planejamento & $\begin{array}{l}\text { Onde queremos } \\
\text { chegar }\end{array}$ & $\begin{array}{c}\text { Amparo legal, Desenho da } \\
\text { UC } \\
\text { Desenho do Sistema } \\
\text { Planejamento }\end{array}$ & $\begin{array}{c}\text { Avaliação do } \\
\text { planejamento e do } \\
\text { desenho da área }\end{array}$ \\
\hline Insumos & $\begin{array}{l}\text { Que recursos } \\
\text { necessitamos? }\end{array}$ & $\begin{array}{c}\text { Recursos disponíveis para a } \\
\text { agencia gestores das áreas e } \\
\text { os Recursos disponíveis } \\
\text { para a UC }\end{array}$ & $\begin{array}{l}\text { Avaliação dos } \\
\text { recursos necessários } \\
\text { ao manejo }\end{array}$ \\
\hline Processos & $\begin{array}{l}\text { Como a gestão é } \\
\text { conduzida? }\end{array}$ & $\begin{array}{c}\text { Planejamento de Manejo, } \\
\text { Práticas de manejo, } \\
\text { Pesquisa, monitoramento e } \\
\text { avaliação }\end{array}$ & $\begin{array}{l}\text { Avaliação de como a } \\
\text { gestão foi conduzida }\end{array}$ \\
\hline Resultados & O que fizemos? & $\begin{array}{l}\text { Resultado da ações, } \\
\text { serviços e produtos do } \\
\text { Manejo }\end{array}$ & $\begin{array}{c}\text { Avaliação da } \\
\text { implementação dos } \\
\text { programas e ações do } \\
\text { manejo; Produtos e } \\
\text { serviços entregues }\end{array}$ \\
\hline $\begin{array}{l}\text { Alcance dos } \\
\text { objetivos }\end{array}$ & Onde chegamos? & $\begin{array}{l}\text { Impacto: efeito do manejo } \\
\text { em relação aos objetivos }\end{array}$ & $\begin{array}{c}\text { Avaliação do alcance } \\
\text { dos objetivos e a } \\
\text { extensão desse } \\
\text { alcance }\end{array}$ \\
\hline
\end{tabular}

Fonte: HOCKINGS et al., 2000; HOCKINGS, 2006.

O marco conceitual estabelece que, para a adequada gestão da UC, é necessário ter clareza sobre os objetivos, importância e alvos de conservação; sobre a situação atual da área protegidas, seu estado de conservação, ameaças e fatores externos que comprometam o alcance/manutenção dos objetivos; sobre as estratégias/ações necessárias para alcance/manutenção dos objetivos e alvos de conservação; sobre os insumos necessários à execução das ações ou processo de gestão para obtenção de resultados, e sobre como esses resultados convertem-se em impactos desejados (HOCKINGS, 2003). 
De forma simultânea, em diversas partes do mundo, grupos e indivíduos trabalhavam com o tema da efetividade, resultando em diretrizes, metodologias e ferramentas para os sistemas de áreas protegidas ou para as áreas protegidas individuais. Algumas das metodologias desenvolvidas para avaliar a efetividade de gestão das áreas protegidas eram adaptadas para determinadas regiões ou habitats. Reconhecendo a necessidade de uma abordagem abrangente, a WCPA desenvolveu um quadro de avaliação que permitia a avaliação de metodologias específicas dentro de uma abordagem global e coerente. A avaliação da efetividade de gestão ganhou a adesão de muitos governos nacionais e ONGs. Algumas avaliações de efetividade foram empreendidas pela The Nature Conservancy (TNC), pelo World Wildlife Fund (WWF) e pelo Centro Agronómico Tropical de Investigación y Enseñanza (CATIE). O Banco Mundial adotou um sistema de avaliação, desenvolvido em parceria com o WWF a partir do marco conceitual da WCPA, como uma ferramenta padrão para todos os projetos de áreas protegidas e que mais tarde foi adotada pelo Global Environmental Facility (GEF) (CIFUENTES et al, 2000; ERVIN, 2003; HOCKINGS, 2000; HOCKINGS, 2003).

No Brasil, as aplicações de avaliações de efetividade de UCs começaram no final da década de 1990. As ferramentas utilizadas nas avaliações de efetividade das UCs brasileiras serão detalhadas no capítulo 2 desta tese.

No final da década de 1990, um estudo encomendado pelo Fundo Mundial para a Natureza/WWF encontrou uma correlação entre má gestão e nível de ameaça em áreas protegidas, concluindo que as informações sobre a capacidade de gestão indicavam o estado provável da conservação da área protegida ou, pelo menos, o grau provável de ameaça (CAREY et al., 2000). Esse estudo recomendava que para manter o status de conservação das áreas protegidas, os gerentes precisavam monitorar a eficácia de suas ações de gestão para que eles pudessem identificar problemas e concentrar os seus recursos e esforços para a solução deles. Na ausência de informação sistemática sobre a eficácia da gestão, segundo Carey et al (2000), os gestores estão "voando às cegas", respondendo apenas às ameaças claramente visíveis, esperando que as abordagens e técnicas de gerenciamento padrão ajudem a alcançar os resultados esperados. O estudo aponta ainda que para melhorar a capacidade de gestão de áreas protegidas, os gerentes precisam compreender melhor as ameaças de cada área protegida, o impacto dessas ameaças sobre os alvos de conservação, bem como a eficácia das suas estratégias de gestão na prevenção e mitigação das ameaças. 
É importante notar a sobreposição de três conceitos que serão abordados ao longo desta tese, pois os métodos de avaliação, mesmo aqueles que não avaliam adequadamente o impacto da gestão nos recursos naturais ou nos alvos de conservação, são comumente identificados como ferramentas ou métodos de avaliação da efetividade. Os conceitos são:

- Eficácia de Gestão - refere-se à performance em relação aos instrumentos e meios para a adequada gestão das UCs. Avaliar a eficácia é uma forma de identificar ou visualizar a distância entre a gestão desejada e a realidade atual, seja para a UC, seja para o sistema do qual ela faz parte. A eficácia de gestão é o conjunto de ações que, influenciadas pelas atitudes, habilidades e competências específicas, permite alcançar/cumprir os objetivos/funções para os quais a área foi criada (CAREY, DUDLEY e STOLTON, 2000; CIFUENTES, IZURIETA e DE FARIA, 2000; DE FARIA, 2006; PATTON, 2007; LEVERINGTON, HOCKINGS e COSTA, 2008). Para De Faria (2006), avaliar a eficácia significa avaliar se a "gestão está seguindo um rumo que conduz as UCs ao alcance de seus objetivos de manejo, ao aproveitamento de suas potencialidades científicas, educacionais, culturais, recreativas e econômicas" (p.45). Além de De Faria (1993; 2006), a distinção entre eficácia e efetividade foi abordada por outros autores: IUCN (1993) e Cayot e Cruz (1998).

- Efetividade de Gestão - refere-se ao impacto/êxito da UC em relação à conservação, à manutenção dos valores da biodiversidade e à sustentabilidade no uso dos recursos naturais. Ou seja, quando a eficácia da gestão resultar em impacto positivo no estado de conservação da biodiversidade e/ou na utilização sustentável dos recursos naturais. Como visto anteriormente, foi destacado por Hockings, Stolton e Dudley (2000) que os três componentes principais de avaliação são: a) questões de design/desenho das áreas protegidas individuais e dos sistemas de áreas protegidas (conjunto); b) adequação dos sistemas e processos de gestão; c) alcance dos objetivos da área protegida. Esta perspectiva também converge com as abordagens de De Faria (1993; 2006), de Cifuentes, Izurieta e De Faria (2000), e De Fries et al. (2007), que associam fortemente o conceito de efetividade ao conceito de impacto.

- Eficiência na Gestão - está associada à otimização ou a organização racional dos meios, tempo e recursos humanos e materiais, de forma a obtenção do resultado esperado vinculado a melhor aproveitamento dos investimentos financeiros, ou seja, eficiência de gestão é ser eficaz ao menor custo. 
Kayano e Caldas (2002) acrescentam contribuições importantes para o entendimento destes três conceitos, principalmente ao distingui-los quanto ao foco do objetivo (avaliar processos ou impactos) e quanto à natureza do impacto: mudanças quantitativas ou mudanças qualitativas (Quadro 5).

Quadro 5 - Conceitos de Efetividade, Eficiência e Eficácia

\begin{tabular}{||l||c|c||}
\hline $\begin{array}{c}\text { OBJETIVOS DA } \\
\text { AVALIAÇÃO }\end{array}$ & \multicolumn{1}{|c||}{ TIPO DE AVALIAÇÃO } & $\begin{array}{c}\text { CRITÉRIOS DE } \\
\text { AFERIÇÃO }\end{array}$ \\
\hline \hline \multirow{2}{*}{ Avaliar Processo } & $\begin{array}{l}\text { Execução Das Metas Propostas } \\
\text { Meios Utilizados }\end{array}$ & Eficácia \\
\cline { 2 - 4 } Avaliar Impacto & $\begin{array}{l}\text { Musto Benefício } \\
\text { Sociais } \\
\text { Mudanças subjetivas quanto ao bem-estar } \\
\text { Mudanças qualitativas nas condições sociais }\end{array}$ & Efetividade \\
\hline \hline
\end{tabular}

Fonte: Kayano e Caldas (2002)

As diferentes abordagens e conceitos convergem para a distinção entre efetividade e eficácia, sendo a primeira associada ao fato de que o alcance dos objetivos deve estar sempre associado a um impacto ou a um efeito. No âmbito das áreas protegidas, tais efeitos podem ser de ordem social (impactos positivos para a comunidade e seus meios de vida) e ambiental (impacto positivo para a biodiversidade).

\subsection{A Institucionalização das avaliações de efetividade}

O início da Institucionalização das avaliações de efetividade no Âmbito do $V$ Congresso Mundial de Parques, realizado em 2003, em Durban, África do Sul

O tema Avaliação de Efetividade de Áreas Protegidas ganhou grande destaque após o V Congresso Mundial de Parques, realizado em 2003, em Durban, África do Sul, e após a Sétima Conferência das Partes da Convenção sobre Diversidade Biológica (COP721/CDB), realizada em 2004, em Kuala Lumpur, Malásia, cujos documentos

\footnotetext{
${ }^{21}$ Até o momento já foram realizadas 12 Conferências das Partes (COPs). A $13^{a}$ será realizada em dezembro de 2016. Lista das COPs:

- COP 01 - First Ordinary Meeting of the Conference of the Parties to the Convention on Biological Diversity, Nassau, Bahamas, 28 November - 9 December 1994

- COP 02 - Second Ordinary Meeting of the Conference of the Parties to the Convention on Biological Diversity, Jakarta, Indonesia, 6 - 17 November 1995

- COP 03 - Third Ordinary Meeting of the Conference of the Parties to the Convention on Biological Diversity, Buenos Aires, Argentina, 4 - 15 November 1996
} 
resultantes, respectivamente o Acordo de Durban e o Plano de Trabalho sobre Áreas Protegidas - Decisão VII/28 e Decisão VII/30 da CDB (UNEP/CBD/COP, 2004), são guias para avaliar a estratégia de conservação da biodiversidade e seus instrumentos.

No V Congresso Mundial de Parques a palavra de ordem era enfatizar os benefícios para além das fronteiras das áreas protegidas. A sessão 13, Avaliação da Efetividade de Gestão, foi coordenada por Marc Hockings ${ }^{22}$, e o grupo de trabalho destacou que um dos principais avanços sobre o tema das áreas protegidas na década de 1990 foi a elaboração de uma gama de metodologias para avaliar a efetividade da gestão. Seguindo as diretrizes apontadas pela WCPA, os indicadores para tal avaliação deveriam incluir a adaptação da metodologia a diversas condições, países e enfoques; à capacidade de obter o maior número de informações com o mínimo de recursos; e à conexão entre os objetivos das áreas protegidas e as ameaças a outros assuntos cruciais para a gestão, como o desenvolvimento local. A discussão continuou com a apresentação dos resultados obtidos a partir da sistematização de 600 avaliações de efetividade de gestão realizadas

- COP 04 - Fourth Ordinary Meeting of the Conference of the Parties to the Convention on Biological Diversity, Bratislava, Slovakia, 4 - 15 May 1998

- COP 05 - Fifth Ordinary Meeting of the Conference of the Parties to the Convention on Biological Diversity Nairobi, Kenya, 15 - 26 May 2000 - EXCOP 1 - First Extraordinary Meeting of the Conference of the Parties to the Convention on Biological Diversity, Cartagena, Colombia \& Montreal, Canada, 22 - 23 February 1999 \& 24 - 28 January 2000

- COP 06 - Sixth Ordinary Meeting of the Conference of the Parties to the Convention on Biological Diversity The Hague, Netherlands, 7 - 19 April 2002

- COP 07 - Seventh Ordinary Meeting of the Conference of the Parties to the Convention on Biological Diversity Kuala Lumpur, Malaysia, 9 - 20 February 2004

- COP 08 - Eighth Ordinary Meeting of the Conference of the Parties to the Convention on Biological Diversity Curitiba, Brazil, 20 - 31 March 2006

- COP 09 - Ninth meeting of the Conference of the Parties to the Convention on Biological Diversity Bonn, Germany, 19 - 30 May 2008

- COP 10 - Tenth meeting of the Conference of the Parties to the Convention on Biological Diversity Nagoya, Aichi Prefecture, Japan, 18 - 29 October 2010

- COP 11 - Eleventh meeting of the Conference of the Parties to the Convention on Biological Diversity Hyderabad, India, 8 - 19 October 2012

- COP 12 - Twelfth meeting of the Conference of the Parties to the Convention on Biological Diversity Pyeongchang, Republic of Korea, 6 - 17 October 2014

- COP 13 - Thirteenth meeting of the Conference of the Parties to the Convention on Biological Diversity Cancun, Mexico, 4 - 17 December 2016

${ }^{22}$ Marc Hockings é professor de Gestão Ambiental da Universidade de Queensland, Austrália, desde 2002, e vice-presidente da WCPA/IUCN, comissão cuja sua vinculação data desde 1996. Antes de entrar para a Universidade, o professor Hockings trabalhou para o Serviço Nacional de Parques de Queensland, onde ganhou experiência em diversos aspectos da conservação e gestão de áreas protegidas. Como vicepresidente da Comissão Mundial de Áreas Protegidas da IUCN (WCPA), ele lidera o programa global de Ciência e Gestão. Ele foi o principal autor de orientações sobre melhores práticas da IUCN sobre a avaliação de efetividade de gestão das áreas protegidas. Em 2008 ele recebeu o Prêmio Kenton Miller para Inovação na área de Sustentabilidade das áreas protegidas pelo conjunto da sua obra sobre efetividade de gestão. 
pela WWF nos anos anteriores ao congresso, que indicaram como principais ameaças às áreas protegidas: caça furtiva de animais; coleta furtiva de plantas; derrubada de florestas; introdução de espécies invasoras; incêndios; intrusão da agricultura e pecuária.

Foi abordada também, pelo grupo de trabalho da sessão 13, a necessidade de reforço na gestão da informação por meio de uma melhor sistematização, apresentação e uso do conhecimento proveniente da fiscalização e avaliação das áreas protegidas. Tais informações deveriam ainda ser direcionadas para uma melhor compreensão das ações voltadas para temas como a restauração ecológica e a interação com populações locais. O grupo concluiu que o crescente interesse sobre a gestão das áreas protegidas representava significativas mudanças na perspectiva da comunidade internacional dedicada ao assunto. Uma delas dizia respeito ao fato de a preocupação pela quantidade das áreas protegidas ter evoluído para uma preocupação, também, com a qualidade das áreas em um contexto mais amplo. Outra se referia à necessidade de que os processos de criação ou aprimoramento destas áreas deixassem de ser fundamentalmente reativos e passassem a ser mais proativos (IUCN, 2004; SOUZA, 2013).

O V Congresso Mundial de Parques ressaltou a preocupação em identificar as lições aprendidas no processo de avaliação da efetividade ao longo dos anos, definindo os temas ou tópicos que merecem maior atenção dos pesquisadores e gestores de áreas protegidas:

- Identificar os modelos, metodologias e ferramentas de avaliação da efetividade;

- Avaliar o enfoque de avaliação nas suas diferentes escalas: sistema e áreas protegidas individuais;

- Identificar os métodos de avaliação da integridade ecológica das áreas protegidas;

- Identificar e selecionar os indicadores sociais, econômicos e de gestão;

- Identificar os métodos ou indicadores para avaliar o nível de satisfação das necessidades das comunidades locais (entorno e dentro da área protegida);

- Avaliar a efetividade de gestão frente aos processos em curso, como por exemplo, as mudanças climáticas.

As recomendações do V Congresso Mundial de Parques reforçaram ainda mais o papel da WCPA e do WCMC, ampliando o esforço para a melhoria das ferramentas e para a aplicação das avaliações de efetividade. Já o Plano de Trabalho sobre Áreas 
Protegidas (UNEP/CBD/COP, 2004), elaborado durante a COP7/CDB, estabeleceu um objetivo específico relacionado com a avaliação de efetividade (Objetivo 4.2): Avaliar e promover a efetividade de gestão de áreas protegidas, cuja meta era até 2010 estabelecer estruturas para o monitoramento e avaliação da efetividade de gestão de áreas protegidas. O Plano de Trabalho também indica a meta de realizar avaliações de efetividade em pelo menos $30 \%$ das áreas protegidas.

Após a 6 a Conferencia das Pares da CDB (COP6), realizada em 2002, em Hague, na Holanda, e a discussão e os encaminhamentos do V Congresso Mundial de Parques, o Brasil demostrou duas frentes de empenho, relacionadas com a criação e gestão de áreas protegidas:

- Definir metas para a conservação da biodiversidade. Em função do compromisso assumido pelas Partes com as Metas CDB 2010 estabelecidas na COP 6, o Brasil estabeleceu a Política Nacional de Biodiversidade Decreto 4339/2002, assim como discutiu e estabeleceu as metas nacionais de conservação da biodiversidade dos ecossistemas terrestres e marinhos por meio de unidades de conservação/UCs, estabelecendo as metas de $30 \%$ do bioma Amazônia e 10\% dos demais biomas e na zona costeira (MMA, 2006 e Resolução CONABIO, 2006). O compromisso de estabelecer metas para conservação da biodiversidade foi reafirmado e ampliado, pelo Brasil e outros 192 signatários da CDB, na $10^{\text {a }}$ Conferência das Partes da CDB - COP 10, realizada em dezembro de 2010, em Nagoya, no Japão. As metas, denominadas agora Metas CDB 2020, aumentaram, de 10\% de todas as regiões ecológicas do planeta para 17\% (Resolução CONABIO, 2013);

- Avaliar a efetividade das UCs - onde implementou, com apoio do WWFBrasil, ICMBio e estados do bioma Amazônia, a primeira estratégia de avaliação de efetividade de UCs em grande escala, entre 2005 e 2007, com a aplicação da ferramenta Rapid Assessment and Prioritization of Protected Area Management/Rappam.

Vale lembrar o fato de que no Brasil estabeleceu-se uma distinção entre Unidades de Conservação/UCs, um termo que é restrito ao país, e outros tipos de áreas protegidas, tais como Áreas de Preservação Permanente (APPs) e Reservas Legais (RLs), Terras Indígenas e Terras de Quilombo. A Lei 9885/2000, que instituiu o Sistema 
Nacional de Unidades de Conservação da Natureza/SNUC ${ }^{23}$, definiu - após longo trâmite, durante toda a década de 1990 - a sistematização, a criação e o gerenciamento das UCs (MERCADANTE, 2001; DRUMMOND et al, 2006; DRUMMOND et al, 2010). De fato, o empenho do Brasil na criação e gestão de UCs pode ser percebido no esforço empreendido para desenvolver o marco legal que orienta e disciplina a implementação de tal estratégia, destacando-se a ratificação da CDB, a instituição do SNUC, a adesão ao Plano de Trabalho sobre Áreas Protegidas da $\mathrm{CDB}^{24}$ e o processo de elaboração do Plano Estratégico Nacional de Áreas Protegidas/PNAP ${ }^{25}$. Embora este último - o PNAP reconheça o esforço de conservação das Terras Indígenas e dos Territórios Quilombolas ${ }^{26}$, as UCs são a principal estratégia de conservação da biodiversidade no país.

\section{O VI Congresso Mundial de Parques, realizado em 2015, em Sydney, na Austrália}

Na ocasião do VI Congresso Mundial de Parques, realizado em 2015, em Sydney, na Austrália, o Brasil ainda caminhava para a definição de diretrizes mais densas para a avaliação da efetividade. Dentre as questões gerais do congresso, vários são os temas conhecidos dos congressos anteriores: ampliação dos investimentos, ampliação e implantação de sistemas de áreas protegidas com foco na necessidade de frear a perda global de biodiversidade, combater as alterações climáticas, reduzir o risco e o impacto de desastres, melhorar a segurança alimentar e a da água e, consequentemente, promover a saúde e o bem-estar da população de forma a garantir que o desenvolvimento humano possa acontecer cada vez mais em harmonia com a conservação da natureza e dos modos de vida tradicionais.

Assim como os demais congressos, em Sidney, os painéis eram motivados por questões mais amplas e a efetividade de gestão das áreas protegidas foi discutida junto com temas como o monitoramento das áreas protegidas e da biodiversidade. Ocorreram duas sessões para tratar da efetividade de gestão das áreas protegidas, ambas coordenadas por Marc Hockings: a) Situação global e lições aprendidas - que se concentrou na apresentação das avaliações aplicadas (regionais e globais) e das lições aprendidas; b)

\footnotetext{
${ }^{23}$ Lei $^{\circ}{ }^{9} 9.985 / 2000$ - SNUC, regulamentada pelo Decreto ${ }^{\circ}$. 4.340, de 22 de agosto de 2002

${ }^{24}$ Decisão V-28 - CDB, 2004

${ }^{25}$ Decreto No 5.758 , de 13 de abril de 2006

${ }^{26}$ O PNAP inclui ainda as APPs e as RLs, tratadas no planejamento da paisagem, no âmbito da abordagem ecossistêmica, com uma função estratégica de conectividade entre fragmentos naturais e as próprias áreas protegidas
} 
Quantificando as avaliações de efetividade - que abordou dois aspectos - i) a qualidade dos dados das ferramentas de avaliação da efetividade de gestão (PAMEs), e ii) a aplicação de resultados das PAMEs - com vistas a contribuir para o desenvolvimento de um sistema de controle de qualidade das próprias PAMEs, além de orientar sobre os princípios, boas práticas, análise de dados e aplicação de resultados das avaliações realizadas por intermédio das PAMEs dentro de uma abordagem de gestão adaptativa (IUCN, 2014).

O monitoramento foi abordado também em duas sessões: a) Medindo o sucesso e o fracasso das áreas protegidas - resultados/impactos para a biodiversidade, que apresentou como são poucos os países ou agências que estão avaliando os resultados da biodiversidade em áreas protegidas terrestres ou marinhas. No nível global foram destacados alguns estudos ${ }^{27}$ sobre áreas protegidas terrestres, que contribuíam para responder perguntas sobre como medir o sucesso e sobre quais os fatores que impulsionavam o sucesso; e b) Monitorando os resultados de conservação dentro e fora das áreas protegidas - que destacou a ausência de indicadores padrões que permitissem a avaliação, em tempo real, do estado de conservação da biodiversidade e que, consequentemente, permitissem medir a efetividade de gestão das áreas protegidas. Essa sessão discutiu as opções de indicadores (sejam eles de espécies ou proxis baseadas nos ecossistemas), os tipos de sistemas de monitoramento (sensoriamento remoto para monitorar as mudanças no uso e cobertura do solo, armadilhas fotográficas ou monitoramento baseado em patrulha por guardas florestais, equipe de gestão, comunidade científica e comunidades locais), novas ferramentas tecnológicas para auxiliar em alguns desses esforços, e recomendou também um olhar para algumas abordagens ou índices: Essential Biodiversity Variables (EBVs), Living Planet Index e Important Bird and Biodiversity Area (IUCN, 2014).

Um pouco antes, entre 2010 e 2011, o Instituto Chico Mendes para Conservação da Biodiversidade (ICMBio) coordenou, sob a responsabilidade da Coordenação de Avaliação e Monitoramento de Unidades de Conservação (CAMUC), um grupo de

\footnotetext{
${ }^{27}$ Predictors of Biodiversity Outcomes in Terrestrial Protected Areas, por Stephen Woodley ; Correlating Management Effectiveness and Biodiversity Outcomes por Megan Barnes and Ian Craigie (WCPA-SSC Joint Task Force on Biodiversity and Protected Areas); Averting biodiversity collapse in tropical forest protected areas por - Jonas Geldmann (WCPA-SSC Joint Task Force on Biodiversity and Protected Areas); Protected Areas as the Last Reserves for Species por Bill Laurance (James Cook University, Australia); Assessing Protected Areas Using Forest Cover Change - what we have learned por - John Robinson (WCS); TBD Deforestation fronts and role of protected areas in stopping deforestation por Rod Taylor (WWF International).
} 
trabalho ${ }^{28}$ com o objetivo de identificar as experiências de monitoramento de efetividade de UCs no Brasil e as opções para avaliar o sistema federal de UCs. Foram realizadas reuniões para troca de experiências, discussão e análise de indicadores; uma viagem de campo (com a presença dos professores Marc Hockings e Fiona Leverington, e as equipes gestoras das UCs Parque Nacional do Viruá e Estação Ecológica de Maracá, representantes do MMA, ICMBio e da empresa NEXUCs); e uma oficina para sistematizar as informações e lições aprendidas sobre efetividade de gestão no período de março/2010 a dezembro/2011. A discussão no âmbito do GT resultou na formulação dos documentos:

- Proposta de Indicadores para o Sistema Federal (ICMBio e WWF-Brasil, 2012) que teve como premissas no seu processo de elaboração: integrar as diversas demandas e experiências já em curso ou sendo implementadas no Brasil, não sobrepor esforços de levantamento e sistematização de dados, e priorizar a interface com o Cadastro Nacional de UCs - CNUC/MMA;

- Considerações para reformulação do RAPPAM (ICMBio e WWF-Brasil, 2012).

O GT teve um papel importante para algo que aconteceu alguns anos mais tarde, em 2014 e 2015, e que agregou novos elementos e complementou as discussões sobre efetividade e monitoramento ocorridas no VI Congresso Mundial de Parques - a criação de uma nova ferramenta, o Sistema de Análise e Monitoramento de Gestão - SAMGe, criada pela Divisão de Monitoramento e Avaliação de Gestão/DMAG, no âmbito da Coordenação Geral de Criação, Planejamento e Avaliação/CGCAP, vinculada à Diretoria de Manejo/DIMAN do ICMBio. O SAMGe foi idealizado para avaliar a efetividade de gestão de UCs e monitorar os instrumentos de gestão, com destaque para as relações entre objetivos, alvos de conservação da natureza e suas inter-relações com a sociedade. $\mathrm{O}$ SAMGe e outras metodologias e ferramentas de avaliação do sucesso de UCs serão abordadas a seguir, no próximo capitulo.

\footnotetext{
${ }^{28}$ Composto por Lilian Hangae - CAMUC/ICMBio; Kátia Lemos Costa - Universidade de Quensland; Daniela de Oliveira - Universidade de Brasilia/CDS; Esther Carone Blumenfeld - Diretoria de Áreas Portegidas/MMA; Ronaldo Weigand Jr - Nave Terra; Erica Coutinho - CAMUC/ICMBio; Giovana Palazzi - P/MMA; Carlos Eduardo Martinelli - ISA/UnB/INPA; Lucia F. Lima - CAMUC/ICMBio; Marcelo Kinouch -CGPI/ICMBio; Tharsila Carranza - Universidade de Cambridge e Mariana Napolitano - WWFBrasil.
} 


\section{Capitulo 2 - Metodologias e ferramentas de avaliação do sucesso de áreas protegidas}

Como já compartilhado no primeiro capítulo, as iniciativas para avaliação da efetividade de áreas protegidas datam de meados dos anos 1990 e ocorreram em sintonia com os estudos e discussões do Grupo de Trabalho de Efetividade de Gestão da WCPA. Após a publicação, em 2000, pela WCPA/IUCN, do primeiro documento sobre o marco conceitual e sobre as diretrizes para a avaliação da efetividade: Evaluating Effectiveness: A framework for assessing management effectiveness of protected áreas (HOCKINGs et al. 2000), este foi amplamente divulgado e adotado pela maioria das ferramentas e/ou metodologias aplicadas desde então.

Em diversas partes do mundo, grupos e indivíduos que trabalhavam com o tema da efetividade, também sugeriram diretrizes, metodologias e ferramentas para os sistemas de áreas protegidas ou para as áreas protegidas individuais, que eram adaptadas para determinadas regiões, habitats ou contexto de proteção. As organizações internacionais que trabalhavam com áreas protegidas, tais como a WCPA da IUCN, o Banco Mundial, Global Environment Facility/GEF, bem como ONGs como a World Wildlife Fund/WWF e The Nature Conservancy tomaram a iniciativa de promover tanto a importância da efetividade da gestão como apoiar tecnicamente o desenvolvimento de ferramentas. A UNESCO, por meio do World Heritage Center também desempenhou um papel importante nesse processo, apoiando tanto o desenvolvimento metodológico como a aplicação de avaliações nos Sítios Naturais do Patrimônio Mundial.

As primeiras avaliações de efetividade foram empreendidas pela The Nature Conservancy/TNC, com o desenvolvimento, no início dos anos 1990 do sistema PROARCA/CAPAS Scorecard ${ }^{29}$ e mais tarde com o desenvolvimento do Parks in Peril Site Consolidation Scorecard ${ }^{30}$; pelo Centro Agronómico Tropical de Investigación y Enseñanza/CATIE, em parceria com World Wildlife Fund/WWF, ao propor um

\footnotetext{
29 O sistema PROARCA/CAPAS baseia-se no "modelo de pontuação" para avaliar a gestão de áreas protegidas desenvolvido pela TNC no início de 1990. A metodologia PROARCA/CAPAS inclui a avaliação de 43 indicadores em cinco temas: recursos naturais e culturais; social; administrativo; político/jurídico e económico/financeiro (COURRAU, 1999).

${ }^{30}$ Esta ferramenta foi adaptada para o contexto Europeu e renomeada como European Site Consolidation Scorecard (Getzner et all, 2012). Disponível em <http://www.intechopen.com/books/protected-areamanagement" title="Protected Area Management" $>$ Protected Area Management). Acesso em 26/10/2015.
} 
procedimento e um esboço de manual para avaliação de efetividade de áreas protegidas ${ }^{31}$; pela Rede WWF com o desenvolvimento do Rapid assessment and priorization of protected area management/Rappam - resultado de um esforço para desenvolver um instrumento de avaliação em consonância com o quadro WCPA. A Aliança Florestal formada, em 1997, pela Rede WWF e Banco Mundial desenvolveu um sistema de avaliação chamado Management Effectiveness Tracking Tool (METT) ou simplesmente Tracking Tool, a partir do marco conceitual da WCPA, como uma ferramenta padrão para todos os projetos de áreas protegidas, sendo este mais tarde adotado também pelo Global Environmental Facility/GEF. O Banco Mundial também desenvolveu uma ferramenta específica para avaliação das áreas protegidas marinhas - a World Bank MPA Scorecard, assim como o WWF em parceria com a IUCN ao sugerir Marine Protected Areas Guidebook um guia de indicadores naturais e sociais para a avaliação de efetividade de gestão de áreas protegidas marinhas. E o desenvolvimento da metodologia New South Wales State of Our Parks (SOP), primeiro sistema de avaliação inteiramente baseado no marco referencial da WCPA/IUCN, aplicado nos parques de New South Wales, Austrália. A UNESCO apoiou o desenvolvimento e a aplicação Enhancing our Heritage Toolkit, um sistema de avaliação da efetividade para os Sítios Naturais do Patrimônio Mundial (CIFUENTES et al, 1999; HOCKINGS, 2000; ERVIN, 2003; HOCKINGS, 2003; STAUB e HATZIOLOS, 2004; POMEROY et al, 2004; POMEROY et al, 2006; HOCKINGS et al, 2008; HOCKINGS et al, 2009; LEVERINGTON et al., 2010).

Leverington et al (2008), ao avaliarem as ferramentas utilizadas no mundo, identificaram 42 diferentes metodologias para avaliação da efetividade da gestão de áreas protegidas. Em 2009 ao atualizar a primeira edição do estudo global, estes autores avaliaram 9.250 relatórios de efetividade de gestão de áreas protegias de diferentes países, que abrangiam cerca de 6.720 áreas protegidas, resultando na identificação de 54 diferentes metodologias (LEVERINGTON et al, 2010). Ao avaliar as ferramentas de avaliação de efetividade utilizadas na Europa, Nolte et al (2010), também identificaram cerca de 30 metodologias adicionais ao primeiro estudo de Leverington (2008) resultando em um universo de cerca de 72 diferentes metodologias de avaliação de efetividade. Tais ferramentas diferem entre si em sua relação ao marco referencial (metodologia de

\footnotetext{
${ }^{31}$ Evaluation of Protected Area Management Effectiveness: Analysis of Procedures and Outline for a Manual, que é uma metodologia de avaliação estruturada, sequencial e simples de usar, com base em um sistema de pontuação que foi desenvolvido para atender as necessidades especiais das áreas protegidas na América Latina (CIFUENTES e IZURIETA, 1999).
} 
referencial), aos objetivos de aplicação, a forma de aplicação, a área de abrangência, aos indicadores, aos critérios de análise e a forma do cálculo de efetividade. Até agora, o Estudo Global (Leverington et al, 2008; Leverington et al, 2010) e reuniu e analisou informações de mais de 40 diferentes metodologias que foram aplicadas em mais de 100 países (Anexo 2).

Avaliação da gestão de áreas protegidas tem recebido atenção crescente embora muitos dos sistemas de avaliação da gestão dependam predominantemente de conhecimentos especializados ou de uma avaliação qualitativa, especialmente onde a ênfase está na avaliação rápida. Dentre as ferramentas com maior amplitude de aplicação no mundo, destacam-se: o METT, aplicado 4046 vezes para 2045 áreas protegidas e com repetidas avaliações realizadas ao longo de anos diferentes disponíveis para 833 áreas; o SOP, aplicado 3552 vezes, em 859 áreas protegidas, e 764 repetições; e o Rappam, aplicado 2276 vezes em cerca de 1930 áreas protegidas e com 322 repetições abrangendo cerca de 50 países na Europa, Ásia, África, América Latina e Caribe (LEVERINGTON et al., 2010; COAD L. et al. 2015).

No Brasil, as primeiras aplicações de avaliações de efetividade de UC começaram no final da década de 1990. Em 1998, o WWF-Brasil em parceria com o Instituto Brasileiro do Meio Ambiente e dos Recursos Naturais Renováveis/IBAMA avaliou o grau de implementação e a vulnerabilidade de 86 UCs federais de proteção integral, mas não utilizou um método específico de avaliação de efetividade. Foi utilizado para aquela avaliação um formulário respondido pessoalmente pelos chefes das UCs. A maioria das questões propostas no formulário foram quantitativas, evitando-se desta maneira opiniões e respostas mais subjetivas e, consequentemente, permitindo uma análise padronizada das respostas. Mas, não foram considerados pontos relevantes como a representatividade dos ecossistemas, a proteção de espécies carismáticas ou ameaçadas de extinção e padrões de biodiversidade dentro das UCs. Também nesta época, e um pouco depois, foram realizadas avaliações com ferramentas como Scenery Matrix, aplicada para avaliação de UCs estaduais de São Paulo e Minas Gerais; Certificação de Unidades de Conservação: Parâmetros e procedimentos para certificação do manejo de unidades de conservação e a Inciativa Parkswatch ${ }^{32}$. A primeira aplicação do método

\footnotetext{
32 Criada em 1999, pelo Centro de Conservação Tropical da Universidade de Duke, nos Estados Unidos é mantida no Brasil pela Fundação $\mathrm{O}$ Boticário de Proteção à Natureza. A iniciativa tem por missão proteger a biodiversidade por meio do levantamento, análise e divulgação da informação do estado das unidades de
} 
Rappam no Brasil ocorreu em 2004, fruto da parceria entre a Secretaria de Meio Ambiente do Estado de São Paulo, por meio do Instituto Florestal, e o WWF-Brasil. Naquela ocasião, a ferramenta foi adotada para avaliar a situação de 25 UCs na região leste do estado São Paulo ${ }^{33}$. Em 2005, o Tracking Toll foi aplicado, inicialmente, a 36 UCs apoiadas pelo Programa Áreas Protegidas da Amazônia/Arpa ${ }^{34}$, sendo, em 2007, adaptada e transformada na Ferramenta de Avaliação da Efetividade do Programa Áreas Protegidas da Amazônia/FAUC (De FARIA, 1995; WWF-Brasil, 2000, WWF-BRASIL et al., 2004, PADOVAN, 2003; LIMA, 2005; PAVESE et al, 2007; LEVERINGTON et al., 2008; BONATO, 2009, WEIGAND JR et al, 2007).

Passados quase 17 anos das primeiras avaliações, e com cerca de quinze metodologias aplicadas as UCs (Quadro 6), o Brasil segue a tendência do contexto mundial, pois a metodologia que envolveu o maior número de UCs no Brasil foi o Rappam. Entre 2005 e 2007, o Rappam foi aplicado em 246 unidades de conservação federais brasileiras, fruto da parceria entre o WWF-Brasil e o IBAMA (IBAMA \& WWFBrasil, 2007). Nos anos de 2008, 2009 e 2010 o método foi aplicado em UCs sob a gestão dos órgãos executores estaduais: Acre, Amapá, Amazonas, Mato Grosso, Mato Grosso do Sul, Rondônia e Pará. O conjunto deste primeiro ciclo de avaliação contribuiu para a conclusão da primeira avaliação das UCs do Programa Arpa, que apoia UCs federais e estaduais do bioma Amazônia, pelo método Rappam (WWF-BRASIL, SEMA-AC, SEFAC \& ICMBIO, 2009; WWF-BRASIL, IEF-AP, SEMA-AP \& ICMBIO, 2009; WWFBRASIL, SEMA-MT \& ICMBIO, 2009; WWF-BRASIL, SDS-AM \& ICMBIO, 2011; WWF-BRASIL, SEDAM-RO \& ICMBIO, 2011; WWF-BRASIL, SEMA-PA \& ICMBIO, 2011; WWF-BRASIL \& IMASUL, 2011). Também nos anos de 2009 e 2010 o Rappam foi reaplicado (segundo ciclo de avaliação) nas UCs federais. E em 2013 o método foi aplicado pela primeira vez para as UCs estaduais do estado de Goiás (WWFBRASIL \& ICMBIO, 2012 e WWF-BRASIL \& Semarh-GO, 2014). Em outubro de 2015, o WWF-Brasil em parceria com o ICMBio iniciou o terceiro ciclo de aplicação do Rappam, começando pelas UCs do Bioma Amazônia, onde o e foi aplicado para as UCs federais e as UCs estaduais apoiadas pelo Programa Arpa, contribuindo para uma série histórica e única das UCs federais do Bioma Amazônia, já que estas foram avaliadas em

conservação. Além do Brasil, onde foram avaliadas nove UCs, a iniciativa está presente em seis países da América Latina: Argentina, Bolívia, Guatemala, México, Venezuela e Peru.

33 Litoral, Vale do Ribeira, Alto Paranapanema, Vale do Paraíba, Serra da Mantiqueira e região metropolitana de São Paulo (WWF-BRASIL et al., 2004).

${ }^{34}$ Em 2005 foi aplicado para 36 UCs, em 2006 para 53 UCs (WEIGAND JR et al, 2007). 
três momentos pelo método Rappam: os ciclos de avaliação de 2005, 2010 e 2015. O Rappam é um método que fornece, de forma simples, aos tomadores de decisão e formadores de políticas, informações relacionadas a UCs para a identificação de tendências e características da gestão que permitem alcançar uma melhor efetividade em um dado sistema ou grupo de áreas protegidas. A existência de uma base consolidada de dados sobre efetividade de gestão permitirá a realização de análises temporais e comparativas do conjunto ou de parte destes dados, assim como a interação destes com outros indicadores importantes (ERVIN, 2003; LEVERINGTON et al., 2008; WWFBRASIL \& ICMBIO, 2010, MMA/Programa Arpa, 2015)

Quadro 6 - Metodologias de avaliação da efetividade utilizadas nas unidades de conservação brasileiras

\begin{tabular}{|c|c|c|c|}
\hline METODOLOGIA & ORGANIZAÇÃO & $\begin{array}{l}\text { PERÍODO DE } \\
\text { APLICAÇÃO }\end{array}$ & ABRANGÊNCIA \\
\hline $\begin{array}{l}\text { 1. RAPPAM - Rapid } \\
\text { Assessment and } \\
\text { Prioritization of } \\
\text { Protected Area } \\
\text { Management }\end{array}$ & $\begin{array}{l}\text { WWF-Brasil e } \\
\text { parceiros }\end{array}$ & 2004 a 2015 & $\begin{array}{c}\text { UCs Federais nos biomas } \\
\text { Amazônia, Caatinga, } \\
\text { Mata Atlântica, Cerrado, } \\
\text { Pampa e Pantanal } \\
\text { Estaduais: SP, AC, AP, } \\
\text { AM, PA, RO, MT, MS, } \\
\text { GO e TO }\end{array}$ \\
\hline $\begin{array}{l}\text { 2. Tracking Tool - } \\
\text { Management } \\
\text { Effectiveness Tracking } \\
\text { Tool } \\
\end{array}$ & $\begin{array}{l}\text { World Bank/WWF } \\
\text { Alliance }\end{array}$ & $\begin{array}{l}2005-2006 \\
2010-2015\end{array}$ & $\begin{array}{c}\text { UCs apoiadas pelo } \\
\text { Programa Arpa (Federais } \\
\text { e Estaduais do Bioma } \\
\text { Amazônia) } \\
\end{array}$ \\
\hline $\begin{array}{l}\text { 3. Degree of } \\
\text { Implementation and the } \\
\text { Vulnerability of } \\
\text { Brazilian Federal } \\
\text { Conservation Areas } \\
\text { (Brazil 1999) }\end{array}$ & $\begin{array}{l}\text { WWF Brasil e } \\
\text { IBAMA }\end{array}$ & 1999 & UCs Federais \\
\hline $\begin{array}{l}\text { 4. Certificação de } \\
\text { Unidades de } \\
\text { Conservação - } \\
\text { Parâmetros e } \\
\text { procedimentos para } \\
\text { certificação do manejo } \\
\text { de unidades de } \\
\text { conservação } \\
\end{array}$ & $\begin{array}{c}\text { Instituto de } \\
\text { Pesquisas da Mata } \\
\text { Atlântica - IPEMA }\end{array}$ & 2002 & UCs Estaduais \\
\hline 5. Scenery Matrix & $\begin{array}{c}\text { Instituto Florestal } \\
\text { do Estado de São } \\
\text { Paulo }\end{array}$ & 1999-2005 & UCs Estaduais \\
\hline $\begin{array}{l}\text { 6. PIP Site } \\
\text { Consolidation - TNC } \\
\text { Parks in Peril Site } \\
\text { Consolidation Scorecard }\end{array}$ & $\begin{array}{c}\text { The Nature } \\
\text { Conservancy - } \\
\text { TNC }\end{array}$ & Vários anos & UCs Federais \\
\hline
\end{tabular}




\begin{tabular}{|c|c|c|c|}
\hline 7. Parkswatch & $\begin{array}{c}\text { Centro de } \\
\text { Conservação } \\
\text { Tropical da } \\
\text { Universidade de } \\
\text { Duke e Fundação O } \\
\text { Boticário } \\
\end{array}$ & $2002-2006$ & UCs Federais \\
\hline $\begin{array}{l}\text { 8. FAUC - Ferramenta } \\
\text { de Avaliação da } \\
\text { Efetividade do } \\
\text { Programa Áreas } \\
\text { Protegidas da Amazônia }\end{array}$ & $\begin{array}{l}\text { Programa áreas } \\
\text { Protegidas da } \\
\text { Amazônia - Arpa }\end{array}$ & 2006-2015 & $\begin{array}{c}\text { UCs apoiadas pelo } \\
\text { Programa Arpa(Federais e } \\
\text { Estaduais do Bioma } \\
\text { Amazônia) }\end{array}$ \\
\hline $\begin{array}{l}\text { 9. Certificação de } \\
\text { Unidades de } \\
\text { Conservação } \\
\end{array}$ & Flora-Brasil & 2007 & UCs Estaduais \\
\hline $\begin{array}{l}\text { 10. Matriz de Cenários - } \\
\text { Adaptação das } \\
\text { metodologias Scenery } \\
\text { Matrix e Tracking Tool }\end{array}$ & $\begin{array}{c}\text { Universidade } \\
\text { Federal de Viçosa }\end{array}$ & 2004 & UCs Estaduais \\
\hline $\begin{array}{l}\text { 11. Adaptação da } \\
\text { metodologia Scenery } \\
\text { Matrix }\end{array}$ & $\begin{array}{c}\text { Fundação Florestal } \\
\text { de São Paulo }\end{array}$ & 2002 & UCs Estaduais \\
\hline $\begin{array}{l}\text { 12.Indicadores da } \\
\text { Efetividade de } \\
\text { Implementação (IEI) das } \\
\text { UCs estaduais }^{35}\end{array}$ & SDS, Amazonas & 2006 & UCs Estaduais \\
\hline $\begin{array}{l}\text { 13. Programa de } \\
\text { Monitoramento da } \\
\text { Biodiversidade e do Uso } \\
\text { de Recursos Naturais em } \\
\text { Unidades de } \\
\text { Conservação Estaduais } \\
\text { do Amazonas } \\
\text { (PROBUC) }\end{array}$ & SDS, Amazonas & 2006 & UCs Estaduais \\
\hline $\begin{array}{l}\text { 14. Protocolo de } \\
\text { avaliação de efetividade } \\
\text { de gestão de mosaicos } \\
\text { de áreas protegidas no } \\
\text { Brasil }\end{array}$ & Gidsicki, D. 2013. & 2013 & $\begin{array}{l}\text { Ferramenta inédita e } \\
\text { ainda sem aplicação }\end{array}$ \\
\hline $\begin{array}{l}\text { 15. Avaliação de } \\
\text { Mosaico }\end{array}$ & WWF & 2015 & $\begin{array}{c}\text { Mosaicos: Amazônia } \\
\text { Meridional (AM, RO e } \\
\text { MT), } \\
\text { Baixo Rio Negro (AM), } \\
\text { Sertão Veredas-Peruaçu } \\
\text { (MG e BA) e Central } \\
\text { Fluminense (RJ). } \\
\end{array}$ \\
\hline
\end{tabular}

Fonte: PADOVAN, 2003; MARINELLI et al., 2006, IBAMA \& WWF-BRASIL, 2007; PAVESE et al, 2007; BONATO, 2009; WWF-Brasil et al, 2009; WWF-Brasil et al, 2011; FONSECA JR et al, 2011; HANGAE e COSTA, 2012; GIDSICKI, D. 2013; WWF-Brasil et al, 2014; HERRMANN e COSTA, 2015

${ }^{35}$ PROBUC é uma iniciativa do governo do Estado do Amazonas, implementada desde 2006, em caráter piloto, que tem como base a participação da comunidade no monitoramento do uso dos recursos naturais. 
E é importante lembrar que as diretrizes do marco da WCPA/IUCN foram elaboradas considerando-se as necessidades e particularidades das avaliações quanto a escala, natureza dos objetivos, ameaças e impactos, e disponibilidade de informações e ele se fundamenta na premissa de que a gestão de uma área protegida começa com a avaliação da situação atual (contexto) em relação ao estado de conservação e às pressões e ameaças ao estado de conservação. A gestão segue com a etapa de planejamento e identificação dos insumos, e com a execução das ações ou processo de gestão para obtenção de resultados, que espera-se convertam-se em impactos desejados (HOCKINGS, 2000).

Os elementos que compõem o marco conceitual da WCPA/IUCN têm sido norteadores, não só para as avaliações no mundo, mas também como referencial para a adaptação e a criação de metodologias e ferramentas de avaliação. Hockings et al (2008) sugere como principais fases de uma avaliação: a definição dos objetivos de avaliação; a escolha do método e o planejamento do processo de avaliação; a realização da avaliação propriamente dita; e a análise, comunicação e divulgação dos resultados. Complementarmente à definição dos objetivos, deve ser definido o escopo ou a abrangência da avaliação, que pode ser aplicada para uma área protegida específica, ou para um grupo de áreas protegidas (agrupadas em função da sua localização geográfica, por bioma, de uma mesma categoria); ou para todas as áreas protegidas de uma mesma esfera administrativa, ou para todas as áreas protegidas de um mesmo órgão executor, ou para todas as áreas protegidas de um país (HOCKINGS et al. 2008).

Utilizados para medir comparativamente os esforços de gestão nas UCs, os métodos de avaliação aportam contribuições significativas para verificar as ações implementadas para a construção de um sistema efetivamente representativo e manejado. É também uma forma importante de verificar que o investimento de tempo e esforço na criação e gestão de dessas áreas resultam nos benefícios que a sociedade procura. As informações oriundas da aplicação das ferramentas de avaliação, na maioria dos casos, podem orientar o órgão gestor da UC e/ou do sistema de UCs na tomada de decisão, quanto à alocação mais eficiente de recursos, de instrumentos de gestão, de pessoal, na priorização de processos intrínsecos à gestão da UC (como proteção, pesquisa e monitoramento). Podem contribuir, também, para identificar lacunas de capacidade técnica, traçar diretrizes de fortalecimento institucional, além de poderem ser utilizadas como um meio para a negociação de apoio técnico, financeiro e político. $\mathrm{O}$ avaliador 
(gestor ou órgão gestor) pode até não ser capaz de resolver todas as lacunas, no entanto, tornando-as explícitas e entender como elas se relacionam com interesses, ideologias, bases de conhecimento, e as posições institucionais dos vários intervenientes, permite aos tomadores de decisão e gestores para planejar e implementar programas mais eficazes (ARAYA, 2003; HOCKINGS et al. 2006; HOCKINGS et al. 2008; HOCKINGS et al, 2009 e DUDLEY et al, 2010).

$\mathrm{Na}$ escolha da metodologia, o importante é que ela seja compatível com a realidade do objeto de avaliação e com as suas características particulares, mas também é fundamental considerar:

- O marco conceitual de avaliação utilizado, pois este deve refletir os ciclos ou etapas de gestão das áreas ou dos sistemas;

- A aplicação de metodologias/ferramentas existentes, ou a necessidade adaptação (indicadores ou etapas com pouca correspondência com a realidade a ser avaliada devem ser retiradas, ou outros indicadores podem ser incorporados) ou o cruzamento de metodologias (resultado da combinação de ferramentas ou metodologias de coletas de dados). A definição da metodologia significa também definir sobre o tipo de dados que serão utilizados: qualitativos, quantitativos, ou a combinação de ambos;

- Os responsáveis pela informação (avaliadores externos, internos ou abordagens participativas); e

- O horizonte temporal de coleta das informações.

Em relação ao processo de análise, Hockings et al (2008) alertam que nas avaliações é importante reconhecer que cada elemento de avaliação pode interagir com os outros elementos, e que um exame dessa relação é importante para compreender a gestão da área avaliada. Para avaliação dos elementos são várias as opções de análise: (i) pontuações (score), que podem representar um meio rápido de expressar as condições avaliadas; (ii) graus, a partir da construção de cenários desejados e não desejados; (iii) análise de fortalezas e ameaças (FOFA ou método SWOT); (iv) avaliação dos resultados, em função do método de avaliação PER (Pressão-Estado-Resposta) ou por meio da realização de análises estatísticas. Algumas metodologias avaliam todos os elementos 
propostos pelo marco conceitual da WCPA, outras só alguns. Mas quantos mais elementos forem avaliados, mais úteis serão as informações para a gestão adaptativa.

Algumas metodologias utilizam dados quantitativos, derivados de dados de monitoramento, outras qualitativos, derivados de pontuação por gestores e partes interessadas. A distinção entre as metodologias baseadas em tipos de dados reflete abordagens diferentes para a avaliação da gestão. Outros usam uma mistura desses dois tipos de dados. Hockings et al (2009) propõe que as decisões sobre a adequação dos dados qualitativos e quantitativos e dos métodos para avaliar a efetividade de gestão de áreas protegidas deve levar em consideração questões como:(i) o objeto de avaliação, (ii) os recursos disponíveis, (iii) os tipos de dados, (iv) a escala, escopo, tempo e quadro de avaliação, e (4) riscos associados à gestão das áreas avaliadas.

Muitos sistemas de avaliação, como Tracking Tool e o Rappam se basearam principalmente em conhecimentos especializados e avaliações qualitativas, especialmente com ênfase está na avaliação rápida. A dependência dos dados qualitativos foi justificada com base na oportunidade de coleta e na facilidade de sistematização dos dados, pois na maioria das vezes o monitoramento quantitativo é limitado e demanda um maior investimento do ponto de vista de recursos e de tempo. Já os métodos quantitativos foram utilizados para avaliar um número limitado de áreas (ERVIN, 2003; DEARDEN e DEMPSEY, 2004; STOLTON et al., 2008; VENTER, NAIMAN, BIGGS \& PIENAAR, 2008; OLIVEIRA, 2012).

A maioria das preocupações com o uso de informações qualitativas gira em torno de questões de confiabilidade e validade, enquanto as questões associadas aos dados quantitativos referem-se principalmente às preocupações sobre a validade, praticidade e custo para coleta de dados para um grande número áreas. Confiabilidade pode ser um problema com a avaliação qualitativa se os especialistas têm diferentes percepções sobre o aspecto de gestão a ser avaliado. Validade pode ser um problema quando um único indicador está sendo usado para avaliar um aspecto mais amplo da área (por exemplo, quando os dados sobre a população de algumas espécies são utilizados para indicar a "saúde" geral de um ecossistema), ou quando dados quantitativos são incompletos (por exemplo ausência de uma linha do tempo). A ausência de recursos tem sido identificada como o obstáculo mais significativo para a gestão de áreas protegidas, pois os recursos para monitoramento e avaliação são severamente limitados na maioria dos países (HOCKINGS et al, 2005). A utilização de indicadores quantitativos, especialmente para 
avaliar o estado e a tendências dos valores da biodiversidade exige um acompanhamento em longo prazo, onerando muitas vezes o custo de implementação das áreas protegidas. (HOCKINGS et al, 2005; DUDLEY et al, 2010).

Ambos os dados quantitativos e qualitativos podem ser usados para avaliar todos os elementos de avaliação, mas alguns como os indicadores de impacto (estado de conservação biodiversidade e redução de ameaças) e os indicadores de resultado devem priorizar os dados quantitativos. Outros, como o envolvimento dos stakeholders (indicador de contexto) e adequação dos processos de gestão (um indicador de processo), são mais adequados para avaliação qualitativa dos gestores e outros interessados. A base de evidências para comprovar a prática de conservação não é forte na maioria dos métodos disponíveis, e o planejamento e tomada de decisão muitas vezes dependem de conhecimento qualitativo e experiencial ao invés de dados quantitativos. Preocupações têm sido levantadas sobre o uso desses dados por questões de coerência e confiabilidade, resultando em uma demanda por uma maior dependência do uso de dados empíricos e estudos controlados na avaliação de conservação.

O debate entre o uso de dados quantitativos versus dados qualitativos é, em parte, o reconhecimento de que uma abordagem única que não irá atender todas as circunstâncias e que o desafio é combinar métodos. Há um crescente reconhecimento de que uma combinação dos dois métodos (quantitativos e qualitativos) pode contribuir para uma única avaliação, quer por contribuir para diferentes fases do processo de avaliação ou por permitir uma triangulação de dados em função de um elemento avaliação. O marco conceitual deve ser utilizado como ponto de partida para adaptação das metodologias existentes ou para conceber metodologias novas sejam elas aferidas por meio de dados quantitativos ou por dados qualitativos, ou ainda a combinação de ambos. E propõe que as decisões sobre a adequação dos dados qualitativos e quantitativos e métodos para avaliar a efetividade de gestão das áreas protegidas devem considerar: (i) o objeto de avaliação, (ii) os recursos disponíveis e os dados, (iii) escala, escopo, tempo e quadro de avaliação, e (iv) riscos associados à gestão da área (FERRARO, 2008; HOCKINGS et al, 2009 e DUDLEY et al, 2010).

Com a intenção de orientar os profissionais responsáveis por conceber e implementar sistemas de avaliação Leverington et al (2010), Hockings, Leverington e Cook (2015) sugeriram e detalharam quatro abordagens de avaliação: 
- Avaliação da extensão e localização das áreas protegidas, incluindo a sua representatividade biológica;

- Avaliação da efetividade das áreas protegidas como um mecanismo de conservação na escala da paisagem;

- Avaliação da efetividade de gestão de áreas protegidas ( $\left.\mathrm{PAME}^{36}\right)$;

- Avaliação da contribuição das áreas protegidas para a conservação de seus valores de biodiversidade.

Essas diferentes abordagens convergem para a distinção entre efetividade e eficácia, sendo a primeira associada ao fato de que o alcance dos objetivos deve estar sempre associado a um impacto ou um efeito. No âmbito das UCs, tais efeitos podem ser de ordem social (impactos positivos para comunidade e seus meios de vida) e ambiental (impacto positivo para biodiversidade). No Brasil alguns métodos foram, são ou estão sendo desenvolvidos para avaliar as evidências de sucesso das UCs, e considerando-se o conjunto de avaliações realizadas podemos identificar alguns tipos de evidências de sucesso a luz das abordagens propostas por Leverington et al (2010), Hockings, Leverington e Cook (2015), como mostra o Quadro 7, e os itens que se seguem:

Quadro 7 - Evidências de sucesso nas UCs Brasileiras x Abordagens de avaliação propostas por Leverington et al (2010), Hockings, Leverington e Cook (2015)

\begin{tabular}{|c|c|c|}
\hline ABORDAGENS & $\begin{array}{c}\text { EVIDENCIAS DE SUCESSO NAS } \\
\text { UCS BRASILEIRAS }\end{array}$ & $\begin{array}{c}\text { INSTRUMENTOS E/OU } \\
\text { FERRAMENTAS } \\
\text { BRASILEIRAS } \\
\end{array}$ \\
\hline $\begin{array}{c}\text { Avaliação da extensão e localização } \\
\text { das áreas protegidas, incluindo a sua } \\
\text { representatividade biológica } \\
\end{array}$ & Representatividade Biológica & $\begin{array}{c}\text { Planejamento Sistemático da } \\
\text { Conservação (PSC) }\end{array}$ \\
\hline $\begin{array}{l}\text { Avaliação da efetividade das áreas } \\
\text { protegidas como um mecanismo de } \\
\text { conservação na escala da paisagem }\end{array}$ & Manutenção da integridade da paisagem & $\begin{array}{l}\text { Taxa de desmatamento - } \\
\text { MATCHING - BIODAM }\end{array}$ \\
\hline PAMES & Eficácia ou performance das UCs & RAPPAM $^{37}$ - FAUC ${ }^{38}$ \\
\hline $\begin{array}{l}\text { Avaliação da contribuição das áreas } \\
\text { protegidas para a conservação de } \\
\text { seus valores de biodiversidade }\end{array}$ & $\begin{array}{l}\text { Efetividade de Gestão ou êxito na } \\
\text { conservação da biodiversidade e na } \\
\text { sustentabilidade de uso dos recursos } \\
\text { naturais }\end{array}$ & $\begin{array}{l}\text { SAMGe - PROBUC }{ }^{39} \text { - } \\
\text { SISUC }{ }^{40} \text { - DURAMAZ }\end{array}$ \\
\hline
\end{tabular}

Fonte: LEVERINGTON et al, 2010; MARCHAND, 2010 e 2014; LE TOURNEAU, 2013; FONSECA, 2011, OLIVEIRA, 2012; MARINELLI, 2011; NOLTE et al, 2013; WEIGAND JR et al, 2014; HOCKINGS, LEVERINGTON E COOK (2015).

\footnotetext{
${ }^{36}$ Abreviação em inglês para Protected Area Management Effectiveness

${ }^{37}$ Rapid Assessment and Priorization of Protected Area Management(Rappam)

${ }^{38}$ Ferramenta de Avaliação da Efetividade do Programa Áreas Protegidas da Amazônia (FAUC)

${ }^{39}$ Programa de Monitoramento da Biodiversidade e do Uso de Recursos Naturais

${ }^{40}$ Sistema de Indicadores Socioambientais para Unidades de Conservação da Amazônia
} 


\subsection{Avaliação da extensão e localização das áreas protegidas, incluindo a sua representatividade biológica}

Essa primeira abordagem avalia a extensão e localização das áreas protegidas, especialmente em relação ao conjunto de alvos de biodiversidade que tais áreas destinamse a conservar, considerando-se a sua localização em relação a representação de ecossistemas, ecorregiões e/ou habitats, e também à distribuição de espécies ou grupos taxonômicos. Muitas das áreas protegidas, principalmente as primeiras, foram criadas em função de suas belezas cênicas ou em função das ameaças externas. No Brasil, embora o decreto de criação do Parque Nacional de Itatiaia destaque muitos dos alvos de conservação daquela área, as criações que se seguiram tiveram diferentes motivações:

matas primitivas, com as altitudes variando de 816 a 2.787
metros, cortada por numerosos pequenos córregos que desaguam
nos rios Aiuruoca, Campo Belo e Preto, que têm ali suas
nascentes, e apresentando flora inteiramente diversa da de outras
montanhas do Brasil, mesmo da de outros contrafortes da Serra
da Mantiqueira; área e flora já estudadas, em todos os seus
aspectos, por geólogos, botânicos e cientistas de toda espécie,
nacionais e estrangeiros; .......para que possa ficar perpetuamente
conservada no seu aspecto primitivo e atender às necessidades de
ordem científicas decorrentes das ditas circunstâncias
(DECRETO N. 1.713 - DE 14 DE JUNHO DE 1937).

Segundo Franco e Drummond (2009), no Brasil dos anos 1920-1940, os conceitos de proteção, conservação e preservação eram intercambiáveis, indicando que a natureza deveria ser protegida, tanto como conjunto de recursos produtivos a serem explorados racionalmente no interesse das gerações presentes e futuras quanto como diversidade biológica a ser objeto de ciência e contemplação estética. Nos vinte anos que se seguiram à criação do Parque Nacional de Itatiaia, a maioria das UCs criadas foi de florestas, reforçando o atendimento às orientações do Código Florestal de 1934, com vistas à manutenção da oferta de madeira e subprodutos florestais. No final dos anos 1950 e início dos anos 1960, vários parques nacionais foram criados. Mas a partir da década de 1970, predominaram outros critérios para a seleção de localidades e a criação de UCs federais - estabelecimento de unidades numerosas, de tipos variados, localizadas em áreas interioranas, remotas ou de fronteira, de grande tamanho e com representatividade ecossistêmica, reforçando os princípios da biologia da conservação (PADUA, 1997; FRANCO e DRUMMOND, 2009; DRUMMOND et al,2010). No final dos anos 1990, o conceito de planejamento sistemático da conservação (PSC) começa a ser incorporado 
pela comunidade acadêmica e pelos tomadores de decisão como ferramenta orientadora para criação de novas áreas.

O PSC é um conjunto de procedimentos e análises (processos) que são utilizados para avaliar sistemas de áreas protegidas, identificar lacunas de conservação e fornecer subsídios para o processo de tomada de decisão sobre o uso do espaço. O PSC auxilia na elaboração de cenários de conservação, a partir da definição clara de alvos e metas de conservação a serem atingidos, que contemplem a proteção da biodiversidade e dos ecossistemas, a persistência de espécies, de processos ecológicos e de paisagens, aproveitando as oportunidades de conservação e minimizando custos MARGULIS e PRESSEY, 2000.

Já os anos seguintes caracterizam como a época de ouro para as UCs brasileiras, pautada pelo aumento do número de áreas e pela implementação do SNUC. Mas o final da década de 2010, a estratégia de expansão do sistema esbarra com projeto de desenvolvimento que vê as UCs como um entrave para o uso e exploração dos recursos naturais (MERCADANTE, 2010).

Esse último cenário só corrobora o fato de que esforços futuros para criação de UCs devem ser complementados por uma gestão adequada das áreas existentes, e uma forma de reforçar a gestão das áreas existentes concentrara-se em melhorar a eficácia do conjunto de áreas de um determinado sistema no cumprimento dos seus objetivos globais de conservação da biodiversidade, alocando estrategicamente os esforços de gestão entre e dentro das áreas existentes para fortalecer suas contribuições coletiva na proteção de espécies ameaças e endêmicas (BALMFORD et al., 2002 LE SAOUT et al, 2013; HOCKINGS, LEVERINGTON E COOK, 2015).

A identificação de lacunas de conservação (novas áreas a serem protegidas) por meio do PSC permite a objetividade e a eficiência, cria memória do processo de identificação de prioridades, promove a participação e gera informações que possibilitam a negociação das áreas e a capacidade de avaliar oportunidades. A identificação de prioridades para a expansão de um determinado sistema de unidades de conservação é baseada nos conceitos de representatividade, persistência, complementariedade, eficiência, flexibilidade, vulnerabilidade e insubstituibilidade. Onde a representatividade significa que os todos alvos de conservação devem estar presentes no sistema de áreas escolhido; a persistência, considera que cada alvo de conservação deve ter um mínimo de 
ocorrências que garanta sua variabilidade e viabilidade a longo prazo; a complementariedade refere-se à estratégia de se verificar, antes da definição do local da unidade de conservação, o que as outras reservas da região contêm visando a selecionar uma área cujas características venham a complementar as já presentes nas outras unidades, com o princípio de maximizar o número de alvos/metas de conservação a serem atingidas; a eficiência, onde a solução escolhida deve apresentar uma ótima relação custo/benefício; a flexibilidade diz respeito às várias formas de combinação para formar um conjunto representativo de áreas protegidas. A existência dessas combinações permite que haja espaço para negociar e para, se possível, evitar conflitos pois as metas de conservação podem ser atingidas pela combinação de diferentes áreas; a vulnerabilidade representa o risco da solução encontrada, dada as modificações frequentes do uso da terra; e a insubstituibilidade, também conhecida como a medida de "importância" (irreplaceability) é a contribuição potencial de um local para o objetivo de conservação ou seja, probabilidade de uma determinada área ter de ser protegida para que um determinado conjunto definido de metas de conservação seja alcançado (MARGULIS e PRESSEY, 2000; RODRIGUES et al, 2004).

Alguns países têm identificado áreas prioritárias para a conservação sob a forma de proteção usando os princípios e ferramentas de PSC, permitindo assim uma avaliação das vantagens e desvantagens e dos custos de oportunidade para ampliar o sistema ou rede de áreas protegidas. Uma revisão recente sobre essas análises mostrou que durante o período de 2010-2012, um total de 705 artigos científicos foram publicados, dos quais 207 incluíam informações potencialmente relevantes para criação de UCs. Segundo Le Saout et al (2013) o PSC também pode ser utilizado para orientar o esforço de gestão das áreas protegidas, garantindo que as áreas com alto grau de insubstituibilidade sejam geridas de forma estratégica e adaptada às características específicas da biodiversidade local. Mas durante a última década, a maioria das análises de lacunas globais e regionais realizadas tiveram como objetivo principal informar a situação dos sistemas de áreas protegidas para a CDB e para a WCPA, no entanto, estes estudos embora concentrem-se na identificação de lacunas e não sugeriam como as redes propostas deveriam ser implementadas e integradas nas políticas nacionais (JUFFE-BIGNOLI et al, 2014).

No Brasil, embora o sistema de unidades de conservação apresente grandes lacunas de representatividade a análise de lacunas para conservação como ferramenta para implementação de sistema de unidades de conservação representativo e abrangente ainda 
é incipiente (SCARAMUZZA et al, 2003; FERREIRA, 2011). Em que pese a existência do instrumento de política pública “Áreas Prioritárias para a Conservação, Utilização Sustentável e Repartição dos Benefícios da Biodiversidade” para apoiar a tomada de decisão, de forma objetiva e participativa, no planejamento e implementação de ações como criação de unidades de conservação, licenciamento, fiscalização e fomento ao uso sustentável, esse instrumento não é utilizado como forma de avaliar o sucesso do conjunto de UCs existentes e planejar a sua complementariedade. As regras para a identificação dessas áreas foram instituídas formalmente pelo Decreto $n^{\circ} 5092$ de 21/05/2004 no âmbito das atribuições do Ministério do Meio Ambiente e estão em consonância com as estratégias recomendadas pela CDB, PAN-Bio e PNAP. O processo de seleção e identificação das áreas prioritárias adota como base o Mapa de Biomas do IBGE e utiliza a abordagem do PSC. A elaboração de uma base de dados representativa dos alvos de conservação escolhidos, assim como as demais fases do processo, como a definição da superfície de custo, dos polígonos prioritários e da recomendação de ações contam com a participação de especialistas convidados, representantes do governo federal, governos estaduais e representantes da sociedade civil. A análise dos dados é feita a partir de ferramentas específicas de modelagem espacial, como o Marxan e Sistemas de Informação Geográfica (SIG). O principal resultado do processo é a identificação das áreas prioritárias e sua classificação em três níveis (prioridade de conservação, importância biológica e urgência de ação), além das recomendações de ações prioritárias para cada área e sua caracterização quanto às ameaças e oportunidades (MMA, 2007).

O Programa Marxan é, atualmente, o software mais utilizado na seleção de áreas a serem protegidas, mas outros programas têm funcionalidade semelhante, a citar C-Plan, Sites, Cluz, Gap Analysis. Mas esses programas compartilham a dependência por uma alta densidade e cobertura de registros de ocorrência de espécies e são extremamente sensíveis a deficiências na qualidade dos dados. Embora uma das principais lacunas a serem preenchidas para a avaliação das lacunas de proteção é o nosso conhecimento sobre a biodiversidade. Segundo sinaliza Whittaker et al. (2005) a maioria das espécies encontradas no planeta ainda não está formalmente reconhecida ou descrita (déficit Linneano), da mesma forma a maioria dos grupos taxonômicos e as distribuições geográficas são pouco conhecidas e possuem inúmeras lacunas (déficit Wallaceano). Ambos os problemas são dependentes de escalas espaciais ou de tempo e maximizar os esforços de coleta e compilação de dados biológicos de forma a tornar essas informações 
disponíveis para o planejamento da conservação representa um grande desafio (POSSINGHAM et al, 2000; BALL e POSSINGHAM, 2000, WATTS et al, 2008; BALL et al, 2009; LOYOLA e. LEWINSOHN, 2009; FERREIRA, 2011; WATTS, 2016).

Sob a coordenação do MMA foram realizados três exercícios de identificação de áreas prioritárias para a conservação. O primeiro exercício, realizado entre os anos de 1998 e 1999, priorizou em escala continental, não só áreas para a conservação da biodiversidade, mas, também, para o seu uso sustentável e para a repartição dos benefícios, permitindo assim além da identificação de tais áreas, avaliar os condicionantes socioeconômicos, as tendências de ocupação humana do território brasileiro e definir as principais ações para gestão dos recursos biológicos. Em razão de sua importância, o processo de identificação de áreas prioritárias para todo o território brasileiro, esse exercício foi integrado à política nacional de meio ambiente, por meio do Decreto $\mathrm{n}^{\mathrm{o}}$ 5.092, de 21 de maio de 2004, e pela Portaria MMA n 126, de 27 de maio de 2004. No Bioma Amazônia, o primeiro exercício identificou 397 áreas prioritárias, cerca de 250 milhões de hectares, para criação de UCs ou reconhecimento de terras indígenas. O segundo exercício, ou a primeira atualização das Áreas Prioritárias para a Conservação, Uso Sustentável e Repartição de Benefícios da Biodiversidade Brasileira realizado em 2006, identificou 399 áreas para de criação de UCs, sendo 216 para criação de UCs de proteção integral e 183 de UCs de uso sustentável, somando cerca de $1.095 .723 \mathrm{~km}^{2}$, representando 15,2 \% da área total do Bioma Amazônia, 13,3\% da Caatinga, 12\% Cerrado, 5\% da Mata Atlântica, 7,5\% Pampa e 15,2\% Pantanal. O terceiro exercício, ou a segunda atualização era prevista para 2012, foi finalizado, em 2015 apenas para os biomas Caatinga, Cerrado e Pantanal. Uma análise dos impactos do segundo exercício para o Bioma Caatinga revelou que as UCs criadas após 2007 correspondem a um acréscimo de 0,14\% e $0,07 \%$ respectivamente de UCs de proteção integral uso sustentável, entretanto apenas 43\% da área total das novas UCs criadas após 2007, sobrepõem com os polígonos indicados pelo segundo processo de atualização de áreas prioritárias para o Bioma Caatinga (CAPOBIANCO et al, 2001; MMA, 2007 e MMA, 2015).

Outra forma de demonstrar o sucesso das UCs no Brasil é através da quantificação espacial da representatividade das regiões biogeográficas protegidas sob a forma de UCs federais e estaduais em cada um dos biomas definidos pelo IBGE. O balizador desse sucesso até 2010 era uma das Metas CDB 2010, - a Meta 11 - a qual a conservação dos 
ecossistemas terrestres e marinhos era representada pela proteção em forma de UC de $30 \%$ do bioma Amazônia e 10\% dos demais biomas e na zona costeira e marinha. Este compromisso foi reafirmado e ampliado pelo Brasil, onde as metas, denominadas agora Metas CDB 2020 ou Metas de Aichi, prevê para meta 11 o aumento de 10\% para 17\% proteção em forma de UCs para todos os biomas Brasileiros, excetuando-se o bioma Amazônia, para qual foi mantido a proteção de $30 \%$ da sua área total. Segundo os dados do Cadastro Nacional de Unidades de Conservação - $\mathrm{CNUC}^{41}$, somadas áreas das UCs de proteção integral e uso sustentável estas correspondem a cerca de $27 \%$ do bioma Amazônia, 10\% da Mata Atlântica, 9\% do Cerrado, 8\% da Caatinga, 5\% do Pantanal, 3\% do Pampa e 1,5\% da Área Marinha, cuja área total corresponde a soma da área do Mar Territorial mais a Zona Econômica Exclusiva. Isso significa que a meta estabelecida pela CDB para 2010 não foi alcançada, e o cumprimento da Meta CDB 2020 demanda um esforço ainda maior, exceto para o Bioma Amazônia (Quadro 8):

Quadro 8 - Área coberta por unidades de conservação por Biomas

\begin{tabular}{|l||c|c||c|c||}
\hline \hline BIOMA & $\begin{array}{c}\text { ÁREA TOTAL } \\
\text { DO BIOMA } \\
\left(\mathbf{K M}^{\mathbf{2}}\right)\end{array}$ & $\begin{array}{c}\text { \% DA ÁREA } \\
\text { TOTAL DO } \\
\text { BIOMA COM } \\
\text { UCS DE PI E US }\end{array}$ & $\begin{array}{c}\text { \% DA ÁREA } \\
\text { TOTAL DO } \\
\text { BIOMA COM } \\
\text { UC DE PI }\end{array}$ & $\begin{array}{c}\text { \% DA ÁREA } \\
\text { TOTAL DO } \\
\text { BIOMA COM } \\
\text { UC DE US }\end{array}$ \\
\hline AMAZONIA & $4.198 .551,00$ & $27,10 \%$ & $9,9 \%$ & $17,10 \%$ \\
\hline MATA ATLANTICA & $1.117 .571,00$ & $9,9 \%$ & $2,5 \%$ & $7,4 \%$ \\
\hline CERRADO & $2.040 .167,00$ & $8,6 \%$ & $3,10 \%$ & $5,5 \%$ \\
\hline CAATINGA & $827.934,00$ & $7,7 \%$ & $1,2 \%$ & $6,5 \%$ \\
\hline PANTANAL & $151.159,00$ & $4,6 \%$ & $2,9 \%$ & $1,7 \%$ \\
\hline PAMPA & $178.704,00$ & $2,7 \%$ & $0,3 \%$ & $2,4 \%$ \\
\hline AREA MARINHA & $3.555 .796,00$ & $1,5 \%$ & $0,10 \%$ & $1,4 \%$ \\
\hline
\end{tabular}

Fonte: CNUC, 2015

Entretanto, se consideramos apenas a contribuição das UCs de proteção integral, mesmo o bioma Amazônia só teria alcançado um terço da meta estabelecida. Com esse cenário é esperado que o sistema de unidades de conservação no Brasil apresente significativas lacunas de representatividade. Mesmo para o bioma Amazônia, não temos clareza da contribuição das UCs existentes na conservação dos padrões e dinâmicas de distribuição das espécies e dos processos ecológicos da biodiversidade regional. A ausência de estudos de representatividade para o SNUC impede uma avaliação mais qualitativa entre os biomas e dentro de cada bioma, pois não sabemos se estamos conservando tudo, ou se estamos sendo redundantes na conservação dos mesmos alvos

\footnotetext{
${ }^{41}$ Dados consolidados por bioma em 15/02/2015 em www.mma.gov.br/cadastro_uc
} 
ou, se na existência de lacunas de representatividade, estamos caminhando para saná-las. Outro aspecto importante em relação de representatividade é utilizar a noção insubstituibilidade para além da identificação de novas áreas, ou seja, esse conceito também pode ser aplicado para orientar o esforço de gestão das áreas ou UCs existentes, possibilitando que as UCs com alvos de conservação altamente insubstituíveis tenham um melhor acompanhamento da sua gestão.

\subsection{Avaliação da efetividade das áreas protegidas como um mecanismo de conservação na escala da paisagem}

Essa é uma abordagem que pretende mostrar como as áreas protegidas podem reduzir impactos de grande escala, como o desmatamento da floresta ou/e a degradação de habitats, ou como a localização da área pode ser correlacionada com os níveis mais baixos de impacto. Perda e degradação de habitat, superexploração de recursos naturais, disseminação de espécies invasoras e mudanças climática influenciam no estado de conservação da biodiversidade e são frequentemente usados como proxy (substituto) de diversidade biológica e servem orientar as estratégias de gestão a fim de evitar e mitigar novas perdas de diversidade biológica.

A diversidade de abordagens em relação as mudanças, uso e cobertura da terra pode produzir variadas interpretações e análises do mesmo fenômeno da mudança terra. Alguns estudos visam quantificar os efeitos ecológicos dos processos de mudança terra, enquanto outros estão preocupados com os fatores subjacentes que causam a mudança terra. Entre os estudos que buscam explicações causais dos processos de mudança terra, alguns tentam explicar os padrões emergentes de mudança de terra com base em dados geográficos (como, por exemplo, o monitoramento por meio do sensoriamento remoto na cobertura florestal) onde a unidade de análise que pode se concentrar em unidades espaciais, tais como pixels em unidades de imagens de sensoriamento remoto; enquanto outros visam a compreensão das cognições socioambiental subjacentes a tomada de decisões, como o contexto institucional das decisões sobre o uso da terra ou sobre os tomadores de decisões individuais si. Dependendo da lente teórica e disciplinar através da qual a análise é feita, explicações sobre os mesmos padrões de mudança da terra podem ser diferentes (MAGLIOCCA et al, 2015). 
Mas o fato é que o uso de dados oriundos do sensoriamento remoto foi amplamente disseminado como ferramenta para avaliação do sucesso das áreas protegidas. Bruner et al (2001) ao avaliar a efetividade de 93 parques $^{42}$ considerando o desmatamento dentro dos limites dos parques desde a criação, e a condição atual daqueles parques em comparação com a condição de seus arredores, encontraram que $83 \%$ dos parques seguraram plenamente o desmatamento em seu interior, sendo que em $43 \%$ deles não foram encontrados registros de desmatamento desde a sua criação e nos $40 \%$ restantes, as áreas anteriormente antropizadas incorporadas as do parque na época da criação, tinham sido capazes de se recuperar, contribuindo para um aumento real da cobertura vegetal. Ao comparar a situação desses parques com seu entorno (buffer de $10 \mathrm{Km}$ ), considerando 5 categorias de pressão, como desmatamento, caça e extração de madeira, e, em menor medida do fogo e pastoreio, Bruner et al encontraram que as condições dentro dos parques eram significativamente melhores do que as áreas circundantes. Eles também encontraram que alguns parques são mais efetivos que os outros, mas de maneira geral eles estão em melhores condições que seus arredores em relação ao desmatamento. Algumas áreas foram mais fortemente impactadas pela exploração madeireira e caça, mas esses impactos ainda foram reduzidos quando em comparação com os seus arredores, e embora os parques ainda estivessem em melhor condição que os seus arredores com respeito a danos causados pelo fogo e pastoreio, essas diferenças foram menores. Essas comparações levaram em consideração o grupo de parques estudados, mas Bruner também realizou comparações individuais: praticamente todos os parques amostrados estavam sob pressão de desmatamento, pastagem, fogo, caça e extração de madeira e a maioria dos parques obtiveram sucesso, pelo menos em algum grau em mitigar essas ameaças. Mais de $80 \%$ dos parques, analisados individualmente, estavam em melhores condições do que os seus arredores em relação ao desmatamento, extração de madeira e fogo e cerca de $60 \%$ dos parques estavam em melhores condições que seu entorno no que diz respeito à caça e pastoreio.

Alguns índices e ferramentas foram e são utilizados no Brasil para avaliar o sucesso das UCs na manutenção da integridade da paisagem. O Brasil possui um programa avançado de monitoramento da cobertura de florestas tropicais, realizado, desde o final da década de 1970, pelo Instituto Nacional de Pesquisas Espaciais - INPE.

\footnotetext{
${ }^{42}$ Distribuídos em 22 países e selecionados em regiões sujeitas a uma significativa pressão humana em relação ao uso da terra e considerando-se o tempo mínimo de 5 anos de criação e com áreas acima 5000 hectares
} 
Desde a década de 1980 o INPE faz o monitoramento contínuo da cobertura florestal da Amazônia, por meio de imagens do satélite LandsSat, nas quais são identificadas áreas de florestas, áreas desmatadas com pasto, novos desmatamentos, a hidrografia, e vegetação não florestal. O INPE, através do Projeto de Monitoramento da Floresta Amazônica Brasileira por Satélite - PRODES tem um papel central na produção e análise de dados do desmatamento da floresta amazônica. O projeto PRODES realiza o monitoramento por satélites do desmatamento por corte raso na Amazônia Legal e produz, desde 1988, as taxas anuais de desmatamento na região, que são usadas pelo governo brasileiro para o estabelecimento de políticas públicas. Entretanto outras instituições, como por exemplo o Instituto do Homem e Meio Ambiente da Amazônia IMAZON, a academia (universidades) e as instituições de pesquisa também utilizam os dados monitorados pelo INPE para análises.

$\mathrm{Na}$ Amazônia, os incêndios estão intimamente ligados ao desmatamento e, portanto, pode ser usado como um proxy para avaliar a eficácia da UC ou outra área protegida na proteção da cobertura florestal. Nepstad et al (2006) ao avaliar a efetividade de parques e reservas indígenas no controle do desmatamento e focos de incêndio na Amazônia, constataram que estas áreas inibem as queimadas nas suas fronteiras. Eles usaram a relação de densidade fogo em um buffer de $20 \mathrm{~km}$ de largura, dentro e fora das fronteiras de cada área para avaliar a proteção dentro contra a perturbação do lado de fora. Entretanto, eles não avaliaram todas as áreas e os padrões de fogo no interior das mesmas (ao contrário usaram uma amostra limitada, não incluindo as unidades de conservação estaduais). Ao avaliar o estudo de Nepstad et al (2006), Adeney et al (2009) destacam que embora estes métodos indiquem que as queimadas param nas fronteiras das áreas protegidas, e que tais métodos não nos dizem nada sobre o que está acontecendo dentro das áreas. Para Adeney et al (2009) o estudo de Nepstad et al (2006), é geograficamente ou temporalmente restrito, pois além de não considerar todas as áreas, também não consideraram explicitamente a localização dessas áreas em relação a possíveis pressões (como, por exemplo, a distância das rodovias e estradas) ou mesmo em relação ao contexto climático ou as variações regionais. Adeney et al (2009) ao questionarem (i) são as reservas realmente efetivas para proteger as florestas da Amazônia do desmatamento e, consequentemente, das queimadas; (ii) se a proteção de fato seria uma consequência da localização de reserva (em lugares remotos, por exemplo elas seriam mais protegidas), ou em função do respeito à legislação; (iii) se seriam alguns tipos de reserva mais eficazes 
do que outras, encontraram, por meio da detecção via satélite dos focos de calor no interior das áreas protegidas e seu entorno, que ocorreram menos queimadas nas áreas protegidas do que fora delas, e que a diferença entre as áreas protegidas e desprotegidas foi maior devido à proximidade destas com as estradas. Também encontram que essas áreas não fornecem proteção absoluta, pois mesmo dentro nas áreas afastadas das estradas, foram observadas maiores queimadas nas em regiões com alto impacto humano do que naquelas com baixo impacto. Mas concluíram, assim como Nepstad et al (2006), que de modo geral, considerando fatores regionais e climáticos associados as queimadas os resultados mostram que as áreas protegidas são uma ferramenta eficaz para reduzir os incêndios florestais na Amazônia.

Soares-Filho et al (2008) ao estudar efeito das áreas protegidas do bioma Amazônia na redução do desmatamento concluiu que as áreas protegidas são, de fato, inibidoras do desmatamento. Foram analisados os dados de desmatamento entre 2002 e 2007, e calculadas as probabilidades históricas de desmatamento em cada uma das 521 áreas protegidas existentes na Amazônia, naquele período, incluindo as UCs de proteção integral, as UCs de uso sustentável, as áreas militares e as terras indígenas. Estas áreas foram comparadas com as probabilidades de desmatamento em suas respectivas áreas de entorno com largura incrementais (buffers) de $10 \mathrm{~km}, 20 \mathrm{~km}$ e $50 \mathrm{~km}$. Os resultados indicaram que as áreas protegidas são inibidoras do desmatamento, e que a probabilidade de ocorrer desmatamento nas zonas de entorno das áreas protegidas é até dez vezes superior àquela do seu interior e cresce em direção às zonas mais distantes dos limites das áreas protegidas. Embora, no seu estudo sobre Cenários de desmatamento para a Amazônia, esse mesmo autor alerte:

“...que mesmo um maciço investimento na implementação e manutenção de uma ampla rede de áreas protegidas não seria suficiente para impedir o empobrecimento em larga escala das principais bacias hidrográficas, ecorregiões e hábitats amazônicos. Portanto, uma estratégia de conservação extensiva deve também envolver a proteção de um arranjo funcional de remanescentes florestais fora das áreas protegidas a fim de se evitar o colapso ambiental dos ecossistemas de florestas úmidas, já em curso em outras partes dos trópicos (Soares_filho et al, 2005, página 148)”.

Cunha (2010) ao calcular a taxa de desmatamento para todas as UCs da Amazônia brasileira, por meio de imagens do monitoramento da cobertura florestal da Amazônia na 
área de cobertura do PRODES, no período de 2001 a 2008, considerou evidente papel das UCs do Bioma Amazônia no combate ao desmatamento. As taxas de desmatamento também foram agrupadas por Cunha (2010) segundo o nível proteção ou categoria de manejo (proteção integral e uso sustentável), mas não em relação ao nível de pressão, localização ou contexto político. Neste caso, foram observados que a taxas de desmatamento em UCs de uso sustentável é maior que nas UCs de proteção integral. Verissmo et al (2011) também chegaram em resultado semelhante em relação a esse último aspecto, pois em números absolutos, as UCs de uso sustentável apresentam maior área desmatada se comparadas às UCs de proteção integral ${ }^{43}$. Esse resultado não surpreende, pois as UCs de uso sustentável ultrapassam em $129.312 \mathrm{~km}^{2}$ as de proteção integral. Entretanto, é necessário destacar que a ocupação e supressão da vegetação nativa é permitida nas UCs de uso sustentável e esta ocupação e /ou supressão pode ocorrer com e sem a participação populações locais, com a observância ou não das regras especificas desta categoria a depender do grau de implementação da unidade.

Nelson e Chomitz (2011) corroboram o entendimento sobre a efetividade das áreas protegidas na redução do desmatamento, especialmente nas áreas que garantem o acesso das populações residentes aos recursos naturais. Os autores também utilizaram os incêndios florestais como um proxy de alta resolução para o desmatamento; e compararam UCs de proteção integral, UCs de uso sustentável e Terras Indígenas, mas encontraram que as UCs reduziram substancialmente a incidência de fogo, sendo que as áreas uso sustentável foram ainda mais eficazes. Mas para Barber et al (2012) as avaliações em ampla escala ou globais tendem sempre a pontar que "sim" as UC contribuem para a redução do desmatamento, embora estudos mais finos ou com UCs individuais muitas vezes demostrem o contrario, que "não". Esses autores analisaram a cobertura floretal dentro das UC, no seu entorno e o desempenho das UCs em função de pressões de desenvolvimento. Avaliação do desempenho em função da pressão considerou que a quantidade de proteção oferecida por uma UC individualmente não depende do que acontece dentro de seus limites, mas também da pressão em seu entorno. Neste contexto as UCs analisadas que apresentaram grandes diferenças entre as taxas de perda da cobertura florestal dentro e no seu entorno foram consideradas bem sucedidas. Aquelas que apresentaram uma pequena diferença foram consideradas mal sucedidas.

\footnotetext{
${ }^{43}$ Quando se considerou o papel das Terras Indígenas, de maneira geral, as UCs do grupo de Proteção Integral apresentam menor proporção de desmatamento, seguidas pelas TIs e as UCs de Uso Sustentável
} 
Uma exceção para este segundo caso ocorre quando existe taxas de perda, tanto dentro como fora, próximo de zero, indicando que estas Ucs são responsáveis pela manutenção da cobertura florestal natural, devido a uma ausência de pressão do desenvolvimento, comuns em UCs isoladas. Esses autores analisaram a extensa rede de UCs na amazônia brasileira (1,8 milhões de km²) em função da evolução das pressões de desenvolvimento humano na paisagem. Considerando o conjunto de UCs foi observada a manutenção da cobertura florestal em 98,6\% das áreas, em grande parte, concordando com estudos globais anteriores. No entanto, o exame detalhado de 474 áreas individuais revelou resultados distintos: Muitas das áreas $\left(544.800 \mathrm{~km}^{2}\right)$ demostraram-se eficientes na proteção em função do seu isolamento. Outras $\left(396.100 \mathrm{~km}^{2}\right)$ de fato demonstraram eficiência na proteção pois estavam submetidas a pressões de de desenvolvimento humano. Por outro lado, $12 \%$ das áreas não conseguiram proteger os $27.300 \mathrm{~km}^{2}$ que englobam, e mais $7 \%$ fornecem apenas uma protecção marginal de $37.500 \mathrm{~km}^{2}$.

O estudo de Barbes corrobora o proposto por Ferraro e Pressey (2015) que destacam que grande parte da literatura sobre o sucesso das áreas protegidas é caracterizada pela comparação de resultados "antes e depois da proteção" ou "com proteção e sem proteção". As comparações tipo "antes e depois" podem ser confundidas por fatores não relacionados com a mudança no status de proteção ao longo do tempo, tal como mudanças na política ou na demanda por recursos naturais. Já as comparações “com e sem", também podem ser confundidas com fatores que são sistematicamente associados aos resultados medidos em relação a onde e quando a proteção está atribuída. Por exemplo, se as áreas protegidas tendem a estarem localizadas em terras com baixa aptidão para a agricultura, as condições contrafactuais (de controle) relevantes não serão representadas nas áreas protegidas localizadas próximas as áreas com elevada aptidão agrícola. Em geral, esses são os modelos mais utilizados para estimar as condições contrafactuais, mas de longe são os mais relevantes.

Para melhores estimativas do sucesso das áreas protegidas na manutenção da paisagem os cientistas avançaram em relação aos dados e as premissas a serem analisadas. Nolte et al (2013) examinaram 292 áreas incluindo UCs de proteção integral, uso sustentável e Terras Indígenas no Bioma Amazônia em relação ao desmatamento evitado, tipo de proteção e de pressão no período de 2000 a 2005. Os autores constataram que todos os tipos de áreas protegidas têm contribuído para evitar o desmatamento na Amazônia brasileira, independentemente da sua categoria de manejo ou dos seus 
objetivos de conservação. Os resultados também reafirmam o importante papel das UCs de proteção integral em relação a áreas de uso sustentável, já que tanto nos locais de baixa e alta pressão, as UCs de proteção integral evitam mais consistentemente o desmatamento do que as áreas de uso sustentável. As diferenças observadas entre essas categorias de manejo foram robustas, pois mesmo antes das iniciativas governamentais para frear $\mathrm{o}$ desmatamento, entre os anos de 2000 e 2005, uma série de áreas de proteção integral foi estabelecida em locais com alta pressão de desmatamento, enquanto que as áreas de uso sustentável foram estabelecidas em locais de baixa pressão. As terras indígenas também se mostraram eficazes para reduzir a pressão de desmatamento, e se mostraram mais eficazes que as UCs de proteção integral e uso sustentável. Nolte et al (2013) avançaram ao considerar além da taxa de desmatamento, as pressões e as categorias de manejo e também por usar o matching, metodologia que identifica grupos de controle artificiais, onde para cada UC (tratada pelo conjunto de pixels protegidos) identifica pixels semelhantes fora das UC (não protegidos).Também chamado de método de correspondência, pois leva em conta dois problemas fundamentais: controle de vieses estatísticos causados pela influência de co-variáveis sobre a probabilidade de conversão antrópica e a não-aleatoriedade da alocação de UC ou áreas protegidas em todo o território (correlação espacial efeito) e o controle de polarização estatística causada pela influência de auto-correlação e efeito de vazamento (PAIVA et al, 2015).

Com uma abordagem semelhante às análises de sucesso na manutenção da integridade da paisagem utilizados nas análises de desmatamento e no matching, o Sistema de Indicadores para o Desenvolvimento Sustentável (Projeto DURAMAZ), possui um indicador para avaliar as dinâmicas da paisagem (indicador 8). Esse indicador é representado por 4 sub-indicadores: a. Situação da área desmatada na área da UCs; b. Situação do desmatamento no entorno; c. Situação do desmatamento nas áreas sensíveis (APPs) e d. Avaliação da dinâmica da paisagem e da biodiversidade (também conhecido como protocolo de avaliação BIODAM). Esse protocolo parte do princípio que é possível avaliar a evolução de habitats e, portanto, das espécies que neles fixaram residência. Para isso usa imagens de satélite Landssat, em momentos distintos no tempo, e uma série de observações de campo sobre a dinâmica da paisagem por meio da avaliação das "condições de vida" de várias espécies de plantas. A ideia é que uma paisagem mais complexa nas suas estruturas horizontais e verticais (estratificação e continuidade) tem uma maior probabilidade de proporcionar melhores condições para espécies que ela 
abriga. Essa avaliação deve ser realizada dentro e no entorno das áreas protegidas (MARCHAND, 2010; LE TOURNEAU et al, 2013).

Em todos os estudos citados, a maioria das áreas protegidas teve uma influência positiva sobre a manutenção dos habitats naturais, embora ocorra uma variação do grau de influência em função do tipo de área protegida, do grupo ou categoria de manejo de um mesmo tipo de áreas protegida (neste caso UC), da restrição de uso, da esfera governamental, da sua localização, do seu tamanho e ainda em função do ano de criação unidade. $\mathrm{O}$ que estes estudos realmente avaliam é a eficácia dessas áreas com foco na preservação do habitat natural e na manutenção da paisagem, ou seja, a eficácia é medida pela influência ou capacidade das UCs ou das áreas protegidas em evitar o desmatamento, os focos de incêndios ou a conversão da cobertura florestal. Os diferentes resultados sobre a eficácia estimada das áreas protegidas e das UCs estão relacionados ao contexto dessas áreas e aos métodos de avaliação escolhidos. Mas é importante destacar que as mudanças nos ecossistemas terrestres resultantes de interações humanas são estruturadas em escolhas orientadas por processos econômicos, políticos, culturais e ambientais de grande escala, embora as interações entre os processos de larga escala e as decisões locais de uso da terra e as decisões e/ou ações institucionais possa levar a resultados diferentes.

Desta forma, embora o sensoriamento remoto possa auxiliar no desenvolvimento de uma abordagem integrada da gestão dos recursos naturais, onde a biodiversidade, as pressões sobre a biodiversidade e as consequências das decisões de gestão possam ser monitorados para demostrar a eficácia das UCs na manutenção da paisagem, a análise apenas desses fatores revela pouco sobre a manutenção do estado de conservação das UCs, e portanto não demostra se essas UCs são efetivas; e pouco sobre os aspectos da gestão relacionados ao sucesso na manutenção dessa integridade, tornando frágil a premissa que uma boa gestão é sinônimo de efetividade, premissa essa que será abordada no item a seguir. 


\subsection{Avaliação da efetividade de gestão de áreas protegidas (PAME ${ }^{44}$ )}

As avaliações usadas nessa terceira abordagem são geralmente denominadas avaliação da efetividade de gestão de áreas protegidas identificadas pela sigla em inglês PAME (Protected Areas Management Efectiveness). No entanto, no âmbito desta Tese as PAMEs, ora serão enquadras como avaliações de eficácia de gestão quando o objetivo for avaliar processos e ora como avaliações de efetividade quando o objetivo e o instrumental analítico permitir avaliar os impactos, ou seja, as evidencias de conservação e do uso sustentável dos recursos naturais, a depender da categoria de dos objetivos de cada UC, embora esse conceito seja objeto de discussão da quarta abordagem proposta por Hockings, Leverington e Cook (2015).

Em termos de efetividade de conservação, as UCs terão alcançado seus objetivos quando a manutenção da integridade, resiliência e funcionamento dos ecossistemas estiverem asseguradas, de modo a garantir a representatividade e viabilidade de todos os níveis de organização da biodiversidade (ecossistemas, espécies e variedade genética). Para se verificar isso em áreas terrestres, a manutenção da cobertura vegetal nativa tem sido o indicador mais utilizado, como vimos na segunda abordagem, admitindo-se a partir daí uma relação direta de status de conservação para os demais níveis da biodiversidade. A efetividade de gestão, que na verdade é a eficácia, tem sido vista como na medida em que a UC tendo os meios, executa as ações relacionadas com o seu papel de promotora da conservação. Essa eficácia tem sido medida pela implementação de um kit básico de gestão, que envolve uma equipe mínima, equipamentos e infraestrutura, recursos e instrumentos de gestão, como o plano de manejo e conselho gestor ${ }^{45}$ (STOLTON et al., 2008 e WEIGAND JR et al, 2014).

As PAMEs foram originalmente desenvolvidas para apoiar gestão adaptativa de áreas protegidas a nível local e ao nível do sistema. Seus principais objetivos são: (i) melhorar a gestão da UC através da disponibilidade e compartilhamento de informação; (ii) atribuir recursos de forma mais eficaz para as UCs; (iii) proporcionar uma melhor prestação de contas e apresentação de relatórios a nível local, nacional ou internacional; e, (iv) aumentar o conhecimento da sociedade sobre as unidades. Neste contexto, atualmente, as avaliações PAME são responsáveis por um conjunto representativo de

\footnotetext{
${ }^{44}$ Abreviação em inglês para Protected Area Management Effectiveness

${ }^{45}$ O capítulo IV da Lei do SNUC, nos artigos 27 e 29, dispõe os instrumentos plano de manejo (Art. 27), conselho gestor (Art. 29)
} 
informações sobre os esforços de gestão nas áreas protegidas. Elas foram aplicadas globalmente, e usam métodos padronizados para a coleta dos dados de gestão. O conjunto de dados recolhidos fornece um recurso valioso para medir e compreender o impacto das intervenções de gestão dessas áreas. As PAMEs avaliam elementos que sugerem a existência de um ciclo de gestão vinculado ao planejamento, aos insumos, processos, produtos e resultados dentro de um determinado contexto. Para cada uma das etapas ou elementos de avaliação existe um conjunto de itens que serão avaliados (COAD et al, 2015; HOCKINGS et al, 2015):

- Contexto - responsável por expressar a situação atual da área protegidas, sua importância no âmbito global, nacional e local, os objetivos de conservação, os valores ou alvos de conservação e seu respectivo estado de conservação, suas pressões e ameaças;

- $\quad$ Planejamento - com indicadores que expressam a situação desejada da área com destaque para aspectos normativos (legislação, politicas), de desenho (formato, tamanho, conectividade) e planejamento da gestão (o que precisa ser feito);

- Insumo - que avalia a situação ou disponibilidade dos recursos necessários à gestão (recursos necessários para implementação do planejamento e da operacionalização da área protegida);

- $\quad$ Resultado ou Produto - que avalia a implementação dos programas - das ações e processo - empreendidos para gestão da área;

- Impacto ou Efeito - que deveria avaliar o real alcance dos objetivos, ou seja, o impacto da gestão em relação aos objetivos da área.

Para Mascia e Pailler (2011), considerando as abordagens de monitoramento e avaliação da conservação, as PAME, sobretudo aquelas baseadas em dados subjetivos coletados por meio de formulários ou questionário, devem ser consideradas como avaliações gerenciais. O elemento de avaliação impacto tende a ser subavaliado pela ausência de indicadores de impacto ou pela baixa contribuição de tais indicadores em relação ao conjunto de indicadores de eficiência de gestão. Uma avaliação rigorosa do impacto das ações de gestão requer uma comparação dos resultados observados na presença e na ausência de uma intervenção de gestão. Essas análises poderiam ser realizadas utilizando qualquer um experimental ou desenho do estudo semi-experimental. Mas em geral, metodologias PAME não utilizam dados quantitativos sobre a biodiversidade e sequer identificam os resultados a luz da presença e ausência das intervenções. As PAME são, portanto, projetadas para capturar informações sobre os 
elementos de gestão considerando a hipótese de que estes contribuem para os resultados da biodiversidade (COAD et al, 2015).

A ferramentas mais utilizada para aferir a eficácia de gestão ou sucesso no avanço da performance das UCs brasileiras é o Rappam, seguida da FAUC que será abordada de forma mais detalhada no capítulo seguinte. Essas ferramentas possuem em comum a adesão ao marco referencial da WCPA, utilizando-se de elementos de avaliação e indicadores que contribuem para identificar a distância entre a gestão desejada e a realidade atual; orientar órgãos gestores na tomada de decisão quanto à alocação mais eficiente dos instrumentos de gestão, processos e insumos (infraestrutura, pessoal, recursos financeiros).

O Rappam é um método que fornece, de forma simples, aos tomadores de decisão e formadores de políticas, informações relacionadas as UCs para a identificação de tendências e características da gestão que permitem alcançar uma melhor efetividade em um dado sistema ou grupo de áreas protegidas. A avaliação da efetividade de gestão proposta no método Rappam busca indicar se as ações desenvolvidas atendem às necessidades das UCs avaliadas de modo a subsidiar as ações de manejo do sistema e garantir que seus objetivos possam ser alcançados. O Rappam é estruturado em três blocos tendo como base os cinco elementos do ciclo de gestão da WCPA: contexto, planejamento, insumos, processos e resultados, sendo cada elemento composto por temas específicos, abordados em diferentes módulos temáticos. O primeiro bloco é representado pelo elemento Contexto, que é responsável por pelas informações gerais da UCs, assim como as informações sobre pressões e ameaças, importância biológica, importância socioeconômica e vulnerabilidade. O segundo bloco, reúne os elementos de gestão: Planejamento, Insumos, Processos e Resultados, e possui ainda um módulo específico, o terceiro bloco, com questões ligadas ao sistema de Unidades de Conservação. Seu ciclo de ocorre de 5 em 5 anos, por meio de formulário eletrônico, respondido pelo gestor da UC e validado pelo órgão gestor.

O método Rappam é adequado para análise integrada do conjunto de áreas, ou seja, no sistema de unidades de conservação, embora seja aplicável apenas a uma UC, e possibilite comparações, em ampla escala, entre várias UCs, o método não foi elaborado para gerar orientações específicas para cada gestor de unidade. O índice geral de efetividade de gestão no Rappam, para o sistema de UCs é expresso como um índice percentual, equivalente a um valor proporcional da efetividade de gestão observada em 
relação à efetividade máxima que poderia ser alcançada por esse conjunto de unidades e é calculado com base nos resultados dos elementos planejamento, insumos, processos e resultados, ponderados pela pontuação máxima possível para esse conjunto de respostas. De forma geral, toma-se como referência os intervalos $[<40 \%],[\geq 40 \% \mathrm{a} \leq 60 \%]$ e $[>60 \%]$ como definidores das respectivas classes de baixa, média e alta efetividade de gestão. Entretanto, o Rappam pode servir como 'alavanca' para identificar aquelas UCs que precisam de estudos mais detalhados e identificar programas ou questões que possam garantir análises e revisões mais completas, O Rappam também pode complementar avaliações mais detalhadas das UCs, auxiliando na identificação das áreas que precisam de estudos mais detalhados e identificando programas ou questões que podem garantir análises e revisões mais completas. O Rappam pode também contribuir para: identificar os pontos fortes e fracos do manejo; analisar as características e a distribuição das diversas ameaças e pressões; identificar áreas de alta importância ecológica e social e pontos de vulnerabilidades; indicar a urgência e prioridades na gestão de unidades de conservação; e, ajudar no desenvolvimento e na priorização de intervenções políticas, contribuindo para a efetividade de manejo das unidades de conservação. Também pode ser muito útil como quadro referencial para o desenvolvimento de ferramentas de monitoramento local, por fornecer critérios para a elaboração de indicadores específicos (ERVIN, 2003; LEVERINGTON et al., 2008; LEVERINGTON et al., 2010; WWF-BRASIL \& ICMBIO, 2010, MMA/ARPA, 2015).

Oliveira (2010) ao investigar o grau de implementação das recomendações presentes nos relatórios da primeira aplicação do Rappam para as UCs Federais, encontrou que o método possibilitou a identificação das principais limitações e prioridades, principalmente no que diz respeito às necessidades de melhoria para cada UC, individualmente, e também, em menor proporção, para o seu conjunto. Embora os relatórios e resultado das avaliações não priorizassem ou identificassem as ações para o incremento sua efetividade de cada UC ou categoria de manejo (IBAMA e WWF-Brasil, 2007). O contexto político da divulgação dos resultados não foi favorável a internalização dos dados, pois coincidiu com o momento de criação do ICMBIO, em 2007, em meio a várias indefinições em relação às atribuições, estruturas institucional e administrativa do novo órgão. Em paralelo foi observada uma resistência interna para acessar, consultar e analisar o banco de dados disponibilizado pelo parceiro de aplicação, o WWF-Brasil, resultando em uma baixa compatibilidade entre os resultados da primeira avaliação e a percepção do esforço de implementação promovido pelo ICMBIO. As informações foram 
utilizadas para consultas pontuais, exceto em relação aos dados sobre a vulnerabilidade das UCs: a pressão, ameaças, ocorrência de espécies invasoras e ameaçadas de extinção, estes foram demandados por pesquisadores. Mas a maior apropriação das informações ocorreu no âmbito dos gestores de UC, pois a aplicação do questionário contribuía, com ênfase na realidade local, para indicação de priorização de algumas áreas de atuação e suas necessidades de ações. A investigação de Oliveira coincidiu com o início da aplicação do segundo ciclo de avaliação do Rappam para as UCs federais, em 2010, para o qual foram realizadas melhorias na interface de preenchimento utilizada, a citar: adequação de perguntas (de forma a ter uma relação mais orgânica com os processos de gestão e planejamento), criação de um aplicativo de preenchimento, organização do banco de dados, envolvimento de um grupo maior de atores no processo de análise e avaliação dos resultados.

WWF-Brasil e ICMBIo (2012) ao comparar os dois ciclos de aplicação do Rappam nas UCs federais ${ }^{46}$, mostrou um maior grau de apropriação dos resultados e uma vontade institucional de considerá-los nos processos de tomada de decisão. O ciclo de avaliação de 2010, também mostrou uma elevação no índice geral de efetividade de gestão da ordem de 7,1 pontos percentuais, saindo de 41\% em 2005 para 48,1\% em 2010, o que representa um incremento de aproximadamente $18 \%$ em relação ao resultado base observado no ciclo de 2005. Indo além da análise do índice de efetividade, a análise dos índices das pressões e das ameaças entre os dois ciclos, mostrou que a criticidade geral das pressões em $2010(12,7 \%)$ apresentou-se bem maior que a criticidade geral das ameaças prevista no ciclo 2005-06 (6,4\%), sinalizando que, após cinco anos, tais pressões exibiram uma severidade acentuadamente maior do que se prefigurava no primeiro ciclo. Esta tendência a um agravamento das pressões continuou presente nos levantamentos de 2010, visto que a criticidade das atuais pressões (12,7\%) permaneceu inferior a expectativa da criticidade de suas ameaças $(13,9 \%)$. Cabe destacar que as pressões e as ameaças analisadas abrangem 16 forças, identificadas como indutores dos mais importantes impactos que incidem sobre as UCs, são elas: extração de madeira, agricultura e silvicultura, pastagem, extração mineral, construção e operação de infraestruturas, caça, pesca, coleta de produtos não madeireiros, turismo e recreação, disposição de resíduos (poluição), processos seminaturais, espécies exóticas invasoras, uso dos recursos por populações residentes, ocupação humana, influências externas e

\footnotetext{
${ }^{46}$ Considerando todos os biomas.
} 
incêndios de origem antrópica. A pressão foi avaliada com base na ocorrência ou impacto prejudicial sobre a integridade da UC das forças acima destacadas considerando-se os cinco anos anteriores a avaliação e as ameaças como a probabilidade dessas mesmas forças ocorrerem futuro próximo. Identificou-se ainda o grau de permanência (o tempo em anos de persistência das pressões e das ameaças) e o nível de criticidade ou severidade que essas pressões e ameaças são percebidas pelo gestor da UC. A criticidade foi inferida como um índice formado pela multiplicação da pontuação de três atributos identificados para cada pressão ou ameaça (abrangência, impacto e permanência). Entretanto, nenhuma análise cruzando os índices, o índice de efetividade geral e o de criticidade foi realizada.

Para a aplicação do terceiro ciclo do Rappam (2015) novas melhorias foram promovidas no formulário de avalição e o resultado do índice geral de efetividade para as UCs federais do Bioma Amazônia ${ }^{47}$ teve um aumento de 41,6\% em 2005 para 46,9\% em 2010 e para 55,4\% em 2015, o que leva a crer que estamos chegando, pelo menos para o bioma Amazônia em um índice de efetividade alta. Mas avaliação da relação entre a situação ou progressão do esforço de gestão das UCs brasileiras e a conservação da biodiversidade ou a adequada utilização dos recursos e seus benefícios ainda é tênue, mesmo que o Rappam permita uma análise além dos valores totais de efetividade, como, por exemplo, uma análise dos módulos de pressão e ameaça, a análise dos resultados de 2015 e a sua comparabilidade com os anos anteriores devem seguir o padrão de análise dos índices de efetividade e de criticidade de forma separada.

Já Ferramenta de Avaliação da Efetividade do Programa Áreas Protegidas da Amazônia (FAUC) é uma adaptação da ferramenta Tracking Tool (METT/TT) aplicadas para as UCs apoiadas pelo Programa em 2005 e 2006. Ela foi criada em 2007 incorporando o marco conceitual da WCPA de forma a permitir à avaliação da efetividade dos recursos investidos, a identificação os marcos referenciais de estabelecimento e consolidação de UCs, a vinculação dos resultados da FAUC aos recursos financeiros investidos pelo Arpa, o uso da pontuação para planejar metas futuras e auxiliar o planejamento operacional anual. Assim como o Rappam, a FAUC não possui elementos que permita a avaliação dos impactos alcançados pelo aumento do desempenho da gestão. As demais ferramentas aplicadas, no Brasil, em menor número abrangência, também se enquadram dentro desta abordagem. Assim como Rappam e a FAUC essas ferramentas são aplicadas por meio de questionários ou formulários que refletem a percepção dos

\footnotetext{
${ }^{47}$ A aplicação do Rappam para os demais biomas (UCs Federais) ocorrerá no segundo semestre de 2016.
} 
gestores de UC no que diz respeito à situação da unidade de conservação. Exceções são as ferramentas Certificação de UCs (PADOVAN, 2002 e 2003) - cuja informação é preenchida por agentes externos - e ParkWatch e Matriz de Cenários (LIMA et al., 2005) que, além da percepção do gestor, acrescenta informações oriundas de dados secundários e observações in loco da equipe de aplicação. De forma semelhante ao universo de metodologias de aplicação global as ferramentas brasileiras dependem predominantemente de uma avaliação qualitativa, especialmente com ênfase na avaliação rápida. A predominante dependência de dados qualitativos é justificada pela ausência de meios e recursos para o monitoramento. Mas apesar da limitação em relação ao processo de aplicação, a aplicação das PAMEs é, atualmente, responsável pelo conjunto de informações sobre as UCs para avaliar o indicador de Efetividade das Áreas Protegidas da-CBD. No nível global essa informação é de responsabilidade da WDPA, gestora do banco de dados mundial de áreas protegidas. Cabe destacar que embora o indicador se refira a efetividade de gestão, as informações possíveis e serem compartilhadas pela WDPA correspondem a Eficácia de gestão das UCs, pois avalia quão bem a área protegida está a ser gerido - ou seja as capturar informações sobre os elementos de gestão considerando a hipótese de que estes contribuem para os resultados da biodiversidade (HOCKINGS ET AL, 2006; PATTON, 2007 in LEVERINGTON et al., 2008; AMAZONAS, 2011; OLIVEIRA, 2012, COAD et al, 2015).

Órgãos gestores e gestores de UCs tem clareza sobre a complexidade da gestão da UCs e do seu conjunto e que as informações necessárias ao seu monitoramento e planejamento não são fáceis de obter. Embora a avaliação da eficácia possa ser um meio concreto para se observar os efeitos e resultados das diferentes práticas de gestão e informar a performance e estruturação das UCs e do sistema de UC ao longo do tempo, tais avaliações dão poucos subsídios para aferir sobre o estado de conservação da biodiversidade, sobre o uso sustentável e sobre a qualidade de vida das populações locais no interior dessas áreas. Importante aliado das atuais ferramentas de efetividade - mas ainda distante do ponto de vista de priorização e implementação - as ferramentas ou as estratégias de monitoramento da biodiversidade e monitoramento socioambiental que poderiam gerar informações preciosas para a gestão da UC, para a avaliação da sua efetividade na proteção dos recursos naturais e para o desenvolvimento socioeconômico das comunidades, como propõe a quarta e última abordagem: contribuição das áreas protegidas para a conservação de seus valores de biodiversidade. 


\subsection{Avaliação da contribuição das áreas protegidas para a conservação de seus valores de biodiversidade}

Essa quarta abordagem é representada pela análise do conjunto de elementos de avaliação de impacto das PAMEs. Ou seja, essa abordagem sugere uma forma de verificação (quantitativa) da informação qualitativa (com ênfase nos valores da biodiversidade/alvos de conservação). A reflexão sobre as evidências de sucesso de conservação da biodiversidade associadas à gestão de unidades de conservação considera que uma UC é efetiva quando a eficiência da sua gestão resultar em impacto positivo no estado de conservação da biodiversidade e na utilização sustentável dos recursos naturais, este último quando tal uso for permitido. Entretanto, nossa compreensão do impacto das intervenções de gestão das UCs sobre os resultados de conservação tem sido impedida pela falta de dados (OLIVEIRA, 2012; COAD et al, 2015).

O sucesso da conservação depende da nossa capacidade de reduzir a pressão humana nas áreas que abrigam a diversidade de serviços e ecossistemas biológicos, no Brasil nas UCs, outras áreas protegidas e seus respectivos entornos. Mas para estabelecer um sistema efetivo de UCs, é necessário ter meios de evidenciar os impactos ambientais (conservação da biodiversidade) e sociais das UC (utilização sustentável dos recursos naturais contribuindo para a manutenção do bem-estar e dos meios de vida das populações residentes no interior e no entorno das UCs). Mas a busca por essas evidências não tem sido uma tarefa fácil. Geldmann et al (2013) ao avaliar 2599 publicações científicas encontraram 76 estudos em 51 artigos que avaliaram os impactos da existência das UCs sobre a cobertura de habitat, e 42 estudos em 35 artigos com a mesma análise sobre populações de espécies. Eles concluíram que há boas evidências de que as áreas protegidas conservaram o habitat florestal, mas que as evidências permanecem inconclusivas quando tratamos da sua contribuição para a manutenção de populações de espécies pois as conexões casuais entre os elementos da gestão e os impactos de conservação raramente são avaliados. Pressey et al (2015) destacam que os esforços para recolher e analisar dados sobre os resultados das áreas protegidas não conseguem informar os tomadores de decisão sobre os impactos ambientais e sociais das áreas protegidas ou sobre as atividades de gestão associados a esses impactos. Mas esses mesmos autores, em um outro artigo (Ferraro e Pressey,2015) apontam que a avaliação do impacto das áreas protegidas está para emergir como um campo de investigação científica com a possibilidade de se tornar uma nova fronteira para a ciência da 
conservação e de mudar a direção da política. Para esses autores a mudança de foco é necessária, poia a avaliação do impacto aborda o fim, não os meios, da conservação da natureza. Os avanços nessa direção dependem da nossa capacidade de inferir causalidade a partir de dados não-experimentais e da nossa compreensão sobre a maneira como as áreas protegidas são concebidas, localizadas e geridas. Com base nestes avanços, os estudos de avaliação de impacto devem utilizar modelos empíricos robustos e um conjunto amplo de dados para estimar os efeitos que as áreas protegidas têm sobre os resultados ambientais e sociais, em relação às condições não observáveis. Esta diferençaentre o que podemos observar e que teríamos observado se tivéssemos feito a conservação de forma diferente, é o impacto que as áreas protegidas têm por objetivo maximizar. $\mathrm{O}$ conceito de "perda evitada" implica na diferença entre o que foi conseguido sob a forma de áreas protegidas e o que teria sido alcançado sob uma forma de conservação de forma diferente. Essa diferença, no entanto, não pode ser inferida a partir de estudos científicos que incidem sobre as condições ou estado de conservação dentro e no torno de áreas protegidas ou nas características de redes de áreas protegidas e de gestão (por exemplo: extensão da área protegida ou a representação dos ecossistemas). Capturar a rica complexidade do desenho e do contexto de implementação de uma área protegida é um desafio para os pesquisadores que procuram estimar os impactos de áreas protegidas, em face de ausência de um referencial teórico, de dados sobre as decisões de gestão dessas áreas e de modelos empíricos que possam avaliar intervenções multidimensionais. Nesse contexto encontra-se também o desafio de avaliar separadamente e também as conexões entre os impactos de ambientais (conservação) e os sociais, associados ao uso dos recursos e seus benefícios.

Compreender a natureza dinâmica dos ecossistemas e as consequências das atividades humanas é essencial para a gestão de UCs que têm por objetivo manter, melhorar ou restaurar a integridade ecológica dos ecossistemas, além de evitar, minimizar ou mitigar ameaças ecológicas para estes sistemas. Mas na prática o monitoramento sistemático para avaliar os resultados ou impactos da gestão da UC tem perdido espaço para as exigências diárias da própria gestão. A ausência de monitoramento compromete a avaliação da efetividade. Na maioria dos casos, até podemos sinalizar que a gestão foi eficaz, pois com insumos e processos obtiveram-se produtos. Em muitos casos, poderemos sinalizar que a gestão, também, foi eficiente, ou seja obtiveram-se produtos com quantidade menores de insumos. Mas, em poucos casos, podemos sinalizar que foi 
a gestão efetiva - que resultados (impactos) são adequados aos esforços empreendidos e aos recursos investidos, e se também estão alinhados aos objetivos da UC (POMEROY et al, 2004; POMEROY et al, 2006).

É importante lembrar que as primeiras discussões e recomendações para a realização das avaliações de efetividade da gestão consideravam a eficácia de gestão como um proxy de conservação da biodiversidade, pois se a UC possui uma boa gestão era de se esperar que que seus objetivos de conservação seriam alcançados. Mas as ferramentas de PAMEs não eram capazes de avaliar o impacto, somente o processo. Os gestores, constantemente, são confrontados com questões cada vez mais complexas e desafiadoras, que exigem uma compreensão ampla da situação da UC (estado de conservação e sua capacidade de atender às demandas das comunidades locais) para a tomada de decisões. Quase uma década e meia depois, e paralela à continua discussão sobre avaliação da efetividade de gestão, destacam-se as primeiras discussões sobre a avaliação da efetividade de conservação (DUDLEY, et al, 2010; COAD et al, 2015).

No contexto mundial, uma análise das 32 ferramentas mais comuns descritas por LEVERINGTON et al (2010) e detalhadas por LEVERINGTON et al (2010b), especificamente em relação ao tratamento ou abordagem das respectivas ferramentas no que diz respeito aos indicadores de impacto/efeito para conservação e para manutenção dos meios de vidas das comunidades locais, mostrou que apenas nove ferramentas incorporaram a avaliação de indicadores de impacto: oito das ferramentas apresentam indicadores específicos para expressar o impacto de conservação ou de integridade ecológica; e três apresentaram também indicadores que expressão o nível de satisfação ou bem estar para comunidades locais (Quadro 9). Sete dessas ferramentas adotam o marco referencial da WCPA, uma adota o marco conceitual da OECD de Pressão-EstadoResposta $(\mathrm{PER})^{48}$ e outra o marco conceitual de certificação ambiental tendo como referência a ISO 14001. No que diz respeito a natureza das informações coletadas, todas trabalham com dados qualitativos, sendo que sete incorporam também dados quantitativos. Os processos e atores envolvidos no processo de avaliação são vários, mais

\footnotetext{
${ }^{48} \mathrm{O}$ marco conceitual PER (Pressão-Estado-Resposta) está fundamentado em uma rede de casualidade onde se acredita que as atividades antrópicas originam pressão sobre o meio ambiente (indicadores de pressão) que por sua vez interferem no meio alterando a qualidade e a quantidade dos recursos naturais (indicadores de estado), e devido a isto, produz-se uma resposta que tende a minimizar ou anular esta pressão (indicadores de resposta).
} 
com forte viés da participação de especialistas no processo de coleta e análise das informações.

Quadro 9 - Ferramentas que incorporam a avaliação do impacto ou efeito de conservação

\begin{tabular}{|c|c|}
\hline FERRAMENTA- MÉTODO & INDICADORES \\
\hline $\begin{array}{l}\text { Evaluation of German Biosphere Reserves } \\
\text { (University of Trier) }\end{array}$ & \multirow{9}{*}{$\begin{array}{l}\text { Mudanças no uso da terra } \\
\text { Integridade de habitas } \\
\text { Espécies ameaçadas de extinção } \\
\text { Demografia } \\
\text { Empregabilidade } \\
\text { Alteração das condições ecológicas da água } \\
\text { Alterações geológicas } \\
\text { Empoderamento das comunidades locais } \\
\text { Esforço ou acesso aos recursos naturais } \\
\text { Abundância de espécies chaves } \\
\text { Tamanho da população } \\
\text { Estrutura da população de espécies chaves } \\
\text { Qualidade da saúde humana } \\
\text { Atores das comunidades locais em posição de } \\
\text { liderança } \\
\text { Distribuição formal do conhecimento na } \\
\text { comunidade }\end{array}$} \\
\hline $\begin{array}{c}\text { How is your Marine Protecd Area Doing } \\
\text { (National Ocean Service /IUCN - CMPA/WWF) }\end{array}$ & \\
\hline $\begin{array}{l}\text { Enhancing our Heritage } \\
\text { (UNESCO - IUCN) }\end{array}$ & \\
\hline $\begin{array}{l}\text { Important Bird Area Monitoring } \\
\text { (Birdlife Internacional) }\end{array}$ & \\
\hline $\begin{array}{c}\text { Quality Park Project Italy } \\
\text { (Italian National Agency for New Tecnologies) }\end{array}$ & \\
\hline $\begin{array}{l}\text { Quality criteria and standards for German } \\
\text { National Parks (Europarc Germany) }\end{array}$ & \\
\hline $\begin{array}{c}\text { Natuurmonumenten Quality Test, Netherlands } \\
\text { (Vereniging Natuurmonumenten) }\end{array}$ & \\
\hline $\begin{array}{l}\text { Catalonia Management Effectiveness Evaluation } \\
\text { (Catalan Institution of Natural History - ICHN) }\end{array}$ & \\
\hline $\begin{array}{c}\text { System of Sustainable Development Indicators } \\
\text { for the Natural Parks of Asturias - IDESPAR } \\
\text { (Universidade de Oviedo) }\end{array}$ & \\
\hline
\end{tabular}

Fonte: LEVERINGTON et al (2010b)

Ao observamos o conjunto de indicadores de tais ferramentas percebe-se que os indicadores de conservação da biodiversidade são, em grande maioria, oriundos de estratégias de monitoramento da biodiversidade. A maioria delas prioriza o monitoramento de uma ou mais proxis de conservação da biodiversidade, uma delas monitoramento da integridade da paisagem - mas comumente adotada e já abordada na segunda abordagem sugerida Hockings, Leverington e Cook (2015).

Avaliações e monitoramento da situação e das tendências em relação ao estado de conservação de espécies ou habitats são rotineiros em países desenvolvidos, pois sem um sistema de monitoramento abrangente e com objetivos bem definidos, as mudanças nos sistemas naturais continuam obscuras para os formuladores de políticas e tomadores de decisão que não têm uma ideia clara sobre os impactos das políticas ambientais adotadas. A mesma lacuna se aplica aos gestores de UCs. Manter um esforço, ao longo dos anos, para a coleta e a sistematização de informações que possam expressar as mudanças significativas na biodiversidade entram em conflito com a quantidade geralmente limitada 
dos recursos financeiros e humanos dos países em desenvolvimento (DANIELSEN, 2009 e SCHMELLER, 2009).

Outras iniciativas também incorporam a avaliação do impacto de conservação. $\mathrm{O}$ National Park Service criou em 1980, um programa para monitorar os mais de 270 parques do sistema um programa conhecido como "monitoramento dos sinais vitais", pois se refere a um conjunto relativamente pequeno de informações, mais ricas em atributos que são usados para acompanhar o estado geral ou "saúde" dos recursos naturais do parque e para fornecer alerta sobre as situações que exigem intervenção. $O$ monitoramento da biodiversidade implica na coleta de dados sobre os componentes da biodiversidade e em analisar os padrões espaciais e temporais desses componentes, incluindo diagnosticar as causas da mudança, além de orientar sobre a necessidade de adequações nos processos de gestão (FANCY, 2009). Um grupo de pesquisadores da Inglaterra preocupados em avaliar o estado de conservação de determinados alvos (espécies, cobertura vegetal, qualidade de vida, etc..) frente ao conjunto de ações ou processos (educação ambiental, práticas de manejo, alocação de recursos) desenvolveu uma ferramenta de avaliação de projetos a Cambridge Conservation Forum (CCF). A CCF tem como objetivo principal identificar a capacidade dos projetos em alterar o estado de conservação do alvo baseada em um marco referencial que prioriza a investigação dos elementos de ligação entre as etapas de execução/implementação (do planejamento as ações), resultados (produtos) e impacto (efeitos conservação) em relação a sete categorias de atividade de conservação ou dimensões de intervenção, sendo as mais relacionadas as gestão de UCs: manejo de espécies e populações, manejo de áreas ou habitas e modos de vida (KAPOS et AL, 2009). Motivados pela mesma preocupação NatureServe, organização não-governamental cuja missão é conectar a pesquisa científica e a conservação desenvolveu uma ferramenta Element Rank Estimator ou Rank Calculator para avaliação do estado de conservação de espécies que tem como base indicadores ou elementos agrupados e três categorias: raridade, tendência, e ameaças (MASTER et al, 2009, FABER-LANGENDOEN et al, 2009).

Estratégias de monitoramento e avaliação são essenciais para documentar as mudanças na biodiversidade ao longo do tempo, para esclarecer sobre importantes processos ecológicos e para medir o sucesso ou o fracasso de intervenções ou instrumentos de conservação (ALCARAZ-SEGURA, 2009; HAN et al, 2014). 
A discussão brasileira mais atual acerca do monitoramento e avaliação da biodiversidade tem como foco a escala nacional e resultou em um compromisso formal do governo Brasileiro - a Resolução CONABIO 06/2013 - para atender as novas metas do Plano Estratégico (Global) de Biodiversidade 2011-2020 da CDB para 2020 - as chamadas "Metas de Aichi". Esse compromisso expressa a escala nacional de atendimento às 20 Metas de Aichi, e é nas Meta Nacionais 11, 12 e 13 que encontramos a estratégia brasileira para melhorar a situação (status) da biodiversidade: protegendo ecossistemas (Meta 11) espécies (Meta 12) e a diversidade genética (Meta 13). Mas é na Meta 11 que encontramos a principal estratégia brasileira de conservação da biodiversidade: as unidades de conservação:

Meta Nacional 11 - Até 2020, serão conservadas, por meio de unidades de conservação previstas na Lei do SNUC e outras categorias de áreas oficialmente protegidas, como APPs, reservas legais e terras indígenas com vegetação nativa, pelo menos $30 \%$ da Amazônia, $17 \%$ de cada um dos demais biomas terrestres e $10 \%$ de áreas marinhas e costeiras, principalmente áreas de especial importância para biodiversidade e serviços ecossistêmicos, assegurada e respeitada a demarcação, regularização e a gestão efetiva e equitativa, visando garantir a interligação, integração e representação ecológica em paisagens terrestres e marinhas mais amplas (Resolução CONABIO 06/2013, página 5).

As metas 12 e 13 trazem, respectivamente a preocupação com a abundância, distribuição, ameaças, risco de extinção de espécies e com as estratégias para minimizar a perda de variabilidade genética:

Meta Nacional 12: Até 2020, o risco de extinção de espécies ameaçadas terá sido reduzido significativamente, tendendo a zero, e sua situação de conservação, em especial daquelas sofrendo maior declínio, terá sido melhorada. (Resolução CONABIO 06/2013, página 5).

Meta Nacional 13: Até 2020, a diversidade genética de microrganismos, plantas cultivadas, de animais criados e domesticados e de variedades silvestres, inclusive de espécies de valor socioeconômico elou cultural, terá sido mantida e estratégias terão sido elaboradas e implementadas para minimizar a perda de variabilidade genética. (Resolução CONABIO 06/2013, página 5).

Como desdobramento da definição das metas nacionais, esperava-se a definição de adequados indicadores de monitoramento e os primeiros passos foram dados, pois o 
Painel Brasileiro de Biodiversidade (PainelBio), cuja secretaria executiva é exercida pela IUCN, promoveu entre 2014 e 2015 a reflexão, discussão e a construção de indicadores para as 20 metas brasileiras de Aichi. A iniciativa do PainelBio resultou na indicação de 37 indicadores para o monitoramento das Metas 11, 12 e 13, sempre orientados por perguntas orientadoras (questões chaves) que auxiliaram na reflexão, discussão e identificação dos indicadores (Quadro 10). Cada indicador possui uma ficha de detalhamento que informa o nome do indicador, a sua descrição, abrangência, relevância para o cumprimento da meta, disponibilidade de acesso e considerações para análise e interpretação. Mas esta proposta de indicadores ainda será avaliada pela Comissão Nacional de Biodiversidade/Conabio, instancia cuja atuação foi minimizada desde a discussão do Plano Estratégico de Conservação da Biodiversidade em 2006 (MMA, 2015 e WEIGAND JR et al, 2014).

Quadro 10 - Metas de Aichi X Indicadores de monitoramento

\begin{tabular}{|c|c|c|}
\hline METAS & PERGUNTAS ORIENTADORAS & INDICADORES SUGERIDOS \\
\hline$=\frac{\tilde{E}}{\tilde{E}}$ & $\begin{array}{l}\text { Qual é a área protegida por unidades } \\
\text { de conservação nos diferentes biomas? } \\
\text { •Qual é a área protegida por terras } \\
\text { indígenas, reservas legais e APPs nos } \\
\text { diferentes biomas? } \\
\text { •Qual a representatividade das } \\
\text { unidades de conservação e terras } \\
\text { indígenas em relação a alvos } \\
\text { prioritários de biodiversidade? } \\
\text { •Qual é o grau de implementação para } \\
\text { os diversos tipos de áreas protegidas? } \\
\text { •Há recursos humanos e financeiros } \\
\text { para a gestão dessas áreas? } \\
\text { •A gestão das áreas protegidas é feita } \\
\text { de forma eficiente e eficaz? } \\
\text { •Há integração da gestão das áreas } \\
\text { protegidas entre si e com as paisagens } \\
\text { mais amplas? }\end{array}$ & $\begin{array}{l}\text { 1.Mudança no uso da terra; 2.Balanço Hídrico } \\
\text { Qualitativo dos Rios e Bacias Hidrográficas; } 3 \text {. } \\
\text { Cobertura Nativa de Unidades de Conservação de } \\
\text { Uso Sustentável e Terras Indígenas; } \\
\text { 4.Desmatamento no interior das Unidades de } \\
\text { Conservação; 5.Focos de calor no interior das } \\
\text { Unidades de Conservação; 6.Queimadas e incêndios } \\
\text { florestais; 7.Relação entre Demanda Total e Oferta } \\
\text { de Água Superficial; } 8 \text {. Índice de Fragmentação e } \\
\text { Conectividade; 9. Áreas Protegidas (UC, TI, Terras } \\
\text { Quilombolas, APP e RL); 10.Cobertura de Áreas de } \\
\text { APP, RL e Remanescentes dos Imóveis Rurais; } \\
\text { 11.Terras Indígenas; 12.Unidades de Conservação; } \\
\text { 13.Área de Florestas Públicas Destinadas para Uso } \\
\text { e Gestão Comunitária; 14. Áreas de APP e RL de } \\
\text { Imóveis rurais em Processo de Recuperação; } \\
\text { 15.Efetividade de gestão; 16.População abrangida } \\
\text { por Terras Indígenas; 17.População abrangida por } \\
\text { UCs de Proteção Integral; 18.População abrangida } \\
\text { por e de Uso Sustentável; 19. Regularização } \\
\text { ambiental de propriedades rurais; 20. Terras } \\
\text { Indígenas com plano de gestão territorial e } \\
\text { ambiental (PGTA); 21.UCs com protocolo de } \\
\text { monitoramento; 22.UCs com termos de } \\
\text { compromisso (Proteção Integral); 23.UCs com } \\
\text { CDRU }{ }^{49} \text { assinados (Uso Sustentável), 24.UCs com } \\
\text { Conselho Ativo; 25.UCs com Regularização } \\
\text { Fundiária e 26.UCs com Equipe efetiva }\end{array}$ \\
\hline
\end{tabular}

49 A Concessão de Direito Real de Uso transfere é o instrumento (contrato administrativo) que transfere os direitos reais da propriedade e pode ser transmissível por ato inter vivos e causa mortis. Pode ser gratuita ou onerosa, individual ou coletiva. 


\begin{tabular}{|c|c|c|}
\hline 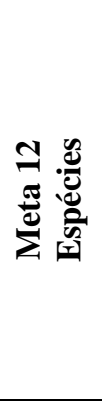 & $\begin{array}{l}\text { •Qual o risco de extinção de espécies } \\
\text { ameaçadas? } \\
\text { •Qual a situação de conservação das } \\
\text { espécies ameaçadas, em especial } \\
\text { daquelas sofrendo maior declínio? } \\
\text { •Os planos de ação para espécies } \\
\text { ameaçadas estão sendo efetivos? } \\
\text { •As avaliações das espécies estão em } \\
\text { andamento? }\end{array}$ & $\begin{array}{l}\text { 1.Espécies da fauna ameaçadas de extinção; } \\
\text { 2.Espécies da flora ameaçadas de extinção; } \\
\text { 3.Percentual de espécies nativas sobre-explotadas } \\
\text { ou ameaçadas de sobre-explotação; 4.Mudança no } \\
\text { uso da terra; 5. Índice de Fragmentação e } \\
\text { Conectividade; } 6 \text {. Espécies da Fauna Ameaçadas de } \\
\text { Extinção com Planos de Ação para Recuperação e } \\
\text { Conservação; 7.Andamento dos Planos de Ação e } \\
\text { 8.Espécies da Fauna Ameaçadas de Extinção } \\
\text { Representadas nas UCs }\end{array}$ \\
\hline 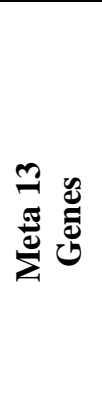 & $\begin{array}{l}\text { - A diversidade genética de } \\
\text { microrganismos, plantas cultivadas, de } \\
\text { animais criados e domesticados e de } \\
\text { variedades silvestres, inclusive de } \\
\text { espécies de valor socioeconômico elou } \\
\text { cultural está sendo mantida? } \\
\text {-As estratégias para minimizar a perda } \\
\text { de variabilidade genética foram } \\
\text { elaboradas e estão sendo } \\
\text { implementadas? }\end{array}$ & $\begin{array}{l}\text { 1.Áreas Protegidas (UC, TI, Terras Quilombolas, } \\
\text { APP e RL); 2.Bancos Genéticos (bancos de } \\
\text { germoplasma); 3.Recursos genéticos depositados } \\
\text { em coleção }\end{array}$ \\
\hline
\end{tabular}

Fonte: WEIGAND JR et al, 2014

A proposta ainda carece de sinergia entre a estratégia e os impactos esperados para a meta 11 que é conservar 30\% da Amazônia, 17\% de cada um dos demais biomas terrestres de vegetação nativa e 10\% de áreas marinhas e costeiras em UCs e outras áreas protegidas, principalmente em áreas de especial importância para biodiversidade e serviços ecossistêmicos, assegurada e respeitada a demarcação, regularização e a gestão efetiva e equitativa, visando garantir a interligação, integração e representação ecológica em paisagens terrestres e marinhas mais amplas.

As iniciativas de conservação no nível de espécies têm como foco as espécies ameaçadas de extinção (meta 12). Será considerada extinta a espécie sem representantes na natureza e em situação ex situ. A melhoria da situação de conservação ocorre quando uma espécie, classificada em uma categoria da Lista Vermelha da UICN, passa de uma categoria mais crítica para outra categoria menos crítica, refletindo sua abundância e distribuição na natureza (MACHADO, DRUMMOND e PAGLIA, 2008; IUCN, 2001). No Brasil, os principais instrumentos de gestão de espécies ameaçadas são as Listas Nacionais Oficiais de Espécies Ameaçadas de Extinção e os Planos de Ação Nacionais para a Conservação de Espécies Ameaçadas de Extinção, onde o MMA atua como coordenador da gestão de espécies ameaçadas, o ICMBIO como responsável pela implementação destes instrumentos (listas e planos) no que tange à fauna ameaçada e o Jardim Botânico do Rio de Janeiro em relação à flora ameaçada. Isto sem restringir a cooperação entre estes órgãos, no que couber. Já a conservação da diversidade genética 
tem seu foco destacado na diversidade genética de microrganismos, plantas cultivadas, de animais criados e domesticados e de variedades silvestres e seu potencial uso para melhoramento genético, segurança alimentar, turismo, inclusive de espécies de valor socioeconômico elou cultural. Tendo por estratégias para minimizar a perda da variabilidade genética: a conservação in situ (por meio da proteção de ecossistemas naturais), a ex situ (por meio da representação das espécies e variedades em coleções de bancos genéticos, parcelas experimentais e em cativeiro) e a conservação on farm (por meio do uso sustentável, cultivo e criação das espécies, variedades e raças por produtores rurais).

Dessa discussão, cabe destacar que nenhum dos indicadores propostos para a Meta 11, que tem as UCs como principal estratégia de conservação da biodiversidade, demostra o impacto de conservação da biodiversidade ou do uso sustentável dos recursos naturais, muito pelo contrário todos os indicadores propostos são indicadores de processo. Os alvos de conservação da biodiversidade, alguns poucos, só são identificados nos indicadores propostos para a Meta 12; e por fim nenhum indicador para demonstrar o sucesso das UCs, sobretudo as UCs de uso sustentável, no uso sustentável dos recursos naturais e na melhoria da qualidade da vida. Podemos afirmar, portanto, que a estratégia brasileira para conservação da biodiversidade tem, até o momento, seu maior foco ou pelo menos uma demonstração de maior empenho e também de mais resultado no âmbito da conservação dos ecossistemas e paisagens, contexto da segunda abordagem proposta por Hockings, Leverington e Cook (2015).

Han et al (2014) recomendam que a documentação dos impactos de conservação e de resposta a biodiversidade deve ser realizado de forma que sejam cientificamente defensáveis, em escalas temporais e espaciais adequadas, e simples o suficiente para informar os tomadores de decisão. Como a maioria dos programas de monitoramento e avaliação existentes foram concebidos para escalas locais, muitas vezes só conseguem produzir informações desagregadas, heterogêneas e não-padronizadas quando avaliados em escalas nacionais ou regionais. Han destaca ainda que capacidades nacionais, particularmente nos países em desenvolvimento, são frequentemente insuficientes para medir muitos indicadores e mesmo quando tais informações estão disponíveis, a falta de padronização pode tornar a avaliação difícil ou impossível.

Em que pese a ausência de diretrizes para a avaliação do sucesso das UCs um dos idealizadores no marco conceitual de avaliação de efetividade da gestão (HOCKINGS et 
al, 2009, DUDLEY et al, 2010 e HOCKINGS et al, 2015) sugere a realização de avaliações conjuntas, priorizando o uso das PAMEs e que estas sejam realizadas considerando-se os objetivos de criação de cada área protegida e considerando-se, sobretudo, as restrições em função das suas diferentes categorias.

Para avaliar como os dados PAME têm sido utilizados na avaliação de impacto, Cook et al (2014) realizaram uma revisão da literatura para avaliar o conhecimento atual sobre as correlações entre a eficácia de gestão, medida com os dados das PAMEs, e os resultados de conservação da biodiversidade medida por métodos externos. Do conjunto de revistos 185 artigos revistos, escolhidos em função do título e do resumo, onde 23 foram separados para uma para análise detalhada do texto principal, nove deles de fato foram considerados para análise da relação entre eficiência de gestão e impacto de conservação. Esses nove artigos referiam-se a estudos realizados em países tropicais em desenvolvimento, principalmente na África e na América Latina. Três desses estudos utilizaram dados de sensoriamento remoto sobre a cobertura florestal para medir o impacto das áreas protegidas na taxa de desmatamento, usando métodos de correspondência estatísticos (matching) para construir as amostras de tratamento e controle, e depois investigou correlações entre os escores ou índices das PAME (aqui considerados não como índices de efetividade de gestão mais como índices de eficiência de gestão) e a sua relação com a manutenção da paisagem (cobertura florestal). Os seis estudos restantes mediram as correlações entre o índice das PAME e seu elementos com o estado de conservação da biodiversidade, usando dados coletados in situ, como a situação e mudanças nas populações de animais, distribuição de espécies. Seis dos nove estudos tiveram como foco o desempenho global de gestão e usado uma única pontuação total PAME por área. Cinco dos nove estudos encontraram uma relação positiva entre a pontuação PAME e resultados de biodiversidade; os outros quatro, incluindo os três estudos que mediram impacto, utilizando uma comparação matching, não encontrou nenhuma correlação. Para esses autores não está claro se a falta de correlação com o impacto é real, ou seja, se a gestão área protegida não tem impacto sobre os resultados de biodiversidade, ou se a eficiência de gestão, medida pela pontuação PAME, não seja não suficiente para garantir a conservação efetiva. É claro que a falta de uma relação pode ser devido a limitações relacionadas com tamanhos de amostra, com as características dos dados utilizados no processo de avaliação pelas PAMEs, ou pela maneira pela que os dados das PAMEs foram usados na análise. 
Em três desses estudos citados por Cook et al (2014), Nolte et al (2013a, 2013b e 2013c) usaram o matching para investigar quais os indicadores de gestão do Rappam apresentam relações mais estreitas com o sucesso das unidades de conservação na redução do desmatamento no bioma Amazônia. Segundo Nolte et al (2013a) ao investigar a relação entre os resultados das ferramentas METT e RAPPAM com focos de queimadas e desmatamento, nenhuma associação estatisticamente significativa foi encontrada entre o desmatamento evitado e os indicadores que refletem alvos preferenciais dos investimentos em conservação. Ainda assim, em Nolte et al (2013b), o conjunto de autores entende que diferentes regimes de governança e localização podem influenciar no sucesso do desmatamento evitado em áreas protegidas (UC e Terras Indígenas) na Amazônia brasileira. As análises de Nolte et al destacaram ainda que a ausência de conflitos e de regularização fundiária das UC é fortemente associada ao sucesso em reduzir as pressões de desmatamento. Os autores sugerem que se quisermos melhorar a eficácia das UCs na redução do desmatamento, primeiro teremos que entender a situação fundiária das UCs. A ausência de regularização e solução de conflitos podem mascarar as relações mais sutis entre os indicadores de gestão e resultados de conservação, não evidenciando como aspectos do planejamento e insumos influenciam na redução do desmatamento.

O resultado encontrado por Nolte et al não inviabiliza o que foi proposto por Hockings et al (2015) pois no âmbito local, da UC, essa relação gestão - status de conservação também é tênue. Os gestores de áreas protegidas muitas vezes não conseguem usar as evidências empíricas como ponto de referência para as suas decisões de gestão. Segundo Cook e Hockings (2012) os motivos para essa deficiência não eram claros, podendo ser desde a ausência de dados, ou a dificuldade em interpretar informações científicas e aplica-las na gestão da unidade, ou simplesmente o fato de que os gestores não valorizam a informação científica nas suas decisões. Mas ao investigar o uso das evidências na gestão de áreas protegidas na Austrália, esses autores identificaram que os gestores, para a adequada priorização das ações de manejo, consideravam os dados oriundos das evidencias empírica como mais valiosos. Entretanto, esses eram os dados mais escassos ou de acesso mais limitado. Na impossibilidade de usar esse tipo de dados, os gestores contam com a experiência e com as informações sistematizadas por eles a partir de múltiplas linhas de evidência, estas sim, frequentemente, fornecem o contexto no qual as decisões são tomadas (COOK e HOCKINGS, 2012). 
Ciente das fragilidades das ferramentas existentes e em função da baixa contribuição no processo de auxílio a tomada de decisão e monitoramento da gestão das UC, algumas ferramentas foram concebidas tentando levantar um conjunto de informações para além das informações que aferem a eficácia de gestão. Entretanto, ferramentas ou metodologias que ousem cruzar dados de eficácia e impacto de conservação se limitam, no Brasil aos estudos realizados por Nolte et al (2013a, 2013b e 2013c).

O Instituto Chico Mendes de Conservação da Biodiversidade (ICMBio) por meio da Coordenação de Monitoramento e Avaliação da Gestão de Unidades de Conservação (COMAG), o WWF-Brasil e a Secretaria de Biodiversidade e Florestas por meio da Diretoria de Áreas Protegidas (DAP/SBF/MMA) empenharam-se no processo de discussão e elaboração do um novo protocolo complementar de monitoramento da gestão de UC. Dessa discussão resultou o Sistema de Análise e Monitoramento de Gestão (SAMGe), uma metodologia de avaliação e monitoramento de gestão, de aplicação rápida, concebida ICMBio, com o apoio operacional do WW-Brasil e do Programa Arpa e do apoio financeiro da Fundação MOORE. Seu escopo e aplicabilidade estão intimamente ligadas ao marco referencial de avaliação da efetividade da WCPA/IUCM e a metodologia Padrões Abertos para a Prática da Conservação ${ }^{50}$, esta última desenvolvida pela Aliança para as Medidas de Conservação, conhecida pela sigla em inglês CMP - The Conservation Measures Partnership, consorcio de organizações formado por African Wildlife Foundation (AWF), The Nature Conservancy (TNC), Wildlife Conservation Society (WCS) e Rede WWF. Padrões Abertos para a Prática da Conservação é uma metodologia que visa fornecer os passos e a orientação geral necessária para a implementação bem-sucedida dos projetos de conservação, reunindo conceitos, alcances e terminologias comuns para o desenho, manejo e monitoramento de projetos ou ações de conservação. O importante sobre os Padrões Abertos não são somente os padrões em si, mas também os meios que os participantes usam para criá-los e manejá-los, e nesse sentido ele se assemelha ao ciclo de avaliação proposto pela WCPA, pois também propõe um ciclo de gestão adaptativa baseada em cinco passos: 1 . Conceitualize o que deseja alcançar no contexto onde está trabalhando; 2. Planeje tanto as suas ações como o monitoramento; 3. Implemente suas ações e sua estratégia de monitoramento; 4. Analise

\footnotetext{
50 O ICMBio utiliza a metodologia para diferentes escopos, como: para elaboração dos Planos Ação
} Nacional para Espécies - PAN's (ICMBio, 2015). 
seus dados e avalie a efetividade de suas atividades. Use todos os seus resultados para adaptar seu projeto ou ação de conservação e elevar ao máximo o seu impacto; e 5. Documente e compartilhe seus resultados com públicos-chave, externos e internos para promover o aprendizado (CMP, 2007; ICMBio, 2015).

O SAMGe deseja aferir, a partir da identificação dos objetivos do SNUC, da categoria e dos objetivos de criação, se o impacto negativo ocorre sobre os alvos e se o impacto positivo é sentido nos elementos econômicos, sociais, de conservação e de manejo. A efetividade de gestão de UCs se dá a partir da análise das inter-relações entre os alvos de conservação (o que se busca manter), os usos (interfaces entre os alvos e a sociedade) e as ações de manejo realizadas pelo órgão gestor. A metodologia tem ainda o papel de servir como subsídio para a tomada de decisão (tanto na unidade quanto para processos relacionados) e aproximar a sociedade da gestão das áreas especialmente protegidas (divulgando resultados e tranversalizando o processo de aplicação). O primeiro modulo de aplicação ${ }^{51}$, considerando aqui módulo como fase de implementação da ferramenta, chamado de "Caracterização Avaliativa", abordou três elementos:

- Contexto: de forma a expressar os objetivos de conservação (objetivos da categoria, da UC e do sistema), os valores ou alvos de conservação de cada UC.

Os objetivos exprimem o que se espera da política pública de conservação da natureza e são os motivos que justificam a intervenção pública na melhoria do estado de conservação de determinado atributo e nos usos relacionados às unidades de conservação. Mas é importante ressaltar que sempre os objetivos estão explicitamente descritos, nesse caso a materialização desse conteúdo se dá através da enumeração dos alvos de conservação. Os alvos de conservação da natureza são os atributos que justificaram a criação da unidade, bem como os que justificam a sua manutenção em determinada categoria e estabelecem uma relação direta com os objetivos da UC.

- Processos, ao expressar, inclusive de forma especializada, usos incentivados, usos permitidos e usos vedados relacionados aos alvos e ações e processos empreendidos para gestão da área;

\footnotetext{
${ }^{51}$ Aplicado incialmente em $62 \%$ das UCs federais
} 
Os usos na UC são as formas que os alvos de conservação se relacionam com a sociedade e com a gestão da UC. Os usos são divididos em 8 usos genéricos ${ }^{52}$ que são especializados e que englobam diversas modalidades de usos, os chamados usos específicos (classificados em uso vedado, permitido, incentivado e uso objetivo). Além dos oito eixos de usos genéricos, existem mais dois eixos de ações de manejo. Uma diz respeito às ações de manejo que são direcionadas para melhoria do estado de conservação de alvos e outra, à instalação e manutenção de infraestrutura.

- Resultado expressando o impacto aferição do impacto negativo e positivo da gestão em relação aos objetivos da UC e decorrente do uso na unidade.

A ferramenta permite observar a relação entre os usos (genéricos e específicos) e os possíveis impactos positivos e/ou negativos. Dentre os impactos positivos, a SAMGe considera os resultados econômicos e sociais e os resultados de conservação e manejo, já para os impactos negativos, considera a severidade e a magnitude do impacto. Para tanto sugere cenários de benefícios (impactos positivos) e impactos negativos e atribui um valor para a ocorrência ou não de uma série de cenários possíveis. Para a avaliação dos impactos negativos os cenários possíveis são os Cenários Econômicos, Cenários Sociais, Cenários de Conservação e Cenários de Manejo. Para os estes cenários, é necessário ainda identificar a abrangência do benefício ou impacto: usuário ou explorador do uso (individuais); entorno ou determinado grupo de pessoas (coletivo); para a sociedade como um todo (difuso). Para avaliar os impactos negativos foram sugeridos cenários severidade e magnitude, onde o gestor de selecionar o valor de 0 a 5 o cenário que melhor represente o impacto negativo de determinado uso na UC.

A segunda etapa de implementação da ferramenta, coincidirá também com a aplicação do segundo módulo de avaliação, ainda em fase de discussão e teste, chamado modulo de "Análise dos instrumentos de gestão". Neste segundo momento serão reavaliados os três primeiros elementos, caracterizados pelos alvos de conservação, pelas ações de manejo e pelos impactos e estes serão cruzados com elementos de avaliação que demostrem o planejamento e os insumos e os resultados esperados em termos de melhoria

\footnotetext{
52 1. Pesquisa científica, 2. Visitação e turismo, 3. Propriedade intelectual derivada (uso e imagem), 4. Uso do solo (posse/propriedade), 5. Uso da fauna, 6. Uso da flora, 7. Uso de recurso abiótico e 8.Utilidade pública e interesse social
} 
do estado de conservação de alvo ou em termos de qualificação dos usos relacionados à UC, como preconiza o marco referencial da WCPA/IUCN (ICMBio, 2015).

A SAMGe traz uma abordagem importante no que diz respeito a relação entre uso e estado dos alvos de conservação, na perspectiva de esclarecer as expectativas para além do objetivo de conservação da biodiversidade, sobretudo para as UCs de uso sustentável e para as ações desenvolvidas no entorno das UCs, onde o uso sustentável é permitido e incentivado e fortemente associado a manutenção dos meios de vida e bem-estar das populações residente dentro e no entorno das UCs.

Entretanto, pouca ou incipiente é a discussão sobre os valores e limites aceitáveis de utilização da biodiversidade em UCs. Capacidade de carga, resiliência, abundância, riqueza, diversidade e variabilidade de espécies - conceitos da biologia da conservação e ao mesmo tempo indicadores do estado de conservação dos ecossistemas protegidos tem tido pouco destaque na discussão (TERBORGH e SCHAIK, 2002; DE FRIES et al, 2007). Neste contexto, encontra-se o impacto ambiental das populações tradicionais (seringueiros, extrativistas, indígenas, pescadores), entre aqueles que consideram que essas populações colaboram para manutenção da biodiversidade e aqueles que pensam que as elas podem oferecer riscos a biodiversidade (GERHARDT, 2007). Algumas pesquisas apontam que a caça, a extração madeireira e a invasão de espécies exóticas comprometem o estado de conservação das espécies (segundo nível de conservação sugerido pela CDB) vegetais (WEINSTEIN e MOEGEMBURG, 2004; FIEDLER, 2008 apud MARCHAND, 2014) e animais (BONAUDO et al., 2005; PERES e NASCIMENTO, 2006 e COLLOMB, 2009 apud MARCHAND, 2014). Outras apontam que o declínio da biodiversidade dentro das UCs e a grande variação no estado dessas áreas, com perdas substanciais na variedade de animais e plantas têm como fatores geradores a perturbação do habitat natural, caça e a exploração das florestas (POSSINGHAM et al, 2006, JOPPA et al, 2008, BRADSHAW et al, 2009, GIBSON, L. et al., 2011; LAURANCE, 2013).

Por outro lado, as populações locais e tradicionais dependem dos recursos naturais para sua manutenção e sobrevivência, por meio da caça, pesca, extrativismo, uso, exploração madeireira, pecuária e agricultura - atividades/usos que a depender da categoria resultam em diferentes graus de restrição, gerando na maioria das vezes uma relação de incompatibilidade de uso e, portanto, ausências de benefícios. Estabelecer critérios de uso, desenvolvidos por manejadores/extratores ou pela pesquisa científica, ou 
por ambos os segmentos em conjunto, pode promover a sustentabilidade por meio de um manejo que favoreça a conservação pelo uso, reduzindo o impacto sobre a transformação das paisagens para outros usos e conservação. Nem sempre o uso gera em algum grau impacto negativo nas dinâmicas populacionais das espécies utilizadas, e o manejo pode desempenhar um papel fundamental para a conservação da natureza (STEENBOCK, 2012).

Além da recente SAMGe, no Brasil duas ferramentas que colaboram para a discussão sobre as evidências de como a gestão das UCs pode contribuir para a utilização sustentável dos recursos naturais pelas comunidades locais e para a manutenção de riquezas naturais como alternativas sustentáveis de desenvolvimento no nível local, são elas: Sistema de Indicadores para o Desenvolvimento Sustentável - DURAMAZ e o Sistema de Indicadores Socioambientais para Unidades de Conservação da Amazônia SISUC.

O papel das UCs na salvaguarda do patrimônio ambiental e cultural de povos e comunidades tradicionais, bem como para apoiar e fomentar o desenvolvimento sustentável desses grupos é vasto, mas MAE (205) destaca que os componentes do bem estar, vividos e percebidos pelas pessoas, são dependentes da situação, refletindo a geografia local, a cultura e as circunstancias ecológicas, ou seja percepção dos benefícios gerados pelas UC dependem da percepção humana em relação ao bem estar, em função de seus valores, práticas e normas sociais, que por sua vez podem ser influenciadas pela cultura local, religião, senso de identidade/pertencimento e a noção de comunidade. Desta forma, as populações residentes em UCs, as comunidades e a sociedade têm diferentes percepções dos benefícios proporcionados pelas UCs. Benefícios, ora são entendidos como os serviços prestados por estas áreas, e ora podem ser entendidos como sinônimo de melhoria ou manutenção do bem-estar das populações/ comunidades locais.

As UCs podem fornecer uma extensa série de bens e serviços para as populações que vivem em seu interior e/ou entorno, bem como para a sociedade como um todo. Scherl, (2006) classifica esses serviços em quatro categorias: provisão, regulação, cultural e de suporte:

-Provisão - inclui os serviços que fornecem produtos naturais com valor de uso direto para as comunidades locais e legalmente acessíveis, como alimento, água potável, madeira e plantas medicinais; 
-Regulação - benefícios provenientes de serviços ecossistêmicos, tais como regulação climática, proteção de bacias, qualidade da água, sequestro de carbono, etc;

-Culturais - valores religiosos, turismo, educação e herança cultural;

-Suporte - formação de solos, ciclo de nutrientes e produção primária.

West et al (2006) ao examinar os efeitos sociais, econômicos e políticos das áreas protegidas para as populações locais, sob um olhar antropológico, destaca que os esforços de conservação podem, por vezes, alterar as formas como as pessoas se veem em relação ao seu entorno, resultando em um impacto social negativo para as populações locais. Canavire-Bacarreza (2013) usou um conjunto de dados biofísicos e socioeconômicos robusto para estimar os impactos das áreas protegidas da Bolívia sobre a pobreza entre os anos de 1992 e 2001, mas não encontrou evidências de que o estabelecimento de áreas protegidas agrava a pobreza, ao contrário, identificou que as comunidades afetadas por áreas protegidas exibiram diferencialmente maiores níveis de redução da pobreza, em comparação com as comunidades não afetadas semelhantes, reforçando a percepção de que os esforços de conservação ambiental por meio das áreas protegidas não geram custos para as comunidades locais. Segundo Clements et al (2014) os impactos, positivo ou negativo, das áreas protegidas sobre as populações locais pobreza têm sido amplamente debatidos, pois mesmo que os benefícios globais de biodiversidade e os serviços ecossistêmicos sejam reconhecidos, os custos da conservação (implementação de áreas protegidas) podem ser desproporcionalmente suportados pela população local. Clements et al destacam o senso comum de que no mínimo os custos de não deveriam gerar prejuízos, e sempre que possível deveriam contribuir para gerar benefícios como a redução da pobreza. Blackman et al (2011), tendo como base o sistema de áreas protegidas do México, afirma que as UCs podem gerar benefícios por meio de significativos benefícios econômicos, como por exemplo: por meio do ecoturismo que também pode atrair melhorias estruturais (estradas, energia, saneamento, etc). Dudley e Stolton (2009) ao proporem uma metodologia, a PAT-BAT para avaliar os benefícios das áreas protegidas para as populações locais associaram o conceito de benefícios ao 
conceito de um recurso que está sendo usado para fornecer ganhos diretos ${ }^{53}$ para os interessados. A metodologia foi desenvolvida tendo como base uma tipologia de valores e resultados que podem ser agregadas para fornecer uma visão geral das áreas protegidas (por exemplo, grupos regionais, os sistemas nacionais, grupos bioma etc). A PA-BAT tem como objetivo avaliar a utilização dos recursos legais e os benefícios que poderiam resultar desse uso (somente os usos permitidos), e, portanto, não é uma ferramenta para a avaliação da utilização global de recursos. A ferramenta é destinada a coletar informações sobre uma ampla gama de benefícios que se obtêm em áreas protegidas, mas não foi projetada para produzir um score de como a área protegida está a este respeito, pois os resultados podem contribuir para produzir um cenário ou uma tendência.

Estudos sobre as UCs brasileiras sugerem que estas representam algumas das poucas opções de renda disponíveis para as populações residentes em áreas afastadas, fornecendo, por exemplo, postos de trabalho associados à gestão da UC, além de fomentar o desenvolvimento de cadeias produtivas associadas à utilização sustentável dos recursos e a repartição dos benefícios associados aos conhecimentos tradicionais (AMEND, 2006). Mas tal possibilidade não atende as especificidades da maioria das populações residentes em UCs da Amazônia brasileira, ou que se localizam em seu entorno, em função do contexto regional de várias dessas UCs (regiões afastadas de centros urbanos, com logística de acesso complexa, etc.). O estudo sobre a contribuição das UCs brasileiras para a economia nacional (MEDEIROS et al, 2011) destaca que do ponto de vista social, a integração das comunidades tradicionais no processo produtivo de utilização dos recursos naturais (extração, transporte, beneficiamento, plantio entre outros), pode gerar o incremento na renda familiar, diminuir a extração ilegal e degradação dessas áreas, conferindo maior proteção dos recursos naturais. Por outro lado, as populações locais e tradicionais do bioma Amazônia dependem dos recursos naturais para sua manutenção e sobrevivência, por meio da caça, pesca, extrativismo, uso, exploração madeireira, pecuária e agricultura - atividades/usos que a depender da categoria resultam em diferentes graus de restrição, gerando na maioria das vezes uma relação de incompatibilidade de uso e, portanto, ausências de benefícios.

Os esforços para avaliar o impacto das UCs na utilização sustentável dos recursos naturais e na promoção do desenvolvimento sustentável para as comunidades residentes

\footnotetext{
${ }^{53}$ Que pode ser em termos de dinheiro ganho, ou recursos de subsistência recolhidos ou ganhos menos tangíveis, como paz espiritual ou o bem-estar mental
} 
no interior e no entorno das UCs também são caracterizados pela ausência de instrumentos de análise adequados ao contexto local e regional. Segundo Wilkie (2006) existe pouca evidência empírica para sustentar afirmações de sucesso ou insucesso, pois é difícil avaliar os impactos sociais das APs sem dados, já que a maioria das avaliações não é baseada em dados ex-ante ou posteriori de bem estar e muitos dos estudos são realizados sem amostras de controle (ou seja, as famílias comparáveis estão perto, mas não em uma área protegida) e consequentemente não avalia se as mudanças no bem-estar das famílias são resultado da criação das UCs ou de outros fatores exógenos, como uma mudança de valores monetários ou de mercadorias; outras também não avaliam os indicadores de bem-estar ao longo do tempo dentro das mesmas famílias locais para uma mesma área protegida. Neste contexto, Wilkie sugere alguns caminhos para avaliar o bem-estar das populações locais e no entorno das APs: uso de ferramentas de sensoriamento remoto para estimar a dinâmica (tempo e espaço) da abundância relativa e distribuição espacial dos tipos naturais e alterações na cobertura do solo; e estudos sobre a auto-percepção da saúde, bem-estar econômico, suficiência alimentar a coesão da comunidade, conflitos entre outros. Já as sugestões de Ferraro (2008) para uma avaliação sobre o impacto das APs sobre as populações residentes e as populações no entorno incluem a utilização (i) de indicadores objetivamente mensuráveis de bem-estar humano em uma escala apropriada de análise (indivíduos, famílias, comunidades e regiões); (ii) indicadores ex-ante e post relevantes (antes e após a criação da área protegida ou algum outro controle para o estado inicial e tendência de bem-estar social); e (iii) indicadores relevantes para os dois objetos de comparação (indivíduos afetados e não afetados pelos APs).

As metodologias brasileiras DURAMAZ e SISUC abordam em certa medida algumas dessas recomendações. O Sistema de Indicadores para o Desenvolvimento Sustentável - DURAMAZ tem o desafio de identificar os fatores determinantes do desenvolvimento sustentável e a sua relação com a manutenção da integridade da paisagem em três tipos de unidade de planejamento territorial: UCs (RESEX e RDS), Projetos de Assentamentos e Terras Indígenas. Apresenta um conjunto de 41 indicadores, cujas análises são complementadas com dados secundários (socioeconômicos, demográficos/biográficos e geográficos) e por meio de questionários biográficos (protocolo de pesquisa denominado Estudo Biográfico das Populações Amazônicas EBIMAZ). Contrapondo os indicadores de "qualidade de vida", os indicadores de 
"proteção do meio ambiente", são incorporados por meio de uma abordagem semelhante às análises de sucesso na manutenção da integridade da paisagem utilizados nas análises de desmatamento, por meio do protocolo de avaliação BIODAM. Droulers et al (2011) ao reportar os resultados do programa DURAMZ em relação ao indicador "dinâmicas do meio ambiente" composto por quatro sub-indicadores que medem o desmatamento ocorrido no interior e no entorno, o desmatamento permitido e a integridade das áreas mais sensíveis como as APPS de 13 áreas compostas por Terras Indígenas, de UCs de uso sustentável e de assentamentos e projetos extrativistas encontrou resultados que variam entre 10 e 9 para as UCs mais preservadas (RDS Mamirauá, RDS Iratapuru e RDS Tupé) e 4,3 para as menos preservadas (RESEX Ciriaco), valores intermediários foram encontrados na APA do Igarapé Gelado (7,03). A única TI foi avaliada positivamente $(9,9)$ e os assentamentos e projetos extrativistas tiveram respectivamente médias de 4, 07 e 9,44 (MARCHAND, 2010; DROULERS et al, 2011; LE TOURNEAU, 2013).

O Sistema de Indicadores Socioambientais para Unidades de Conservação da Amazônia e pode ser entendido como uma ferramenta de apoio à gestão - mais especificamente de apoio ao conselho gestor da UC - e de monitoramento dos processos socioambientais. Traz como fio condutor a compreensão de como os objetivos estão sendo alcançados, das dificuldades, dos aspectos positivos e das formas de melhoria e avanço. A ferramenta conta com um conjunto de 29 perguntas orientadoras distribuídas nos temas economia (5), meio ambiente (7), sociocultural (8) e gestão de UC (9), e possui um arranjo semelhante às ferramentas que avaliam o sucesso da gestão, entretanto, com um forte viés dos aspectos socioambientais. A avaliação das perguntas/indicadores é realizada pelos membros do Conselho da UC, em contraponto à equipe gestora das ferramentas FAUC e RAPPAM, mas igualmente baseia-se na percepção e subjetividade dos respondentes, ponderados nesta ferramenta pela percepção do grupo ou coletivo de governabilidade sugerida pelo Conselho Gestor. O conjunto de indicadores do tema meio ambiente auxilia na identificação do alcance dos objetivos da UC, principalmente no que tange à sustentabilidade no uso, contribuindo para verificação da disponibilidade de uso do recurso, por meio da percepção de estoque, esforço de acesso e esforço de restauração e recuperação (MARINELLI, 2011).

A diversidade de inciativas e propósitos demostram que a busca pelo conhecimento e entendimento de quais são os impactos oriundos de uma estratégia de conservação que prioriza o estabelecimento e implementação de UCs tem como atores 
dois grupos de representantes: os preservacionistas e/ou conservacionistas, e os socioambientalistas. Embora os conflitos entre esses dois grupos, que surgiram no final da década de 1980 e início da década de 1990, persistam até hoje, os mesmos não impedem a implementação de estratégias que visam articular proteção integral e uso sustentável. Mosaicos, corredores ecológicos e reservas da biosfera e gestão integrada estão entre elas, e têm uma base conceitual sólida na abordagem ecossistêmica, definida na Decisão V da $6^{\text {a }}$ Conferência das Partes da CDB, realizada em Haia, na Holanda, em 2002, e no manejo biorregional, conceito desenvolvido por Kenton Miller, desde o final da década de 1960 (DRUMMOND et al., 2010). Mas até o momento são poucas as iniciativas de avaliação do impacto das UCs que contemple as expectativas de conservação da biodiversidade e de uso sustentável dos recursos em relação aos fatores associados a gestão das UCs.

Considerando as abordagens aqui descritas e o conjunto de ferramentas existentes, avaliar o sucesso das unidades de conservação para conservação da biodiversidade e para a sustentabilidade do uso dos recursos não é uma tarefa fácil e tão pouco um tema cujo debate se aproxime do fim. Com a intenção de contribuir para as reflexões sobre esse debate o próximo capítulo acolhe como ponto de partida os princípios que orientam a criação, os conceitos de implementação e consolidação do o Programa Áreas Protegidas da Amazônia/Arpa - estratégia é única e específica para atingir em quantidade e representatividade a proteção e a conservação da biodiversidade no Brasil - para apresentar e discutir sua estratégia de avaliação da efetividade, ou melhor, sua estratégia para avaliar o sucesso das UCs na conservação da biodiversidade e na sustentabilidade do uso dos recursos naturais. 


\section{Capitulo 3 - O Programa Áreas Protegidas da Amazônia (Arpa)}

O Programa Áreas Protegidas da Amazônia - o Programa Arpa, criado por decreto em agosto de $2002^{54}$, é a principal estratégia de conservação por meio de UCs no Brasil e tem por objetivo expandir, consolidar e manter 60 milhões de hectares do bioma Amazônia - parcela significativa do Sistema Nacional de Unidades de Conservação (SNUC), correspondendo à proteção de $15 \%$ do bioma. O programa é coordenado pelo Ministério do Meio Ambiente (MMA), em parceria técnico-financeira com governos estaduais e municipais, com o Fundo Brasileiro para a Biodiversidade (Funbio) - executor financeiro, com o Fundo Global para o Meio Ambiente (GEF) - por meio do Banco Mundial, com o WWF-Brasil, e com o governo alemão - por meio do KfW, todos doadores originais do Arpa. Após a criação do programa, outros doadores somaram-se ao Arpa: Natura e Fundação O Boticário de Proteção à Natureza, primeiros doadores privados; Ministério do Meio Ambiente Alemão (BMU); Fundo Amazônia, cuja gestão e administração são realizadas pelo Banco Nacional de Desenvolvimento Econômico e Social (BNDES); Banco Interamericano de Desenvolvimento (BID); Gordon and Betty Moore Foundation; Margaret A. Cargill Foundation; Linden Trust for Conservation, e alguns outros doadores anônimos. Mas, para compreender a concepção do Arpa é necessário voltar alguns anos antes e entender o processo de criação de UCs no Brasil e no bioma Amazônia.

\subsection{Primeiras iniciativas e motivações para a criação de UCs no Bioma Amazônia e do Programa Arpa}

As primeiras ideias sobre a criação de áreas protegidas no Brasil datam de fins do século XIX. O engenheiro André Rebouças (1838-1898) sugeriu, em 1876, a criação de dois parques nacionais: um na Ilha do Bananal (rio Araguaia) e outro em Sete Quedas (rio Paraná). O governo federal, em 1891, por meio do Decreto Federal $n^{\circ}$. 8.843, criou uma grande reserva florestal (onde hoje situa-se o estado do Acre) com 2,8 milhões de hectares. Ambas as iniciativas foram frustradas: os parques propostos por Rebouças não foram criados naquele momento. A reserva florestal nunca foi implementada, mas podemos citá-la como a primeira iniciativa de criação de uma área protegida na região Norte do país (DRUMMOND et al., 2006; PÁDUA, 1997). Os cientistas Alberto

\footnotetext{
${ }^{54}$ Decreto $^{\circ} 4.326$ de 8 agosto de 2002, revogado pelo Decreto ${ }^{\circ} 8.50$ de 20 de agosto de 2015 (Anexo 4)
} 
Loefgren (1854-1918) e Herman von Ihering (1850-1930) obtiveram mais sucesso, já no início do século $\mathrm{XX}$ : o primeiro conseguiu que fosse estabelecida, em terras adquiridas pelo governo federal a seu conselho, uma estação biológica situada na localidade de Itatiaia, no estado do Rio de Janeiro - onde mais tarde, em 1937, foi criado o Parque Nacional de Itatiaia; o segundo estabeleceu, com recursos próprios, a Estação Biológica do Alto da Serra, situada na crista da Serra do Mar, e a doou ao governo do Estado de São Paulo (DRUMMOND et al., 2006).

A região Sudeste, onde a ocupação dos espaços e a utilização dos recursos naturais foram mais intensas, foi também onde se concentrou a criação das primeiras áreas naturais protegidas. Além das citadas estações biológicas, a região abrigou quatro das cinco áreas protegidas surgidas na década de 1930: a Estação Florestal Experimental Dr. Epitácio Santiago, hoje Floresta Nacional de Lorena (1934); o Parque Nacional de Itatiaia (1937), ampliação da estação biológica criada por Loefgren; a Floresta Estadual Bebedouro (1937); e o Parque Nacional da Serra dos Órgãos (1939). No contexto regional, a região Sul recebeu apenas uma das cinco UCs criadas na década de 1930 - o Parque Nacional do Iguaçu (1939). As primeiras UCs criadas na região Nordeste foram a Floresta do Araripe (1946) e a Floresta Nacional de Sobral (1947). Na região CentroOeste, a Floresta Nacional de Silvânia (1949) foi a primeira UC. Nos 20 anos que se seguiram à criação do Parque Nacional de Itatiaia, a maioria das UCs criadas incidiu sobre áreas florestadas, reforçando o atendimento às orientações do Código Florestal de 1934 de manutenção da oferta de madeira e subprodutos florestais.

A criação das primeiras UCs na região Norte, na região que hoje chamamos de Amazônia Legal, o Parque Nacional do Araguaia (1959) e a Floresta Nacional de Caxuanã (1961), se insere no boom de UCs criadas no final da década de 1950 e início da década de 1960. Neste período foram criadas 23 UCs (12 federais e 11 estaduais), dentre elas 18 parques contemplando os biomas Mata Atlântica, Cerrado e Caatinga. De meados da década de 1960 até a meados da década de 1970, mais 23 parques foram criados (20 estaduais e 3 federais). É importante destacar que a partir da década de 1970, o Brasil institucionalizou mais efetivamente as práticas voltadas à preservação e conservação da natureza, e em 1973, através do Decreto Federal n. 73.030, criou o primeiro órgão federal de ação ambiental, a SEMA - Secretaria Especial do Meio Ambiente (Ministério do Interior), que proporcionou a criação de inúmeras UCs e realizou estudos para a 
formulação de uma política ambiental de alcance nacional (CAMPOS e CASTRO, 2006; DRUMMOND et al, 2010; DRUMMOND et al, 2012).

Mas como já destacado no capítulo anterior as UCs criadas no período de 1937 a 1975 não se basearam em critérios técnicos e científicos. Isso vale mesmo para a maior área protegida na época: o Parque Nacional da Amazônia, de 1974, com cerca de 1,1 milhões de hectares, localizado no estado do Pará. Ainda assim, seja pelos atributos naturais ou pelo contexto histórico e político, a criação dessas UCs demarcou um período importante na reserva de áreas destinadas à conservação da natureza no Brasil e que hoje contribuem para garantir a representatividade de diferentes ecossistemas. Na região Norte, onde as lacunas de áreas protegidas eram evidentes em meados da década de 1970, a criação do Parque Nacional da Amazônia pode até não ser considerado como um marco da preocupação com a manutenção da biodiversidade, mas traz em seu nome o simbolismo do início de uma preocupação mundial com a região amazônica e o bioma Amazônia. Abrangendo 49,3\% do território nacional (cerca de 4,19 milhões de km2), o bioma Amazônia contém a maior bacia hidrográfica, o maior volume de água doce do planeta e representa o maior bloco contínuo de floresta tropical no mundo, caracterizada por uma notável riqueza de espécies. O bioma ocupa a totalidade de cinco unidades da federação (Acre, Amapá, Amazonas, Pará e Roraima), grande parte de Rondônia (98,8\%), mais da metade de Mato Grosso (54\%), além de parte de Maranhão (34\%) e Tocantins (9\%) (PÁDUA, 1997; MMA, 2008; DRUMMOND et al, 2010).

A crescente preocupação nacional e internacional com o futuro da Amazônia culminou, em meados da década de 1970, no estudo - Uma análise de prioridades em conservação da natureza na Amazônia - que foi a primeira iniciativa de identificação de áreas protegidas com base em critérios técnicos e científicos. Coordenado por Pádua e Wetterberg, o estudo se baseou em uma análise biogeográfica que utilizou regiões fitogeográficas, tipos vegetacionais, áreas sob algum tipo de proteção legal, polos de desenvolvimento e o conceito de refúgios do pleistoceno - correspondentes a centros de endemismo de aves, lagartos, plantas e borboletas. Os dados e informações para a análise dos parâmetros citados acima originaram-se de fontes diversas, nem sempre homogêneas, com escalas imprecisas. Acabaram ficando de fora as informações da fase inicial do Projeto RADAM/1973-1983 (WETTERBERG, 1976; PÁDUA, 1997; MITTERMEIER et al, 2005). 
Mas, tais fatos não prejudicaram a importante e pioneira contribuição do estudo às propostas de áreas contidas nas $1^{\mathrm{a}}$ e $2^{\mathrm{a}}$ etapas do Plano do Sistema Nacional de Unidades de Conservação no Brasil, publicadas, respectivamente, em 1979 e 1982, que definiam os objetivos nacionais para os grupos de manejo caracterizados como Proteção Integral e Uso Sustentável, e estabeleciam o papel do Governo Federal, dos estados e dos municípios na orientação, coordenação e execução das medidas necessárias à utilização racional, à proteção e conservação dos recursos naturais renováveis e ao desenvolvimento florestal do país. Outro aspecto importante, no que diz respeito às etapas de 1979 e 1982, é que, pela primeira vez, foram propostas e criadas UCs, muitas delas com grandes dimensões, em áreas de expansão da fronteira de recursos naturais (Quadro 11). Ou seja, a estratégia passou a ser se antecipar à ocupação dos territórios por atividades humanas mais impactantes, ao invés de localizar a maioria das UCs em áreas de ocupação antiga, como era a regra antes de 1979 (PÁDUA, 1997; CAMPOS e CASTRO, 2006; DRUMONND et al, 2010).

Quadro 11 - Área máxima e mínima das UCs criadas na década de 1980-1989

\begin{tabular}{||l|c|c|c|c||}
\hline \multirow{2}{*}{$\begin{array}{l}\text { ÁREA EM } \\
\text { HECTARES }\end{array}$} & \multicolumn{2}{|c|}{ BIOMA AMAZÔNIA } & \multicolumn{2}{c|}{ DEMAIS BIOMAS } \\
\cline { 2 - 5 } & PI & US & PI & US \\
\hline \hline Mínima & 146,66 & $3.180,02$ & 4,52 & 9,47 \\
\hline Máxima & $2.367 .333,44$ & $4.524 .779,16$ & $550.749,09$ & $662.669,33$ \\
\hline
\end{tabular}

Fonte: CNUC, 2009

Um esforço paralelo, empreendido por Paulo Nogueira Neto, na década de 1980, à frente da Secretaria Especial de Meio Ambiente (SEMA), resultou na criação de nove estações ecológicas no bioma Amazônia, quatro delas por um único decreto - Decreto 86.061/81: Maracá, Maracá-Jipióca, Rio Acre e Anavilhanas. A localização dessas UCs foi baseada nos domínios morfo-climáticos descritos pelo geógrafo Aziz Ab`Saber. As demais foram criadas depois: Jari (1982), Caracaraí (1982), Jutaí-Solimões (1983), Juami-Japurá (1985) e Niquiá (1985). Em seguida, ocorreu a criação, pelo estado de Rondônia, da Estação Ecológica Samuel - criada por uma resolução (Resolução CONAMA 010/3 de 1987) para compensar e reparar os danos causados pela instalação da Usina Hidrelétrica de Samuel (RYLANDS e PINTO, 1998; RYLANDS e BRANDON, 2005; DRUMONND et al, 2010).

Durante toda a década de 1980, foram criados cerca de 20 milhões de hectares em UCs no bioma Amazônia, no âmbito federal e estadual, que somados aos hectares criados nos demais biomas totalizavam 26,5 milhões de hectares (Quadro 12). 
Quadro 12 - Áreas de Unidades de Conservação criadas por grupo de manejo, por década (1930-1999)

\begin{tabular}{|r||r||r|r|r|r||r||}
\hline \multirow{2}{*}{ DÉCADAS } & \multicolumn{3}{|c|}{ BIOMA AMAZÔNIA } & \multicolumn{3}{c|}{ TODOS OS BIOMAS } \\
\cline { 2 - 7 } & UCs de PI & UCs de US & $\begin{array}{l}\text { TOTAL } \\
\text { PI E US }\end{array}$ & \multicolumn{1}{c|}{ UCs de PI } & UCs de US & \multicolumn{1}{c|}{$\begin{array}{l}\text { TOTAL } \\
\text { PI E US }\end{array}$} \\
\hline $1934-1939$ & & & & $217.800,52$ & 384,45 & $218.184,97$ \\
\hline $1940-1949$ & & & & $62.492,65$ & $42.366,48$ & $104.859,14$ \\
\hline $1950-1959$ & & & & $614.030,87$ & 421,75 & $614.452,62$ \\
\hline $1960-1969$ & 0,00 & $322.694,34$ & $322.694,34$ & $419.638,38$ & $349.736,43$ & $769.374,80$ \\
\hline $1970-1979$ & $4.827 .879,26$ & $549.066,87$ & $5.376 .946,13$ & $5.880 .614,98$ & $549.066,87$ & $6.429 .681,85$ \\
\hline $1980-1989$ & $7.992 .944,45$ & $12.542 .668,65$ & $20.535 .613,10$ & $10.460 .327,57$ & $16.070 .513,13$ & $26.530 .840,71$ \\
\hline \hline $1990-1999$ & $5.203 .557,30$ & $20.964 .420,52$ & $26.167 .977,82$ & $6.696 .391,32$ & $32.967 .145,08$ & $39.663 .536,41$ \\
\hline
\end{tabular}

Fonte: CNUC, 2009

Entretanto, houve a partir de 1990 descontinuidade no processo de identificação e criação de UCs de proteção integral e, consequentemente, menor crescimento deste grupo de manejo no bioma Amazônia na década seguinte (1990 -1999), quando apenas 5 milhões de hectares foram criados ( $89 \mathrm{UCs}$ ), o que configurava, ainda, um cenário pouco favorável à conservação da natureza, e que representava $25 \%$ do total da área de UCs de uso sustentável criada. A manutenção da biodiversidade ainda era uma consideração pequena frente ao avanço da fronteira agrícola e ao desmatamento na região Norte. Mas, mesmo que os resultados do crescimento das UCs tenham sido tímidos, ocorreram, na década de 1990, várias iniciativas e recomendações com o intuito de priorizar e incentivar a criação e implementação de áreas para a conservação da biodiversidade:

1. A pressão e a comoção da comunidade internacional em relação à degradação da Amazônia, com repercussão no cenário político e nos meios de comunicação, como por exemplo a reportagem da revista americana Times, em setembro de 1989, intitulada Torching the Amazon: Can the Rain Forest be Saved? Destruction of the Amazon is "one of the great tragedies of history";

2. A realização do Workshop 90 - Áreas Prioritárias para Conservação na Amazônia, em 1990, em Manaus, promovido pela Conservação Internacional (CI), pelo IBAMA e pelo Instituto Nacional de Pesquisas da Amazônia (INPA), que reuniu mais de 100 especialistas (cientistas e conservacionistas) dos países amazônicos, com a finalidade de mapear e indicar áreas para a criação de UCs na Amazônia. As indicações tiveram como base análises biogeográficas de endemismo, riqueza de espécies, ocorrência de espécies raras ou ameaçadas, presença de fenômenos geológicos ou geoquímicos de especial 
interesse e o grau presente ou futuro de ameaças à integridade dos ecossistemas (RYLANDS e PINTO 1998; RYLANDS e BRAN DON,2005);

\section{A realização, no Brasil, da Conferência das Nações Unidas sobre o Meio Ambiente $e$}

Desenvolvimento - Rio 92; em 1992, que teve com o um de seus dos principais resultados

a Convenção sobre Diversidade Biológica (CDB), que recomenda - em seu Artigo 8, da conservação in situ, na alínea $b$, desenvolver, se necessário, diretrizes para a seleção, estabelecimento e administração de áreas protegidas ou áreas onde medidas especiais precisem ser tomadas para conservar a diversidade biológica (MMA, 2000);

4. O lançamento, no âmbito da Rio-92, do Programa Piloto para Conservação das Florestas Tropicais (PPG7) $)^{55}$, conhecido como o maior programa de cooperação multilateral relacionado a uma temática ambiental de importância global, para apoiar o desenvolvimento de estratégias inovadoras para a proteção e o uso sustentável da Floresta Amazônica e da Mata Atlântica. As estratégias do PPG7 objetivavam melhorias na qualidade de vida das populações locais, para maximizar os benefícios ambientais das florestas tropicais, de forma consistente com as metas de desenvolvimento do Brasil. A implantação de uma metodologia de desenvolvimento sustentável visava contribuir com a redução contínua do índice de desmatamento;

\section{A realização, em 1994, do Workshop Geographic Conservation Investment Priorities}

in Latin America and the Caribbean, organizado pelo WWF, que teve por objetivo desenvolver critérios para auxiliar a priorização, em termos geográficos, da alocação de

\footnotetext{
${ }^{55}$ O Programa Piloto para a Proteção das Florestas Tropicais do Brasil (PPG7) foi o esforço mais abrangente implementado pelos governos federal e estadual para apoiar a preservação e o uso sustentável dos ecossistemas amazônicos e foi o maior programa de concessão multilateral para a conservação ambiental em um único país. A pedido dos países do G-7 e do Brasil, o Banco Mundial coordenou o PPG7, supervisionou os projetos em andamento do programa, e administrou o Fundo Fiduciário para Florestas Tropicais do PPG7 (RFT), cujos subsídios eram fornecidos pelos países do G-7, pela União Europeia, pelos Países Baixos, e pelo governo brasileiro. Dentre os projetos-piloto implementados, estavam: a criação de reservas extrativistas; a demarcação de terras indígenas; abordagens inovadoras para a gestão de florestas; iniciativas de desenvolvimento com base local; estratégias de fortalecimento de centros-chave de pesquisa; e a melhoria no planejamento e execução de políticas ambientais em nível estadual. Um dos maiores e mais complexos entre os projetos do PPG7 foi o Projeto de Política de Recursos Naturais, que visava o desenvolvimento da capacidade institucional dos estados e municípios amazônicos para gerir eficazmente os seus recursos naturais. Um resultado significativo do projeto foi a realização de zoneamento econômicoecológico (ZEE) na maioria dos estados, para o ordenamento do território e do uso de recursos, aplicação da lei, fiscalização, licenciamento e monitoramento ambiental. O PPG7 ajudou a promover mudanças construtivas dentro do contexto institucional e político mais amplo na Amazônia brasileira, tais como a formulação da Política Nacional Integrada para a Amazônia Legal (1995), o apoio ao empoderamento da sociedade civil organizada e das organizações não governamentais da Amazônia, com destaque para o Grupo de Trabalho Amazônico - GTA, um catalizador de novas formas de colaboração entre os governos federal, estaduais e municipais e a sociedade civil.
} 
recursos para a conservação da biodiversidade. Uma análise geográfica identificou 57 unidades biogeográficas ecologicamente distintas, as chamadas ecorregiões, sendo 23 delas na Amazônia brasileira (RYLANDS e PINTO 1998; RYLANDS e BRANDON, 2005).

Nos anos seguintes o governo federal e os governos estaduais começaram a implementar e adotar diversas ações, acordos e políticas para reduzir o desmatamento e aumentar as iniciativas para apoiar o desenvolvimento sustentável na Amazônia. Em 1996, ocorreu a primeira de uma série de medidas provisórias (MPs) editadas para alterar o Código Florestal de $1965^{56}$, visando restringir a abertura de novas áreas em florestas. As MPs passaram a permitir o desmatamento de apenas $20 \%$ nas regiões de floresta no bioma Amazônia. Na MP 2.080/00, a reserva legal em áreas de floresta passou a ser de $80 \%$, e mais tarde, uma alteração realizada em 2001, passou a considerar que o tamanho mínimo da reserva legal iria depender do tipo de vegetação existente e da localização da propriedade. No bioma Amazônia, o mínimo a ser mantido continuava 80\%, nos demais biomas a situação era a seguinte: Cerrado Amazônico, 35\%; e para as demais regiões e biomas, 20\%. Em 1998, foi aprovada a Lei de Crimes Ambientais, Lei nº 9.605, de 12 de fevereiro de 1998, que dispõe sobre as sanções penais e administrativas derivadas de condutas e atividades lesivas ao meio ambiente, e em abril deste mesmo ano, o então Presidente da República, Fernando Henrique Cardoso, se comprometeu com a meta de conservar $10 \%$ de cada ecossistema brasileiro.

Em 1999, se iniciou o processo de elaboração do Mapa de Áreas Prioritárias para Conservação do Bioma Amazônia, no âmbito do Projeto de Conservação e Utilização Sustentável da Diversidade Biológica Brasileira (PROBIO), do MMA, coordenado pelo Instituto Socioambiental (ISA), cuja etapa mais importante foi Seminário de Consulta de Macapá. Um pouco depois, o Projeto de Lei no 2.892/92 do Sistema Nacional de Unidades de Conservação (SNUC), após um longo processo de tramitação, consultas públicas e debates nas comissões temáticas, resultou na Lei ${ }^{\circ}$ 9.985, aprovada em 18 de julho de 2000. Em 2002, entrou em operação o Sistema de Vigilância da Amazônia (Sivam), criado para realizar o controle do tráfego aéreo e o monitoramento ambiental

\footnotetext{
${ }^{56}$ A Lei 4.771/65 estabeleceu limitações ao direito de propriedade no que se refere ao uso e exploração do solo e das florestas. O texto criou a previsão para Áreas de Preservação Permanente (APPs) e, posteriormente, após alteração feita em 1986, para áreas de Reserva Legal (RL).
} 
da Amazônia, e cuja concepção fora aprovada pelo Conselho de Defesa Nacional já na década de 1990.

O Projeto para a criação do Programa Áreas Protegidas da Amazônia (Programa Arpa) teve origem neste contexto, entre os anos de 1997 e 1998, no âmbito da aliança entre o Fundo Mundial para a Natureza (WWF) e o Banco Mundial ${ }^{57}$, que via a necessidade de desenvolver uma estratégia complementar à ação do PPG7 na proteção dos ecossistemas ameaçados, em particular o bioma Amazônia. O projeto para a criação do Programa Arpa contou, durante o seu período de preparação, com o esforço colaborativo do WWF, do Banco Mundial e de um comitê consultivo, que funcionou desde os estágios iniciais de preparação para supervisionar a concepção do projeto. Esse comitê era composto pelo MMA, IBAMA, WWF, Funbio, Conselho Nacional dos Seringueiros (CNS) e Grupo de Trabalho Amazônico (GTA). Além do comitê, ONGs como Funatura, USAID, Instituto Sociedade, População e Natureza (ISPN), The Nature Conservancy (TNC), Instituto Sócio Ambiental (ISA) e Conservation International (CI) - e o British Council, a Agência de Cooperação Técnica Alemã (GTZ) e o Programa das Nações Unidas para o Desenvolvimento (PNUD) foram consultados durante esta fase inicial de preparação.

A ideia do programa Arpa ganhou força com a intenção existente, na época, de dobrar o tamanho do Sistema de Unidades de Conservação, reforçando o compromisso assumido pelo governo brasileiro, em 1998, de proteger 10\% do bioma Amazônia sob a forma de UCs de proteção integral. Em sua proposta inicial (Documento de Conceito de Projeto - DCP), o projeto para a criação do Programa Arpa incluía apenas as ações de conservação voltadas para as UCs de proteção integral, que naquele momento eram em menor número na região amazônica. Mas, após o primeiro processo de consulta com os estados e com a sociedade civil, o esboço inicial foi modificado, resultando em uma meta específica para criação de UCs de uso sustentável (WORLD BANK, 2002a; BANCO MUNDIAL, 2002)

Em 1999, no âmbito do Seminário de Macapá, a proposta para a criação do Arpa foi discutida com representantes dos povos indígenas, ONGs, setor privado e órgãos governamentais. O Arpa, que já incorporava os resultados do Seminário de Macapá, foi

57 Em Junho de 1997, WWF e o Banco Mundial anunciaram uma aliança global para a conservação florestal e o uso sustentável. O chamado plano para a defesa de $10 \%$ de cada um dos principais tipos de floresta do mundo até ao ano 2000. 
discutido mais amplamente ao longo dos dois anos seguintes e uma proposta final para a sua criação foi apresentada às organizações sociais da Amazônia ${ }^{58}$ e ao Conselho do Funbio, que tem uma ampla representação da sociedade civil organizada. Outros processos participativos ocorreram desde a fase inicial de desenvolvimento do projeto Arpa e ajudaram a verificar os procedimentos que visavam garantir o controle social durante a sua implementação. A Iniciativa/Aliança WWF e Banco Mundial também fomentou o debate sobre o desenvolvimento de uma metodologia de consulta pública para as UCs a serem criadas no âmbito do Arpa e sobre as salvaguardas ambientais e sociais a serem asseguradas. Essas discussões ocorreram no âmbito de duas oficinas realizadas, em outubro e novembro de 2000, nos estados de Rondônia e Roraima. Neste momento, a proposta para a criação do Arpa já incorporava uma visão ampla de conservação para o bioma Amazônia, que englobava estudos gerais para a identificação de áreas para a criação de UCs; apoio à criação e à implementação de UCs; e apoio ao planejamento, consolidação e manutenção no longo prazo da viabilidade financeira das ações de conservação, considerando um arranjo inovador envolvendo parceria público-privada e uma multiplicidade de atores para o controle social. Uma premissa central do Arpa é a de que o sucesso da identificação, criação, demarcação e proteção das UCs depende do envolvimento direto e da participação da população local. O Arpa não apoiaria a criação ou consolidação de UCs sobrepostas às terras indígenas, com o intuito de evitar conflitos. A integração da proposta do projeto Arpa com os governos estaduais ocorreu, nos dois anos seguintes, sob a coordenação do MMA no âmbito do programa Agenda Positiva para a Amazônia, resultando em um diálogo com agentes econômicos e sociais da região, que incluíam os governos locais, as ONGs, o setor privado, as universidades e as comunidades locais e indígenas (CAPOBIANCO et al, 2001; BANCO MUNDIAL, 2002; WORLD BANK, 2002a; WORLD BANK, 2002b; MMA/ARPA, 2002).

A Secretaria de Assuntos Internacionais (SEAIN) do Ministério do Planejamento, Orçamento e Gestão, que atua como ponto focal operacional do GEF ${ }^{59}$ no Brasil, em 2002, endossou o projeto e considerou o Programa Arpa como uma estratégia de conservação consistente e de alta prioridade nacional. Ainda no ano de 2002, o

\footnotetext{
58 GTA, CNS, CONTAG, COIAB e ASMUBIP

59 O GEF (Global Environment Fund), administrado, conjuntamente, pelo Banco Mundial, PNUD e Programa das Nações Unidas para o Meio Ambiente (PNUMA) funciona como um mecanismo de cooperação internacional, com o objetivo de aportar recursos novos e adicionais na forma de doação, para financiar iniciativas que possam resultar em benefícios ambientais em escala mundial nas áreas de mudança climática; diversidade biológica; e águas internacionais.
} 
Governo Federal informou ao Banco Mundial que o Funbio seria o executor dos recursos oriundos do GEF, e que junto com o WWF e o KFW assegurariam o compromisso das primeiras doações para a execução do $\operatorname{Arpa}^{60}$. A assinatura do memorando de intenções entre o Governo Federal, o Banco Mundial e o GEF culminou na criação do Arpa em agosto de 2002, com a edição do Decreto n ${ }^{\circ}$ 4326, seguido de seu anúncio durante a Rio + 10 (BANCO MUNDIAL, 2002; WORLD BANK, 2002a; WORLD BANK, 2002b; MMA/ARPA, 2015).

A implementação do Arpa, iniciada logo após a sua criação, começou a surtir efeito. A partir do início do século XXI, houve uma retomada expressiva da criação de UCs. Entre os anos 2000 e 2009, foram criadas 121 UCs, que correspondem a cerca de 66 milhões de hectares. A maioria dessas UCs e a maior parte da área abrangida por elas se situa no bioma Amazônia, e a criação delas coincidiu com a implementação da primeira fase do Programa Arpa, que tinha como objetivo promover, em 10 anos, a expansão e a consolidação do Sistema Nacional de Unidades de Conservação (SNUC - Lei N$^{\circ}$ 9985/2000) na Amazônia brasileira, por meio da criação e consolidação de 50 milhões de hectares em áreas protegidas, garantindo que as UCs brasileiras deixassem de ser apenas territórios delimitados em mapas e passassem a exercer uma função importante tanto para a conservação da biodiversidade quanto para o desenvolvimento sustentável local. Durante esses anos, foram criadas, em área, mais UCs na Amazônia do que em todo o período anterior, e o total de UCs na Amazônia passou a representar 78\% do total de UCs no âmbito do SNUC (Quadro 13).

\section{Quadro 13 -. Áreas de Unidades de Conservação criadas por grupo de manejo, na década de 2000-2009}

\begin{tabular}{|c|c|c|c|c|c|c|}
\hline \multirow{2}{*}{ DÉCADAS } & \multicolumn{3}{|c|}{ BIOMA AMAZÔNIA } & \multicolumn{3}{|c|}{ TODOS OS BIOMAS } \\
\hline & UCS DE PI & UCS DE US & \begin{tabular}{|l|} 
TOTAL \\
PIE US \\
\end{tabular} & UCS DE PI & UCS DE US & \begin{tabular}{|l|} 
TOTAL \\
PIE US \\
\end{tabular} \\
\hline 2000-2009 & $23.003 .147,32$ & $42.838 .756,38$ & 65.841.903,70 & $26.659 .902,57$ & $51.398 .888,72$ & $78.058 .791,29$ \\
\hline $\begin{array}{r}\text { Acumulado } \\
\text { de } 1934-2009\end{array}$ & $41.027 .528,32$ & $77.217 .606,77 \|$ & $118.245 .135,10$ & $51.011 .198,86$ & $101.378 .522,92$ & $152.389 .721,78$ \\
\hline
\end{tabular}

Fonte: CNUC, 2009

\footnotetext{
${ }^{60}$ GEF US\$ 30 milhões, o WWF cerca de US\$ 12 milhões e o KfW 17 milhões de euros.
} 
Atualmente, o SNUC é representado por uma área de 155.119.600 hectares, distribuída em 1940 UCs enquadradas em 12 categorias $^{61}$ : 954 federais, com 76.384 .500 hectares; 781 estaduais, com 76.084.800 hectares; e 205 municipais com 2.650.300 hectares ${ }^{62}$. A área protegida representa $17,2 \%{ }^{63}$ do território nacional, com forte desequilíbrio entre as proporções das áreas das UCs de uso sustentável (102.318.900 hectares) e as áreas das UCs de proteção integral (52.800,700 hectares). O bioma Amazônia está protegido por 322 UCs, que ocupam uma área de 113.630.400 hectares, e que correspondem a $27,1 \%$ da área total do bioma. Mas, se forem descontadas as sobreposições, a área é de 111.750 .900 hectares, o que corresponde a 26,4\% do total do bioma Amazônia. Destes, 40.207.100 hectares (9,6\% da área total do bioma) estão protegidos por UCs de proteção integral e 70.182 .000 hectares $(16,7 \%$ da área total do bioma) por UCs de uso sustentável (CNUC, 2015).

O Programa Arpa garante proteção para $14 \%$ do total do bioma Amazônia e pretende ultrapassar a cifra de 15\% prevista para o final da Fase III em 2039, que é de 60 milhões de hectares, 10 milhões de hectares a mais do que a meta prevista quando da sua criação em 2002. Cabe destacar que esse compromisso foi reforçado quando da instituição da Fase III, por meio da Portaria MMA n 187 , de 22 de maio de 2014, e do Decreto $\mathrm{n}^{\circ}$ 8.505, de 20 de agosto de 2015. Trata-se de uma cifra expressiva, sobretudo quando se considera que o apoio do Arpa restringe-se a 5 das 12 categorias de UCs do SNUC: Parques, Reservas Biológicas, Estações Ecológicas, Reservas Extrativistas e Reservas de Desenvolvimento Sustentável. Estas categorias seriam aquelas de maior impacto em termos de conservação da biodiversidade e geração de bem-estar na região, atraindo assim maior interesse de potenciais doadores. Ficaram de fora duas das categorias mais expressiva do ponto de vista de área: as Florestas, cerca de 33 milhões de hectares e as Áreas de Proteção Ambiental, com cerca de 19,5 milhões hectares - que só perdem em extensão para as Florestas e para os Parques, com 26 milhões de hectares.

O Arpa abrange cerca de 59 milhões de hectares distribuídos em 114 UCs (Anexo 3), 69 federais, com 36.904.030,2 hectares, 45 estaduais, com 22.274.953,8 hectares, com forte equilíbrio entre as proporções das áreas das UC de proteção integral,

\footnotetext{
${ }^{61}$ Estação Ecológica, Monumento Natural, Parque, Refugio de Vida Silvestre, Reserva Biológica, Floresta, Reserva Extrativista, Reserva de Desenvolvimento Sustentável, Reserva de Fauna, Área de Proteção Ambiental e Área de Relevante Interesse Ecológico e Reserva Particular do Patrimônio Natural.

${ }^{62}$ Não considerando para esta consolidação o mapeamento das áreas sobrepostas.

${ }^{63}$ Soma-se aqui mais $1,5 \%$ das UCs localizadas na área marinha.
} 
com 60\% (35.421.434,89 hectares), e as UCs de uso sustentável, com 40\% (23.757.549,13 hectares). Se o bioma Amazônia está protegido por 322 UCs, que ocupam uma área de 111.750 .900 hectares. 53\% desta área estão sob o apoio do Programa Arpa, sendo que ele protege $88,09 \%$ da área total de UCs de proteção integral do bioma e 33,85\% da área total das UCs de uso sustentável (CNUC, 2015, MMA/ARPA, 2016).

Tabela 1 - Áreas de Unidades de Conservação apoiadas pelo Programa Arpa por categoria de manejo e esfera administrativa

\begin{tabular}{||c||c||r|r||r||r||c||}
\hline ESFERA & \multicolumn{1}{|c|}{ ESC } & \multicolumn{1}{|c|}{ PARQUE } & \multicolumn{1}{c|}{ REBIO } & \multicolumn{1}{c|}{ RDS } & \multicolumn{1}{c|}{ RESEX } & \multicolumn{1}{c|}{$\begin{array}{l}\text { GOTALAL } \\
\text { GERAL }\end{array}$} \\
\hline \hline ESTADUAL & $4.589 .566,81$ & $3.778 .204,09$ & 1.151 .760 & 10.991 .818 & $1.763 .604,47$ & $\mathbf{2 2 . 2 7 4 . 9 5 3 , 8}$ \\
\hline \hline FEDERAL & $5.663 .646,38$ & 17.152 .622 & $3.085 .635,6$ & 64.735 & $10.937 .391,2$ & $\mathbf{3 6 . 9 0 4 . 0 3 0 , 2}$ \\
\hline \hline TOTAL GERAL & $\mathbf{1 0 . 2 5 3 . 2 1 3 , 1 9}$ & $\mathbf{2 0 . 9 3 0 . 8 2 6 , 1}$ & $\mathbf{4 . 2 3 7 . 3 9 5 , 6}$ & $\mathbf{1 1 . 0 5 6 . 5 5 3}$ & $\mathbf{1 2 . 7 0 0 . 9 9 5 , 6 7}$ & $\mathbf{5 9 . 1 7 8 . 9 8 4 , 0}$ \\
\hline
\end{tabular}

Fonte: MMA/ARPA, 2016

Tabela 2 - Áreas de Unidades de Conservação do Bioma Amazônia e apoiadas pelo Programa Arpa por categoria de manejo

\begin{tabular}{|c|c|c|c|c|c|c|}
\hline ABRANGÊNCIA & ESC & PARQUE & REBIO & RDS & RESEX & $\begin{array}{l}\text { TOTAL } \\
\text { GERAL }\end{array}$ \\
\hline $\begin{array}{c}\text { BIOMA } \\
\text { AMAZÔNIA }\end{array}$ & $10.772 .100,00$ & $26.051 .300,00$ & $4.927 .100,00$ & 10.992 .900 & $13.747 .600,00$ & $66.491 .000,00$ \\
\hline $\begin{array}{l}\text { APOIADAS PELO } \\
\text { PROGRAMA ATPa }\end{array}$ & $10.253 .213,19$ & $20.930 .826,1$ & $4.237 .395,6$ & 11.056 .553 & $12.700 .995,67$ & $59.178 .984,00$ \\
\hline
\end{tabular}

Fonte: CNUC, 2015 e MMA/ARPA, 2016

Se considerarmos apenas as categorias apoiadas pelo Programa Arpa, as UCs apoiadas pelo programa representam 89\% da área do total das UCs do bioma Amazônia, protegendo $84,8 \%$ da área das categorias Esec, Parque e Rebio, e 96\% da área das categorias RDS e Resex (MMA/ARPA, 2015, CNUC, 2015, MMA/ARPA, 2016).

\subsection{Arranjo Institucional e de implementação do Programa Arpa}

O Programa Arpa, atualmente, agrega diferentes entes públicos e privados para alcançar seu objetivo de promover a conservação na Amazônia, por meio do apoio às UCs e em bases sustentáveis. Na esfera pública concentram-se as atividades de coordenação, execução técnica e monitoramento, de forma a assegurar a criação, consolidação e a manutenção das UCs no longo prazo. A coordenação do programa é exercida pelo Ministério do Meio Ambiente (MMA), e a execução pelo Instituto Chico Mendes de Conservação da Biodiversidade (ICMBio) e pelos os órgãos estaduais de meio ambiente do Acre, Amazonas, Mato Grosso, Rondônia, Tocantins, Pará e Maranhão. Na esfera privada concentram-se as atividades de captação e gestão dos recursos financeiros 
oriundos dos contratos de doação. O arranjo operacional que vincula o MMA, órgãos executores e o Funbio inovou ao permitir que recursos de doação fossem integralmente internalizados no Brasil via uma organização da sociedade civil de interesse público (Oscip). Cabe ao Funbio, licitar bens e contratar os serviços necessários para a execução do projeto com recursos de doação; fazer desembolsos e a execução financeira e a contabilidade do projeto; criar e estabelecer um Fundo para Áreas Protegidas (FAP); além de coordenar os estudos sobre os instrumentos financeiros e legais para a sustentabilidade em longo prazo das áreas protegidas.

O Arpa conta ainda com uma estrutura gerencial composta pelo Comitê de Programa (com representantes dos governos estaduais e federal e da sociedade civil) e um Painel Científico de aconselhamento. $\mathrm{O}$ arranjo operacional em vigência tem o desafio de implementar a Fase III durante os próximos 25 anos e é expresso por meio da Figura 1.

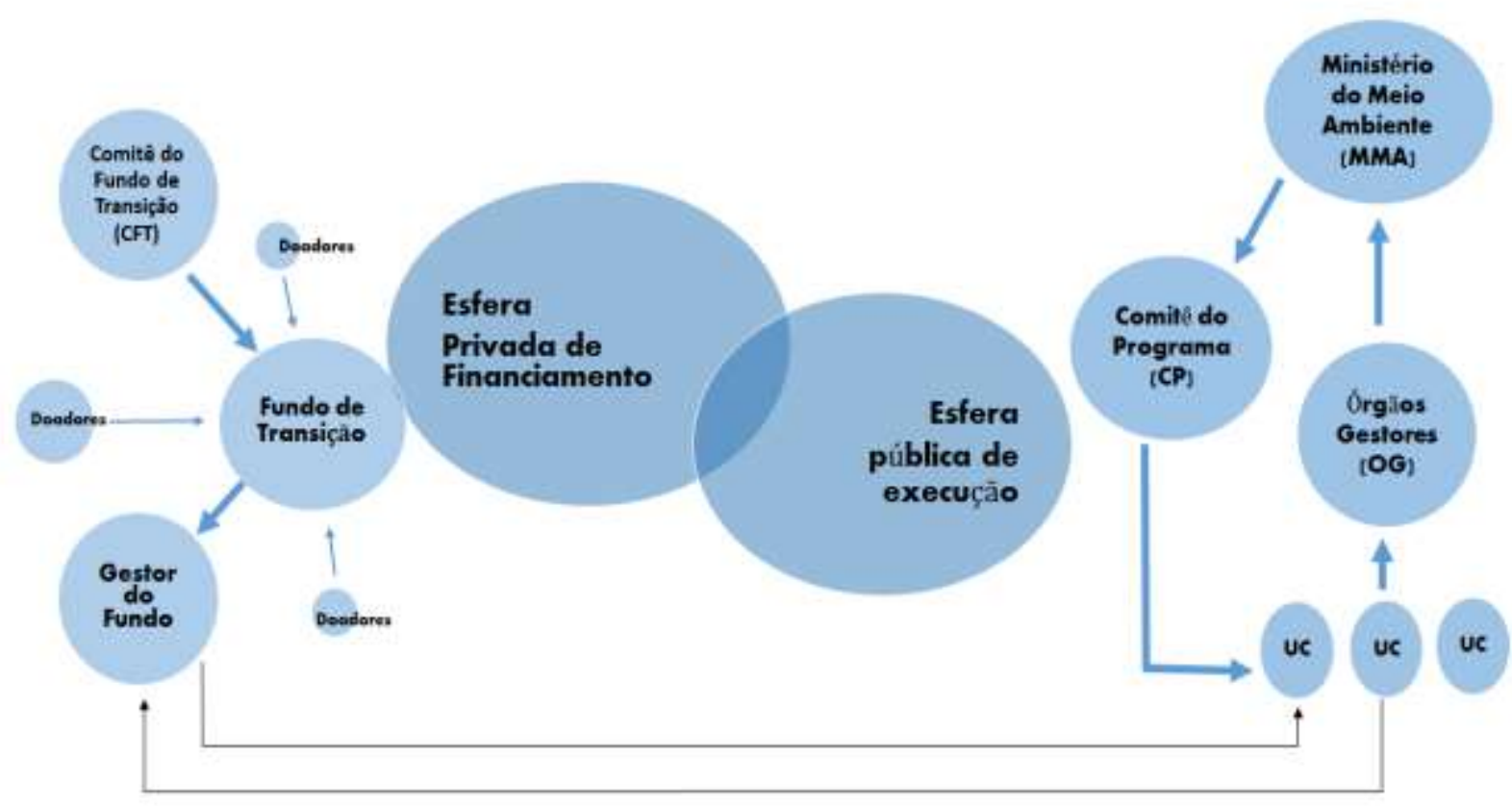

Figura 1 - Arranjo organizacional do Programa Arpa ${ }^{64}$.

${ }^{64}$ O Comitê do Programa (CP) é a instância de direção do Programa Arpa responsável por deliberar sobre o planejamento estratégico do Arpa e estabelecer procedimentos, diretrizes e critérios para a formalização de convênios e contratos nele previstos. O CP é composto pelo Secretário-Executivo do Ministério do Meio Ambiente, que o presidirá; dois representantes do Ministério do Meio Ambiente; o Presidente do Instituto Chico Mendes de Conservação da Biodiversidade - Instituto Chico Mendes; um representante do Ministério do Planejamento, Orçamento e Gestão; um representante do Ministério da Fazenda; um representante indicado pelos órgãos estaduais responsáveis pela gestão de unidades de conservação integrantes do 
O Arpa foi concebido como um projeto decenal, a ser implementado em três fases distintas e complementares, a primeira delas com duração inicial de quatro anos. $\mathrm{O}$ projeto original foi estruturado em cinco componentes, que juntos contribuiriam para expandir e consolidar o sistema de UCs no Bioma Amazônia, como mostra o Quadro 14. A primeira fase, incialmente prevista para ser implementada em 2002-2006, teve sete anos de duração, e tinha por objetivo ampliar a proteção sob a forma de UCs no bioma Amazônia, promover a consolidação física das UCs apoiadas, estruturar uma estratégia financeira de apoio a longo prazo - o Fundo de Áreas Protegidas (FAP) - e monitorar

Programa, em caráter rotativo; dois representantes da sociedade civil com relevância social e ambiental na região amazônica; e três representantes dos doadores de recursos privados.

A Unidade de Coordenação do Programa (UCP) é responsável pela coordenação executiva do Programa Arpa, integra a estrutura da Diretoria de Áreas Protegidas (DAP) da Secretaria de Biodiversidade e Florestas (SBF) do MMA sendo composta por membros de sua equipe técnica e administrativa

O Painel Científico de Aconselhamento (PCA) é a instância de consulta técnico-científica, composta por indivíduos com notório conhecimento sobre a dinâmica do bioma Amazônico.

O Ponto Focal é o representante do Órgão Gestor (OG) executor do Programa Arpa, responsável pela troca ou fornecimento de informações das UCs ao respectivo OG, ao MMA e ao Gestor do Fundo. O Ponto Focal deve ser um funcionário do OG habilitado para tomar decisões sobre o andamento da execução física das UCs.

O Fórum Técnico é composto por um representante de cada OG (preferencialmente os Pontos Focais), pelo GF, representante da Comissão de Gestores e UCP, sendo coordenado por esta última. A periodicidade mínima de reuniões deve ser semestral, com reuniões extraordinárias, sempre que necessário, convocadas pela UCP.

A Comissão de Gestores é uma instância representativa dos gestores das UCs apoiadas pelo Programa Arpa com a finalidade de fortalecer o papel dos responsáveis pela execução direta do Programa Arpa, contribuir para a melhoria de sua implementação e facilitar a troca de informações a partir do estabelecimento de um canal de comunicação direta entre os gestores e os demais membros.

O Fundo de Transição (FT) é um mecanismo de financiamento de longo prazo e extinguível, de caráter privado, criado por meio de contratos entre entidades, pessoas físicas e jurídicas, doadoras brasileiras e estrangeiras, Especificamente, o FT objetiva, além de para assegurar a conservação da biodiversidade e dos serviços ecossistêmicos em 60 (sessenta) milhões de hectares da Amazônia Brasileira através da gestão efetiva das UCs apoiadas pelo Programa Arpa, prover recursos e incentivos para que os governos Federal e estaduais possam aumentar, de forma gradativa, os recursos fornecidos pelos governos ao Programa Arpa, de forma que, após um período de 25 (vinte e cinco) anos, esses governos financiem $100 \%$ (cem por cento) dos custos do Programa Arpa, sem qualquer suporte adicional do FT ou de quaisquer outros fundos de doadores. São doadores do FT ONGs, agências bilaterais e multilaterais, organismos e empresas nacionais e internacionais, bem como indivíduos dispostos a contribuir com a preservação da biodiversidade da Amazônia apoiando o Programa Arpa.

O Comitê do Fundo de Transição (CFT) é a instância decisória do FT que tem por finalidade supervisionar o cumprimento do MOP de forma a viabilizar que o FT cumpra com o seu Objetivo. O CFT é composto por 08 (oito) membros votantes, sendo 06 (seis) membros nomeados pelos doadores e 02 (dois) membros nomeados pelo Governo Federal Brasileiro (Ministério do Meio Ambiente e o Ministério do Planejamento, Orçamento e Gestão), que devem necessariamente serem membros do Comitê do Programa. Compete ao CFT aprovar ou não novos doadores e/ou doações para o FT. O FT tem sua governança feita por meio do CFT e pelo Gestor do Fundo, escolhido pelo CFT, com a finalidade de praticar os atos necessários para que o FT atinja seu Objetivo.

O Gestor do Fundo (GF) é uma entidade escolhida pelo CFT para realizar a administração dos recursos disponíveis no FT. Na Fase III, em função da importância das atribuições do GF e suas responsabilidades e reconhecendo o alto nível de experiência, expertise, reputação e competência que o Funbio desenvolveu em relação ao Programa Arpa, o Funbio foi nomeado como GF do FT no momento da criação do FT. O GF é responsável pelo controle contábil de todas as movimentações financeiras relacionadas ao FT, e também será pelas compras e contratações previstas nos orçamentos bianuais. 
algumas das UCs federais apoiadas e seu entorno. O FAP, concebido como um instrumento complementar ao orçamento público, que visa dar agilidade e autonomia de gestão ao uso de recursos pelo gestor da UC, é um fundo fiduciário do tipo endownment fund (fundo de doação), que investe apenas os rendimentos reais do capital depositado. Devido ao sucesso alcançado ao final da primeira fase, o Arpa foi redesenhado como política pública e a vigência das suas fases ainda em andamento é objeto de constante revisão. Ao final da Fase I, com vigência no período de 2003- 2010, previa-se uma Fase II, que seria implementada no período de 2010 a 2015, e uma Fase III, de 2015 a 2018. Entretanto, a vigência atual (ano base 2016) para cada uma delas é: Fase II, de 2010 a 2017, e Fase III, de 2014 a 2039. A sobreposição das duas últimas fases e a ampliação do prazo de implementação da Fase III serão explicadas nos parágrafos que se seguem (MMA/ARPA, 2015).

Quadro 14 - Componentes de apoio da Fase I

\begin{tabular}{|c||l||}
\hline \multicolumn{1}{|c||}{ COMPONENTE } & \multicolumn{1}{c|}{ DESCRIÇÃO } \\
\hline \hline 1 & Criação, implantação e consolidação de novas UCs \\
\hline 2 & Consolidação de UCs já existentes \\
\hline 3 & Mecanismos financeiros para sustentabilidade de UCs \\
\hline 4 & Monitoramento das UCs \\
\hline \hline 5 & Coordenação e Gerenciamento do Projeto \\
\hline
\end{tabular}

Fonte: Banco Mundial, 2002

A Fase II, iniciada em 2010, apoia cerca de 52 milhões de hectares (32,7 milhões de hectares são oriundos da Fase I do Programa), promovendo a criação, o estabelecimento e a consolidação de UCs. Para a Fase II, novas metas foram estabelecidas e o total de áreas a serem protegidas pelo programa passou de 50 milhões para 60 milhões de hectares, ou seja, foram acrescentados mais 10 milhões de hectares, aumentando a meta de criação de novas UCs, de 37,5 para 45 milhões de hectares ${ }^{67}$. A meta de capitalização do FAP também foi ampliada, para US\$ 70 milhões. Com o aporte de cerca

\footnotetext{
65 Tinha a finalidade de apoiar o levantamento de informações de dados biológicos, sociais e econômicas sobre a região amazônica; a elaboração de estudos, consultas e propostas; e criação das UCs

${ }^{66}$ Tinha a finalidade de apoiar a coordenação global da execução do Projeto e dos diferentes componentes garantindo a execução das atividades de gerenciamento como a elaboração de relatórios técnicos, elaboração de planos operacionais anuais, acompanhamento e avaliação das atividades do projeto, aquisição e de gestão financeira e atividades de comunicação e divulgação e/ou quaisquer pedidos de informações por parte dos doadores

67 A meta global do Arpa para a criação de UCs era originalmente de 37,5milhões de hectares e foi redefinida em 45 milhões de hectares. Isto se deve ao fato de, na primeira fase do Programa, a meta de criação de UCs, prevista em 18 milhões de hectares, ter sido ultrapassada em 7 milhões de hectares. Para a segunda e a terceira fase foram mantidas as metas originais para o componente Criação de Unidades de Conservação que são de 13,5 e 6,5 milhões de hectares, respectivamente.
} 
de US\$ 115 milhões e uma previsão de US\$ 121 milhões, a Fase III se iniciou em 2014, concomitantemente com o final da execução da Fase II, e será a mais longa de todas, com previsão de 25 anos de duração (TUA et al, 2011; GELUDA et al, 2012; MMA, 2013; MMA/ARPA, 2015).

\begin{tabular}{|c|c|}
\hline FASE & METAS PREVISTAS \\
\hline \multirow{4}{*}{$\begin{array}{c}\text { FASE } \\
\text { I }\end{array}$} & Atualizar o Mapa de Áreas Prioritárias do Bioma Amazônia \\
\hline & Criar 18 milhões de hectares em UCs de proteção integral \\
\hline & Criar 9 milhões de hectares em UCs de uso sustentável \\
\hline & Estabelecer um fundo fiduciário para apoiar as UCs consolidadas pelo Arpa \\
\hline \multirow{5}{*}{$\begin{array}{l}\text { FASE } \\
\text { II }\end{array}$} & Atualizar o Mapa de Áreas Prioritárias do Bioma Amazônia \\
\hline & Criar 13 milhões de hectares de UCs \\
\hline & $\begin{array}{l}\text { Consolidar } 32 \text { milhões de hectares de UCs já apoiadas pelo Arpa na Fase I, sendo } \\
23 \text { milhões de hectares no Grau I e } 9 \text { milhões de hectares no grau II }\end{array}$ \\
\hline & $\begin{array}{l}\text { Consolidar 6,5 milhões de hectares de UCs de proteção integral já existentes - } \\
\text { criadas antes de } 2000\end{array}$ \\
\hline & Capitalizar o FAP em US\$ 70 milhões \\
\hline \multirow{2}{*}{$\begin{array}{l}\text { FASE } \\
\text { III }\end{array}$} & Consolidar 60 milhões de hectares de UCs \\
\hline & Garantir a manutenção de (pós-consolidação) de 60 milhões de hectares de UCs \\
\hline
\end{tabular}

Fonte: FUNBIO/MOP, 2002 e FUNBIO/MOP, 2005, MMA/ARPA, 2010; MMA/ARPA 2015; BNDES, 2015

Após o início da Fase II, no final de 2010, os parceiros WWF-Brasil e Funbio iniciaram, com apoio da Linden Trust for Conservation, um processo de detalhamento das projeções de custos de consolidação e manutenção das UCs apoiadas pelo Programa Arpa. Os modelos e projeções de custo apontaram para uma indisponibilidade de recursos para a consolidação plena e manutenção de todas as UCs apoiadas pelo Programa Arpa. As estimativas de custos para a criação, consolidação e manutenção das UCs do Programa Arpa, foram produzidas a partir de um processo detalhado e consultivo que envolveu mais de 30 especialistas em UCs, provenientes de diversas organizações incluindo o MMA, ICMBio, Funbio e WWF. O propósito desse exercício foi estimar as necessidades de médio e longo prazo para um nível mínimo de conservação efetiva das UCs do Programa Arpa, somando 60 milhões de hectares. Foi desenvolvido um modelo que considerou a estrutura de planejamento e as metas do Programa Arpa para estimar, de forma confiável, a demanda de recursos. A estrutura de planejamento, que orientou a organização da modelagem, auxiliou não só a coleta de dados, mas reforçou a coerência do seu desenho para implementar o apoio às UCs em quatro etapas, não necessariamente sucessivas: 
criação, consolidação grau I, consolidação grau II e pós-consolidação ou manutenção. As estimativas de custo foram desenvolvidas a partir do registro de gastos das atividades específicas de gestão das UCs do Programa Arpa, e foram ajustadas considerando o registro de gastos e insumos do ICMBio e dos profissionais das UCs, bem como as condições econômicas. Posteriormente, as estimativas de custo foram agregadas para produzir a estimativa total de investimento necessário no Programa Arpa, incluindo também as despesas/custos de operação e de salários por ano (TUA et al, 2011; GELUDA et al, 2012; MMA/ARPA, 2015).

Em razão dos resultados apresentados, nos anos seguintes (2013 e 2014), WWFBrasil, Funbio, Ministério do Meio Ambiente MMA, Instituto Chico Mendes de Conservação da Biodiversidade (ICMBio), Fundação Moore e Linden Trust Fund trabalharam juntos, com o intuito de discutir e propor um processo único de captação para garantir o aporte de recursos financeiros necessários ao funcionamento do Arpa. Tal iniciativa, denominada Compromisso com a Amazônia - Arpa para Vida, foi lançada em 2012, durante a Rio+20 e visava assegurar a manutenção no longo prazo e a proteção da biodiversidade e dos serviços ambientais da maior floresta tropical do mundo para a posteridade, representando 15\% da Amazônia Brasileira ou 60 milhões de hectares ${ }^{68}$. A Iniciativa Arpa para a Vida propôs alterações em relação aos arranjos financeiros para o Programa Arpa e a realização de novos esforços de captação. Em maio de 2014, WWF, Funbio, MMA, ICMBio, Moore, LTC e outros parceiros ${ }^{69}$ assinaram o Memorando de Entendimento (MOU), documento que formalizou essa nova estratégia de financiamento para as UCs apoiadas pelo Arpa. O MOU assegura o esforço de captação de recursos financeiros para a gestão das UCs apoiadas pelo Programa Arpa (60 milhões de hectares), aliando a preservação e a promoção do desenvolvimento socioeconômico regional, por meio da criação de um Fundo de Transição, que receberá cerca de 215 milhões de dólares, e do aumento gradativo de aportes de recursos públicos. Consequentemente, o Programa Arpa adotou essa nova estratégia financeira instituindo: a Fase III, por meio da Portaria MMA nº187, de 22 de maio de 2014; o Decreto ${ }^{\circ}$ 8.505, de 20 de agosto de 2015; a elaboração de um novo Manual Operacional (MOP); e a criação de um Fundo de Transição, que consiste em um novo mecanismo de financiamento que permite o aumento gradativo do aporte de recursos públicos para a gestão e manejo das UCs no prazo de 25

\footnotetext{
${ }^{68}$ Incluindo a criação de 6 milhões de hectares de novas áreas

${ }^{69}$ Ministério para a Cooperação e Desenvolvimento Alemão (BMZ); o Banco Interamericano de Desenvolvimento (BID) e o Global Environment Facility (GEF).
} 
anos. Nos primeiros anos dessa nova estratégia, as UCs consolidadas, seja em Grau I ou II, passarão a receber apoio do Fundo de Transição para a implementação das ações de manutenção (pós-consolidação), pois este recebeu os recursos do Fundo de Áreas Protegidas, que foi extinto em 2014 com o início da Fase III. Dessa forma, os compromissos originalmente estabelecidos para a Fase II serão cumpridos e o número de UCs apoiadas pelo Fundo de Transição crescerá gradualmente. (Portaria MMA, 2014; MMA/MOP, 2015).

Quadro 16 - Metas previstas X Metas Alcançadas relacionadas ao FAP

\begin{tabular}{|c|c|c|}
\hline FASE & METAS PREVISTAS & METAS ALCANÇADAS \\
\hline $\begin{array}{c}\text { FASE } \\
\text { I }\end{array}$ & $\begin{array}{c}\text { Estabelecer um fundo fiduciário } \\
\text { para apoiar as UCs consolidadas } \\
\text { pelo Arpa }\end{array}$ & $\begin{array}{c}\text { Captação de cerca de US\$ } 25 \text { milhões para o } \\
\text { Fundo de Áreas Protegidas (FAP) }\end{array}$ \\
\hline $\begin{array}{l}\text { FASE } \\
\text { II }\end{array}$ & $\begin{array}{c}\text { Capitalizar o FAP em US\$ } 70 \\
\text { milhões }\end{array}$ & $\begin{array}{c}\text { Em } 2012 \text { o FAP foi criado para apoiar a } \\
\text { manutenção, a longo prazo, das (UC) } \\
\text { consolidadas no Grau II }{ }^{70} . \text {. Mas posterioment, } \\
\text { com a instituição da Fase III, Recursos do FAP, } \\
\text { US\$65 milhões, foram transferidos para o Fundo } \\
\text { de Transição }\end{array}$ \\
\hline
\end{tabular}

Fonte: FUNBIO/MOP, 2002 e FUNBIO/MOP, 2005, MMA/ARPA, 2010; BNDES, 2015

\subsection{Programa Arpa e o apoio à criação de UCs}

O apoio à criação de UCs no Programa Arpa se caracteriza pelo apoio aos estudos necessários e à preparação técnica das propostas para a criação de novas UCs. A Lei 9.885/2000 - SNUC estabelece que "a criação de uma unidade de conservação deve ser precedida de estudos técnicos e de consulta pública que permitam a identificar a localização, a dimensão e os limites mais adequados para a unidade". O apoio do Programa a este processo engloba os passos necessários para a preparação da minuta dos decretos de criação, seguindo os marcos legais definidos na Lei do SNUC. As novas áreas podem ser estabelecidas em nível federal, estadual e/ou municipal ${ }^{71}$.

O processo de identificação e priorização das UCs a serem criadas e regularizadas no âmbito do Programa, nas Fases I e II, é um processo contínuo até o

\footnotetext{
${ }^{70}$ Dentre as UCs apoiadas pelo Arpa, na época da criação do FAP (2012), apenas duas estavam aptas a receber recursos do FAP, o Parque Estadual do Cantão (do governo do Tocantins) e a Reserva Biológica do Jaru, do ICMBio, em Rondônia

71 A implementação da Fase III limitou as esferas de apoio, apoiando somente os processos de criação Federais e Estaduais.
} 
alcance da meta geral de criação. Na Fase I, a seleção dessas áreas baseou-se nos resultados do Seminário de Macapá, em 1999, e em estudos realizados pelo IBAMA e WWF-Brasil, que resultaram na identificação das ecorregiões.

Na Fase II, a seleção de novas áreas para apoio aos estudos de criação teve como base a atualização do Mapa de Áreas Prioritárias para Conservação da Biodiversidade no bioma Amazônia e a Estratégia de Conservação e Investimento 2010-201472. É importante destacar que a meta de criação prevista para a Fase II, de 13,5 milhões de hectares, não apresenta distinção entre os grupos de manejo proteção integral e uso sustentável, embora o MOP da Fase I recomendasse a distinção (BANCO MUNDIAL, 2002; MMA, 2007; MMA, 2008; MMA/ARPA, 2013)

A criação de novas UCs na Fase III do Arpa faz parte do conjunto de condições de desembolso estabelecido no Manual Operacional do Programa (MOP) para esta fase. No antigo desenho da Fase III existia uma meta de criação de 6,5 milhões de hectares, mas na nova Fase III, instituída por portaria ministerial em maio de 2014, não existe meta de criação prevista, mas a criação entra como condição de desembolso. A condição de desembolso $\mathrm{n}^{\mathrm{o}} 8$ do MOP prevê seis milhões de hectares de novas UCs a serem criadas oficialmente a partir de 1/1/2014 no âmbito do Arpa. Esse esforço de criação de UCs deve considerar o seguinte cronograma: em 2014, 1milhão de hectares; em 2015, 2 milhões de hectares; em 2016, 3 milhões de hectares. Apesar do texto determinar como indicador hectares criados agregados ao Arpa, estes hectares criados não são automaticamente incorporados no programa, como muitos poderiam interpretar, pois não constituem uma meta do programa, pois não se encontram descritos no novo MOP, que detalha as metas do programa. Para a seleção dessas áreas os órgãos gestores de UCs deverão submeter as propostas de criação para a UCP, para a preparação de documentação para a análise do PCA. O PCA deverá considerar critérios como: aderência ao Mapa de Áreas Prioritárias, representatividade de ecossistemas, endemismo e ameaça de espécies, repartição de benefícios e preponderância da localização no bioma Amazônia. Uma vez aprovadas as

\footnotetext{
72 A ECI é uma ferramenta para a seleção e priorização de avanços das unidades de conservação apoiadas pelo Programa Arpa, que também tem a função de auxiliar à seleção de novas áreas para criação de UCs. Concebida em 2006 em função da necessidade de alocar recursos expressivos e limitados, nos processos de criação, nas ações de implementação e consolidação das UCs apoiadas, a ECI tem a finalidade de maximizar os resultados do Programa, e posteriormente atendimento das prioridades levantadas pelo Mapa de Áreas Prioritárias de 2007, a partir dos recursos disponibilizados, e garantir o alcance das metas. Na Fase II, a ECI, que antes era um relatório, toma uma nova forma, e passa a ser uma ferramenta informatizada de apoio à decisão e à negociação, não substituindo a análise técnica ou a negociação entre os parceiros do Programa Arpa (MMA/ARPA, 2011).
} 
propostas pelo PCA, a UCP deverá aplicar as ferramentas de Planejamento do Programa

Arpa para alocar recursos para apoio às atividades, respeitando os tetos aprovados pelo

Comitê do Programa e pelo Comitê do fundo de Transição (MMA/MOP, 2015).

\begin{tabular}{|c|c|c|}
\hline FASE & METAS PREVISTAS & METAS ALCANÇADAS \\
\hline \multirow{2}{*}{$\begin{array}{l}\text { FASE } \\
\quad \text { I }\end{array}$} & $\begin{array}{l}\text { Atualizar o Mapa de Áreas } \\
\text { Prioritárias do Bioma Amazônia }\end{array}$ & $\begin{array}{c}\text { O mapa para o bioma Amazônia foi atualizado }{ }^{73} \text { e } \\
\text { definiu } 824^{74} \text { áreas prioritárias, das quais } 334 \text { eram } \\
\text { novas áreas e } 490 \text { já eram áreas sob alguma forma de } \\
\text { proteção. }\end{array}$ \\
\hline & $\begin{array}{l}\text { Criar } 18 \text { milhões de hectares em } \\
\text { UCs de proteção integral e } \\
\text { Criar } 9 \text { milhões de hectares em UCs } \\
\text { de uso sustentável }{ }^{75} \text {. }\end{array}$ & $\begin{array}{c}\text { Foram 13,2 milhões de hectares de UCs de proteção } \\
\text { integral e 10,8 milhões de hectares de UCs de uso } \\
\text { sustentável }\end{array}$ \\
\hline \multirow{2}{*}{$\begin{array}{l}\text { FASE } \\
\text { II }\end{array}$} & $\begin{array}{l}\text { Atualizar o Mapa de Áreas } \\
\text { Prioritárias do Bioma Amazônia }\end{array}$ & $\begin{array}{c}\text { Em execução. Em março de } 2016 \text { o Funbio iniciou o } \\
\text { processo de seleção para contratar consultoria (PJ) } \\
\text { para promover a atualização do Mapa de Áreas } \\
\text { Prioritárias } \\
\end{array}$ \\
\hline & $\begin{array}{l}\text { Criar 13,5 milhões de hectares (sem } \\
\text { fase distinção entre PI e US, embora } \\
\text { o MOP da Fase I recomendasse a } \\
\text { distinção }^{76} \text {. }\end{array}$ & $\begin{array}{l}\text { Até abril de } 2015 \text { foram criados } 1.520 .392 \text { hectares } \\
\text { de novas UCs }{ }^{77} \text { e apoiados } 19 \text { processos de criação } \\
\text { (6,8 milhões de hectares })\end{array}$ \\
\hline
\end{tabular}

\footnotetext{
${ }^{73}$ Essa atualização foi incorporada ao mapa geral de todos os biomas aprovado pela Deliberação CONABIO $\mathrm{n}^{\circ} 46$, de 20 de dezembro de 2006. As novas áreas prioritárias ainda foram reconhecidas pela Portaria MMA $\mathrm{n}^{\circ} 9$, de 23 de janeiro de 2007, para efeito da formulação e implementação de políticas

${ }^{74}$ Dessas 824 áreas prioritárias ocupam cerca de $80 \%$ do bioma, dos quais mais da metade (490 áreas ou 44,3\% do bioma) já estão sob algum tipo de proteção - unidades de conservação ou terras indígenas (MMA, 2007)

${ }^{75}$ Essas metas contribuiriam para a meta geral inicial do programa que era de 28,5 milhões de hectares de novas UCs de "proteção integral" no Bioma Amazônia até o ano 2012 (data inicialmente prevista para o final do programa). Essa meta foi estabelecida no contexto da área total de abrangência do Programa, 50 milhões de hectares (BANCO MUNDIAL, 2002). As etapas subseqüentes do programa (Fases II e III de 3 anos cada) seriam responsáveis por criar mais 19,5 milhões de hectares de UC. As metas de PI e US para as Etapas II e III deveriam ser definidas ao final da Etapa I. Na Fase I o projeto tinha dois componentes diretamente relacionados as UCs, o Componente 1 responsável pela Criação e Estabelecimento de UCs, onde as UCs criadas no âmbito do Arpa seriam consideradas estabelecidas, e o componente 2 onde as UCs existentes (criadas antes 2002) seriam consideradas como consolidadas, mas só passariam da modalidade de apoio estabelecimento para modalidade de apoio consolidação as UCs de PI.

${ }^{76} \mathrm{Na}$ fase II mesmo com o Arpa passando de uma meta geral de 50 para 60 milhões de hectares a meta de criação continuou atrelada ao desenho dos 50 milhões de hectares (pois o total criado em 10 anos seria 28,5, mas o Arpa criou 24,5 na Fase I, ultrapassando a meta da Fase I e quase alcançando a meta total). As metas da Fase II foram descritas no documento de governo, no antigo MOP da Fase II e nos PADs com o Banco Mundial e KfW. Atualmente, o MOP da fase II é o mesmo da Fase III e as metas encontram-se descritas nos PADs e no Documento de Governo (MMA/ARPA, 2010), não apresentando distinção entre as metas de PI e US.

${ }^{77}$ São contabilizados como meta alcançada na Fase II, cerca de 1,5 milhões de hectares referentes a Ucs que foram criados entre 2008 e 2010, que também incluem UCs criadas no bioma Amazônia, mesmo sem ter os estudos apoiados pelo Arpa, mas estas tiveram as consultas públicas, realizadas com o apoio do Arpa.
} 


\begin{tabular}{|c|c|}
\hline $\begin{array}{l}\text { Antiga } \\
\text { Fase } \\
\text { III }\end{array}$ & 6,5 milhões de hectares ${ }^{78}$ \\
\hline $\begin{array}{l}\text { Nova } \\
\text { Fase } \\
\text { III }^{79}\end{array}$ & $\begin{array}{l}\text { Sem meta de criação prevista. A } \\
\text { criação entra como condição de } \\
\text { desembolso }\end{array}$ \\
\hline
\end{tabular}

Fonte: MOP/FUNBIO, 2002; BANCO MUNDIAL, 2002b; MMA/ARPA, 2010; MMA/ARPA, 2015

Considerando-se o cenário político pouco favorável para a criação de UCs durante o início da implementação da Fase II e que se estende ao início de Fase III, é correto considerar que qualquer demanda de apoio à criação de UCs seja bem-vinda, mas isso não ajuda no desafio do Arpa de contribuir para a proteção de uma parcela representativa do bioma Amazônia. Sem a realização de um estudo de lacunas de proteção e um processo bem informado de apoio à criação de UCs, corre-se o risco de proteger muito do mesmo e deixar ecossistemas importantes de fora e sem o apoio do Arpa.

\subsection{Programa Arpa e o apoio à consolidação e à manutenção de UCs}

A consolidação de UCs no âmbito do Arpa envolve investimentos que permitem dotá-las dos instrumentos necessários à sua gestão (plano de manejo, conselho, plano de proteção, infraestrutura - equipamentos e instalações, sistema de monitoramento) e auxiliá-las na manutenção das atividades que garantem a efetiva proteção da biodiversidade (monitoramento, funcionamento do conselho gestor, fiscalização, levantamento fundiário, pesquisas e inventários.

Na fase I do Programa, o apoio à consolidação ocorria em duas etapas. A primeira, chamada estabelecimento, era o apoio ao conjunto de ações que contribuíam para completar o estabelecimento físico das UCs e integrá-las ao sistema regional de UCs. As UCs criadas no âmbito do Arpa eram consideradas estabelecidas uma vez que atingissem uma capacidade gerencial básica para garantir a sua integridade no curto prazo e viabilizar o seu planejamento para o médio prazo, de acordo com a sua categoria de manejo. A consolidação na Fase I tinha por objetivo principal promover a implementação

\footnotetext{
${ }^{78}$ Essa é a meta da antiga Fase III, descrita nos documentos de projeto do Arpa da Fase I (BANCO MUNDIAL, 2002b), no Documento de Governo da Fase II (MMA/ARPA, 2010), no MOP da Fase I (FNBIO/MOP, 2002) e o antigo MOP da Fase II (FUNBIO/MOP, 2010).

${ }^{79}$ Portaria MMA $187 / 2014$.
} 
de 12 UCs de proteção integral, com cerca de 6,7 milhões de hectares, pré-selecionadas e comumente chamadas de UCs pré-existentes, em função do ano de criação dessas UCs ser anterior a criação do Programa Arpa. Os critérios para a seleção dessas UCs incluíram: a ausência de conflitos com as terras indígenas ou comunidades; a existência de uma situação fundiária resolvida ou favorável para uma solução; a viabilidade logística de implementação durante a vigência da Fase I; a presença de capacidade institucional local e a presença de ONG; a existência de condições interinstitucionais ou outras externalidades que tornassem o esforço de consolidação efetivo; e a importância biológica. Mas, a distinção entre apoio ao estabelecimento de UCs e o apoio à consolidação foi uma realidade apenas da Fase I.

Na Fase II, a lógica de estabelecimento e consolidação cedeu lugar a dois graus de consolidação, Grau I e Grau II, o que acabou com a lógica de progressão que existia entre estabelecimento e consolidação para as UCs de proteção integral - únicas UCs no período de execução da Fase I que poderiam ser beneficiadas pela progressão. A consolidação, na Fase II, pressupõe a implantação de uma estrutura mínima de gestão que garanta a integridade das UCs, no curto prazo, e viabilize o planejamento de médio prazo para que as UCs possam cumprir as finalidades para as quais foram criadas. A divisão em graus de consolidação I e II define o conjunto de atividades a serem apoiadas pelo Programa Arpa em função das características socioambientais (como, por exemplo, grau de ameaça e vulnerabilidade) e da situação geográfica das UCs, e não mais em função do seu grupo de manejo, proteção integral ou uso sustentável. Com o fim da progressão, qualquer categoria de UC está apta a receber apoio para consolidação, seja ela de Grau I ou Grau II. Os dois graus de consolidação também foram mantidos no desenho e nas recomendações de implementação da Fase III (MMA/ARPA, 2010; TUA et al, 2011; GELUDA et all, 2012, MMA/ARPA,2015).

Tabela 3 - UCs apoiadas pelo Programa Arpa nas Fases I, II e III por grau de consolidação

\begin{tabular}{|c|c|c|c|c|}
\hline $\begin{array}{c}\text { FASE DE } \\
\text { ENTRADA NO } \\
\text { Arpa } \\
\end{array}$ & $\begin{array}{l}\text { UCS NO } \\
\text { GRAU I }\end{array}$ & $\begin{array}{l}\text { UCS NO } \\
\text { GRAU II }\end{array}$ & $\begin{array}{l}\text { UCS GRAU } \\
\text { I E II }\end{array}$ & $\begin{array}{l}\text { UCS APOIADAS } \\
\text { (ACUMULADO) }\end{array}$ \\
\hline Fase I & 33 & 30 & 63 & 63 \\
\hline Fase II) & $27^{80}$ & 6 & 33 & 96 \\
\hline \begin{tabular}{ll|} 
Fase III) \\
\end{tabular} & $18^{81}$ & & 18 & 105 \\
\hline TOTAL GERAL & 78 & 36 & 114 & - \\
\hline
\end{tabular}

Fonte: MMA/ARPA, 2016

\footnotetext{
8026 UCs em novembro/2011 e 1 UC em dezembro/2014.

819 UCs em maio/2015 e 9UCs agosto/2015.
} 
O grau I de consolidação compreende o apoio aos instrumentos básicos e necessários para a gestão da UC, enquanto que o grau II possibilita o apoio a mais instrumentos para que a UC possa fazer frente às ameaças e pressões antrópicas e para a realização de um conjunto adicional de atividades, tais como pesquisa e monitoramento socioambiental. As UCs apoiadas pelo programa são beneficiadas com bens, obras e contratação de serviços necessários para a realização de atividades de integração com as comunidades de entorno, formação de conselhos, planos de manejo, levantamentos fundiários, fiscalização e outras ações necessárias ao seu bom funcionamento. Para cada grau de consolidação existe um conjunto de marcos referenciais (MRs) a ser alcançado. A etapa de consolidação, seja ela Grau I ou Grau II, é finalizada quando a UC alcança todos os MRs referentes ao seu grau de consolidação.

O Arpa possui 15 MRs, sendo que dez deles só são aplicáveis às UCs de Grau I, e três são marcos que devem ser alcançados sem contar com o apoio financeiro do Programa; são eles: atualizações das informações das UCs apoiada no CNUC, alocação orçamentária anual própria e equipe técnica mínima. O detalhamento dos MRs e os parâmetros considerados para o alcance da consolidação em Grau I e em Grau II estão descritos nos Quadro 18 e 19.

Quadro 18 - Marcos Referenciais do Programa Arpa X Padrões de alcance

\begin{tabular}{|c|c|c|c|}
\hline $\mathbf{N}^{\circ}$ & $\begin{array}{c}\text { MARCO } \\
\text { REFERENCIAL }\end{array}$ & GRAU I & GRAU II \\
\hline 1 & Plano de Manejo & Plano de Manejo Aprovado & Plano de Manejo atualizado \\
\hline 2 & Gestão Participativa & $\begin{array}{c}\text { Conselho oficialmente } \\
\text { constituído }\end{array}$ & $\begin{array}{l}\text { Conselho capacitado e em } \\
\text { funcionamento }\end{array}$ \\
\hline 3 & $\begin{array}{c}\text { Termos de } \\
\text { Compromisso (UC de } \\
\text { PI) } \\
\end{array}$ & N/A & $\begin{array}{l}\text { Construção e assinatura dos } \\
\text { Termos de Compromisso }\end{array}$ \\
\hline 4 & $\begin{array}{l}\text { Concessão de Direito } \\
\text { Real de Uso (UC de US) }\end{array}$ & N/A & $\begin{array}{c}\text { Desenvolvimento e assinatura } \\
\text { das CCDRU }\end{array}$ \\
\hline 5 & Sinalização & $\begin{array}{l}\text { Sinalização dos principais } \\
\text { pontos de acesso as UC }\end{array}$ & $\begin{array}{c}\text { Manutenção e reforço da } \\
\text { sinalização da UC em } \\
\text { alinhamento com o Plano de } \\
\text { Manejo } \\
\end{array}$ \\
\hline 6 & Demarcação Estratégica & N/A & $\begin{array}{l}\text { Materialização dos limites da } \\
\text { Unidade de Conservação em } \\
\text { pontos estratégicos da UC }\end{array}$ \\
\hline 7 & Situação Fundiária & N/A & $\begin{array}{c}\text { Levantamento da situação } \\
\text { fundiária e preparação para } \\
\text { ações de regularização fundiária }\end{array}$ \\
\hline 8 & $\begin{array}{c}\text { Planejamento } \\
\text { Operacional Anual - } \\
\text { Proteção }\end{array}$ & $\begin{array}{l}\text { Plano de Proteção } \\
\text { Implementado }\end{array}$ & $\begin{array}{c}\text { Proteção e Operacionalização da } \\
\text { UC alinhada com o Plano de } \\
\text { Manejo }\end{array}$ \\
\hline
\end{tabular}




\begin{tabular}{|c|c|c|c|}
\hline 9 & Equipamentos & $\begin{array}{l}\text { Aquisição (e manutenção) de } \\
\text { um conjunto Básico de } \\
\text { equipamentos para a } \\
\text { operacionalização da UC }\end{array}$ & $\begin{array}{l}\text { Aquisição e manutenção de um } \\
\text { conjunto de equipamentos } \\
\text { necessários para a UC fazer } \\
\text { frente às ameaças e atividades } \\
\text { mais avançadas de gestão. }\end{array}$ \\
\hline 10 & Instalações & $\begin{array}{l}\text { Manutenção mínima de } \\
\text { instalações existentes }\end{array}$ & $\begin{array}{l}\text { Construção (e manutenção) de } \\
\text { Sede ou centro de convivência } \\
\text { para atividades de } \\
\text { administração, alojamento e } \\
\text { armazenamento de } \\
\text { equipamentos. }\end{array}$ \\
\hline 11 & Pesquisa/Inventário & N/A & $\begin{array}{c}\text { Desenvolvimento de pesquisas e } \\
\text { estudos sobre desafios de } \\
\text { manejo das UC }\end{array}$ \\
\hline 12 & Monitoramento & $\begin{array}{l}\text { Monitoramento de ao menos } \\
\text { um indicador da } \\
\text { biodiversidade, uso de } \\
\text { recursos ou integridade da } \\
\text { paisagem }\end{array}$ & $\begin{array}{l}\text { Implementação dos Protocolos } \\
\text { de Monitoramento do Programa }\end{array}$ \\
\hline 13 & $\begin{array}{c}\text { Atualizações das } \\
\text { Informações no CNUC }\end{array}$ & $\begin{array}{c}\text { Informações básicas do } \\
\text { Cadastro atualizadas }\end{array}$ & $\begin{array}{l}\text { Informações completas do } \\
\text { Cadastro atualizadas }\end{array}$ \\
\hline 14 & $\begin{array}{l}\text { Alocação orçamentária } \\
\text { anual própria }\end{array}$ & $\begin{array}{c}\text { Alocação orçamentária } \\
\text { compatível com as } \\
\text { necessidades de manutenção } \\
\text { da UC e complementar à } \\
\text { alocação do Programa - média } \\
\text { de avanço anual OG. }\end{array}$ & $\begin{array}{c}\text { Alocação orçamentária } \\
\text { compatível com as necessidades } \\
\text { de manutenção da UC e } \\
\text { complementar à alocação do } \\
\text { Programa - média de avanço } \\
\text { anual OG. }\end{array}$ \\
\hline 15 & Equipe Técnica mínima & $\begin{array}{c}\text { Equipe Técnica de pelo menos } \\
2 \text { pessoas com presença efetiva } \\
\text { na UC }\end{array}$ & $\begin{array}{c}\text { Equipe Técnica de pelo menos } 5 \\
\text { pessoas com presença efetiva na } \\
\text { UC }\end{array}$ \\
\hline
\end{tabular}

Fonte: MMA/ARPA, 2015

Após a consolidação, seja em Grau I ou Grau II, as UCs deverão manter o seu respectivo nível de consolidação, estabelecido em função do alcance do conjunto de MRs durante toda a vigência do Programa Arpa. Na manutenção ou fase de pós-consolidação, não há diferença nas atividades a serem desempenhadas em relação às UCs em função de seus respectivos graus de consolidação. Serão aportados recursos para revisão do plano de manejo; manutenção do funcionamento do conselho da UC; proteção da UC; monitoramento da biodiversidade (protocolos básicos de biodiversidade, integridade da paisagem, e uso de recursos); manutenção de equipamentos e instalações; manutenção da sinalização e da demarcação; operacionalização geral; e reposição de equipamentos. 
Quadro 19 - Metas previstas X metas alcançadas para consolidação de UCs

\begin{tabular}{|c||c|c||}
\hline \hline FASE & METAS PREVISTAS & METAS ALCANÇADAS \\
\hline \hline \multirow{2}{*}{$\begin{array}{c}\text { FASE } \\
\text { II }\end{array}$} & $\begin{array}{c}\text { Consolidar 32 milhões de } \\
\text { hectares de UCs já apoiadas pelo } \\
\text { Arpa na Fase I, sendo 23 milhões } \\
\text { de hectares no Grau I e 9 milhões } \\
\text { de hectares no grau II }\end{array}$ & $\begin{array}{c}\text { Foram consolidadas no Grau I, 13 UCs que } \\
\text { correspondem a 5,57 milhões de hectares, e no } \\
\text { Grau II, 2 Ucs, que correspondem a 428.563,08 } \\
\text { mil de hectares }\end{array}$ \\
\cline { 2 - 3 } & $\begin{array}{c}\text { Consolidar 6,5 milhões de } \\
\text { hectares de UCs de proteção } \\
\text { integral já existentes - criadas } \\
\text { antes de 2000 }\end{array}$ & Em execução \\
\hline
\end{tabular}

Fonte: MOP/FUNBIO, 2002; BANCO MUNDIAL, 2002b; MMA/ARPA, 2010; MMA/ARPA, 2015

É importante destacar que a etapa de pós-consolidação, cuja previsão mais otimista é de que contemple todas as UCs apoiadas pelo Arpa a partir de 2020, se estenderá até 2039, dentro da lógica de que os recursos associados a estas atividades serão financiados pelo Fundo de Transição, de forma a permitir o aumento gradativo do aporte de recursos pelos órgãos gestores, sendo estes, a partir de 2039, responsáveis pela totalidade dos custos de manutenção das UCs apoiadas.

Após apresentar o histórico de criação do programa e sua forma de funcionamento e abrangência, o capítulo seguinte, o Capitulo 4, apresenta e discute a metodologia adotada pelo Arpa para avaliar as evidências de conservação da biodiversidade e da sustentabilidade no uso dos recursos naturais nas UCs por ele apoiadas. 


\section{Capitulo 4 - A estratégia do Programa Áreas Protegidas da Amazônia para avaliar o sucesso das UCs na conservação da Biodiversidade e na sustentabilidade do uso dos recursos naturais}

O empenho do Brasil na criação e gestão de unidades de conservação é percebido no esforço empreendido, nas últimas duas décadas, para o desenvolvimento do marco legal que orienta e disciplina a implementação de tal estratégia, destacando-se a ratificação da Convenção sobre Diversidade Biológica (CDB), a instituição do Sistema Nacional de Unidades de Conservação da Natureza (SNUC), a adesão ao Plano de trabalho sobre áreas protegidas da CDB e o processo de elaboração do Plano Estratégico Nacional de Áreas Protegidas (PNAP). E embora este último - PNAP - reconheça o esforço de conservação das Terras Indígenas e dos Territórios Quilombolas, as Unidades de Conservação (UCs) são a principal estratégia de conservação da biodiversidade no país e integram o SNUC. Ao se comprometer em ampliar o esforço de conservação da biodiversidade, o governo Brasileiro se comprometeu também em ampliar o esforço de monitoramento para demonstrar que as UCs são geridas de maneira efetiva e equitativa, que são ecologicamente representativas e satisfatoriamente interligadas (SNUC, 2000; MERCADANTE, 2001; DRUMMOND et al, 2006 e 2010).

Neste contexto entender a estratégia adotada pelo Programa Arpa para avaliar o sucesso das UCs por ele apoiadas na conservação da biodiversidade e na sustentabilidade do uso dos recursos naturais pode ajudar a entender os desafios no monitoramento do Sistema Nacional de Unidades de Conservação da Natureza (SNUC). Durante seus 14 anos de existência, o Arpa foi constantemente monitorado pelas instâncias de governança que integram seu arranjo institucional, e que trazem em si mecanismos de acompanhamento da execução física (cumprimento de metas) e financeiras. Para além do monitoramento do Arpa enquanto projeto (fruto de acordos de parceria e doação com o governo federal), o monitoramento e avaliação das UCs do Programa Arpa considerando o programa como uma ferramenta de implementação de parte do sistema nacional de unidades de conservação - sempre foi uma prioridade desde a sua concepção, e o presente capítulo destaca os elementos e os avanços dessa estratégia ao longo das suas três fases. 


\subsection{Fase I: Uma estratégia de avaliação para mostrar o sucesso de execução do Programa Arpa}

A Fase I tinha como proposta de avaliação um misto entre a avaliação do processo de implementação do projeto e o mapeamento dos impactos gerados pelo Programa Arpa no que diz respeito ao apoio as ações de criação, estabelecimento e consolidação de UCs. O primeiro Project Appraisal Document (PAD), documento do Banco Mundial (2002) que agrupa as informações sobre o Projeto que serviram de base para a tomada de decisão sobre a doação, traz as informações iniciais sobre a forma de implementação do programa, e recomendava o estabelecimento de um sistema avaliação e monitoramento, por meio da implementação do Componente 4 - Monitoramento e Avaliação de $\mathrm{UCs}^{82}$. A implementação desse componente ajudaria a melhorar o processo de tomada de decisão, de planeamento e de gestão do projeto, desde que as informações sobre a efetividade da gestão das UC fossem precisas e confiáveis.

A estratégia de implementação do componente 4, no início da Fase 1, sugeria a implementação de um sistema piloto envolvendo inicialmente cinco das UCs apoiadas pelo Programa, após a aprovação do sistema piloto, este deveria até o final da Fase 3 incorporar as demais UCs apoiadas. Para tanto, as ações desenvolvidas deveriam contribuir para o levantamento de informações sobre o estado da biodiversidade (grupos de indicadores-chave), as pressões e ameaças aos ecossistemas (níveis de ameaça), os recursos hídricos e o clima, sobre o efeito de ilha (níveis de conectividade), sobre a eficácia ${ }^{83}$ de gestão, além de informações sobre o uso e ocupação do solo (desmatamento, construção de estradas, crescimento urbano, assentamento e atividades agrícolas ou pecuárias) dentro e no entorno das $\mathrm{UC}^{84}$. As recomendações sugeriam a organização de um sistema de monitoramento e os indicadores para esse sistema de monitoramento seriam desenvolvidos em coordenação com o já existente Sistema de Monitoramento de Biodiversidade (SIMBIO) na época coordenado pelo Ibama (atualmente o ICMBio) para garantir que as informações das UCs apoiadas pelo Programa alimentassem o SIMBIO por meio de indicadores compartilhados. O Ibama e Funbio eram os responsáveis responsável por esse componente. Dentre as ações-chave para o sucesso desse

\footnotetext{
${ }^{82}$ É importante destacar que o componente 4 teve outras denominações ao longo da Fase I

83 Tradução literal para o termo e mais adequado ao sentido do texto, embora o termo seja comumente utilizado no Brasil e no âmbito do Programa Arpa como efetividade de gestão.

${ }^{84}$ Texto original: como a erosão do solo e assoreamento por desmatamento e construção de estradas, o crescimento urbano, planejado e assentamentos não planejados, sobrepastoreio, e outras atividades baseadas na comunidade e em torno de áreas protegidas.
} 
componente incluíam-se também a consolidação de um banco de dados com informações sobre UCs no bioma amazônico, o qual deveria incorporar um mecanismo de troca de informação, para apoiar o planejamento e a gestão das UCs; a validação da classificação/níveis para monitoramento das UCs; o desenvolvimento de indicadores e de uma metodologia para avaliar a relação custo-eficácia da gestão das UCs apoiadas; além da coleta, análise e consolidação das informações para completar as bases de dados para os cinco UCs selecionadas, como por exemplo, trabalho de campo, sensoriamento remoto, coleta de dados secundários (BANCO MUNDIAL, 2002). Uma metodologia de análise de risco desenvolvida pela WCPA e pelo WWF também seria utilizada, de forma auxiliar, na identificação dos instrumentos e indicadores para o monitoramento. Essa metodologia sugeria que cada unidade seria classificada de acordo com dois níveis de risco:

- Nível 1 para as UCs sob elevada pressão e ameaça humana (maior perda de biodiversidade) deveriam ser priorizados instrumentos como o monitoramento em campo e indicadores de efetividade;

- Nível 2 para as UCs menos vulneráveis a pressão humana inferior, e com outros fatores ameaça a biodiversidade deveriam ser priorizados os sistemas de informações geográficas e sensoriamento remoto e indicadores de efetividade.

Embora essas recomendações fizessem parte o PAD da Fase I, ao longo da sua implementação alguns caminhos foram percorridos para implantação da estratégia sugerida. Um deles foi a avaliação do Projeto Arpa em seu nível estratégico, onde dentre as formas de avaliação e monitoramento sugeridas, destacavam-se as missões de supervisão (conduzidas pelas principais agências doadoras), a atuação das instâncias de governança do Programa Arpa por meio da análise e aprovação dos relatórios de execução (física e financeira) ${ }^{85}$ e as auditorias independentes (consultores externo contratados para auditar a execução das atividades previstas para cada componente de apoio).

O outro se caracteriza pela priorização da avaliação da eficácia do projeto e das unidades de conservação por ele apoiadas. Na Fase 1 foi desenvolvido e, parcialmente, implementado o Sistema Integrado de Coordenação e Gerenciamento do Programa Arpa - SISArpa cuja finalidade era integrar, aprimorar e consolidar as informações referentes

\footnotetext{
${ }^{85}$ Realizadas pela equipe da Unidade Coordenadora do Programa (UCP) eram realizadas e submetidas a aprovação do Comitê do Programa.
} 
ao Programa Áreas Protegidas da Amazônia, permitindo o fluxo de decisões estratégicas para o Programa, além de compartilhar com a sociedade e gestores ambientais informações sobre as UCs apoiadas pelo Arpa. O SISArpa também tinha o desafio de evitar a duplicidade de esforços na coleta de informação e compatibilizar as informações do Arpa com o CNUC do MMA e o Sistema Cérebro ${ }^{86}$ do Funbio, além de compartilhar dados e informações por meio de um esforço cooperativo e interinstitucional entre o MMA, os órgãos executores e parceiros do Programa.

O desenvolvimento do SISArpa contemplava 3 grandes grupos de informações que envolviam os processos de avaliação, planejamento e gestão. Para o processo de avaliação foram desenvolvidos três módulos: (i) Solicitação de Apoio (no qual era possível a cada órgão gestor parceiro do Programa cadastrar e justificar as solicitações de apoio aos processos de criação de UC), (ii) Informações Gerais (que vinculava as informações sobre as UCs contidas no CNUC com informações especificas do apoio do Programa Arpa à cada UC, como ação apoiada, grau de consolidação, tipo de UC no Arpa, etc...); (iii) Avaliação da Efetividade - uma versão online da Ferramenta de Avaliação da Efetividade do Programa Áreas Protegidas da Amazônia/FAUC que permitia identificar a situação atual de cada UC apoiada pelo Programa em relação aos indicadores de resultado, chamados de marcos referenciais estabelecimento e consolidação de UCs.

Para o planejamento, também foram desenvolvidos três módulos: (i) Planejamento de Metas (modulo vinculado aos resultados do modulo de avaliação e que permitia, por meio de um sistema de pontuação, planejar metas futuras e simplificar o planejamento orçamentário), (ii) Plano de Trabalho (módulo onde era possível detalhar as atividades a serem desenvolvidas para o alcance das metas pactuadas no módulo Planejamento de Metas) e (iii) Planejamento de Insumos, módulo sob a responsabilidade do Funbio, no qual os gestores identificavam os insumos necessários ao desenvolvimento das atividades identificadas no módulo Plano de Trabalho (WEIGAND JR et al, 2007).

O monitoramento da gestão tinha continuidade no Sistema Cérebro (desenvolvido e gerenciado pelo Funbio) que é um sistema informatizado, responsável pelo controle contábil de todas as movimentações financeiras e o registro das transações no âmbito do Programa Arpa, que com o resultado dos módulos anteriores resultava na elaboração do POA. O desafio inicial para a implantação do SISArpa foi vincular as

\footnotetext{
${ }^{86}$ Responsável pelo gerenciamento financeiro do Programa ARPA.
} 
etapas de planejamentos (Planejamento de Metas, Plano de Trabalho e Planejamento de Insumos) a partir do resultado da análise da situação atual de cada UC (FAUC), a cada ciclo de elaboração do Plano Operacional Anual (POA).

O SISArpa funcionou durante a Fase 1, e a sua implementação possibilitou principalmente a discussão sobre o marco conceitual para avaliação da efetividade e a construção da Ferramenta de Avaliação da Efetividade do Programa Áreas Protegidas da Amazônia/FAUC. A primeira versão da FAUC, criada em 2007 e utilizada até 2010, era o resultado da adaptação da ferramenta Management Effectiveness Tracking Tool (METT-TT).

A Tracking Tool foi introduzida no Programa Arpa em 2004, a partir de um acordo firmado entre o governo e os doadores. A ferramenta era uma demanda do GEF que a aplica em todos os projetos de áreas protegidas que apoia. A ferramenta foi desenvolvida tendo como base o marco referencial da WCPA/IUCN. Entretanto, após ter sido traduzida, uma equipe, envolvendo representantes do MMA, Ibama, WWF-Brasil e a Cooperação Técnica Alemã (GTZ), considerou que a ferramenta precisava de adaptações para o Brasil. A ferramenta era representada por um formulário de avaliação composto de 30 questões, respondidas pela atribuição de uma pontuação que variava de 0 (insatisfatório) até 3 (excelente). Uma série de quatro alternativas de resposta é dada para cada questão, com o propósito de ajudar os assessores a decidirem sobre a pontuação atribuída. Ainda em 2004, a equipe da UCP introduziu quatro novas questões e adaptou outras, para que as questões pudessem contemplar as unidades de conservação de uso sustentável. Outras adaptações foram feitas com base na lei do Sistema Nacional de Unidades de Conservação (SNUC). Em 2005, a Tracking Tool adaptada foi aplicada a 34 unidades de conservação (UCs). Esses dados consistiram na primeira avaliação das UCs apoiadas pelo Arpa, formando uma "linha base" para avaliações posteriores.

Em 2006, novas adaptações foram introduzidas a Tracking Tool: (i) as questões foram divididas por subprojeto do Plano Operativo Anual (POA), uma vez que as ações financiadas pelo Arpa eram classificadas em cada UC por esses subprojetos, permitindo assim avaliar a efetividade dos recursos investidos em cada subprojeto; (ii) com a distribuição das questões classificação por subprojeto foi possível identificar as questões correspondentes aos marcos referenciais de estabelecimento e consolidação de UCs. Desta forma era possível verificar com apoio da ferramenta, a contribuição das UCs para o avanço das metas do Arpa, assim como fazer uma previsão de alcance dessas para os 
anos seguintes. Mas apesar dos avanços introduzidos nos anos anteriores a Tracking Tool adaptada apresentava uma lista abrangente de perguntas em consonância com os elementos de avaliação do marco referencial da WCPA/IUCN, mas que não contemplava o ciclo completo de gestão para todos os aspectos abordados. As alternativas de respostas sugeridas para cada questão, não tratavam somente do que foi perguntado, ou seja, para uma determinada questão, uma das alternativas de resposta correspondia a dois cenários distintos; a pontuação correspondente a cada alternativa de resposta apresentava variações abruptas, induzindo o gestor da UC relatar menor avanço que o que foi alcançado, ou a relatar um avanço inexistente.

Em 2007, a Unidade de Coordenação do Programa Arpa promoveu novas adaptações na ferramenta, a começar pelo nome: Ferramenta de Avaliação de Unidades de Conservação (FAUC). A FAUC introduz uma série de mudanças: (i) no lugar de questões, utiliza-se "indicadores"; (ii) adota um sistema de pontuação gradual (0 a 100\%); (iii) cada indicador passa abordar um único aspecto da gestão da UC; (iv) para cada indicador as alternativas de respostas foram revisadas de forma a torná-las mais claras e objetivas; (v) os indicadores são divididos por fase de implementação da UC (criação, estabelecimento e consolidação ${ }^{87}$ ), evitando que indicadores que não se aplicam à fase de apoio da UC no âmbito do Programa Arpa tenham que ser respondidos, reduzindo-se assim o esforço de preenchimento da ferramenta, e (vi) a pontuação continua a ser usada para planejamento de metas dos marcos referenciais. Apesar das alterações a FAUC consegue manter a correspondência com as questões do TT mundial e dos TTs adaptados ao Programa em 2004, 2005 e 2006 (WEIGAND JR et al, 2007).

Um exemplo das adaptações empreendidas pode ser observado nos Quadros 20 a 24, ao mostrar o registro das alterações promovidas nas Questões 16 e 19 do Tracking Tool (TT). A questão 16 do TT trata do grau de participação dos residentes da UC, seja a UC de uso sustentável ou de proteção integral, e pressupõe uma evolução da participação, desde o processo de consulta à tomada de decisão. Na adaptação para a FAUC usou-se a premissa que um grau de participação mínimo seria os residentes na UC ou seu entorno serem informados das decisões, assim escala da participação dos comunitários foi um

\footnotetext{
${ }^{87}$ Cada fase e também dividida em subprojetos, uma classificação definida a partir da estrutura de apoio do Arpa às UCs. Os subprojetos servem para classificar e organizar tanto a avaliação quanto o planejamento, os insumos e a ação. Por meio do ciclo PDCA, a cada indicador, estabelece-se uma base para a avaliação do próximo, e a base para a projeção de metas.
} 
pouco mais detalhada que a proposta dessa questão no TT, embora a avaliação de qualidade da participação continue incompleta.

Quadro 20 - Questão 16 do Tracking Tool

\begin{tabular}{|c|c|c|}
\hline \begin{tabular}{ll|} 
NÚMERO & DA \\
QUESTÃO &
\end{tabular} & ALTERNATIVAS DE RESPOSTA & PONTUAÇÃO \\
\hline \multirow{4}{*}{$\begin{array}{l}\text { 16. Os comunitários que } \\
\text { residem ou usam a UC } \\
\text { contribuem nas decisões } \\
\text { de gestão? }\end{array}$} & $\begin{array}{l}\text { Os comunitários não têm nenhuma participação nas } \\
\text { decisões relacionadas à gestão da UC }\end{array}$ & 0 \\
\hline & $\begin{array}{l}\text { Os comunitários têm alguma participação nas } \\
\text { discussões relativas à gestão, mas não têm } \\
\text { envolvimento direto nas decisões resultantes (os } \\
\text { comunitários informam suas necessidades) } \\
\end{array}$ & 1 \\
\hline & $\begin{array}{l}\text { Os comunitários contribuem diretamente para } \\
\text { algumas decisões relacionadas à gestão (algumas } \\
\text { decisões de gestão são negociadas com os } \\
\text { comunitários) }\end{array}$ & 2 \\
\hline & $\begin{array}{l}\text { Os comunitários atuam diretamente na maioria das } \\
\text { decisões de gestão }\end{array}$ & 3 \\
\hline
\end{tabular}

Quadro 21 - Questão 10 -FAUC Consolidação. Subprojeto Participação e Integração com o Entorno.

\begin{tabular}{|c|c|c|c|c|c|}
\hline ORDEM & \begin{tabular}{|l} 
NO. DA \\
QUESTÃO \\
NO TT \\
2006
\end{tabular} & $\begin{array}{c}\text { NO DA } \\
\text { QUESTÃO } \\
\text { NO TT } \\
2004\end{array}$ & INDICADOR & $\begin{array}{l}\text { CENÁRIO DO } \\
\text { INDICADOR }\end{array}$ & $\begin{array}{c}\text { PONTUAÇÃO } \\
(\%)\end{array}$ \\
\hline \multirow{4}{*}{ PIE10 } & \multirow{4}{*}{16} & \multirow{4}{*}{22} & \multirow{4}{*}{$\begin{array}{l}\text { Qualidade de } \\
\text { participação dos } \\
\text { comunitários } \\
\text { residentes na UC } \\
\text { ou no seu entorno } \\
\text { na sua gestão }\end{array}$} & Nenhum & 0 \\
\hline & & & & $\begin{array}{l}\begin{array}{l}\text { São informados } \\
\text { das decisões }\end{array} \\
\end{array}$ & 33 \\
\hline & & & & $\begin{array}{l}\text { São consultados } \\
\text { sobre a gestão }\end{array}$ & 66 \\
\hline & & & & $\begin{array}{l}\text { Participam das } \\
\text { decisões sobre a } \\
\text { gestão }\end{array}$ & 100 \\
\hline
\end{tabular}

A questão 19 trata de dois aspectos: a constituição do conselho e a participação dos seus membros. Assim, a questão foi desmembrada, em duas questões no âmbito da FAUC, uma destinada a etapa de estabelecimento (que prevê o estabelecimento do conselho da UC) e outra para a etapa de consolidação (cuja a meta é ter o conselho em funcionamento).

Quadro 22 - Questão 19: Tracking Tool

\begin{tabular}{|l|l|c|}
\hline $\begin{array}{l}\text { NÚMERO } \\
\text { QUESTÃO }\end{array}$ & DATERNATIVAS DE RESPOSTA & PONTUAÇÃO \\
\hline \hline & $\begin{array}{l}\text { A unidade de conservação não possui conselho } \\
\text { instituído }\end{array}$ & 0 \\
\hline
\end{tabular}




\begin{tabular}{|c|c|c|}
\hline \multirow{3}{*}{$\begin{array}{l}\text { 19. A unidade de } \\
\text { conservação possui } \\
\text { conselho funcionando? }\end{array}$} & $\begin{array}{l}\text { O conselho da unidade está em processo de } \\
\text { formacão }\end{array}$ & 1 \\
\hline & $\begin{array}{l}\text { A unidade possui conselho legalmente constituído, } \\
\text { porém a participação dos membros não é efetiva ou } \\
\text { representa parcialmente o conjunto de atores sociais } \\
\text { interessados }\end{array}$ & 2 \\
\hline & $\begin{array}{l}\text { A unidade possui conselho legalmente constituído, é } \\
\text { representativo dos diferentes setores e a participação } \\
\text { dos membros é efetiva }\end{array}$ & 3 \\
\hline
\end{tabular}

Quadro 23 - Questão 8: FAUC Estabelecimento. Subprojeto Participação e Integração com o Entorno. Marco Referencial: Formação do conselho consultivo ou deliberativo da UC.

\begin{tabular}{|c|c|c|c|c|c|}
\hline ORDEM & \begin{tabular}{|c|} 
NO. DA \\
QUESTÃo \\
NO TT \\
2006 \\
\end{tabular} & \begin{tabular}{|c|} 
NO DA \\
QUESTÃO \\
NO TT \\
2004 \\
\end{tabular} & INDICADOR & $\begin{array}{l}\text { CENÁRIO DO } \\
\text { INDICADOR }\end{array}$ & $\begin{array}{c}\text { PONTUAÇÃO } \\
(\%)\end{array}$ \\
\hline \multirow{4}{*}{ PIE8 } & \multirow{4}{*}{19} & \multirow{4}{*}{31} & \multirow{4}{*}{$\begin{array}{l}\text { Grau de } \\
\text { formação do } \\
\text { conselho } \\
\text { consultivo ou } \\
\text { deliberativo }\end{array}$} & Não iniciada & 0 \\
\hline & & & & $\begin{array}{l}\text { Mobilização } \\
\text { realizada }\end{array}$ & 50 \\
\hline & & & & $\begin{array}{l}\text { Composição } \\
\text { definida e } \\
\text { membros } \\
\text { capacitados } \\
\end{array}$ & 90 \\
\hline & & & & $\begin{array}{l}\text { Conselho } \\
\text { instituído pelo } \\
\text { órgão gestor }\end{array}$ & 100 \\
\hline
\end{tabular}

Quadro 24 - Questão 13: FAUC Consolidação. Subprojeto Participação e Integração com o Entorno. Marco Referencial: Funcionamento do conselho consultivo ou deliberativo da UC.

\begin{tabular}{|c|c|c|c|c|c|}
\hline ORDEM & \begin{tabular}{|l} 
NO. DA \\
QUESTÃO \\
NO TT \\
2006 \\
\end{tabular} & \begin{tabular}{|c|} 
NO DA \\
QUESTÃo \\
NO TT \\
2004 \\
\end{tabular} & INDICADOR & $\begin{array}{l}\text { CENÁRIO DO } \\
\text { INDICADOR }\end{array}$ & $\begin{array}{c}\text { PONTUAÇÃO } \\
(\%)\end{array}$ \\
\hline \multirow{4}{*}{ PIE13 } & \multirow{4}{*}{19} & \multirow{4}{*}{31} & \multirow{4}{*}{$\begin{array}{l}\text { Grau de } \\
\text { atividade do } \\
\text { conselho gestor, } \\
\text { considerando-se } \\
\text { a frequiência e a } \\
\text { regularidade de } \\
\text { reuniões. }\end{array}$} & $\begin{array}{l}\text { Nenhum - não se } \\
\text { reúne há mais de } \\
\text { um ano }\end{array}$ & 0 \\
\hline & & & & Baixo & 33 \\
\hline & & & & Médio & 66 \\
\hline & & & & \begin{tabular}{|lr||} 
Alto - & cumpre \\
calendário & de \\
reuniões & \\
\end{tabular} & 100 \\
\hline
\end{tabular}

As adaptações introduzidas na FAUC tiveram a finalidade de permitir a avaliação da eficácia dos recursos investidos pelo Programa, a identificação os marcos referenciais de estabelecimento e consolidação de UCs, a vinculação dos resultados da FAUC aos recursos financeiros investidos pelo Arpa, além de usar o resultado da FAUC (nível ou status de alcance de cada marco referencial) para planejar metas futuras e auxiliar o 
planejamento do POA. A FAUC era preenchida pelos gestores de UCs e seus dados eram avaliados e validados pelos órgãos gestores e equipe da UCP por meio de um formulário online que integrava o SISArpa. A versão aplicada durante a Fase I do Arpa era composta por três 3 formulários: o primeiro aplicado as aos Processos de Criação, com 21 questões ou indicadores, o segundo aplicado para as UCs em fase de estabelecimento, 51 questões e o terceiro aplicado para as UCs em fase de consolidação com e 93 questões que refletiam a situação de 15 marcos referencias (MRs) de consolidação. A FAUC foi aplicada de 2007 a 2010 resultando em quatro series de avaliação aplicadas a cerca de 109 UCs criadas e 32 em processos de criação de UCs. Se consideramos que os dados das avaliações TT 2004, TT 2005 e TT 2006 foram convertidos segundo a lógica de pontuação do FAUC, permitindo a comparação entre as duas ferramentas são 7 séries de aplicação da ferramenta. Uma avaliação dos desdobramentos e utilização das informações e resultados das avaliações oriundas da aplicação da FAUC apontou que as avaliações da situação das UCs apoiadas e dos resultados alcançados pelo Programa auxiliaram o planejamento da Fase II, planejamento este que envolveu não só a definição de metas, mas que contribuiu para atualizar a Estratégia de Conservação e Investimento do Programa - ECI estratégia responsável por calcular a estimativa dos recursos necessários a implementação da Fase II $^{88}$.

Fora do SISArpa uma outra ferramenta de auxílio a avaliação da gestão, principalmente a capacidade gerencial das equipes da UCs para a gestão, foi implementada no âmbito do projeto - o programa de treinamento Gestão por Resultados/PGR, apoiado pela parceira de cooperação técnica Alemã, a GTZ. O Programa Gestão por Resultado foi também uma iniciativa de desenvolvimento da capacidade gerencial das UCs apoiadas pelo Arpa. Implementado no período de 2006 a 2009, em 15 UCs apoiadas pelo Programa, o PGR foi concebido a partir do Modelo de Excelência em Gestão Pública (MEGP), proposto pelo Programa Nacional de Excelência de Gestão Pública e Desburocratização - GesPública. Os resultados observados nas equipes das UCs sinalizaram a melhoria no relacionamento interno da equipe, maior iniciativa de articulação com órgão gestores, integração de ações com o entorno das UCs

\footnotetext{
${ }^{88}$ A ECI também seria utilizada na Fase II para selecionar as novas áreas para criação de UCs que maximizavam o atendimento das prioridades levantadas pelo Mapa de Áreas Prioritárias; e para identificar a melhor combinação de ações a serem apoiadas pelo Arpa, maximizando a sua efetividade, tanto no que diz respeito à representatividade ecológica como à distribuição dos recursos.
} 
e desempenho positivo nas ações de planejamento e operacionalização técnica, como proteção e funcionamento do conselho (ARAÚJO, 2007).

Mas as UCs apoiadas pelo Arpa na Fase I também foram avaliadas por mais uma ferramenta o Rapid Assessment and Priorization of Protected Area Management (Rappam). Apesar de ser a ferramenta mais aplicada no Brasil desde 2004 e desenvolvida pelo WWF, parceiro técnico e doador do Programa Arpa, os documentos que orientavam a implementação do Programa (o PAD e posterior o Manual Operacional ${ }^{89}$ ), e mesmo o Documento Conceito que orientou a proposta de criação do Programa Arpa, não sugeriam ou indicavam o Rappam como uma das possíveis ferramentas de avaliação da efetividade da gestão. A ênfase dada a utilização e adaptação do TT e posteriormente a criação da FAUC parece demonstram que a preocupação inicial dessas ferramentas era com a avaliação do Projeto no seu nível estratégico, embora do ponto de vista do Sistema de Gerenciamento proposto, o SISArpa, elas tenham sido classificadas como ferramentas de avaliação da efetividade.

Ainda assim, o Rappam foi aplicado para as UCs federais apoiadas pelo Arpa em 2005 e para as UCs estaduais apoiadas pelo Arpa entre 2008 e 2009, caracterizandose como o primeiro ciclo de avaliação. A segunda aplicação, em 2010, ocorreu somente para as UCs federais e coincidiu com o final da Fase I do Programa. Apesar do apoio ao total de 63 UCs na Fase II, apenas 32 delas participaram das duas aplicações do método Rappam, em 2005 e 2010. A metade das UCs é de proteção integral e a outra, de uso sustentável. Observou-se aumento significativo da efetividade de gestão entre 2005 e 2010, passando de 39\%, considerado baixo, para 56\%. Este último valor está situado na faixa média, mas próxima ao limite superior que é de 60\%. Para as unidades de proteção integral federais analisadas, houve crescimento de $46 \%$ para $59 \%$ e para as UCs federais de uso sustentável passou de 32\% para 53\%. A avaliação Rappam 2010 mostrou que a efetividade de gestão das UCs do Arpa foi maior que a das demais unidades da Amazônia, como uma diferença de $17 \%$ para as UCs federias de proteção integral (as unidades de conservação de proteção integral analisadas aqui, a efetividade de gestão das UCs do Programa Arpa foi 58\% e das demais unidades da Amazônia, 41\%) e de 10\% para as UCs de uso sustentável - UCs do Arpa de uso sustentável foi de 55\% sendo que para as demais unidades da Amazônia foi de 43\% (WWF-Brasil, 2012).

\footnotetext{
${ }^{89}$ BANCO MUNDIAL, 2002 e FUNBIO/MOP, 2005.
} 
Como é característico das PAMEs, o resultado da aplicação do Rappam na Fase I consegue demonstrar que a eficácia de gestão das UCs apoiadas pelo Arpa aumentou de 2005 a 2010, e que as UCs apoiadas pelo Arpa possuem um índice de efetividade maior que aquelas não apoiadas pelo Arpa, considerando as mesmas categorias de apoio do Programa. Segundo a premissa das PAMEs, uma boa eficácia de gestão pressupõe que as UCs apoiadas pelo Arpa contribuem mais para a conservação da biodiversidade que as não apoiadas pelo Arpa. Mas, na Fase I, não fazia parte do desenho do sistema de gerenciamento desenvolvido pelo Arpa (SISArpa) as informações relacionadas ao monitoramento e avaliação da biodiversidade ou mesmo uma sugestão de integração entre estas e as informações sobre a performance de gestão das UCs.

O monitoramento da biodiversidade, que na estratégia inicial do Programa tinha caráter piloto e experimental, mas que estava vinculada a avaliação da efetividade de gestão, pois considerara com fundamental o levantamento das informações que demonstravam o impacto positivo da gestão na conservação da biodiversidade ${ }^{90}$, passou a época da implementação a ter desafios maiores e independentes da avaliação de efetividade. O MOP da Fase I passa a ter metas que não configuram o sistema piloto, mas sim um sistema em nível regional, eram elas:

- Estabelecer um sistema de monitoramento e avaliação da biodiversidade nos níveis regional e das UCs - que significava o desenvolvimento de protocolos ${ }^{91}$ baseados em um programa do início dos anos 1990 chamado Sistema de Monitoramento Ambiental para Unidades de Conservação - SIMBIO;

- Implementar a metodologia de monitoramento e avaliação da biodiversidade em cinco UCs existentes;

- Realizar a capacitação e treinamento para aplicação da metodologia de avaliação e monitoramento da biodiversidade, bem como desenvolver e disseminar os manuais para aplicação da metodologia (FUNBIO/MOP, 2005).

\footnotetext{
${ }^{90}$ Informações sobre o estado da biodiversidade (grupos de indicadores-chave), as pressões e ameaças aos ecossistemas (níveis de ameaça), os recursos hídricos e o clima, sobre o efeito de ilha (níveis de conectividade), sobre a eficácia de gestão, além de informações sobre o uso e ocupação do solo (desmatamento, construção de estradas, crescimento urbano, assentamento e atividades agrícolas ou pecuárias) dentro e no entorno das UC

${ }^{91}$ A ideia era desenvolver protocolos que permitissem a comparação de dados em um amplo espectro de UCs.
} 
Durante toda a Fase I, foi empreendido um grande esforço na definição das atividades e parcerias para o alcance das metas estabelecidas no MOP, mas essas definições se restringiram apenas à coleta de dados, sem explicitar métodos de armazenamento, de análise dos dados e, principalmente, sem estabelecer como essas informações poderão ser usadas para melhorar a gestão das áreas protegidas e avaliar o sucesso do programa em promover a persistência da biodiversidade nas áreas apoiadas pelo Arpa. Nenhum sistema replicável de monitoramento foi desenvolvido na Fase I. Mas foram desenvolvidos protocolos para a padronização de dados entre as UCs; realizados trabalhos de campo em seis UCs ${ }^{92}$; instaladas algumas estações de monitoramento para coleta de dados; e realizados cursos de monitoramento para padronizar os métodos de pesquisa. Tal esforço teve como resultado poucos dados disponíveis e comparáveis, não permitindo que estes ajudassem na avaliação da biodiversidade, auxiliassem nas ações de tomada de decisão do Programa ou se configurasse um sistema de avaliação aplicável em termos de escala, tempo e custos para as UCs apoiadas pelo Arpa. Não foi gerado, no âmbito desta iniciativa, relatórios que respondesse sobre as prioridades de gestão ou prioridades ou sobre situação de pressão e ameaças nas UCs. Dados secundários ou informações oriundas do sensoriamento remoto também não foram compiladas ou sugeridas uma estratégia de parceria para o monitoramento, compilação e análise desses dados (WILES, 2006 e BATH, 2009).

A ampliação do escopo das ações chaves e o contexto de implementação da Fase I do Programa ajudam a justificar o baixo desempenho e o pouco avanço no tema monitoramento da biodiversidade, a citar:

- Mudança de expectativa e escala ao trocar a implementação de um sistema piloto para criar um sistema de M\&A que com a finalidade de atuar em todo SNUC;

- Desvinculação da implantação do Componente 4 (Monitoramento de UCs) da Unidade de Coordenação do Projeto/UCP, sugerindo a instituição de uma Unidade de Monitoramento e Avaliação/UMA. Esta UMA que seria também responsável por monitorar e avaliar o projeto tecnicamente, nunca existiu na estrutura do programa, mas de certa forma suas responsabilidades foram assumidas no âmbito do SIMBIO;

\footnotetext{
92 PARNA da Serra do Divisor, PARNA do Jaú, ESEC Maracá, REBIO do Jaru e REBIO do Rio Trombetas; e uma de Uso Sustentável - RESEX do Lago Capanã Grande.
} 
- Reestruturação do IBAMA para criar o ICMBio em 2007 teve um grande impacto sobre as atividades realizadas por este executor, seja a implementação do Componente de Monitoramento da Biodiversidade, seja na implementação das ações de estabelecimento e consolidação de UC. As ações de criação de UC seguiram sem maiores problemas, pois esta agenda foi durante um tempo assumida equivocadamente pela Secretaria de Biodiversidade e Florestas;

- Ausência de uma discussão mais conceitual sobre os indicadores do monitoramento, pois os indicadores propostos pelo SIMBIO apresentaram um requerimento exagerado de dados de campo $^{93}$, que resultava em uma implementação cara, cuja utilidade para o Programa não era muito clara;

- Dificuldade na implementação efetiva do Painel Científico de Acompanhamento (PCA), que poderia ter um importante papel na estruturação de um programa de monitoramento mais objetivo e com maior integração entre seus componentes;

- Dificuldade no estabelecimento de parcerias com a comunidade científica.

Mas, um forte indicador do sucesso do Arpa em relação à conservação da biodiversidade em escalas maiores na Fase I foi à constatação de que as UCs apoiadas pelo Programa ajudaram para reduzir o desmatamento no bioma Amazônia. A análise das series anuais de desmatamento foi usada como uma proxy de conservação da biodiversidade que refletia o sucesso do programa na manutenção da integridade dos hábitats no interior das UCs apoiadas por ele, corroborando a afirmação de NaughtonTreves et al (2005) de que a floresta intacta é um importante sinal de que as UCs estão mostrando resultados. Avaliações realizadas, ao final da Fase I do Programa, por parceiros e pela academia sinalizaram a eficiência das UCs apoiadas pelo Arpa no combate ao desmatamento. O WWF-Brasil et al (2012) em uma análise preliminar sobre o desmatamento dentro das UCs apoiadas e não apoiadas pelo Arpa, apontou que de forma geral, as UCs integrantes do Arpa foram menos afetadas pelo desmatamento do que o conjunto daquelas que não recebem o apoio do Programa. Soares Filho et al (2008) ao

93 Os indicadores de biodiversidade selecionados para iniciar um protocolo mínimo de monitoramento foram peixes, répteis, anfíbios, aves, mamíferos, lepidópteras, himenópteras, estrutura da vegetação. Indicadores específicos como espécies exploradas para comércio, subsistência ou extrativismo, assim como espécies ameaçadas de extinção e invasoras serão inseridos de acordo com as particularidades da unidade (Roseli et al, 2013). 
estudar o papel das áreas protegidas ${ }^{94}$ do bioma Amazônia, com ênfase nas áreas apoiadas pelo programa Arpa, na redução do desmatamento concluiu que que as áreas protegidas são, de fato, inibidoras do desmatamento, e que as áreas de proteção integral apoiadas pelo Arpa se mostram significativamente mais refratárias ao desmatamento do que as não apoiadas pelo Arpa, sendo necessária uma análise mais detalhada para identificar quais fatores locais contribuíram para a redução do desmatamento em função do apoio do Arpa. Embora coubesse ao SIMBIO apresentar uma proposta para o monitoramento da paisagem, nenhum dos resultados apresentados contou com a colaboração do SIMBIO.

Se o papel das unidades de conservação como barreira ao desmatamento da Amazônia é consenso entre alguns pesquisadores, os aspectos da gestão ou governabilidade relacionados a esta barreira visível (desmatamento ou a integridade da paisagem) ainda intrigam. Estudos que buscavam explicar a relação entre o sucesso no esforço de combate ao desmatamento e a efetividade de gestão das UCs apontaram para baixa relação entre os indicadores de gestão. O estudo realizado por Nolte et al (2013a) destaca a relação significativa de um de gestão do Rappam (o indicador de contexto sobre a situação fundiária), como possível elemento que explique o sucesso no combate ao desmatamento. A análise de Nolte et al apontou que a ausência de conflitos e de regularização fundiária das UC é fortemente associada ao sucesso em reduzir as pressões de desmatamento, pois a ausência de regularização e solução de conflitos podem mascarar as relações mais sutis entre os indicadores de gestão e resultados de conservação, não evidenciando como aspectos do planejamento e insumos influenciam na redução do desmatamento. Aspectos estes que que eram o foco das avaliações de efetividade implementadas pelo Programa Arpa na sua primeira fase.

Outro aspecto importante, mas pouco explorado, sobretudo nos estudos de Nolte et al (2013a, 2013b e 2013c) é o desmatamento em relação as categorias de manejo, que no caso das UCs apoiadas pelo Arpa se restringem as categorias Parque, REBIO, Estação Ecológica, RESEX e RDS, já que as RESEX e as RDS permitem atividades extrativistas que podem afetar a integridade da paisagem. Naughton-Treves et al (2005) já alertava que embora a floresta intacta fosse um importante sinal de que as UCs estão cumprindo para conservação, evitar o desmatamento não é o bastante, pois a biodiversidade pode ser

\footnotetext{
${ }^{94}$ Neste estudo foram consideradas como áreas protegidas tanto as unidades de conservação quanto as terras indígenas e áreas militares.
} 
seriamente comprometida com ameaças invisíveis. Marchand (2014) destaca que apesar das dinâmicas de desflorestamento estarem cada vez mais conhecidas na Amazônia brasileira, seja pela ampla série de dados a respeito do desmatamento anuais (sistema PRODES), detecções em quase tempo real (sistema DETER) e, na região do arco do desmatamento, pela análise do estágio da vegetação derrubada (sistema DEGRAD), o que está acontecendo em baixo do dossel arbóreo é objeto de várias controversas científicas.

Mas ao longo da Fase I do Arpa foram poucos os exemplos ou as iniciativas para verificar o que estava acontecendo sob o dossel arbóreo. Podemos afirmar que a estratégia de monitoramento e avaliação do Programa na Fase I dividia-se em duas dimensões (gestão e biodiversidade) e três esferas (projeto, sistema e UC), como mostra o Quadro 25.

Quadro 25 - Dimensões de monitoramento do Programa Arpa na Fase I

\begin{tabular}{|c||l||}
\hline \multicolumn{1}{|c||}{ DIMENSÕES } & \multicolumn{1}{c|}{ ESFERA } \\
\hline \hline \multirow{2}{*}{ GESTÃO } & $\begin{array}{l}\text { Projeto - onde foi possível monitorar e avaliar o cumprimento das } \\
\text { metas e mecanismos de implementação previstos no contrato de } \\
\text { doação entre o governo Brasileiro e o GEF (por meio da sua } \\
\text { agência executora o Banco Mundial) e o KFW }\end{array}$ \\
\cline { 2 - 2 } & $\begin{array}{l}\text { UCs apoiadas - onde foi possível avaliar a performance de cada } \\
\text { UC em relação a sua instrumentalização para gestão }\end{array}$ \\
\hline \hline \multirow{2}{*}{$\begin{array}{c}\text { CONSERVAÇÃO DA } \\
\text { BIODIVERSIDADE }\end{array}$} & $\begin{array}{l}\text { Sistema de UC - onde foi possível avaliar o sucesso do conjunto de } \\
\text { UCs apoiadas pelo Arpa em relação as demais UCs localizadas no } \\
\text { bioma Amazônia em relação a redução do desmatamento }\end{array}$ \\
\hline \hline
\end{tabular}

Em relação a dimensão de gestão é certo avaliar que a estratégia adotada e seus resultados estão longe de informar a efetividade de gestão das UCs apoiadas pelo Arpa nenhum indicador de impacto foi compilado pela FAUC. A ausência de uma estratégia adequada para a dimensão conservação da biodiversidade, fez com que os documentos de avaliação do Programa apontassem para a necessidade de uma Fase II com um programa de monitoramento detalhado, que destacasse os principais conceitos envolvidos no monitoramento da biodiversidade e possibilitasse demonstrar:

- A eficiência das UCs em proteger parcelas representativas da biodiversidade no âmbito da paisagem e de espécies;

- A adequação do desenho das Unidades de Conservação (tamanho, forma, conectividade); 
- As principais ameaças à integridade das UCs e a situação das UCs do Programa frente a essas ameaças;

- A sustentabilidade do uso dos recursos biológicos nas UCs de Uso Sustentável;

- O efeito das mudanças ecossistêmicas sobre o conjunto de UCs apoiadas pelo Programa (mudanças climáticas, hidrologia, poluição ${ }^{95}$ ).

O programa de monitoramento do Arpa deveria demonstrar clareza sobre as formas/meios ou instrumentos de armazenamento e análise das informações coletadas, incluindo o levantamento de possíveis parcerias para o tratamento das informações; e indicar como o monitoramento proposto poderá apoiar a gestão do Programa Arpa e das UCs na tomada de decisões e definição de prioridades de ações. Nelson et al (2006) já alertava que era importante para o Arpa avaliar as metas atingidas pelo Programa não apenas do ponto de vista quantitativo, mas em termos de seus avanços na representatividade do sistema de unidades de conservação na Amazônia, pois este tipo de avaliação permitiria que os esforços futuros priorizem as eventuais lacunas que permaneçam no atual sistema. Já a Fase seguinte, parece demonstrar um aprendizado em relação a avaliação do sucesso das UCs apoiadas pelo Arpa na conservação da biodiversidade e do uso sustentável dos recursos naturais.

\subsection{Fase II: 0 resgate das orientações iniciais para avaliação e monitoramento do Programa Arpa}

Dentre as atividades de preparação para o início da Fase II, a Unidade de Coordenação do Programa Arpa, a UCP, empreendeu no período de 2008 a 2010, um processo de construção e discussão do Documento de Programa do Governo Brasileiro (MMA/ARPA, 2010). Este documento, finalizado em 2010, subsidiou a elaboração do Manual Operacional do Arpa para a Fase II. O primeiro, traz como avanço uma abordagem de descrição do Programa Arpa que mescla a estrutura de projeto (onde objetivo geral do Programa Arpa é alcançado através da implementação integrada de quatro componentes durante a Fase $\mathrm{II}^{96}$ ) a um programa de governo - tentando definir as

\footnotetext{
${ }^{95}$ Essas mudanças, por se darem de forma mais lenta e ainda não serem perceptíveis, atualmente não têm sido consideradas como ameaças

${ }^{96}$ Componente 1. Criação de Unidades de Conservação; Componente 2. Consolidação e Gestão de Unidades de Conservação; Componente 3. Sustentabilidade Financeira; Componente 4. Monitoramento, Coordenação e Gerenciamento do programa
} 
estratégias que assegurem o alinhamento do Projeto aos princípios e à abordagem estratégica do Governo Federal para o Programa em relação às políticas para as UCs e outras áreas protegidas.

Do ponto de vista de estrutura de projeto o monitoramento e avaliação do Arpa previsto na Fase I, é tratado na Fase II também no âmbito de um Componente 4 que tem sua abrangência ampliada envolvendo além do Monitoramento, a Coordenação e Gerenciamento do programa. E que para isso foi dividido em dois subcomponentes: Subcomponente 4.1.Monitoramento, Coordenação e Gerenciamento do Programa e Subcomponente 4.2. Gerenciamento Financeiro e Logístico do Arpa.

O subcomponente 4.1 passou a incorporar o monitoramento físico (nos níveis estratégicos, gerencial e operacional) e o monitoramento ambiental. A diferença de terminologia adotada nos documentos que orientavam a implementação da Fase I (PAD e MOP) é estendida aos objetivos e ações que envolvem cada uma dessas dimensões.

O monitoramento físico continuaria sob a coordenação da UCP nos diferentes níveis de planejamento e execução do Programa Arpa, mas contaria com o apoio de diferentes instrumentos: a Matriz Lógica do programa para atualização e acompanhamento dos indicadores definidos pelos doadores do Programa (nível estratégico); a Ferramenta de Avaliação da Efetividade para acompanhar a evolução do desempenho do Programa e das UCs por ele apoiadas em relação às metas estabelecidas nos planejamentos estratégicos plurianuais (nível gerencial); e o acompanhamento da execução dos planos operativos anuais (POAs), através dos sistemas de gerenciamento financeiro do programa (nível operacional).

No nível gerencial, a Fase II contou com mais uma adaptação ${ }^{97}$ na Ferramenta de Avaliação de Unidades de Conservação do Programa Arpa (FAUC) para incorporar a nova estrutura proposta para a segunda fase do Programa Arpa (que não mais trabalha com as etapas criação, estabelecimento e consolidação, e sim criação de UC, Consolidação Grau I e Grau II e Pós-Consolidação) e alinhar os seus indicadores aos de referenciais de excelência preconizados pelo Programa Nacional da Gestão Pública e Desburocratização - GesPública ${ }^{98}$ (MOPG/GESPUBLICA, 2008) aplicados as UCs que

\footnotetext{
${ }^{97}$ Realizada pela empresa NEXUCs (http://www.nexucs.com.br/)

${ }^{98}$ O GesPública, instituído pelo Decreto no 5.378, de 23 de fevereiro de 2005, que possui o status de política pública para a gestão de órgãos e entidades públicos é coordenado pela Secretaria de Gestão do Ministério do Planejamento, Orçamento e Gestão.
} 
participaram do Programa de Gestão para Resultados (PGR) na Fase I. Araujo e PintoCoelho (2004) e Araujo et al, (2009), já haviam proposto a utilização do Modelo de Excelência em Gestão Pública (MEGP) como uma ferramenta para avaliar a efetividade da gestão de unidades de conservação. E a demanda de adaptação da FAUC na Fase II, proposta pela Unidade de Coordenação do Arpa, colaborou para a tentativa de alinhamento do marco referencial da WCPA e do MEGP.

O MEGP avalia e analisa os sistemas de gestão das organizações públicas com base em critérios de excelência. Estes critérios agrupam requisitos necessários para se construir um sistema de gestão orientado para a obtenção de resultados excepcionais e os critérios de excelência estão alicerçados em um conjunto de princípios e fundamentos organizacionais que combinam a legalidade e a importância social do serviço público com a ênfase no desempenho e nos resultados da iniciativa privada. Desse modo, a avaliação com o apoio do MEGP tem como objetivo promover e disseminar os princípios e fundamentos que norteiam a formação de uma cultura organizacional orientada para a sociedade e para a busca de resultados. Os critérios de excelência que compõem o MEGP são: 1) liderança; 2) estratégias e planos; 3) cidadãos 4) sociedade; 5) informações e conhecimento; 6) gestão de pessoas; 7) gestão de processos; 8) resultados (GESPÚBLICA, 2008, MMA/ARPA, 2010).

As principais contribuições do MEGP à nova adaptação da FAUC foram a inclusão dos fundamentos de aprendizado organizacional da gestão pública (liderança, processo decisório e gestão do capital intelectual) e o seu impacto na efetividade da gestão das UCs, sob a premissa que as UCs com melhores desempenho serão aquelas que aprenderem mais e melhor como cumprir a sua missão. Este aspecto foi estruturalmente considerado na FAUC através da inclusão de mais um elemento de avaliação ao ciclo de avaliação proposto pela WCPA, o elemento de Reflexão e Aprendizado. Para tanto foram inseridas todas as questões do critério de melhoria das práticas de gestão. A questões e os cenários da FAUC foram novamente alterados. Os Quadros 26 e 27, mostra como ficou a alteração realizada na questão que reflete a performance da UC em relação aos MRs Formação do conselho gestor e Funcionamento do Conselho Gestor, já ilustrados nos Quadros 23 e 24. 
Quadro 26 - Questão 20 do FAUC/2010

\begin{tabular}{|c|c|c|}
\hline QUESTÃO & CENÁRIO DO INDICADOR & $\begin{array}{c}\text { PONTUAÇÃO } \\
(\%) \\
\end{array}$ \\
\hline \multirow{5}{*}{$\begin{array}{l}\text { A UC possui um } \\
\text { Conselho Gestor } \\
\text { oficialmente } \\
\text { constituído. }\end{array}$} & $\begin{array}{l}\text { A unidade não iniciou o processo de formação do } \\
\text { Conselho Gestor. }\end{array}$ & 0 \\
\hline & $\begin{array}{l}\text { A unidade identificou os potenciais atores para } \\
\text { constituírem o Conselho Gestor }\end{array}$ & 33 \\
\hline & $\begin{array}{l}\text { A unidade já promoveu a sensibilização dos } \\
\text { potenciais atores para constituírem o Conselho } \\
\text { Gestor. }\end{array}$ & \\
\hline & $\begin{array}{l}\text { A unidade já promoveu as reuniões para formação } \\
\text { do Conselho e as organizações envolvidas } \\
\text { indicaram os seus representantes. } \\
\end{array}$ & \\
\hline & $\begin{array}{l}\text { O Conselho foi formado e a sua existência } \\
\text { formalmente reconhecida através da publicação de } \\
\text { portaria pelo órgão gestor. }\end{array}$ & 100 \\
\hline Prática de Gestão & $\begin{array}{l}\text { A UC possui um Conselho Gestor formado } \\
\text { reconhecido (Portaria publicada). }\end{array}$ & e oficialmente \\
\hline Critério GESPUBLICA & Sociedade + Cidadãos & \\
\hline Elemento WCPA & Resultado & \\
\hline
\end{tabular}

Quadro 27 - Questão 21 do FAUC/2010

\begin{tabular}{|c|c|c|}
\hline QUESTÃO & CENÁRIO DO INDICADOR & $\begin{array}{c}\text { PONTUAÇÃO } \\
(\%)\end{array}$ \\
\hline \multirow{5}{*}{$\begin{array}{l}\text { A UC possui um } \\
\text { Conselho Gestor } \\
\text { funcionando } \\
\text { regularmente } \\
\text { contribuindo para sua } \\
\text { efetiva gestão. }\end{array}$} & O Conselho Gestor não possui regimento interno.. & 0 \\
\hline & O Conselho Gestor possui regimento interno. & 33 \\
\hline & $\begin{array}{l}\text { O Conselho Gestor passou por um processo de } \\
\text { capacitação.. }\end{array}$ & \\
\hline & $\begin{array}{l}\text { O Conselho Gestor da unidade se reúne } \\
\text { regularmente de acordo com seu regimento interno }\end{array}$ & \\
\hline & $\begin{array}{l}\text { Conselho Gestor contribui de forma efetiva com a } \\
\text { gestão da unidade. }\end{array}$ & 100 \\
\hline Prática de Gestão & \multicolumn{2}{|c|}{$\begin{array}{l}\text { UC possui um Conselho Gestor formado e oficialmente reconhecido, } \\
\text { que se reúne regularmente (atas das reuniões ordinárias e } \\
\text { extraordinárias) e atua de contribuindo com a melhoria do } \\
\text { desempenho da unidade (participa da definição das estratégias, } \\
\text { possui grupos de trabalho atuantes, toma conhecimento elou } \\
\text { participa do planejamento (POA) da UC, etc.). }\end{array}$} \\
\hline Critério GESPUBLICA & \multicolumn{2}{|c|}{ Sociedade + Cidadãos } \\
\hline Elemento WCPA & \multicolumn{2}{|l|}{ Resultado } \\
\hline
\end{tabular}

A aplicação da FAUC/2010 passa a ter um calendário de aplicação semestral com uma alternância de finalidade e formulário: FAUC AVANÇO, onde são compartilhadas apenas as questões que correspondem ao elemento de avaliação Resultado da WCPA e correspondem a verificação da performance dos MRs e FAUC EFETIVIDADE que tem a finalidade de avaliar e eficácia de gestão da UC e do conjunto de UCs apoiadas pelo Arpa. A UCP é responsável pelo instrumento, calendário e pela 
orientação de aplicação, e os OGs são responsáveis pela validação da FAUC das UCs sob sua responsabilidade.

Embora tenha sido um ganho alinhar as iniciativas de monitoramento da performance gerencial das UCs apoiadas pelo Arpa, a nova adaptação não conseguiu manter a correspondência da FAUC com o TT mundial. As questões que correspondiam ao elemento de avaliação foram retiradas, e tão pouco conseguiu avançar na avaliação do impacto da gestão sobre a conservação da biodiversidade.

O monitoramento ambiental que abrange o monitoramento da biodiversidade nas UCs apoiadas passa a ser coordenado pela UCP e não mais pelo ICMBio e deveria ser implementado sob a responsabilidade dos órgãos executores e as respectivas equipes de suas UCs, objetivando avaliar a efetividade dos esforços empreendidos pelo programa em relação de assegurar a conservação de uma amostra representativa da biodiversidade da região e contribuir para o seu desenvolvimento sustentável. O Documento de governo propõe que as ações de monitoramento deveriam ser implementadas prioritariamente nas unidades de conservação em grau avançado de consolidação (Grau II $^{99}$ ) e de acordo com a disponibilidade de recursos indicados pela Estratégia de Conservação e Investimento, e nos temas biodiversidade, paisagem, clima e socioambiental (ver detalhamento no quadro 28 abaixo). A operacionalização dos monitoramentos in situ propostos seria realizada com os recursos financeiros destinados a consolidação e Gestão das UCs apoiadas pelo Arpa por meio de seus Planos Operacionais Anuais (POAs). Ao componente 4 cabia arcar com os recursos para a gestão do subcomponente e para os demais monitoramentos.

Quadro 28 - -Dimensões de monitoramento do Programa Arpa na Fase II

\begin{tabular}{|c|c|}
\hline TEMAS & AÇÕES \\
\hline BIODIVERSIDADE & $\begin{array}{l}\text { Monitoramento in situ de uma amostra de unidades de conservação } \\
\text { apoiadas a partir dos critérios de priorização do programa e da análise } \\
\text { da paisagem, envolvendo: } \\
\text { - Grupos estratégicos para permitir uma análise sistêmica: } \\
\text { ○ Biomassa e estrutura de vegetação; } \\
\text { ○ Mamíferos de médio e grande porte; } \\
\bigcirc \text { Peixes de igarapés e riachos; e } \\
\text { ○ Anfíbios. } \\
\text { - Grupos específicos para as unidades de conservação monitoradas, } \\
\text { com foco nas suas prioridades de conservação (recursos hídricos, } \\
\text { espécies ameaçadas, espécies motivadoras da criação da unidade } \\
\text { de conservação, etc.). }\end{array}$ \\
\hline
\end{tabular}

\footnotetext{
${ }^{99}$ Terminologia utilizada para classificar o grau de apoio/nível de apoio a consolidação de UCs, como destacado no capitulo 2 desta tese)
} 


\begin{tabular}{|c||l||}
\hline PAISAGEM & $\begin{array}{l}\text { Análise das pressões e representatividade ecossistêmica de todo o } \\
\text { conjunto de unidades de conservação apoiadas }\end{array}$ \\
\hline \hline CLIMA & $\begin{array}{l}\text { Organização das informações de parâmetros climatológicos do INPE, } \\
\text { INMET, SIPAM e ANA para as estações localizadas no interior ou no } \\
\text { entorno de unidades e identificação da necessidade de expansão da } \\
\text { cobertura de dados para permitir a análise e acompanhamento das } \\
\text { ameaças de mudanças climáticas }\end{array}$ \\
\hline \hline SOCIOAMBIENTAL & $\begin{array}{l}\text { Utilização de um conjunto de indicadores pré-definidos para } \\
\text { acompanhar o uso de recursos, aspectos sócio-econômicos, culturais } \\
\text { e as vivências comunitárias nas unidades de conservação que são } \\
\text { monitoradas in situ }\end{array}$ \\
\hline
\end{tabular}

Fonte: MMA/ARPA (2010)

O documento de governo que começou a ser redigido em 2008, passou por um processo de consulta pública, sendo aprovado pelo CP em 2010, foi contemporâneo a iniciativas importantes para o fortalecimento das ações de conservação da biodiversidade por meio de UCs no âmbito do Ministério do Meio Ambiente, como o início da discussão para a elaboração da Estratégia Nacional de Monitoramento da Biodiversidade, cujo objetivo seria possibilitar a produção, integração e disponibilização de informações, essenciais para a gestão ambiental e tomada de decisão política nacional, principalmente nos processos que envolvem: Monitorar e avaliar o estado da biodiversidade e a sustentabilidade de seu uso frente aos impactos e mudanças ambientais, assim como avaliar se as medidas que estão sendo tomadas para reduzir a sua perda têm sido efetivas; e Avaliar o cumprimento de metas e acordos Internacionais, particularmente as metas da $\mathrm{CDB}$, relativas à redução da perda da biodiversidade, e cujos resultados já abordamos no início deste capítulo. Na fase II também foi construído um documento Diretrizes Operacionais para o Monitoramento in situ da Biodiversidade em Unidades de Conservação (MMA, 2010) onde a questão chave para o Programa de Monitoramento da Biodiversidade é saber como está à biodiversidade no nível de unidade de conservação, de ecossistemas (bioma) e de espécies. Esse documento traz as informações técnicas sobre a estrutura e implementação do Monitoramento Ambiental, no âmbito da segunda fase do Arpa, sugerindo uma rede de monitoramento da biodiversidade in situ nas UCs, deverá contar com uma ampla gama de parceiros. Os principais pontos desta rede serão responsáveis por tarefas determinadas e mobilização de outros parceiros, ou pontos da rede, para alcançar o cumprimento das tarefas e prazos estabelecidos. Durante a 
implementação da Fase II outra parceria estabelecida entre o ICMBIo e o MMA, no contexto da cooperação Brasil-Alemanha para o Desenvolvimento Sustentável, no âmbito da Iniciativa Internacional de Proteção ao Clima (IKI) do Ministério Federal do Meio Ambiente, Proteção da Natureza, Construção e Segurança Nuclear (BMU) da República Federal da Alemanha - a implementação do projeto "Monitoramento da biodiversidade relevante para o clima em nível de áreas protegidas tomando em conta medidas de mitigação e adaptação", cujo objetivo era a implementação do monitoramento da biodiversidade nas UCs no Brasil, de forma coordenada, fornecendo dados que são relevantes para a proteção do clima.

O resultado dessas iniciativas e as reflexões que a implementação das mesmas possa agregar ao monitoramento ambiental no Programa Arpa ainda não é conhecido. Com a prorrogação da Fase II até 2017, as avaliações realizadas se limitam ao monitoramento físico, no âmbito das atividades estratégicas e gerenciais.

\subsection{Fase III: Avaliação da Gestão e Impacto do impacto de conservação das UCs apoiadas pelo Programa Arpa}

Mesmo elaborada sem uma reflexão sobre os resultados da Fase II, a Fase III traz avanços em relação às recomendações para o monitoramento do Programa. O MOP para Fase III, elaborado com a colaboração dos parceiros vinculados a iniciativa "Compromisso com a Amazônia - Arpa para Vida" define o monitoramento como um processo contínuo, cujo esforço de coleta, organização e sistematização das informações (abrangência e dimensões monitoradas) serão objetos de revisão e complementação no longo prazo. No novo MOP o monitoramento deixa de ser um componente, com metas ou ações chaves e passa a ser um dos processos/meios para garantir a consolidação de 60 milhões de hectares sob a forma de proteção de UCs e passa a ter dois níveis de abrangência do Programa Arpa e das UCs e três dimensões: financeira, de gestão e de impacto na conservação/benefícios socioeconômicos.

A iniciativa "Compromisso com a Amazônia - Arpa para Vida" cujo objetivo era discutir e propor um processo único de captação para garantir o aporte de recursos financeiros necessários ao funcionamento do Programa Áreas Protegidas da Amazônia de forma a assegurar a manutenção no longo prazo e a proteção da biodiversidade e dos serviços ambientais da maior floresta tropical do mundo para a posteridade, representando 15\% da Amazônia Brasileira ou 60 milhões de hectares, foi lançada em 2012, durante a Rio+20 e posteriormente formalizada por meio do Memorando de Entendimentos (MOU) 
assinado pelo MMA, por representantes de parceiros e doadores do Programa Arpa, como: o ICMBio; o Ministério para a Cooperação e Desenvolvimento Alemão (BMZ); o Banco Interamericano de Desenvolvimento(BID); o Fundo Brasileiro para a Biodiversidade (Funbio); a Fundação Gordon e Betty Moore; o WWF-Brasil; o WWFUS; e o Global Environment Facility (GEF) no dia 21 de maio de 2014, em Brasília, DF. O desdobramento dessa iniciativa culminou na portaria de lançamento da Fase III. Portaria MMA nº 187 de 22 de maio de 2014, e do Decreto no 8.505, de 20 de agosto de 2015 (Anexo 4).

A Dimensão Financeira é o acompanhamento da projeção da necessidade e disponibilidade de recursos, alocação e execução dos recursos (recursos previstos versus recursos executados) provenientes dos doadores, orçamento público e outras fontes. As formas de acompanhamento (coleta e sistematização das informações) devem considerar os sistemas e/ou ferramentas atuais, bem como a sua necessidade de adequação no longo prazo. E os responsáveis pelo monitoramento são GF, OGs e UCP/MMA. Esse processo deverá ser coordenado pela UCP/MMA em articulação com os órgãos gestores de UCs e com o Gestor do Fundo de Transição (ver arranjo organizacional do Programa Arpa Figura 1).

A dimensão de Gestão foi concebida de forma a subsidiar o acompanhamento analítico e gerencial do Programa Arpa e permitir a verificação da efetividade do Programa Arpa, vis a vis a efetividade das Unidades de Conservação e do alcance dos objetivos estabelecidos, apoiando a tomada de decisão e orientando o manejo adaptativo. Esta dimensão deve identificar a distância entre a gestão desejada e o status atual, seja para a unidade ou para o sistema do qual ela faz parte. As ferramentas básicas de monitoramento para esta dimensão são: FAUC e Rappam.

A FAUC é a mesma ferramenta utilizada na Fase II, mas o próprio MOP recomenda a manutenção da aplicação apenas do Módulo Avanço (aquele que avaliação o status dos Marcos referencias de avanço em cada um dos graus de consolidação), sendo esta a principal ferramenta para acompanhar o desempenho do Programa Arpa e das UCs por ele apoiadas em relação às metas, aos marcos referencias estabelecidos nos planejamentos estratégicos plurianuais e aos Planos de Consolidação abrange a dimensão de Gestão. A efetividade de gestão no Programa será acompanhada anualmente pela ferramenta de monitoramento da gestão desenvolvida pelo ICMBio, a SAMGE e de 5 em 5 anos por meio do resultado da aplicação do RAPPAM. E é a primeira vez que o Rappam aparece oficialmente descrito nos documentos do Programa Arpa como ferramenta de 
avaliação da efetividade do Programa Arpa. Além de definir o uso de novas ferramentas, o Programa Arpa define por efetividade o alcance dos objetivos das UCs e do Sistema Nacional de Unidades de Conservação - SNUC, e também recomenda que a efetividade seja aferida por meio da análise integrada das informações providas pelo monitoramento de três dimensões: financeira, de gestão e de impacto na conservação/benefícios socioeconômicos e nos dois níveis de abrangência do Programa Arpa e das UCs., adotando as recomendações de Hockings et al (2009 e 2010) que também sugere a realização de avaliações conjuntas e recomenda que as avaliações de efetividade devam ser realizadas considerando-se os objetivos de criação de cada área protegida e considerando-se, sobretudo, as restrições em função das suas diferentes categorias.

A terceira dimensão de monitoramento sugerida na Fase III é a dimensão de Impacto de Conservação e Benefícios Socioeconômicos que tem por finalidade avaliar os impactos dos esforços empreendidos pelo Programa Arpa, com respeito aos seus objetivos de conservação, abrangendo a biodiversidade, os serviços ecossistêmicos, a sustentabilidade no uso dos recursos naturais e os benefícios socioeconômicos, no intuito de orientar o manejo adaptativo da gestão do Programa Arpa e das UCs. Essa dimensão se subdivide em: Monitoramento da Conservação da Biodiversidade e Monitoramento dos benefícios Socioeconômicos.

O Monitoramento da Conservação da Biodiversidade tem a finalidade de: verificar o alcance dos objetivos de conservação da biodiversidade, sustentabilidade do uso dos recursos naturais e da manutenção dos serviços ecossistêmicos nos níveis do Programa Arpa e das UCs apoiadas por ele; e prover informações para a melhoria da gestão da biodiversidade e manejo de recursos naturais das UCs. As ferramentas de acompanhamento (coleta e sistematização das informações) devem considerar os sistemas disponíveis, a citar: Prodes, TerraClass, Avaliação das Áreas Prioritárias, SisBio e protocolos de monitoramento específicos ou outros que venham a substituí-los ou aprimorá-los. Já o monitoramento do uso de recursos naturais, principalmente nas UCs de usos sustentável, deverá ser implementado por meio de protocolo a ser desenvolvido por cada OG de acordo com as necessidades e objetivos da gestão e uso de recursos nas UCs, e submetido para aprovação do Programa Arpa - esses protocolos devem ser implementados a título de contrapartida. Para o monitoramento da biodiversidade na $\mathrm{s}$ UCs de Grau II deverão ser utilizados os protocolos aprovados pelo Programa Arpa. Protocolos adicionais de monitoramento da biodiversidade ou uso de recursos naturais 
podem ser custeados com apoio pelo Programa Arpa desde que seja garantida a implementação dos protocolos oficiais. O Programa Arpa deverá avaliar e adotar protocolos básicos de monitoramento da biodiversidade, que deverão ser implementados de acordo com a descrição contida nos componentes do Programa.

O Monitoramento dos benefícios Socioeconômicos tem a finalidade de verificar o alcance dos benefícios socioeconômicos e a contribuição para o bem-estar da população associada direta ou indiretamente às UCs. Segundo o MMA/MOP (2015) o Programa Arpa deverá avaliar e adotar protocolos básicos de monitoramento dos benefícios socioeconômicos. Os aspectos monitorados e as formas de acompanhamento devem considerar as iniciativas já existentes que contemplaram os seguintes aspectos:

- Monitoramento do aspecto distributivo dos benefícios locais gerados pelos gastos nas UCs e dos recursos alocados por instituições parceiras à gestão das UCs;

- Monitoramento da renda advinda de atividades produtivas de comunidades; e

- Monitoramento de benefícios diretos e indiretos das UCs como: participação social, segurança alimentar, saúde, segurança territorial, conflitos e postos de trabalho e serviços ecossistêmicos.

Quadro 29 -- -Dimensões de monitoramento do Programa Rapa na Fase III

\begin{tabular}{||c||l||}
\hline \multicolumn{1}{||c||}{ TEMAS } & \multicolumn{1}{|c|}{ AÇÕES } \\
\hline \hline \multirow{2}{*}{ FINANCEIRA } & $\begin{array}{l}\text { Avaliação e monitoramento da execução financeira } \\
\text { Monitoramento do aporte de recursos, investimentos e aplicações }\end{array}$ \\
\hline \hline \multirow{3}{*}{ GESTÃO } & $\begin{array}{l}\text { Avaliação da performance ou progresso dos marcos } \\
\text { referenciais/FAUC, } \\
\text { Acompanhamento do plano de consolidação (PEP), } \\
\text { Avaliação da efetividade de gestão: FAUC/RAPPAM/SAMGe }\end{array}$ \\
\hline \hline \multirow{3}{*}{ IMPACTO } & $\begin{array}{l}\text { Conservação da Biodiversidade } \\
\text { Integridade da paisagem, representatividade, degradação e uso do solo, } \\
\text { biodiversidade e uso do recurso }\end{array}$ \\
\cline { 2 - 3 } & $\begin{array}{l}\text { Benefícios Socioeconômicos } \\
\text { Benefícios locais gerados pelos gastos nas UCs } \\
\text { Recursos alocados pelas parceiras na gestão } \\
\text { Benefícios Sociais }\end{array}$ \\
\hline
\end{tabular}

Fonte: MMA/ARPA, 2015

Neste contexto, alguns estudos foram realizados concomitante a discussão da Fase III, sob a coordenação do WWF-Brasil e com o apoio da Fundação Betty e Gordon Moore e da Fundação Margaret A. Cargill, como forma de subsidiar a definição de indicadores de sucesso das ações apoiadas pelo Programa para a dimensão de 
monitoramento do impacto na Conservação e dos Benefícios socioeconômicos proposta pelo MOP-Fase III (Quadro 30).

Quadro 30 - Estudos nas dimensões do impacto na Conservação e dos Benefícios
socioeconômicos do Programa Arpa
\begin{tabular}{|c|c||}
\hline DIMENSÃO DE & ESTUDOS E INICIATIVAS REALIZADAS \\
IMPACTO PREVISTA & Cobertura e uso do solo nas UCs do Bioma Amazônia \\
PARA FASE III & Situação do uso do solo em áreas alagáveis \\
\hline Conservação & $\begin{array}{c}\text { Impacto dos gastos das unidades de conservação do } \\
\text { Programa ARPA na economia local }\end{array}$ \\
\hline \hline & Benefícios Sociais das UCs do Programa Arpa \\
\hline
\end{tabular}

O estudo sobre a Cobertura e Uso do Solo nas UCs do Bioma Amazônia considerou a avaliação do uso do solo no interior e entorno das áreas protegidas para os períodos de 2002-2008 e 2008-2010. Os dados sobre a mudança da cobertura vegetal foram coordenados pelo Laboratório de Ecologia da Paisagem do WWF-Brasil (LEP) e agregam informações que qualificam o desmatamento em cada UC e no seu entorno. Os dados utilizados são originários do mapeamento TerraClass ${ }^{100} 2008$ e 2010. Com estes dados é possível fazer uma avaliação da dinâmica do uso e ocupação das áreas desflorestadas, possibilitando a comparação entre o mapeamento TerraClass 2008 e o TerraClass 2010. Os dados disponíveis são: a identificação das classes de uso (Terraclass e Prodes) para as UCs e seu entorno; a ocupação fundiária nesse entorno de $10 \mathrm{~km}$. Sendo as classes de uso identificadas no Terraclass e Prodes: (i) Terras Indígenas; (ii) UCs de Proteção Integral; (iii) UCs de Uso Sustentável; (iv) Assentamentos ; (v) APA; Glebas Federais.

O estudo sobre $O$ Uso do solo em Áreas Alagáveis também foi coordenados pelo Laboratório de Ecologia da Paisagem do WWF-Brasil (LEP) teve a finalidade de identificar áreas sazonalmente alagáveis em unidades de conservação da Amazônia e seu entorno $(10 \mathrm{Km})$ de acordo com a base produzida pelo projeto LBA; identificar remanescentes de vegetação natural e desmatamento dentro dos limites das áreas sazonalmente alagáveis nas UCs da Amazônia e seu entorno; identificar aproveitamentos hidrelétricos existentes ou planejados que tenham potencial de interferir nos pulsos

\footnotetext{
${ }^{100} \mathrm{O}$ projeto Terraclass - executado pelo Instituto Nacional de Pesquisas Espaciais - Centro Regional da Amazônia (INPE/CRA), pela Embrapa Amazônia Oriental (CPATU), e pela Embrapa Informática Agropecuária (CNPTIA) - tem por objetivo qualificar o desflorestamento da Amazônia legal, tendo por base as áreas desflorestadas mapeadas e publicadas pelo Projeto PRODES (Monitoramento da Floresta Amazônica Brasileira por Satélite).
} 
naturais de inundação das áreas sazonalmente alagáveis dentro de Unidades de Conservação da Amazônia.

O estudo sobre o Impacto dos gastos das unidades de conservação do Programa Arpa na economia local, coordenado pelo Programa Amazônia do WWF-Brasil, foi realizado como uma forma de subsidiar o processo de discussão de indicadores e de definição um sistema de monitoramento dos gastos locais e dos recursos alocados por parceiras na gestão das UCs. A intenção por traz desta proposta era avaliar o impacto da implementação do Programa (ações de criação. Consolidação e manutenção) nas populações diretamente envolvidas com a gestão das UCs, com especial relevância para as populações locais, e como esses impactos se relacionam com outras atividades econômicas desenvolvidas localmente.

O estudo sobre os Benefícios Sociais das UCs do Programa Arpa, também realizado sob a coordenação do WWF-Brasil, tinha uma menor preocupação em propor uma metodologia especifica de avaliação, mas sim identificar as possíveis contribuições da gestão de unidades de conservação (criação e implementação) para o alcance ou manutenção dos direitos sociais para as populações residente e/ou do entorno dessas áreas. Para essa avaliação levou-se em consideração o marco conceitual de duas metodologias: PA-BAT (Dudley e Stolton, 2009) e a Ocean Helth Index (Elfes et al, 2014). A partir delas foi identificado um conjunto de valores e beneficios convergentes com o que prevê a constituição Brasileira em relação aos direitos sociais, em seu Art. $6^{\circ}$ :

São direitos sociais a educação, a saúde, a alimentação, o trabalho, a moradia, o lazer, a segurança, a previdência social, a proteção à maternidade e à infância, a assistência aos desamparados, na forma desta Constituição.

Foram identificados 11 elementos-chave ou temas para investigação junto a representantes dos conselhos das UCs (Quadro 31). Para cada elemento e/ou tema foram identificadas 1 ou 2 perguntas para avaliar a situação do elemento em questão. Participaram do estudo o conjunto de 22 UCs federais do Bioma Amazônia representado por $64 \%$ de UC de Proteção Integral e $36 \%$ por Unidades de Uso Sustentável. Dentre as 22 UCs federais, 18 UCs são apoiadas pelo Programa Arpa. Três categorias de UCs de proteção integral foram investigadas (Parque Nacional, Reserva Biológica e Estação Ecológica), destacando-se a categoria Parque Nacional, que representou $78 \%$ do total das 
UCs de Proteção Integral. E apenas uma categoria de uso sustentável, Reserva Extrativista, foi investigada.

As perguntas foram respondidas por pelo menos 2 (dois) membros do conselho de cada UC: um representando a sociedade civil e outro representando a administração pública para cada UC). O contato com os conselheiros foi realizado por meio de diferentes meios de comunicação (ligação telefônica, correspondência eletrônica, e Skype) e os problemas encontrados para o estabelecimento de uma forma de comunicação para a realização do levantamento foram vários: ausência de sinal, ocupado, desligado ou fora área de cobertura, indisponibilidade para a entrevista, etc. Ao todo foram consultados 34 membros do Conselho de UCs: 16 (47\%) representantes da Sociedade civil e 18 (53\%) da administração pública.

Quadro 31 - Temas investigados no estudo sobre os Benefícios Sociais das UCs do Programa Arpa

\begin{tabular}{|c|c|}
\hline ELEMENTO & PROPÓSITO \\
\hline Contexto Humano & $\begin{array}{l}\text { Informações sobre a presença e densidade de populações residentes } \\
\text { dentro da UC e seu entorno, bem como a situação fundiária. }\end{array}$ \\
\hline $\begin{array}{r}\text { Contexto de Gestão } \\
\text { da UC }\end{array}$ & $\begin{array}{l}\text { Informações sobre os instrumentos de básicos de gestão da UC: plano de } \\
\text { manejo, conselho e insumos disponíveis. }\end{array}$ \\
\hline Qualidade de Vida & $\begin{array}{l}\text { Os indicadores deste elemento deram subsídios para avaliar qual o } \\
\text { impacto da criação e da implementação da UC na qualidade de vida das } \\
\text { pessoas que residem no interior e no entorno da unidade. }\end{array}$ \\
\hline $\begin{array}{l}\text { Segurança } \\
\text { Territorial }\end{array}$ & $\begin{array}{l}\text { Os indicadores (questões) deste elemento devem dar subsídios para } \\
\text { identificar o grau de permanência (direito de uso, moradia e utilização } \\
\text { dos recursos) das comunidades/famílias na área da UC. }\end{array}$ \\
\hline $\begin{array}{l}\text { Segurança } \\
\text { Alimentar }\end{array}$ & $\begin{array}{l}\text { Os indicadores (questões) deste elemento devem dar subsídios para } \\
\text { identificar o grau de dependência das comunidades/famílias, no que diz } \\
\text { respeito ao acesso a alimentos/recursos oriundos das UC. }\end{array}$ \\
\hline Saúde & $\begin{array}{l}\text { Os indicadores (questões) deste elemento devem dar subsídios para } \\
\text { identificar os benefícios da UC para a saúde }\end{array}$ \\
\hline $\begin{array}{r}\text { Educação e } \\
\text { Conhecimento } \\
\text { Tradicional }\end{array}$ & $\begin{array}{l}\text { Os indicadores (questões) deste elemento devem dar subsídios para } \\
\text { identificar se a UC auxilia como vetor de acesso a educação formal, ou } \\
\text { como promotora de ações de educação ambiental e/ou interpretação } \\
\text { ambiental. }\end{array}$ \\
\hline Postos de trabalho & $\begin{array}{l}\text { Os indicadores (questões) deste elemento devem dar subsídios para } \\
\text { identificar se a UC contribui para geração de postos de trabalho e renda. }\end{array}$ \\
\hline Lazer e Recreação & $\begin{array}{l}\text { Os indicadores (questões) deste elemento devem dar subsídios para } \\
\text { identificar se a UC é utilizada como espaço de recreação, lazer e turismo }\end{array}$ \\
\hline Segurança & $\begin{array}{l}\text { Os indicadores (questões) deste elemento devem dar subsídios para } \\
\text { identificar se a UC auxilia na proteção das comunidades locais e do } \\
\text { entorno }\end{array}$ \\
\hline Governança & $\begin{array}{l}\text { Os indicadores (questões) deste elemento devem dar subsídios para } \\
\text { identificar a contribuição da UC como vetor de implementação de } \\
\text { políticas publicas }\end{array}$ \\
\hline
\end{tabular}


As análises foram realizadas considerando as informações do formulário aplicado (Anexo 5), priorizando o agrupamento dessas informações em quatro dimensões: Gestão, Insumos, Contexto e Benefícios Sociais ${ }^{101}$. De modo geral o cenário resultante dessa análise apontou que:

- Na dimensão gestão os conselheiros têm conhecimento do grau de elaboração e/ou implementação do Plano de Manejo e da atuação dos Conselhos das UCs. Foi observada uma coincidência em 97\% das situações sobre o status do Plano de Manejo, quando comparamos a situação informada no CNUC e as informações oriundas dos Conselheiros;

- Na dimensão contexto, o relato dos conselheiros sinaliza para presença de populações e/ou comunidades dentro e no entorno das UCs de proteção integral, sendo que perfil de ocupação dentro da UC é representado por $62 \%$ por população tradicional, $15 \%$ indígena e os demais $23 \%$ populações não tradicionais. Nas UCs de uso sustentável, cuja presença de populações e/ou comunidades foi observada em todas as UCs investigadas o perfil é representado por $84 \%$ por população tradicional, 7\% indígena e os demais 7\% populações não tradicionais. Mas nesta dimensão o destaque fica para a percepção da existência de conflitos relacionados à situação fundiária que foi relatada por 59\% e 50\% dos conselheiros das UCs de proteção integral e uso sustentável, respectivamente. Dentre os conflitos identificados nas UCs de proteção integral encontra-se a sobreposição com Terras Indígenas, ausência de clareza sobre os limites das UCs (Demarcação dos limites), existência de indenizações não concluída, a ocorrência de ocupações ilegais, a demanda pelo uso dos recursos naturais (água, solo e vegetação) e a visão de que as UCs impedem o desenvolvimento, Para as UCs de uso sustentável, a sobreposição com UC de proteção integral, também a ausência de clareza sobre os limites das UCs (Demarcação dos limites), a especulação imobiliária, os processos de ampliação da área da UCe as políticas de assentamento do INCRA;

- Na dimensão benefícios sociais existe uma percepção de que a gestão das UCs de uso sustentável promove uma interação mais positiva, quando consideramos a melhoria na qualidade de vida das populações que residem no interior, que as UCs

\footnotetext{
${ }^{101}$ Os dados referentes as dimensões Gestão e Insumos refletem o resultado da aplicação piloto do Protocolo de Monitoramento da Efetividade, aplicado no âmbito do Projeto SNUC/Moore com o ICMBio com informações complementares do RAPPAM 2005 e 2010, além de informações do Cadastro Nacional de UC e do Observatório de UC/WWF-Brasil.
} 
de Proteção Integral. Mas o alto grau de dependência das populações residentes e do entorno das UCs (PI e US) em relação à segurança alimentar e a fonte de renda, de certa forma, coloca em evidência a necessidade de um monitoramento mais adequado do uso dos recursos naturais, assim como uma maior integração da gestão da UC com o seu entorno. Por outro lado, as UCs foram consideradas como vetores (ou facilitadoras) do acesso das populações residente e entorno aos serviços de educação ${ }^{102}$ e que o conselho pode ser considerado um fórum de discussão e definição de encaminhamentos que possibilitem melhorias nas áreas de Saúde, Educação e Segurança Territorial (moradia), Alimentação, e Proteção.

Face ao escopo e ao esforço realizado para elaboração do cenário das contribuições da gestão das UCs, a citar o caráter subjetivo das respostas e às vezes dos critérios estabelecidos como respostas para algumas perguntas; a existência de realidades especifica de cada interlocutor que podem não refletir a realidade predominante do conjunto de comunidades ou beneficiarias dentro e no entorno da UC e a dificuldade de acesso $^{103}$ aos conselheiros, considera-se que o esforço necessário para aplicar essa metodologia para todas as UCs Programa Arpa, de forma a garantir uma maior capilaridade de percepções (aumentar o número de conselheiros contatados) e um bom entendimento das dimensões avaliadas, é uma tarefa difícil e talvez pouco efetiva. $\mathrm{O}$ estudo não orienta para a definição de indicadores sociais, mas é um subsídio importante para estimular a reflexão sobre os tipos de benefícios sociais das UCs, sobre a metodologia baseada na auto-percepção e sobre o esforço de coleta.

Embora esses quatro estudos - Cobertura e uso do solo nas UCs do Bioma Amazônia, Situação do uso do solo em áreas alagáveis, Impacto dos gastos das unidades de conservação do Programa Arpa na economia local e Benefícios Sociais das UCs do Programa Arpa - tenham sido realizados para subsidiar a definição dos indicadores propostos para o monitoramento e avaliação do sucesso das ações apoiadas pelo Programa na Fase III, nenhum deles foi submetido para avaliação do Painel Cientifico de Aconselhamento ou aos membros da Sociedade Civil Organizada, bem como nenhuma análise ou discussão sobre esses dados foi fomentada, seja no âmbito do próprio PCA, ou

\footnotetext{
102 O mesmo não acontece para com os serviços de saúde

103 Ausência de uma uniformidade dos meios de comunicação disponíveis (rede de telefonia, e-mail, etc.), o curto período de tempo para um nivelamento, junto aos conselheiros, sobre o formulário de modo a permitir um melhor entendimento face aos diferentes perfis dos conselheiros, e para as entrevistas.
} 
do Fórum Técnico, ou de outras instancia do MMA ou de parceiros e doadores do Programa Arpa.

De fato, a Fase III está apenas começando, mas os desafios para avaliar o sucesso das UCs na conservação da Biodiversidade e na sustentabilidade do uso dos recursos naturais são velhos conhecidos do Programa Arpa e semelhantes aos apresentados na Fase I do Programa. A conclusão, a seguir traz uma reflexão sobre as lições apreendidas e sobre os desafios para avaliar o sucesso das UCs na conservação da Biodiversidade e na sustentabilidade do uso dos recursos naturais. 


\section{Conclusão}

No Brasil, o monitoramento da biodiversidade é um tema constante nas estratégias de estabelecimento de um sistema abrangente de UCs mas, a exemplo do esforço empreendido para medir a eficácia de gestão das UCs, as avaliações do impacto das UCs na conservação da biodiversidade, não foram igualmente priorizadas. Não se discute que monitoramento da biodiversidade, do uso dos recursos naturais e da qualidade de vida das populações locais são necessários para a gestão e a conservação de áreas protegidas, mas a abrangência do monitoramento, seus indicadores e como implementa-lo é um gargalo ainda sem solução. Mesmo a estratégia, mais ousada de conservação da biodiversidade para o Bioma Amazônia, o Programa Arpa, avançou pouco nesse sentido. Por outro lado, a preocupação em perpetuar às avaliações de efetividade, nesta tese identificadas pela sigla PAME, sejam elas por meio da FAUC, Rappam, ou mesmo o Tracking Toll, embora essas reflitam em última instancia a avaliação da eficácia da gestão, tem resultado em uma mudança na estrutura organizacional dos órgãos gestores para que o tema do monitoramento da efetividade tenha um papel de destaque. Entretanto, embora as informações sobre a gestão das UCs sejam utilizadas no âmbito local, pelos gestores de UCs, o esforço para utilização de tais informações nos processos de formulação de políticas e tomada de decisão, ainda encontra pouca aderência nas instancias responsáveis pelo planejamento da gestão e da tomada de decisão.

Dentre as abordagens de avaliação de efetividade da gestão de UCs aplicadas no Brasil, a mais utilizada contempla a avaliação do conjunto das UCs, no âmbito do SNUC, quanto a extensão e a representatividade dessa extensão em relação a abrangência (em área) dos biomas brasileiros. Essa estratégia de avaliação também é aplicada para avaliação individual de cada bioma, sobretudo o Bioma Amazônia, no qual além da contribuição das UCs também considera a contribuição das Terras Indígenas na manutenção da integridade da paisagem e como uma barreira ao desmatamento. A adesão as Metas de Aichi sugere ainda a possibilidade de considerar a abrangência das APPs neste tipo avaliação.

Entretanto as avaliações que priorizam apenas a manutenção da cobertura vegetal são questionadas, pois a biodiversidade pode ser seriamente comprometida com ameaças invisíveis. Sem o monitoramento dos impactos da gestão no âmbito da conservação e da 
utilização sustentável dos recursos, não é possível avaliar a efetividade das UCs ou das áreas protegidas.

No âmbito das estratégias de avaliação do sucesso das UCs na conservação da biodiversidade na utilização sustentável dos recursos, quando couber, um dos desafios é a identificação de um desenho conceitual de monitoramento da biodiversidade para as UCs, que a luz das iniciativas já estabelecidas permita integrar as diferentes dimensões de resultados: extensão e localização, representatividade, eficácia de gestão e impacto de conservação.

A identificação de indicadores mínimos de monitoramento da conservação da biodiversidade pode ser uma alternativa, assim como as ferramentas que se propõem avaliar a integridade da paisagem devem englobar o monitoramento e a avaliação as mudanças espaço-temporais na estrutura, composição, na distribuição das condições abióticas (por exemplo, temperatura, pluviosidade) e no funcionamento dos ecossistemas a luz das estratégias de gestão. Métodos que auxiliam a identificar os fatores determinantes do uso sustentável dos recursos naturais e a sua relação com a manutenção da integridade da paisagem e o impacto socioambiental, verificando a disponibilidade de uso do recurso, por meio da percepção de estoque, esforço de acesso, o esforço de restauração e recuperação da paisagem, bem como outros benefícios sociais gerados pelas unidades de conservação também são desejáveis e necessários.

A implementação das Fase I e II, e o processo de elaboração da Fase III do Programa Arpa foram responsáveis por valiosas reflexões sobre a estratégia de avaliação do sucesso das UCs, embora essas reflexões tenham ficado restritas a esfera da execução gerencial, com as ferramentas que avaliam a performance ou a progressão em relação aos instrumentos de gestão. O esforço de estruturação de ferramentas para avaliação da eficácia estava diretamente relacionado a necessidade de informações que permitiam ao Programa demonstrar seu sucesso na dimensão estratégica de alcance das metas de criação e consolidação, com foco na abordagem de sucesso que contempla a avaliação da extensão e localização das UCs por ele apoiadas. A avaliação da eficácia também auxiliava e auxilia o processo de elaboração dos POAs, garantindo assim um maior controle da execução financeira. Embora a preocupação com a eficácia de execução seja uma preocupação constante do gestor financeiro e dos doadores, nenhuma avaliação de eficiência de gestão foi realizada ou demandada pelos documentos que orientam a execução do Programa, ou seja não foram realizadas avaliações para verificar a alocação 
de recursos a luz dos resultados alcançados, ou a relação entre investimentos e melhoria na gestão das UCs, ou ainda a identificação de quais investimentos alcançam ou alavancam melhores resultados.

As lições aprendidas resultaram na separação clara, para a Fase III, entre as estratégias de avaliação da performance de gestão (eficácia) e as estratégias de avaliação de efetividade (impacto de conservação e usos dos recursos naturais). A apropriação do conceito de efetividade, é refletida no documento que orienta sobre as estratégias de monitoramento e avaliação da Fase III, o Manual Operacional do Programa (MOP - Fase III), ao admitir a distinção entre eficácia e efetividade de gestão, sendo esta última associada ao impacto positivo da gestão na conservação da biodiversidade e no uso sustentável dos recursos naturais.

Embora um passo importante tenha sido dado em relação a adequação e distinção dos conceitos de eficácia e efetividade, que durante as fases anteriores eram vistos como sinônimos, a forma de aferição da efetividade de gestão, associada ao impacto na conservação da biodiversidade e na utilização sustentável dos recursos, ainda é um caminho a ser percorrido. UCs com baixos índices de eficácia de gestão podem simplesmente ter a sua biodiversidade protegida simplesmente pelo fato de estarem isoladas geograficamente, ou por estarem inserida em um contexto onde o amparo legal de criação da unidade de conservação é respeitado. O contrário também é possível, um alto índice de eficácia de gestão pode ser encontrado em uma unidade onde o tamanho é um fator limitante para a manutenção de populações viáveis de determinadas espécies, e a variabilidade prejudicada pela ausência de conectividade ou pelo efeito de borda. Mas não falta só avançar na forma de aferição da efetividade, também é necessário utilizar adequadamente as informações produzidas e disponibilizadas pelas avaliações de eficácia realizadas durante o período de implementação do Programa, como por exemplos a avaliação do esforço de gestão (eficácia) em função da representativa dos ecossistemas de forma a avaliar se a gestão é eficaz onde precisa ser e a já citada avaliação de eficiência, que envolve as informações de eficácia e recursos alocados.

Ao definir para Fase III, dimensões de monitoramento da gestão e do impacto e sugerir a doação de uma nova ferramenta a SAMGe, o Programa dá sinais do caminho que deseja percorrer, entretanto essa trajetória passa ainda pelo esforço de discutir, elaborar e implementar os meios para que essa caminhada ocorra. A exemplo do que aconteceu nas Fase I e II, nem sempre o que foi sugerido pelos documentos orientadores, 
como o PAD e MOP foi de fato implementado. Cabe destacar que a FAUC foi adaptada, três anos após a sua criação, sem que esta adaptação a torna-se de fato uma ferramenta de efetividade de gestão de UC, pois as adequações foram realizadas em função das diferentes expectativas em relação necessidade de um monitoramento gerencial, possivelmente em função de uma pressão em relação a execução financeira do Programa.

Neste contexto, a Fase III tem a seu favor uma proposta de monitoramento com três dimensões distintas: financeira, de gestão e de impacto, assim como um arranjo operacional que vincula o desembolso dos recursos de doação a performance de execução e a demonstração de impacto de conservação da biodiversidade, para aprovar o desembolso e a alocação de recursos para as UCs. Embora os indicadores sugeridos pelo MOP da Fase III (MMA/MOP, 2015) tenha um forte viés na efetividade das áreas protegidas como um mecanismo de conservação da integridade da paisagem e da gestão por meio de PAMEs as demais abordagens propostas por Leverington et al (2010), Hockings, Leverington e Cook (2015) também são contempladas, como a avaliação da representatividade biológica e a avaliação da contribuição das áreas protegidas para a conservação de seus valores de biodiversidade. Embora sejam poucas as experiências no Arpa e fora dele de monitoramento do uso sustentável dos recursos naturais e do impacto desta utilização na conservação e na manutenção do meio de vidas das populações residentes dentro das unidades de conservação.

Outra lacuna de avaliação diz respeito a avaliação dos benefícios socioeconômicos, cujo referencial teórico foi pouco discutido e, portanto, possui um baixo nível de apropriação, refletido na ausência de detalhamento deste tema nos documentos do Programa e na ausência de uma discussão sistêmica nas diferentes instâncias de implementação. A terceira fase também não traz nenhum mecanismo de incentivo ao desenvolvimento de ações no entorno das UCs apoiadas pelo Arpa, diferente da Fase I e Fase II, com o subcomponete Integração com as comunidades do entorno, que tem a finalidade de fortalecer comunidades beneficiárias de UCs de uso sustentável e residentes nas áreas de entorno de UCs de proteção integral, apoiadas pelo Arpa, integrando-as aos objetivos das unidades, maximizando a participação social na conservação da biodiversidade e induzindo o desenvolvimento sustentável na região. A ausência de uma estratégia que relacione o uso sustentável e a conservação da biodiversidade, também é uma lacuna, pois o apoio as iniciativas que promovam o uso sustentável dos recursos naturais pelas populações residentes dentro destas UCs devem 
ser monitoradas vis a vis o seu impacto na conservação da biodiversidade. Mas favor desses desafios o Programa conta com parceiros que podem ajudar nessa discussão e reflexão, são eles: os membros da Sociedade Civil Organizada, os membros do Painel Científico de Aconselhamento, o Fórum Técnico e a Comissão de Gestores, atores que estão mais próximos das populações residentes e no entorno das UCs. Embora, um estado de alerta deva ser acionado, pois a participação da sociedade civil no âmbito das instancias de discussão e implementação do programa presenciaram uma a perda de oportunidades de manifestação, ocorrida em função das estratégias adotadas pela UCP para implementação do Programa durante a Fase II.

De modo geral, os órgãos gestores, e mesmo o próprio Arpa, encontram-se em uma situação que exige mudança, pois as informações disponíveis, resultado da aplicação das atuais ferramentas de avaliação (FAUC, Rappam e TT), não são suficientes para avaliar a efetividade de gestão das UCs; e a busca por novas informações ainda encontrase desvinculada de um método de coleta e análise que permita avaliar a efetividade, auxiliar a gestão adaptativa e orientar a tomada de decisão. Mas ainda não está claro se este cenário surge da ausência de dados específicos, ou da dificuldade em interpretar as informações disponíveis a favor da gestão da UC, ou ainda pela ausência de instrumentos que permitam a implementação das decisões. Embora de certa forma, e sobretudo para o Programa Arpa, alguns elementos necessários à essa reflexão estejam disponíveis (Resultado do Rappam 2005, 2010 e 2015), uso e cobertura do solo; identificação das pressões e ameaças, dados de execução financeira, etc.

Do ponto de vista do arranjo institucional do Arpa, talvez falte às instâncias do Programa sugerir e fomentar a investigação para a integração de abordagens e o desenvolvimento de métodos que possam integrar os resultados das diferentes iniciativas de monitoramento previstas para o Arpa na Fase III. Neste contexto o diálogo entre a academia, instituições de pesquisa científica, órgão gestores e as ferramentas de gestão de UCs é fundamental, e tal aproximação permitiria um melhor entendimento das respostas que diferentes variáveis ecológicas podem dar frente às diferentes ações de gestão de UCs, ou seja auxiliar na busca por parâmetros ou indicadores mais adequados para caracterizar o status de conservação da biodiversidade e dos benefícios para as comunidades nas áreas protegidas - características qualitativas e/ou quantitativas que auxiliam na detecção e o monitoramento de eventuais mudanças de forma a auxiliar os tomadores de decisões na gestão do sistema de UCs ou na gestão de UC. 


\section{Bibliografia}

Adeney, J. Marion, Norman L. Christensen, and Stuart L. Pimm. 2009. "Reserves Protect against Deforestation Fires in the Amazon" PLoS ONE 4 (4). doi:10.1371/journal.pone.0005014.

Alcaraz-Segura, Domingo, Javier Cabello, José M. Paruelo, and Miguel Delibes. 2009. "Use of Descriptors of Ecosystem Functioning for Monitoring a National Park Network: A Remote Sensing Approach" Environmental Management 43 (1): 3848. doi:10.1007/s00267-008-9154-y.

Alencar, Ane, Daniel Nepstad, David Mac Grath, Paulo Moutinho, Pablo Pacheco, Maria Del Carmem Vera Diaz, and Britaldo Soares Filho. 2004. "Desmatamento Na Amazônia: Indo Além Da "Emergência Crônica" Edited by Instituto de Pesquisa Ambiental da Amazônia (IPAM). Belém, Pará, Brasil.

Amend, M. R.; Reid, J.; Gascon, C. "Benefícios econômicos locais de áreas protegidas na região de Manaus, Amazonas”. Megadiversidade, v. 2, n. 1-2, p. 11, 2006.

Araújo, M. A. R. e Pinto-Coelho, R. M. 2004. "Porque as unidades de conservação são precariamente geridas no Brasil". VI Congresso Brasileiro de Unidades de Conservação, Anais. Curitiba, Outubro de 2004.

Araújo, Marco Antônio Reis, Marques, Cleani Paraiso e Cabral, Rogério F. Bittencourt. 2009. "Melhorando a efetividade da gestão de unidades de conservação: a experiência do Programa de Gestão para Resultados - PGR”. Brasília: MMA. Cadernos Arpa 3. 56p

Araújo, Marcos Antonio Reis. 2007. "Unidades de Conservação no Brasil: da república à gestão de classe mundial”. Belo Horizonte: SEGRAC, 272 p. Disponível em: <http://www.ract.com.br/UCs_Brasil.pdf>. Acesso em: 11 dez. 2014. .

Araya, Eduardo Núñez. 2003. "Método para la Planificación del Manejo de Áreas Protegidas". Santiago, Chile: CORPORACIÓN NACIONAL FORESTAL. Santiago, Chile.

Ball, I. R. and H. P. Possingham, 2000. MARXAN (V1.8.2): Marine Reserve Design Using Spatially Explicit Annealing, a Manual pdf (267KB). Diponivel em: http://marxan.net/downloads/uq_marxan_web_2/marxan_manual_1_8_2.pdf

Ball, I.R., H.P. Possingham, and M. Watts. 2009. "Marxan and relatives: Software for spatial conservation prioritisation. Chapter 14" in Spatial conservation prioritisation: Quantitative methods and computational tools. Eds Moilanen, A., K.A. Wilson, and H.P. Possingham. Oxford University Press, Oxford, UK.

Balmford, A. 2002. "Economic Reasons for Conserving Wild Nature" Science 297 (5583): 950-53. doi:10.1126/science.1073947.

Banco Mundial. 2002. Documento de avaliação de projeto de uma doação proposta do Fundo Global para o Meio Ambiente/GEF para o Fundo Brasileiro Para A Biodiversidade/Funbio para um Projeto de Áreas Protegidas na Região Amazônica. Brasília, DF. 
Barber, Christopher P., Mark A. Cochrane, Carlos Souza, and Adalberto Veríssimo. 2012. "Dynamic Performance Assessment of Protected Areas" Biological Conservation 149 (1). Elsevier Ltd: 6-14. doi:10.1016/j.biocon.2011.08.024.

Bath, Paqquita. 2009. “Avaliação Independente Do Projeto Arpa (Fase I: 2004 - 2008). Consultora Idenpendente. Documento Técnico, 81 ps Brasilia, DF: MMA/SBF/Arpa

Blackman, Allen, Alexander Pfaff, and Juan Robalino. 2011. "Mexico's Natural Protected Areas: Enhancing Effectiveness and Equity" Washington D.C, Durham N.C and Turrialba, Costa Rica.

BNDES. Fundo Amazônia. 2015. "Relatório de Avaliação de Resultados do Programa Áreas Protegidas da Amazônia. Período de Implantação do Projeto: julho de 2010 a abril de 2015". Documento Técnico do Programa Arpa.

Bonatto, Frederico, Mariana Napolitano Ferreira, e Fernan Enrique Figueroa. 2009. "Efetividade de Gestão Das Unidades de Conservação de Uso Sustentável Do Estado Do Tocantins" Natureza \& Conservação 7 (1): 95-104.

Bonaudo, Th., Lependu, Y., Faure, J.-F., Quanz, D., "The effects of deforestation on wildlife along the transamazon highway”, European Jornal on Wildlife, n ${ }^{\circ} 51$, p.199-206, 2005.

Bradshaw, C. J. A., Sodhi, N. S. \& Brook, B. W. "Tropical turmoil-a biodiversity tragedy in progress". Front. Ecol. Environ 7, 79-87 (2009).

Bruner, Aron G., Raymond E. Gullison, Richard E. Rice, and Gustavo A.B. da Fonseca. 2001. "Effectiveness of Parks in Protecting Tropical Biodiversity" Science (New York, N.Y.) 291 (5501): 125-28. doi:10.1126/science.291.5501.125.

Bursztyn, Maria Augusta; Bursztyn, Marcel. 2012. "Fundamentos de Política e Gestão Ambiental: caminhos para a sustentabilidade". Rio de Janeiro: Garamond. 612 p.

Cabello, Javier, Nestor Fernandez, Domingo Alcaraz-Segura, Cecilio Oyonarte, Gervasio Pineiro, Alice Altesor, Miguel Delibes, and José M. Paruelo. 2012. "The Ecosystem Functioning Dimension in Conservation: Insights from Remote Sensing" Biodiversity and Conservation 21 (13): 3287-3305. doi:10.1007/s10531-012-03707.

Campo, Agostinho Carneiro e Selma Simões de Castro. 2006. "Unidades de Conservação, a Importância dos Parques e o Papel da Amazônia” Terra Livre 1 (26): 127-41.

Canavire-Bacarreza, Gustavo, and Merlin M Hanauer. 2013. "Estimating the Impacts of Bolivia's Protected Areas on Poverty" World Development 41. Elsevier Ltd: 26585. Doi:10.1016/J.Worlddev.2012.06.011.

Capobianco, J. P. R.; Veríssimo, A.; Moreira, A; Sawyer, D.; Santos, I.; Pinto, L.P. (Orgs.). 2001. "Biodiversidade na Amazônia Brasileira - Avaliação e identificação de ações prioritárias para a conservação, utilização sustentável e repartição de benefícios”. São Paulo: Estação da Liberdade: Instituto Socioambiental, 540 p.

Carey, C., Dudley, N. and Stolton, S. 2000. "Squandering Paradise: The importance and vulnerability of the world's protected areas". WWF, Gland, Switzerland. 
Cayot, L. and F. Cruz. 1998. "Manual para la Evaluación de la Eficiencia de Manejo del Parque Nacional Galápagos". SPNG- Servicio Parque Nacional Galápagos. Instituto Ecuatoriano Forestal y de Áreas Naturales y Vida Silvestre. Puerto Ayora, Islas Galápagos., Puerto Ayora, Galápagos, Ecuador.

Cifuentes, M. and Izurieta, A. 1999. "Evaluation of Protected Area Management Effectiveness: Analysis of Procedures and Outline for a Manual". Paper prepared for IUCN Management Effectiveness Task Force meeting, The Broads Authority, UK, October 1999.

Cifuentes, Miguel, Arturo Izurieta, and Helder Henrique de Faria. 2000. "Medición de La Efectividad Del Manejo de Areas Protegidas”. Turrialba: WWF, IUCN, GTZ.

Clements, Tom, Seng Suon, David S Wilkie, and E J Milner-Gulland. 2014. "Impacts of Protected Areas on Local Livelihoods in Cambodia" World Development. Elsevier Ltd: 1-10. doi:10.1016/j.worlddev.2014.03.008.

CMP - The Conservation Measures Partnership. 2007. "Padrões Abertos Para a Prática da Conservação Aliança Para as Medidas de Conservação". 44ps.Disponível em: http://cmp-openstandards.org/wp-content/uploads/2014/03/CMP-Open-StendardsVersion-2-0-Portuguese.pdf

CNUC/Cadastro Nacional de Unidades de Conservação.2009 - acesso disponível em WWW.mma,gov.br/cnuc

CNUC/Cadastro Nacional de Unidades de Conservação.2015 - acesso disponível em WWW.mma,gov.br/cnuc

Coad, Lauren, Fiona Leverington, Kathryn Knights, Jonas Geldmann, April Eassom, Valerie Kapos, Naomi Kingston, et al. 2015. "Measuring Impact of Protected Area Management Interventions: Current and Future Use of the Global Database of Protected Area Management Effectiveness" Philosophical Transactions of the Royal Society of London B 370: 20140281. doi:10.1098/rstb.2014.0281.

Coad, Lauren, Fiona Leverington, Neil D Burgess, Ivon C Cuadros, Jonas Geldmann, Toby R Marthews, Jessie Mee, et al. 2013. "Progress Towards the CBD Protected Area Management Effectiveness Targets” Parks Journal 19 (1): 13-24.

Cook, Carly N., and Marc Hockings. 2011. "Opportunities for Improving the Rigor of Management Effectiveness Evaluations in Protected Areas" Conservation Letters 4 (5): 372-82. doi:10.1111/j.1755-263X.2011.00189.x.

Cook, Carly N., R. W Bill Carter, and Marc Hockings. 2014. "Measuring the Accuracy of Management Effectiveness Evaluations of Protected Areas" Journal of Environmental Management 139 (2014). Elsevier Ltd: 164-71. doi:10.1016/j.jenvman.2014.02.023.

Cook, Carly N., R. W Bill Carter, Richard A. Fuller, and Marc Hockings. 2012. "Managers Consider Multiple Lines of Evidence Important for Biodiversity Management Decisions". Journal of Environmental Management 113: 341-46. doi:10.1016/j.jenvman.2012.09.002. 
Cunha, André. 2010. “A Contribuição das Unidades de Conservação da Amazônia Brasileira para a Redução do Desmatamento, e o Papel Suplementar do Programa Arpa" Brasilia, DF.

Danielsen, Finn, Neil D Burgess, Andrew Balmford, Paul F Donald, Mikkel Funder, Julia P G Jones, Philip Alviola, et al. 2009. "Local Participation in Natural Resource Monitoring: A Characterization of Approaches" Conservation Biology: The Journal of the Society for Conservation Biology 23 (1): 31-42. doi:10.1111/j.15231739.2008.01063.x.

De Faria, Helder Henrique.. 1995. "Procedimento para medir a efetividade do manejo de áreas silvestres protegidas”. Revista do Instituto Florestal, v. 7, n. 1, p.35-55. São Paulo, SP.

De Faria, Helder Henrique.. 1993. "Elaboración de un Procedimiento para medir la efectividad de manejo de áreas silvestres prote- gidas y su aplicación en dos áreas protegidas de Costa Rica”. Tesis Magister Scientiae. CATIE, Turrialba, Costa Rica, $91 \mathrm{p}$

De Faria, Helder Henrique. 2004. "Eficácia de Gestão de Unidades de Conservação Gerenciadas Pelo Instituto Florestal de São Paulo, Brasil”. Dissertação Mestrado. Universidade Estadual Paulista, Faculdade de Ciências e Tecnologia.

De Faria, Helder Henrique.. 2006. "Aplicação do EMAP e Rotinas Estatísticas Complementares Na Avaliação da Eficácia de Gestão de Unidades de Conservação" Revista Ciências Do Ambiente On Line (2):44-62.

De Fries, Ruth, A Hansen, B L Turner, Robin Reid, And Jianguo Liu. 2007. "Land use change around protected areas: management to balance human needs and ecological function". Ecological Applications 17, no. 4 (June): 1031-8.

Dearden, P. and Dempsey, J. 2004., "Protected areas in Canada: decade of change". Canadian Geograper/Le Géographe canadien, 48: 225-239. doi:10.1111/j.00083658.2004.00057.x

Deshler,W.O. 1982. «A systematic approach to effective management of protected areas". in World National Parks Congress, Bali, IUCN Commission on National Parks, Bali, Indonesia.

Droulers, Martine, François-michel Tourneau, Stephanie Nasuti, Florent Kohler, Anna Greissing, Philippe Lena, and Vincent Dubreuil. 2011. "DURAMAZ, Um Sistema de Indicadores de Desenvolvimento Sustentável Na Amazônia" Sustentabilidade Em Debate 2 (2): 165-86.

Drummond, José Augusto, Franco, José Luiz de Andrade and Oliveira, Daniela. 2012. "An Assessment of Brazilian Conservation Units - a Second Look" Novos Cadernos NAEA 15 (1): 53-83. doi:dx.doi.org/10.5801/ncn.v15i1.924.

Drummond, José Augusto, Jose Luiz de Andrade Franco, e Alessandra Bortoni Ninis. 2006. O Estado Das Áreas Protegidas Do Brasil - 2005. Brasília/DF

Drummond, José Augusto; Franco, José Luiz De Andrade E Oliveira, Daniela. 2010. "Uma análise sobre a história e a situação das unidades de conservação no Brasil". 
In: Conservação da Biodiversidade: Legislação e Políticas Públicas. GANEN, Roseli Senna (Org.). Brasília: Câmara dos Deputados, pp. 341-386.

Dudley, Nigel, and Sue Stolton. 2009. "The Protected Areas Benefits Assessment Tool: A methodology". WWF. 43ps Disponivel em file:///C:/Users/Usuario/Downloads/pa_bat_final_english.pdf

Dudley, Nigel, Hockings, Marc and Stolton, Sue. 2010. "Precious places: Getting the arguments right". In Sue Stolton and Nigel Dudley (Ed.), Arguments for protected areas: Multiple benefits for conservation and use (pp. 253264) London, U.K. ; Washington, DC, U.S.A.: Earthscan.

Elfes, Cristiane T, Catherine Longo, Benjamin S Halpern, Darren Hardy, Courtney Scarborough, Benjamin D Best, Tiago Pinheiro, and Guilherme F Dutra. 2014. "A Regional-Scale Ocean Health Index for Brazil" PloS One 9 (4): e92589. doi:10.1371/journal.pone.0092589.

Ervin, J. 2003. WWF Rapid Assessment and Prioritization of Protected Area Management (Rappam) Methodology Rapid. WWF - World Wide Fund for Nature.

Ervin, J. 2003. "WWF- Metodologia Para Avaliação Rápida E a Priorização Do Manejo de Unidades de Conservação (Rappam)". WWF - World Wide Fund for Nature.

Faber-Langendoen, D., L. Master, J. Nichols, K. Snow, A. Tomaino, R. Bittman, G. Hammerson, B. Heidel, L. Ramsay, and B. Young. 2009. "NatureServe Conservation Status Assessments: Methodology for Assigning Ranks". NatureServe, Arlington, VA.

Fancy, S G, J E Gross, and S L Carter. 2009. "Monitoring the Condition of Natural Resources in US National Parks" Environmental Monitoring and Assessment 151 (1-4): 161-74. doi:10.1007/s10661-008-0257-y.

Ferraro, P J, and R L Pressey. 2015. "Measuring the Difference Made by Conservation Initiatives: Protected Areas and Their Environmental and Social Impacts" Philosophical Transactions of the Royal Society B: Biological Sciences 370: 20140270. doi:10.1098/rstb.2014.0270.

Ferraro, Paul J, Merlin M Hanauer, Daniela A Miteva, Gustavo Javier Canavirebacarreza, and Subhrendu K Pattanayak. 2013. "More Strictly Protected Areas Are Not Necessarily More Protective: Evidence from Bolivia, Costa Rica, Indonesia, and Thailand" doi:10.1088/1748-9326/8/2/025011.

Ferraro, Paul J. 2008. "Protected Areas and Human Well-Being" In Economics and Conservation in the Tropics: A Strategic Dialogue, 8.

Ferreira, Mariana Napolitano. 2011. "Planejamento Sistemático Das Unidades de Conservação No Estado Do Tocantins”. Tese de Doutorado. Universidade de São Paulo.

Fonseca Junior, S. F., C. E. Marinelli, H. S. a. Carlos, J. R. Weigand, R. B. Fernandes, J. V. C. Silva, M. C. Silva, P. F. Lemos, and D. Calandino. 2011. "Programa de Monitoramento Da Biodiversidade E Do Uso de Recursos Naturais - ProBUC: A Experiência Das Unidades de Conservação Estaduais do Amazonas”. SDS/CEUC, AM. 
Fox, Helen E., Michael B. Mascia, Xavier Basurto, Alice Costa, Louise Glew, Dennis Heinemann, Leah B. Karrer, et al. 2012. "Reexamining the Science of Marine Protected Areas: Linking Knowledge to Action" Conservation Letters 5 (1): 1-10. doi:10.1111/j.1755-263X.2011.00207.x.

Franco, José Luiz de Andrade, and José Augusto Drummond. 2009. "Proteção a Natureza e Identidade Nacional no Brasil, Anos 1920-1940”. Rio de Janeiro: Ed.Fiocruz, 272p

Franco, José Luiz De Andrade, Gilberto De Menezes Schittini, And Vivian Da Silva Braz. 2015. "História Da Conservação Da Natureza E Das Áreas Protegidas: Panorama Geral" Historia, Rio Grande 6 (2): 233-70.

Franco, José Luiz de Andrade. 2000. Natureza no Brasil: Idéias, Políticas, Fronteiras (1930-1992). In: SILVA, Luiz Sérgio Duarte da (org.). Relações Cidade-Campo: Fronteiras. Goiânia: UFG/AGEPEL.

Françoso, Renata D., Reuber Brandão, Cristiano C. Nogueira, Yuri B. Salmona, Ricardo Bomfim Machado, and Guarino R. Colli. 2015. "Habitat Loss and the Effectiveness of Protected Areas in the Cerrado Biodiversity Hotspot" Natureza \& Conservacao 13 (1): 35-40. doi:10.1016/j.ncon.2015.04.001.

Franks, Phil, and Kate Schreckenberg. 2016. "Advancing Equity in Protected Area Conservation" The International Institute for Environment and Development (IIED). doi:10.13140/RG.2.1.2817.0649.

FUNBIO. 2010. "Manual Operacional Para Contratações e Aquisições do Funbio" Rio de Janeiro, RJ.

FUNBIO/MOP, 2002. Manual Operacional do Programa Áreas Protegidas da Amazônia. Rio de Janeiro/RJ

FUNBIO/MOP. 2005. Manual Operacional do Programa Áreas Protegidas da Amazônia. Rio de Janeiro/RJ

Geldmann, J, M Barnes, L Coad, Id Craigie, M Hockings, and N Burgess. 2013. "Effectiveness of Terrestrial Protected Areas in Reducing Biodiversity and Habitat Loss" Collaboration for Environmental Evidence, 1-61. http://www.environmentalevidence.org/ SR10007.html.

Geldmann, Jonas, Lauren Coad, Megan Barnes, Ian D. Craigie, Marc Hockings, Kathryn Knights, Fiona Leverington, et al. 2015. "Changes in Protected Area Management Effectiveness over Time: A Global Analysis". Biological Conservation 191. Elsevier B.V.: 692-99. doi:10.1016/j.biocon.2015.08.029.

Geluda, Leonardo, Manoel Serrão, Manuela Muanis, Jon Tua, Daniela Oliveira, Marisete Catapan, and Samuel Tararan. 2012. "Quanto Custa O Programa Áreas Protegidas da Amazônia? Uma Modelagem Financeira para as Unidades de Conservação do Arpa". Rio de Janeiro, RJ: Fundo Brasileiro para a Biodiversidade.

Gerhardt, Cleyton H.. 2007. "Populações Locais e Áreas Naturais Protegidas: As controvérsias entre pesquisadores". In: Seminário de Áreas Protegidas e Inclusão Social (SAPIS), Teresópolis. III Seminário Brasileiro sobre Áreas Protegidas e Inclusão Social. 
Gibson, L. et al. 2011. "Primary forests are irreplaceable for sustaining tropical biodiversity". Nature 478, 378-381.

Gidsicki, Daniele. 2013. "Protocolo de Avaliação de Efetividade Gestão de Mosaicos de Áreas Protegidas No Brasil" In Cadernos da Reserva da Biosfera da Mata Atlântica, No 42, edited by Conselho Nacional da Reserva da Biosfera da Mata Atlântica Conselho, 47. São Paulo, SP: Conselho Nacional da Reserva da Biosfera da Mata Atlântica. Disponível em http://www.bibliotecaflorestal.ufv.br/handle/123456789/8440.

Han, Xuemei, Regan L. Smyth, Bruce E. Young, Thomas M. Brooks, Alexandra Sanchez De Lozada, Philip Bubb, Stuart H M Butchart, et al. 2014. "A Biodiversity Indicators Dashboard: Addressing Challenges to Monitoring Progress towards the Aichi Biodiversity Targets Using Disaggregated Global Data" PLoS ONE 9 (11). doi:10.1371/journal.pone.0112046.

Hangae, Lillian eKatia Lemos Costa. 2012. "Efetividade de Gestão de Áreas Protegidas". In VII Congresso Brasileiro de Unidades de Conservação, edited by Fundação Grupo Boticário de Proteção à Natureza, 23. Natal, RN.

Herrmann, Gisela e Claudia Costa. 2015. "Gestão Integrada de Áreas Protegidas: Uma Análise de Efetividade de Mosaicos". Brasília, DF: WWF-Brasil. http://d3nehc6yl9qzo4.cloudfront.net/downloads/wwf_estudo_de_efetividade.pdf.

Hockings, M. T., S. Stolton, and N. Dudley. 2000. "Management Effectiveness-Assessing Management of Protected Areas?" Disponível em http://planet.botany.uwc.ac.za/NISL/Conservation Biology/Fifth_World_Parks_congress_Durban_2003/stream outputs/session 2b-3b learning from experiencelHockings 2b.pdf.

Hockings, Marc, Carly N. Cook, R. W. Carter, and Robyn James. 2009. “Accountability, Reporting, or Management Improvement? Development of a State of the Parks Assessment System in New South Wales, Australia" Environmental Management 43 (6): 1013-25. doi:10.1007/s00267-009-9277-9.

Hockings, Marc, Fiona Leverington, and Carly Cook. 2015. "Protected Area Management Effectiveness" In Protected Area Governance and Management, edited by Sue Feary and Ian Pulsford Graeme L. Worboys, Michael Lockwood, Ashish Kothari, 889-928. Canberra, Australia: ANU Press, The Australian National University.

Hockings, Marc, Leverington, Fiona and James, Robyn. 2005. "Evaluating management effectiveness". In Graeme L. Worboys, Michael Lockwood and Terry De Lacy (Ed.), Protected area management: Principles and practices 2 ed. (pp.553568) Oxford, U.K.: Oxford University Press.

Hockings, Marc, Robyn James, Sue Stolton, Nigel Dudley, Vinod Mathur, Jonh Makombo, Jose Courrau, and Jeffrey Parrish. 2008. "Enhancing Our Heritage Toolkit: Assessing Management Effectiveness of Natural World Heritage Sites". Paris, France: UNESCO World Heritage Centre.

Hockings, Marc, Sue Stolton, Fiona Leverington, Nigel Dudley, and José Courrau. 2006. "Evaluating Effectiveness: a Framework for Assessing Management Effectiveness 
of Protected Areas". 2 Edition. Edited by Peter Valentine. Best Practice Protected Area Guidelines Series. 2a ed. Gland, Switzerland and Cambridge, UK: IUCN, Gland, Switzerland and Cambridge, UK. doi:ISBN 978-2-8317-0939-0.

Hockings, Marc, Sue Stolton, Nigel Dudley, and Robyn James. 2009. "Data Credibility: What Are the 'Right' Data for Evaluating Management Effectiveness of Protected Areas?" In Environmental Program and Policy Evaluation: Addressing MethodologIcal Challenges, edited by M. Birnbaum \& P. Mickwitz, 53-63. New Directions for Evaluation. doi:10.1002/ev.

Hockings, Marc. 2003. "Systems for Assessing the Effectiveness of Management in Protected Areas" BioScience 83153 (9): 823-32. doi:10.1641/0006$3568(2003) 053$.

IBAMA e WWF-Brasil. 2007. "Efetividade de gestão das unidades de conservação federais do Brasil. Brasília, DF.

Instituto Brasileiro de Reforma Agraria (IBRA), and Instituto Brasileiro de Desenvolvimento Florestal (IBDF). 1969. Parques Nacionais E Reservas Equivalentes No BRasil. Rio de Janeiro, RJ.

Instituto Chico Mendes de Conservação da Biodiversidade e WWF-Brasil. 2012. "Efetividade de Gestão Das Unidades de Conservação Federais: Avaliação Comparada Das Aplicações Do Método Rappam Nas Unidades de Conservação Federais, Nos Ciclos 2005-06 E 2010”. Brasília, DF. Disponível em http://www.icmbio.gov.br/portal/images/stories/comunicacao/downloads/relatrio rappam 2005 x 2010 - verso integral.pdf.

Instituto Chico Mendes de Conservação da Biodiversidade (ICMBio). 2014. "Portaria ICMBio, No 5 de Janeiro de 2014". Brasilia,DF.

Instituto Chico Mendes de Conservação da Biodiversidade (ICMBio). 2015. "Sistema de Análise E Monitoramento de Gestão - SAMGe VOLUME 01 - MANUAL CARACTERIZAÇÃO AVALIATIVA" Vol. 01. Brasilia, DF

IUCN (International Union for Conservation and Nature), WWF-Brasil, and IPÊ. 2011. "Metas de Aichi : Situação Atual No Brasil"'

IUCN (International Union for Conservation and Nature). 1982. "The World National Park Congress, 11-22 October 1982, Bali, Indonesia" In The World National Park Congress, 11-22 October 1982, Bali, Indonesia, 131. INTERNATIONAL UNION FOR CONSERVATION OF NATURE.

IUCN (International Union for Conservation and Nature). 1987. "The Bali Action Plan: Report during the World Parks Congress, Oct. 11-22, 1982”. Edited by Jeffrey A. MacNeely et Kenton R. Miller. National Parks, Conservation and Development. Ottawa, Canadá: Commission on National Parks and Protected Areas/IUCN.

IUCN (International Union for Conservation and Nature). 1993. "Parks for Life: Report of the IV World Congress on National Parks and Protected Areas" Gland, Switzerland.

IUCN (International Union for Conservation and Nature). 1999. "Interactional Workshop on Management Effectiveness of Protected Areas" Gland, Switzerland. 
IUCN (International Union for Conservation and Nature). 2001. "IUCN Red List Categories and Criteria: Version 3.1". IUCN Species Survival Commission. IUCN, Gland, Switzerland and Cambridge, UK

IUCN (International Union for Conservation and Nature). 2004. "2003 DURBAN WORLD PARKS CONGRESS" In VTH IUCN WORLD PARKS CONGRESS (WPC), Durban, South Africa in September 2003, 14:6. Disponível em http://cmsassets.dev.getunik.net/iucn/downloads/14_2lowres.pdf\#page=44 Inpapers 2://publication/uuid/67F9F185-047F-479A-9ABC-3C54868492F1.

IUCN (International Union for Conservation and Nature). 2009. "Proceedings of the International Workshop on the Future of the CBD Programme of Work on Protected Areas: Jeju Island, Republic of Korea" In International Workshop on the Future of the CBD Programme of Work on Protected Areas: Jeju Island, Republic of Korea, edited by Sue Stolton and Nigel Dudley, 129. Gland, Switzerland: INTERNATIONAL UNION FOR CONSERVATION OF NATURE.

IUCN (International Union for Conservation and Nature). 2014. "IUCN World Parks Congress 2014 - Report” In IV UCN World Parks Congress 2014, Sydney, Australia, November 2014, 1-43. Sydney, Australia: International Institute for Sustainable Development (IISD). http://www.iucn.org/about/work/programmes/gpap_home/gpap_events/gpap_wpc/.

Jon Tua, Manuela Mossé Muanis, Leonardo Geluda, Daniela de Oliveira and Greg Love. 2011. "Amazon Region Protected Areas (Arpa) 2011-2020 Financial Plan Report". Report prepared with support from the Gordon and Betty Moore Foundation, Fundo Brasileiro para a Biodiversidade (Funbio), and the World Wildlife Fund.

Joppa, Lucas N, Scott R Loarie, and Stuart L Pimm. 2008. "On the Protection of "“ Protected Areas" Proceedings of the National Academy of Sciences of the United States of America 105 (18). National Acad Sciences: 6673-78. doi:10.1073/pnas.0802471105.

Juffe-Bignoli, D., Burgess, N.D., Bingham, H., Belle, E.M.S., de Lima, M.G., Deguignet, M., Bertzky, B., Milam, A.N., Martinez-Lopez, J., Lewis, E., Eassom, A., Wicander, S., Geldmann, J., van Soesbergen, A., Arnell, A.P., O’Connor, B., Park, S., Shi, Y.N., Danks, F.S., MacSharry, B., Kingston, N. 2014. "Protected Planet Report 2014”. UNEP-WCMC: Cambridge, UK. doi:DEW/1233/CA.

Kachelriess, Daniel, Martin Wegmann, Matthew Gollock, and Nathalie Pettorelli. 2014. "The Application of Remote Sensing for Marine Protected Area Management" Ecological Indicators 36. Elsevier Ltd: 169-77. doi:10.1016/j.ecolind.2013.07.003.

Kapos, V., A. Balmford, R. Aveling, P. Bubb, P. Carey, A. Entwistle, J. Hopkins, et al. 2009. "Outcomes, Not Implementation, Predict Conservation Success" Fauna \& Flora International 43 (03): 7. doi:10.1017/S0030605309990275.

Kayano, J. \& Caldas, E. L. 2002. "Indicadores para o diálogo”. In: CACCIA-BAVA, S.; PAULICA, V.; SPINK, P. (orgs). Novos contornos da gestão local: conceitos em construção. Polis: Programa Gestão Pública e Cidadania / FGV - EAESP, São Paulo. 
Kinouche. Marcelo. S/DATA. "Considerações para reformulação do RAPPAM". Documentos Técnicos/ICMbio. Brasília. DF

Laurance, William F. 2013. "Does Research Help to Safeguard Protected Areas?" Trends in Ecology and Evolution 28 (5). Elsevier Ltd: 261-66. doi:10.1016/j.tree.2013.01.017.

Le Saout, Soizic, Michael Hoffmann, Yichuan Shi, and Adrian Hughes. 2013. "Protected Areas and Effective Biodiversity Conservation" Science 342: 803-5. doi:10.1126/science.1239268.

Le Tourneau, François Michel, Guillaume Marchand, Anna Greissing, Stéphanie Nasuti, Martine Droulers, Marcel Bursztyn, Philippe Léna, and Vincent Dubreuil. 2013. "Assessing the Impacts of Sustainable Development Projects in the Amazon: The DURAMAZ Experiment" Sustainability Science 8 (2): 199-212. doi:10.1007/s11625-013-0200-1.

Le Tourneau, François-Michel, Guillaume Marchand, Anna Greissing, Stéphanie Nasuti, Martine Droulers, Marcel Bursztyn, Philippe Léna, and Vincent Dubreuil. 2013. "The DURAMAZ Indicator System: A Cross-Disciplinary Comparative Tool for Assessing Ecological and Social Changes in the Amazon" Philosophical Transactions of the Royal Society of London. Series B, Biological Sciences 368 (1619): 20120475. doi:10.1098/rstb.2012.0475.

Leverington, Fiona, Katia Lemos Costa, Helena Pavese, Allan Lisle, and Marc Hockings. 2010. "A Global Analysis of Protected Area Management Effectiveness" Environmental Management 46 (5): 685-98. doi:10.1007/s00267-010-9564-5.

Leverington, Fiona, Anne Kettner, Christoph Nolte, Melitta Marr, Sue Stolton, Helena Pavese, Susanne Kleemann-Stoll, and Marc Hockings. 2010. "Protected Area Management Effectiveness Assessments in Europe - Supplementary Report". BFN Skripten 271b. Born, Germany.

Leverington, Fiona, Marc Hockings, Helena Pavese, Katia Lemos Costa, and José Courrau. 2008. 'Management effectiveness evaluation in protected areas - A global study. Supplementary report No.1: Overview of approaches and methodologies.' The University of Queensland, Gatton, TNC, WWF, IUCN-WCPA, Australia

Lima, Gumercindo Souza, and Guido Assunção Ribeiro Wantuelfer Gonçalves. 2005. "Avaliação Da Efetividade de Manejo Das Unidades de Conservação de Proteção Integral Em Minas Gerais" Revista Árvore 4: 647-53.

Loyola, Rafael D, and Thomas M Lewinsohn. 2009. "Diferentes Abordagens Para a Seleção de Prioridades de Conservação Em Um Contexto Macrogeográfico" Megadiversidade 5: 27-42.

Machado, A.B., Drummond, G.M. \& Paglia, A.P. (Org.). 2008. "Livro vermelho da fauna brasileira ameaçada de extinção". Ministério do Meio Ambiente, Brasília, DF, v.2., $1420 \mathrm{p}$ 
MacKinnon, John, and Kathy MacKinnon. 1986. "Managing Protected Areas in the Tropics". IUCN Conservation Library. Cambridge, UK: IUCN. doi:10.2307/2403639.

MacKinnon, John, Kathy Mackinnon, Graham Child, and Jim Thorsell. 1990. "Manejo de Áreas Protegidas En Los Trópicos". Gland, Suisse: INTERNATIONAL UNION FOR CONSERVATION OF NATURE.

Magliocca, Nicholas R, Thomas K Rudel, Peter H Verburg, William J McConnell, Ole Mertz, Katharina Gerstner, Andreas Heinimann, and Erle C Ellis. 2015. "Synthesis in Land Change Science: Methodological Patterns, Challenges, and Guidelines" Regional Environmental Change 15 (2): 211-26. doi:10.1007/s10113-014-0626-8.

Marchand, Guillaume. 2010. “Un Système D'indicateurs Pour Évaluer Les Impacts Territoriaux Des Politiques de Développement Durable Dans Les Zones Rurales d'Amazonie Brésilienne: L'expérience IDURAMAZ" Université Sorbonne Nouvelle - Paris 3.

Marchand, Guillaume . 2014. "Avaliação da gestão da fauna silvestre na comunidade de São João do Tupé (Manaus, Amazonas) pelo meio de um sistema de indicadores". Confins Online, 20|2014, posto online no dia 07 Março 2014, e consultado em 10 Setembro 2016. Disponível em : http://confins.revues.org/8829 ; DOI : $10.4000 /$ confins. 8829

Margules, C. R. e Pressey, R. L. 2000. "Systematic conservation planning”. Nature, 405, 243-253.

Marinelli, Carlos Eduardo, Raquel Carvalho, and Paula Soares Pinheiro. 2006. "Indicadores de Efetividade Da Implementação de Unidades de Conservação Estaduais Do Amazonas" Manaus: Secretaria de Estado do Meio Ambiente e Desenvolvimento Sustentável (SDS).

Marinelli, Carlos Eduardo. 2011. "De Olho Nas Unidades de Conservação: Sistema de Indicadores Socioambientais para Unidades de Conservação da Amazônia Brasileira” São Paulo: Instituto Socioambiental (ISA).

Mascia, Michael B, and Michael B Mascia. 2003. "The Human Dimension of Coral Reef Marine Protected Areas: Recent Social Science Research and Its Policy Implications" Conservation Biology 17 (2): 630-32. doi:10.1046/j.15231739.2003.01454.x.

Mascia, Michael B., and C. Anne Claus. 2009. "A Property Rights Approach to Understanding Human Displacement from Protected Areas: The Case of Marine Protected Areas" Conservation Biology 23 (1): 16-23. doi:10.1111/j.15231739.2008.01050.x.

Mascia, Michael B., and Sharon Pailler. 2011. "Protected Area Downgrading, Downsizing, and Degazettement (PADDD) and Its Conservation Implications" Conservation Letters 4 (1): 9-20. doi:10.1111/j.1755-263X.2010.00147.x.

Master, L., D. Faber-Langendoen, R. Bittman, G. A. Hammerson, B. Heidel, J. Nichols, L. Ramsay, And A. Tomaino. 2009. NatureServe Conservation Status Assessments: Factors for Assessing Extinction Risk. NatureServe, Arlington, VA. 
McCormick, J. 1992. "Rumo ao paraíso: a história do movimento ambientalista". Rio de Janeiro: Relume-Dumará.

McNeely, J.A., J. Harrison, and P. Dingwall. 1994. "Protecting Nature: Regional Reviwes of Protected Areas" In IVth World Congress on Ntional Parks and Protected Areas, Caracas, Venezuela, 402. Gland, Suisse: IUCN, Gland, Switzerland and Cambridge, UK.

Medeiros, R.; Young; C.E.F.; Pavese, H. B. \& Araújo, F. F. S. 2011. "Contribuição das unidades de conservação brasileiras para a economia nacional". Brasília: UNEPWCMC, 120p.

Mercadante, Maurício. 2001. "Uma Década de Debate e Negociação: a História da Elaboração da Lei do SNUC". In: BENJAMIN, Antônio Herman (Coordenador), Direito Ambiental das Áreas Protegidas. Rio de Janeiro, Forense.

Mercadante, Mauricio. 2010. "Avanços E Retrocessos Pós SNUC” Disponível em: https://uc.socioambiental.org/o-snuc/depoimento-avan\%C3\%A7os-e-retrocessosp\%C3\%B3s-snuc.

Ministério do Meio Ambiente (MMA), 2010. “Amazon Protected Areas Program (Arpa) first phase results". MMA, ICMBio, Governos estaduais da Amazônia brasileira, WWF-Brasil, Funbio, KfW, GTZ e Banco Mundial. 212p.

Ministério do Meio Ambiente (MMA). 2000. "Convenção Da Diversidade Biológica" Serie Biodiversidade 2: 30. doi:10.1896/1413-4411.6.1.59c.

Ministério do Meio Ambiente (MMA). 2006. "Diretrizes e Prioridades do Plano de Ação para Implementação da Política Nacional da Biodiversidade PAN-Bio". Brasília, DF

Ministério do Meio Ambiente (MMA). 2007. “Áreas Prioritárias Para a Conservação, Uso Sustentável e Repartição de Benefícios da Biodiversidade Brasileira: Atualização - Portaria MMA n 9 , de 23 de Janeiro de 2007”. Série Biodiversidade e Florestas. doi:10.1007/s13398-014-0173-7.2. Brasília, DF.

Ministério do Meio Ambiente (MMA). 2013. "Resolução CONABIO No 06” Brasília, DF

Ministério do Meio Ambiente (MMA). 2014. "Portaria No 187” Brasília, DF: Diário Oficial da União, No 97, Seção 1, página 103.

Ministério do Meio Ambiente (MMA). 2015. "Segunda Atualização das Áreas Prioritárias para Conservação, Uso Sustentável e Repartição dos Benefícios da Biodiversidade da Caatinga - Relatório Final” Brasília, DF.

Ministério do Meio Ambiente (MMA). 2015. "Subsídios Para Um Plano de Ação Governamental E Diretrizes Para O PPA 2016-19: Conservação E Uso Sustentável da Biodiversidade". Brasília, DF.

Ministério do Meio Ambiente (MMA/ARPA). 2007. "Priority Areas for Conservation, Sustainable Use, and Sharing of the Biodiversity Benefits - Amazon Biome". Environment. Brasília, DF: MMA/SBF/ARPA/UCP. 
Ministério do Meio Ambiente (MMA/ARPA). 2010. "Documento de Programa do Governo Brasileiro: Programa Áreas Protegidas da Amazônia - Arpa" Brasília, DF. doi:10.1590/S0100-69912007000300001.

Ministério do Meio Ambiente (MMA/ARPA). 2011. "Estratégia de Conservação E Investimento - ECI 2011-2014: Ferramenta Para a Seleção E Priorização de Avanços Das Unidades de Conservação Apoiadas Pelo Programa Áreas Protegidas Da Amazônia - Arpa. Elaboração: Ronaldo Weigand Jr., Com Daniela de Oliveira. Brasília, DF: MMA/SBF/ARPA/UCP.

Ministério do Meio Ambiente (MMA/ARPA). 2011. "Manual Fundo de Áreas Protegidas (FAP)” MMA/SBF/ARPA/UCP, Brasília, DF: MMA/SBF/ARPA/UCP.

Ministério do Meio Ambiente (MMA/ARPA). 2011. "Relatório de Avanço Da Consolidação Da Gestão Das Unidades de Conservação Apoiadas Pelo Programa Arpa” Brasília, DF: MMA/SBF/ARPA/UCP.

Ministério do Meio Ambiente (MMA/ARPA). 2012. "Regimento Interno Do Fundo De Áreas Protegidas" Brasília, DF: MMA/SBF/ARPA/UCP.

Ministério do Meio Ambiente (MMA/ARPA). 2013. "Relatório Técnico- Financeiro 2011-2012 Do Programa Áreas Protegidas Da Amazônia" Brasília, DF: MMA/SBF/ARPA/UCP.

Ministério do Meio Ambiente (MMA/ARPA). 2014. "Documento de Consolidação de Marcos Referênciais, Pessoal, Biênio 2014/2015" Brasília, DF: MMA/SBF/ARPA/UCP.

Ministério do Meio Ambiente (MMA/ARPA). 2014. "Programa Áreas Protegidas da Amazônia (Arpa) Conheça O Maior Programa de Conservação E Uso Sustentável de Florestas Tropicais Do Planeta". Brasília, DF: MMA/SBF/ARPA/UCP.

Ministério do Meio Ambiente (MMA/ARPA). 2014. "Relatório Técnico-Financeiro (2013-2014)" Brasília, DF: MMA/SBF/ARPA/UCP.

Ministério do Meio Ambiente (MMA/ARPA). 2015. "Manual Operacional Do Programa Áreas Protegidas Da Amazônia (MOP - Fase III)” MMA/SBF/ARPA/UCP.

Ministério do Planejamento e Gestão (MOPG/GESPUBLICA). 2008. Programa Nacional de Gestão Pública e Desburocratização. Critérios de Avaliação 2008. Brasília: DF.

Mittermeier, R. A., Da Fonseca, G. A.B., Rylands, A. B. And Brandon, K. (2005), A Brief History of Biodiversity Conservation in Brazil. Conservation Biology, 19: 601-607. doi:10.1111/j.1523-1739.2005.00709.x

NASH, Roderick. 2001. "Wilderness and the American Mind". Yale: Yale University Press.

Naughton-Treves, L., Buck, M. and K. Brandon. 2005. "The Role of Protected Areas in Conserving Biodiversity and Sustaining Local Livelihoods". Annual Review of Environment and Resources. 30:219-252. 
Nelson, Andrew, and Kenneth M. Chomitz. 2011. "Effectiveness of Strict vs. Multiple Use Protected Areas in Reducing Tropical Forest Fires: A Global Analysis Using Matching Methods" PLoS ONE 6 (8). doi:10.1371/journal.pone.0022722.

Nelson, Bruce, Ana Albernaz, and Britaldo Soares Filho. 2006. "Estratégias de Conservação para o Programa Arpa: Representatividade Ecológica e Ameaças". Documento Técnico. Brasilia, DF: MMA/SBF/ARPA/UCP.

Nepstad, D., Schwartzman, S., Bamberger, B., Santilli, M., Ray, D., Schlesinger, P., Lefebvre, P., Alencar, A., Prinz, E., Fiske, G. And Rolla, A. 2006. "Inhibition of Amazon Deforestation and Fire by Parks and Indigenous Lands". Conservation Biology, 20: 65-73. doi:10.1111/j.1523-1739.2006.00351.x

Nolte C, Leverington F, Kettner A, Marr M, Nielsen G, Bomhard B, Stolton S, StollKleemann S, Hockings M. 2010. "Protected area management effectiveness assessments in Europe. A review of application, methods and result"s. BfN Skripten 271a. German Federal Agency for Nature Conservation: Bonn, Germany

Nolte C, Agrawal A. 2013. "Linking management effectiveness indicators to observed effects of protected areas on fire occurrence in the Amazon rainforest". Conservation Biology 27(1):155-65

Nolte, Christoph, Arun Agrawal, and Paulo Barreto. 2013. "Setting priorities to avoid deforestation in Amazon protected areas: are we choosing the right indicators?" Environmental Research Letters 8(1):015049. doi:10.1088/1748-9326/8/1/015039

Nolte, Christoph, Arun Agrawal, Kirsten M. Silvius, and Britaldo S. Soares-Filho. 2013. "Governance Regime and Location Influence Avoided Deforestation Success of Protected Areas in the Brazilian Amazon" Proceedings of the National Academy of Sciences 110 (13): 4956-61. doi:10.1073/pnas.1214786110.

Nolte C. 2014. "Governance, management, and conservation success of protected areas in Brazil and Colombia". PhD thesis. University of Michigan: Ann Arbor, USA

Oliveira, Daniela e Franco, José Luiz De Andrade. 2010. "Efetividade de Gestão de Unidades de Conservação: Resultados e Implementação das Avaliações". Trabalho Apresentado no V ENANPPAS: V Encontro Nacional da ANPPAS em 4 a 7 de outubro de 2010, Florianópolis/SC.

Oliveira, Daniela. 2012. "Avaliação de Efetividade de Gestão de Unidades de Conservação: O Mosaico Do Apuí - Amazonas/AM" Dissertação de Mestrado. Universidade de Brasília.

Padovan, Maria Penha. 2002. "Parâmetros e procedimentos para a certificação do manejo de unidades de conservação". In: III CONGRESSO BRASILEIRO DE UNIDADES DE CONSERVAÇÃO, 2002, Fortaleza, CE. Anais: Rede Nacional Pró-Unidades de Conservação/Fundação O Boticário de Proteção à Natureza. P:33-44.

Padovan, Maria Penha. 2003. “Certificação de Unidades de Conservação”. São Paulo: Conselho Nacional da Reserva da Biosfera, 56p.

Pádua, M. T.J. 1997. "Sistema Nacional de Unidades de Conservação: de onde viemos para onde vamos?" Anais do Congresso Brasileiro de Unidades de Conservação. 
Curitiba: IAP - UNILIVRE - Rede Nacional Pró-Unidades de Conservação. p. 214236, 1997.

Paiva, Rodrigo José Oliveira, Ricardo Seixas Brites, and Ricardo Bomfim Machado. 2015. "The Role of Protected Areas in the Avoidance of Anthropogenic Conversion in a High Pressure Region: A Matching Method Analysis in the Core Region of the Brazilian Cerrado" PLoS ONE 10 (7): 1-24. doi:10.1371/journal.pone.0132582

Pavese, Helena Boniatti, Fiona Leverington, and Marc Hockings. 2007. "Estudo Global Da Efetividade de Manejo de Unidades de Conservação: A Perspectiva Brasileira" Natureza \& Conservação 5 (1). Curitiba, Paraná, Brasil: 65-77.

Petrova, Saska. 2014. Communities in Transition: Protected Nature and Local People in Eastern and Central Europe. Ashgate Publishing Ltd. 206p.

Pettorelli, Nathalie. 2013. "Satellite Data-Based Indices to Monitor Land Use and Habitat Changes" In Biodiversity Monitoring and Conservation: Bridging the Gap between Global Commitment and Local Action, edited by Jonathan E.M. Baillie and Sarah M. Durant. (C2013 Ben Collen, Nathalie Pettorelli, First Edit, 98-119. London: John Wiley \& Sons, Ltd.

Pomeroy, Robert S, John E Parks, and Lani M Watson. 2004. "How Is Your MPA Doing? A Guidebook of Natural and Social Indicators for Evaluating Marine Protected Area Management Effectiveness". IUCN, Gland, Switzerland and Cambridge, UK.

Pomeroy, Robert S., John E. Parks, and Lm Watson. 2006. "Comment va votre AMP? Guide sur les indicateurs naturels et sociaux destinés à évaluer l'efficacité de la gestion des aires marines protégées". Glans, Suisse: UICN, Gland, Suisse et Cambridge, Royaume-Uni.

Possingham, Hugh, Ian Ball, and Sandy Andelman. 2000. "Mathematical Methods for Identifying Representative Reserve Networks" In Quantitative Methods for Conservation Biology, 291-306. New York, NY: Springer New York. doi:10.1007/0-387-22648-6_17.

Possingham, H. P., Wilson, K. A., Andelman, S. J. \& Vynne, C. H. 2006. in Principles of Conservation Biology. Eds Groom, M. J., Meffe, G. K.\& Carroll, C. R.

Pressey R L, Visconti P, Ferraro P J. 2015 "Making parks make a difference: poor alignment of policy, planning and management with protected-area impact, and ways forward”. Phil. Trans. R. Soc. B 370, 20140280. (doi:10.1098/rstb.2014.0280)

Rodrigues, Ana S L, Sandy J Andelman, Mohamed I Bakarr, Luigi Boitani, Thomas M Brooks, Richard M Cowling, Lincoln D C Fishpool, et al. 2004. "Effectiveness of the global protected area network in representing species diversity". Nature 428. April: 9-12, 2004.

Roselli, Katia Cury, R. Brandão, B.F. Brito, F.F.B. Bucci, e A.A. Jacob. 2013. "Monitoramento de Biodiversidade Em Unidades de Conservação Federais Da Amazônia - Aplicação do SIMBIO no âmbito do Programa Áreas Protegidas da Amazônia (Arpa)" Disponivel em http://comfauna.org/monitoramento?de?biodiversidade?em?unidades?de?conserva 
cao?federais?da?amazonia?aplicacao?do?simbio?no?ambito?do?programa?Arpa, acesso em 05/06/2016.

Rylands, A. B. and Brandon, K. 2005. "Brazilian Protected Areas". Conservation Biology, 19: 612-618. doi:10.1111/j.1523-1739.2005.00711.x

Rylands, A.B. \& L.P.S. Pinto. 1998. "Conservação da Biodiversidade na Amazônia Brasileira: uma análise do sistema de unidades de conservação". Cadernos Fundação Brasileira Desenvolvimento Sustentável 1: 14-15.

Scaramuzza, C.A.M, e R.B Machado. 2003. “Aplicação do Planejamento Sistemático da Conservação na Definição de Áreas Prioritárias para Conservação no Estado de Goiás" Seb-Ecologia.Org.Br. Disponível em http://sebecologia.org.br/viiceb/resumos_professores/Conferidos/PDF/Scaramuzza.pdf.

SCHERL, L. M.; WILSON, A.; WILD, R.; et al. 2006. "As áreas protegidas podem contribuir para a redução da pobreza? Oportunidades e limitações”. Gland, Suiça e Cambridge, Reino Unido: IUCN Unidade de Serviços de Publicação.

Schmeller, Dirk S, Pierre-Yves Henry, Romain Julliard, Bernd Gruber, Jean Clobert, Frank Dziock, Szabolcs Lengyel, et al. 2009. "Advantages of Volunteer-Based Biodiversity Monitoring in Europe" Conservation Biology: The Journal of the Society for Conservation Biology 23 (2): 307-16. doi:10.1111/j.15231739.2008.01125.x.

Secretaria de Estado de Meio Ambiente e Desenvolvimento Sustentável (SDS), and Centro Estadual de Unidades de Conservação (CEUC). 2009. "AMAZONAS CONSERVATION NETWORK Final Report, April (2005) to August (2008) Submitted" Manaus, AM.

Silva, Cristina Isis Buck. 2012. "Use of systematic conservation planning in the zoning of conservation in the Amazon". Dissertação (Mestrado em Capacidade de suporte, Ecologia animal, Ecologia vegetal, Ecossistemas, Interação inseto-planta, Lim) Instituto Nacional de Pesquisas da Amazônia, Manaus.

Soares-Filho, B.; Moutinho, P.; Nepstad, D.; Anderson, A.; Rodrigues, H.; Garcia, R.; Dietzsch, L.; Merry, F.; Bowman, M.; Hissa, L.; Silvestrini, R. \& Maretti, C. 2010. "Role of Brazilian Amazon protected areas in climate change mitigation". PNAS: www.pnas.org/cgi/doi/10.1073/pnas.0913048107.

Soares-Filho, Britaldo Silveira, Daniel Curtis Nepstad, Lisa Curran, Gustavo Coutinho Cerqueira, Ricardo Alexandrino Garcia, Claudia Azevedo Ramos, Eliane Voll, et al. 2005. "Cenários de Desmatamento Para a Amazônia" Estudos Avançados 19 (54): 137-52. doi:10.1590/S0103-40142005000200008.

Soares-Filho, Britaldo Silveira, Laura Dietzsch, and Paulo Moutinho. 2008. "Redução das Emissões de Carbono do Desmatamento no Brasil : O Papel Do Programa Áreas Protegidas Da Amazônia (Arpa)". Brasília, DF: WWF-Brasil, The Woods Hole Reserch Center, INPA e UFM. http://scholar.google.com/scholar?hl=en\&btnG=Search\&q=intitle:Redu??o+de+E miss?es+de+Carbono+associadas+ao+desmatamento+no+Brasil:+O+papel+do+pr ograma+de+?reas+protegidas+da+Amaz?nia+(ARPA)\#0. 
Souza, João Vitor Campos de. 2013. "Congressos Mundiais de Parques Nacionais da UICN (1962-2003): Registros e reflexões sobre o Surgimento de um novo paradigma para a conservação da natureza". Dissertação de Mestrado. Universidade de Brasília/CDS.

Staub, Francis, and Marea E Hatziolos. 2004. "Score Card to Assess Progress in Achieving Management Effectiveness Goals for Marine Protected Areas" Prepared for the World Bank. The World Bank. 29p

Steenbock, Walter, Karina Ferreira de Barros, Nivaldo Peroni, and Maurício Sedrez dos Reis. 2012. "Uso E Manejo de Recursos Vegetais Em Unidades de Conservação" Biodiversidade

Brasileira 2 http://www.icmbio.gov.br/revistaeletronica/index.php/BioBR/article/view/268/189.

Stephens, Philip A., Nathalie Pettorelli, Jos Barlow, Mark J. Whittingham, and Marc W. Cadotte. 2015. "Management by Proxy? The Use of Indices in Applied Ecology" Journal of Applied Ecology 52 (1): 1-6. doi:10.1111/1365-2664.12383.

Stolton, Sue, Nigel Dudley, and Jonathan Randall. 2008. "Arguments for Protection Natural Security Protected Areas and Hazard Mitigation”. Research Report by WWF and Equilibrium". WWF.128p.

Terborgh, John E Schaik, Carel Van. 2002. "Por que o mundo necessita de parques?" In: TERBORGH, John; SCHAIK, Carel van; DAVENPORT, Lisa; RAO, Madhu (orgs). Tornando os parques eficientes: estratégias para a conservação da natureza nos trópicos. Cutitiba: Editora da UFPR e Fundação O Boticário, pp. 25-36.

Thorsell J.W. 1982. "Evaluating effective management in protected areas: An application to Arusha National Park, Tanzania". Gland (Switzerland): IUCN Commission on National Parks and Protected Areas

Tua, Jon, Manuela Mossé Muanis, Leonardo Geluda, Daniela de Oliveira, and Greg Love. 2011. "Amazon Region Protected Areas (Arpa) 2011-2020 Financial Plan Report"

Turner, W. 2014. "Sensing Biodiversity" Science 346 (6207): 301-2. doi:10.1126/science.1256014.

Turner, W., C. Rondinini, N. Pettorelli, B. Mora, A. K. Leidner, Z. Szantoi, G. Buchanan, et al. 2015. "Free and Open-Access Satellite Data Are Key to Biodiversity Conservation" Biological Conservation 182. Elsevier Ltd: 173-76. doi:10.1016/j.biocon.2014.11.048.

UNEP/CBD/COP. 2004. "Seventh Ordinary Meeting of the Conference of the Parties to the Convention on Biological Diversity, 9 - 20 February 2004 - Kuala Lumpur, Malaysia" In Seventh Ordinary Meeting of the Conference of the Parties to the Convention on Biological Diversity, 9 - 20 February 2004 - Kuala Lumpur, Malaysia.

Venter, FJ, Naiman, B, Biggs, HC \& Pienaar, DJ 2008, 'The evolution of conservation management philosophy: Science, environmental change and social adjustments in Kruger National Park" Ecosystems, vol 11, no. 2, pp. 173-192, 10.1007/s10021-0079116-X 
Veríssimo, A., A. Rolla, A. P. Maior, A. Monteiros, B. Brito, C. Souza Jr, e C. Augusto. 2011. "Áreas Protegidas na Amazônia Brasileira: Avanços e Desafios". IMAZON e ISA.

Watts, M.E., C.K. Klein, R. R. Stewart, I. R. Ball, and H. P. Possingham. 2008. "Marxan con Zonas (V1.0.1): Conservación por zonas mediante calibración espacial explicita". 44p. Disponível em http://marxan.net/downloads/documents/Marxan_with_Zones_User_Manual_v101 _Spanish.pdf. Acesso em 04/05/2016.

Watts, M.E. 2016. "Marxan.io user guide: A web app for systematic conservation planning". Australian Research Council Centre of Excellence for Environmental Decisions. The University of Queensland. 25p. Disponível em http://marxan.net/downloads/Marxan_io_rev25_user_guide.pdf. Acesso em 04/05/2016.

Weigand Jr, Ronaldo, Daniela Oliveira, e Vera Maria Weigand. 2014. "White Paper Conceitos e Indicadores da Implementação das Metas Nacionais de Biodiversidade (CDB 2020) Referentes Ao Objetivo Estratégico C 'Melhorar a Situação Da Biodiversidade Protegendo Ecossistemas, Espécies E Diversidade Genética' (Metas 11 a 13)" Brasília, DF.

Weigand Jr, Ronaldo, Pereira, Tatiany Barata, Daniela Oliveira. "Avaliação da Efetividade de Unidades de Conservação no Programa Áreas Protegidas da Amazônia (Arpa)" Resumo in Anais do II Congresso Latino-americano de Parques, Bariloche/Argentina, 2007.

Weigand Jr, Ronaldo, Tatiane Barata e Daniela Oliveira. 2007. "Ferramenta de Avaliação de Unidades de Conservação (FAUC): Registro da Adaptação da Ferramenta Tracking Tool para o Programa Áreas Protegidas Da Amazônia (Arpa)" Brasilia, DF.

West, Paige and Igoe, -James and Brockington, Dan. 2006. "Parks and Peoples: The Social Impact of Protected Areas". Annual Review of Anthropology, Vol. 35, October 2006. Available at SSRN: https://ssrn.com/abstract=1081408

Wetterberg, G.B., Pádua, M.T.J., Castro, C.S. e Vasconcellos, J.M.C. 197. "Uma Análise de Prioridades em Conservação da Natureza na Amazônia". Série Técnica ${ }^{\circ} 8$. Projeto de Desenvolvimento e Pesquisa Florestal - PNUD/FAO/IBDF/BRA-45, 1976. $6 \mathrm{p}$

Whittaker, Robert J., M. B. Araujo, R. J. Jepson, P., Ladle, J. E. M. Watson, and K. J. Willis. 2005. "Conservation Biogeography: Asessment and Prospect" Diversity and Distributions 11: 3-23. doi:10.1111/j.1366-9516.2005.00143.x.

Wiles, Janice, Ricardo Carvalho, Rogerio Cabral, and Weber Amaral. 2006. “Avaliação Independente - Programa Areas Protegidas da Amazonia (Arpa)” Brasília, DF.

Wilkie, D. S.; Morelli, G. A.; Demmer, J.; et al.2006. "Parks and people : assessing the human welfare effects of establishing protected areas for biodiversity conservation". Conservation Biology: the journal of the Society for Conservation Biology, v. 20, n. 1, p. 2006, 2006. 
World Bank. 2002a. "Brazil: Amazon Region Protected Areas Project (GEF)". Washington, DC: World Bank. http://documents.worldbank.org/curated/en/2002/07/1964254/brazil-amazonregion-protected-areas-project-gef

World Bank. 2002b. "Amazon Region Protected Areas Project - Global Environment Facility Trust Fund Grant Agreement". Washington, DC: World Bank. http://documents.worldbank.org/curated/en/2002/10/5087796/conformed-copy$\underline{\text { tf051240-amazon-region-protected-areas-project-global-environment-facility-trust- }}$ fund-grant-agreement

WWF Brasil. 2000. “Áreas Protegidas ou Espaços Ameaçados: O Grau de Implementação e a vulnerabilidade das Unidades de Conservação federais Brasileiras de Uso Indireto". Coordenação: Rosa M. Lemos de Sá e Leandro Ferreira. Brasília, DF.

WWF-BRASIL \& ICMBIO. 2012. "Efetividade da gestão das unidades de conservação federais do Brasil: resultados de 2010”. Brasília, DF

WWF-BRASIL \& IMASUL. 2011. "Efetividade de Gestão das unidades de conservação no Estado do Mato Grosso do Sul". Brasília, DF

WWF-BRASIL \& Semarh-GO. 2014. "'Implementação da avaliação rápida e priorização da gestão de unidades de conservação (Rappam) em unidades de conservação estaduais em Goiás". Brasília, DF

WWF-Brasil, e Instituto Florestal. 2004. "Rappam - Implementação da Avaliação Rápida e Priorização do Manejo de Unidades de Conservação do Instituto Florestal e da Fundação Florestal de São Paulo”. WWF-Brasil.

WWF-BRASIL, IEF-AP, SEMA-AP \& ICMBIO. 2009. "Efetividade de Gestão das unidades de conservação no Estado do Amapá”. Brasília, DF

WWF-BRASIL, SDS-AM, ICMBIO. 2011. "Efetividade de Gestão das unidades de conservação do Estado do Amazonas". Brasília, DF

WWF-BRASIL, SEDAM-RO, ICMBIO. 2011. "Efetividade de Gestão das unidades de conservação do Estado de Rondônia". Brasília, DF

WWF-BRASIL, SEMA-AC, SEF-AC \& ICMBIO. 2009. "Efetividade De Gestão das unidades de conservação no Estado do Acre”. Brasília, DF.

WWF-BRASIL, SEMA-MT \& ICMBIO. 2009. "Efetividade de Gestão das unidades de conservação no Estado do Mato Grosso”. Brasília, DF

WWF-BRASIL, SEMA-PA, ICMBIO. 2011. "Efetividade de Gestão das unidades de conservação do Estado do Pará”. Brasília, DF

WWF-Brasil. 2010. “Arpa: Desmatamento e Mudanças Climáticas”, Brasília, DF: WWFBrasil.

WWF-Brasil. 2012. "ATA Reunião da Assembleia de Doadores do FAP e Anexos" Brasília, DF: WWF- Brasil 
Anexo 1 - Formulário para avaliação da efetividade das áreas protegidas proposto por MacKinnon e MakKinnon, 1986, e MacKinnon e MakKinnon,1990.

\section{THE LIST BELOW HAS BEEN USED BY IUCN'S CNPPA TO INDICATE THE TYPE OF QUESTIONS THAT A PROTECTED AREA MANAGER SHOULD CONSIDER IN EVALUATING THE EFFECTIVENESS OF THE MANAGEMENT OF HIS AREA.}

1. Clearly defined specific objectives to guide management, this area:
a) has written objectives specific to the area.
b) has only broad objectives.
c) lacks specific objectives at present.

2. Legislation, this area:

a) is fully protected by the national or provincial legislation and has a compatible set of regulations specific to the area.

b) is protected by national legislation but does not have a set of regulations specific to the area. .

c) is inadequately protected by national legislation and lacks local regulations.

d) is sufficiently protected by national legislation and does not require local regulations.

3.Basic resources information, this area has the following:
a) Inventory of mammals
b) inventory of birds
c) inventory of other vertebrates
d) complete inventory of plants
e) partial inventory of plants
f) vegetation map
g) inventory of invertebrates
h) geological map
i) soil map
j) climatic data
k) hydrological data
1) topographic map
m) aerial photographs
n) bibliography of publications

4. Basic ecological information, this area has the following:
a) studies of wildlife population dynamics
b) studies of population status and trends of key species .
c) information on relationships between tildlife and the habitat
d) studies of predator-prey relationships
e) information on the carrying capacity of the habitat for key species
f) information on disease reservoirs among the wildlife
g) studies on ecological succession
h) information on fire history and its effects

5. Watershed management, this area, (check more than one if necessary): _

a) protects a watershed or watersheds considered to contribute to the welfare of downstream human populations (e.g. drinking water, irrigation, flood control). 
b) protects a watershed or watersheds considered to contribute to downstream ecological process (e.g. estuarine and coastal fisheries).

c) because of its importance to human welfare, is left unmanipulated (in a natural state).

d) is lightly manipulated, through natural means (e.g. fire control, reforestation).

e) is manipulated through engineering works (checkdams, streams channelisation, terracing).

6. Genetic resources, this area:

a) has a number of species of plants/animals of potential or actual benefit to humanity and these receive special attention in management decisions.

b) probably has a number of species of plants/animals of potential or actual benefit to humanity, but there is little available data about them so they receive little special attention.

c) has little data available but genetic resources are still given special consideration in management decisions.

d) is managed on the basis of overall intrinsic values of nature so genetic resources are not given specific attention.

e) is managed to preserve biological diversity and genetic conservation incidental to this.

7. Management plan, this area:

a) has an approved management plan which is being implemented and monitored

b) has a management plan but it has not been accepted/approved/implemented.

c) has a management plan in preparation.

d) lacks a management plan at present.

e) lacks a management plan and local circumstances do not call for one at this time.

8. Zoning, this area:

a) has a zoning plan which effectively controls

human impact and development reiative to carrying capacity.

b) has a zoning plan which partially controls human impact and development relative to carrying capacity.

c) does not yet have a zoning plan, but such a plan is being prepared.

d) does not have a zoning plan.

e) does not have a zoning plan, nor is a plan required a.t present.

9.Boundaries, this area:

a) has physically and narratively demarcated boundaries which effectively define the area.

b) has demarcated boundaries in certain key areas and this is felt adequate.

c) has some boundaries demarcated, but these are felt insufficient.

d) lacks demarcation of boundaries.

e) lacks or partially lacks formal demarcation of boundaries but this is deemed appropriate for the current situation.

10. Ecologically sufjkient boundaries, this area:

a) encloses an entire ecosystem, so is fully self-sufficient.

b) comprises the upper part of a watershed, but has no control over the lower parts.

c) comprises the lower part of a watershed, but has no control over the upper parts.

d) comprises only a fragment of a total ecosystem, requiring intensive management to maintain natural functioning.

11. Protection of natural resources, this area:

a) is fully and effectively protected from resource exploitation.

b) is protected at a level appropriate to area objectives.

c) is used only by local people for their own needs. 
d) suffers from illegal harvesting of vegetation, illegal grazing, or poaching of animals.

e) permits exploitation of selected resources.

12.Research, this area at this time:

a) has a strong, well-integrated programme of basic and applied research which provides support to the management objectives.

b) has only basic, academic research which provides indirect input to improved management.

c) has ad hoc research which may provide support to management objectives.

d) has no research, either basic or applied.

e) has no on-going or planned research programme and local circumstances do not call for one at this time.

13.Formal education, this area:

a) has adequate educational facilities or extension programmes and is well used by local/national educational institutions.

b) is used by local/national educational institutions for planned, supervised field trips but there are few local facilities.

c) is used by students for informal, unsupervised field trips.

d) is seldom used for educational purposes.

14. Informaleducation, this area has the following visitor facilities:
a) Leaflets
b) Maps
c) Marked trails
d) Signs
e) Guide service
f) Information centre
g) Audio-visual programmes
h) Public transportation
i) Hides

15. Tourism, this area:

a) is important for tourism and has all necessary facilities for present levels of visitor use.

b) receives so many tourists that the reserve staff has little time for other management activities.

c) receives many tourists, but facilities are inadequate.

d) is of only minor importance for tourism at present.

e) does not include tourism as an objective.

16. Political support (check more than one if necessary):

a) the central government has made a commitment to attain the conservation objectives of the area.

b) the regional government has made a commitment to attain the conservation objectives of the area.

c) the local people support the protection of the area.

d) lack of political support is a major problem.

e) insufficient support (or active opposition) by local people is a major problem.

17. Local participation, this area:

a) has a local advisory committee or otherwise involves local people in decisionmaking.

b) involves at least some officials of local government.

c) involves local people only informally.

d) does not involve local people at all.

18.Benefits to local people, this area: 
a) brings real benefits to the local people in terms of watershed protection, employment opportunities, buffer zone development, economic subsidy, or other related developments

b) brings some benefits to the local people.

c) brings virtually no benefits to the local people.

19. Budget, this area:

a) has sufficient budget to attain its objec- tives as stated in management plan.

b) receives a budget which is insufficient to allow the management plan to be fully implemented.

c) receives a budget which allows only basic maintenance and staffing.

d) lacks a budget.

20. Maintenance, this area:'

a) has a budget for maintenance and this is sufficient to keep equipment/facilities in reasonable working order.

b) has a budget for maintenance but this is insufficient to keep equipment/facilities in reasonable working order.

c) does not have any budget for maintenante but maintenance of equipment/facilities is still acceptable.

d) has no budget for maintenance and equipment/facilities suffering as a result

21. Personnel and training, this area:

a) has sufficient trained personnel to attain the specified management objectives.

b) lacks sufficient personnel and access to training programmes.

c) has no personnel or training opportunities.

22. Equipment, this area: $\mathrm{p}$,

a) is sufficiently well equipped to attain its management objectives.

b) needs more vehicles/boats.

c) needs more uniforms/equipment for rangers.

d) needs more housing/guard-posts/headquarters buildings

e) needs more survey equipment

f) needs more medical/first aid equipment.

g) needs more communication equipment.

h) needs more office equipment.

23. Role of external support, this area (check more than one if necessary):

a) is sufficiently well managed and funded that no outside support has been requested.

b) has received/is receiving external support.

c) receives additional support from within the country.

d) needs outside support, which is being sought.

e) needs outside support but such support is not being sought.

f) has voluntary workers/honorary officers helping in management projects. 


\section{Anexo 2 - Metodologias de Avaliação da Efetividade de Gestão (Estudo Global)}

\begin{tabular}{|c|c|c|}
\hline ACRONIMO $^{104}$ & NOME ORIGINAL DA METODOLOGIA & $\begin{array}{l}\text { ORGANZAÇÃO } \\
\text { RESPONSÁVEL } \\
\end{array}$ \\
\hline RAPPAM & $\begin{array}{l}\text { Rapid Assessment and Prioritisation of } \\
\text { Protected Area Management }\end{array}$ & WWF \\
\hline Tracking tool & Management Effectiveness Tracking Tool & World Bank/WWF Alliance \\
\hline $\mathrm{EOH}$ & Enhancing our Heritage & UNESCO / IUCN / UNF \\
\hline AEMAPPS & $\begin{array}{l}\text { AEMAPPS: MEE with Social Participation - } \\
\text { Colombia }\end{array}$ & $\begin{array}{l}\text { Parques Nacionales Naturales de } \\
\text { Colombia/WWF Colombia }\end{array}$ \\
\hline Brazil 1999 & $\begin{array}{l}\text { Degree of Implementation and the Vulnerability } \\
\text { of Brazilian Federal Conservation Areas }\end{array}$ & WWF Brazil with IBAMA \\
\hline TNC CAP & Conservation Action Planning & TNC \\
\hline Catalonia MEE & Catalonia MEE & $\begin{array}{l}\text { Institució Catalana d'Història } \\
\text { Natural }\end{array}$ \\
\hline $\begin{array}{l}\text { How is Your MPA } \\
\text { Doing }\end{array}$ & How is Your MPA Doing & $\begin{array}{l}\text { NOAA/National Ocean } \\
\text { Service/IUCNWCPA Marine, } \\
\text { WWF }\end{array}$ \\
\hline MARIPA-G & $\begin{array}{l}\text { Monitoring and Assessment with Relevant } \\
\text { Indicators of Protected Areas of the Guianas } \\
\text { (MARIPA-G) }\end{array}$ & WWF Guianas \\
\hline Belize MEE & $\begin{array}{l}\text { Belize National Report on Management } \\
\text { Effectiveness }\end{array}$ & Forest Department Belize \\
\hline Ecuador MEE & $\begin{array}{l}\text { Ecuador MEE: Indicadores para el Monitoreo y } \\
\text { Evaluación del Manejo de las Áreas Naturales } \\
\text { Protegidas del Ecuador }\end{array}$ & Ministry of Environment \\
\hline Finland MEE & Management Effectiveness Study - Finland & Metsahallitus \\
\hline Galápagos MEE & $\begin{array}{l}\text { Manual para la evaluación de la Eficiencia de } \\
\text { Manejo del Parque Nacional Galápagos. SPNG }\end{array}$ & SPNG \\
\hline MEE Indian & MEE Indian & IIPA/ Centre for equity studies \\
\hline Peru MEE & Peru MEE & INRENA \\
\hline Tasmanian WHA & Tasmanian World Heritage MEE & Tasmanian PWS \\
\hline MEMS & $\begin{array}{l}\text { Metodología de Evaluación de Efectividad de } \\
\text { Manejo (MEMS) del SNAP de Bolivia }\end{array}$ & SERNAP \\
\hline Mesoamerica MPA & $\begin{array}{l}\text { Rapid Evaluation of Management Effectiveness } \\
\text { in Marine Protected Areas of Mesoamerica. }\end{array}$ & MBRS/PROARCA/CAPAS \\
\hline NSW SOP & NSW State of Parks & NSW DEC \\
\hline Others & Other reports: Brief summaries & \\
\hline Padovan 2002 & Padovan 2002 & IPEMA \\
\hline Parks profiles & Parks profiles & Parkswatch \\
\hline PROARCA/CAPAS & PROARCA/CAPAS scorecard evaluation & PROARCA/CAPAS \\
\hline Qld Park Integrity & Qld Park Integrity assessment & $\begin{array}{l}\text { Queensland Parks and Wildlife } \\
\text { Service }\end{array}$ \\
\hline Scenery matrix & Scenery matrix & Forestry institute (IF-SP) \\
\hline
\end{tabular}

104 Acrônimos estabelecidos para facilitar a identificação das ferramentas pelos autores do Estudo Global, e pode não refletir a abreviação utilizada pela organização responsável pelo método. 


\begin{tabular}{|c|c|c|}
\hline Mexico SIMEC & $\begin{array}{l}\text { Mexcican System of Information, Monitoring } \\
\text { and Evaluation for Conservation }\end{array}$ & $\begin{array}{l}\text { National Commission of } \\
\text { Protected areas of Mexico } \\
\text { (CONANP) }\end{array}$ \\
\hline $\begin{array}{l}\text { PIP Site } \\
\text { consolidation }\end{array}$ & TNC Parks in Peril Site Consolidation Scorecard & TNC/USAID \\
\hline Valdiviana & Valdiviana Ecoregion Argentina & WWF \\
\hline Venezuela Vision & Venezuela Vision & DGSPN - INPARQUES \\
\hline Victorian SOP & Victorian State of Parks & Parks Victoria \\
\hline WWF/CATIE & WWF/CATIE Evaluation Methodology & WWF/CATIE \\
\hline Marine tracking tool & WWF-World Bank MPA score card & WWF-World Bank \\
\hline PAN Parks & PAN Parks & PAN Parks Foundation \\
\hline MEVAP & Monitoring and Evaluation of Protected Areas & $\begin{array}{l}\text { C.U.R.S.A. (University } \\
\text { Consortium for Socioeconomic } \\
\text { and Environmental Research) }\end{array}$ \\
\hline $\begin{array}{l}\text { West Indian Ocean } \\
\text { MPA }\end{array}$ & West Indian Ocean Workbook & $\begin{array}{l}\text { West Indian Ocean Marine } \\
\text { Science Association }\end{array}$ \\
\hline $\begin{array}{l}\text { Egyptian Site-level } \\
\text { Assessment }\end{array}$ & $\begin{array}{l}\text { Management Effectiveness Evaluations of Egypt } \\
\text { National Parks }\end{array}$ & $\begin{array}{l}\text { Nature Conservation Sector } \\
\text { (NCS), Egyptian Environmental } \\
\text { Affairs }\end{array}$ \\
\hline $\begin{array}{l}\text { Africa rainforest } \\
\text { study }\end{array}$ & Africa rainforest study & academic/WCS \\
\hline Alder & \multicolumn{2}{|c|}{ Marine Protected Area Evaluation Model (Alder) } \\
\hline $\begin{array}{l}\text { Central African } \\
\text { Republic }\end{array}$ & Central African Republic & academic/WWF \\
\hline CI METT & $\begin{array}{l}\text { Conservation International Management } \\
\text { Effectiveness Tracking Tool }\end{array}$ & Conservation International \\
\hline Fraser Island WHA & Fraser Island World Heritage Area & Hockings \\
\hline Korea METT & $\begin{array}{l}\text { Korea survey on protected area management } \\
\text { status }\end{array}$ & Korea Parks service \\
\hline MEE - Congo & \multicolumn{2}{|l|}{ MEE - Congo } \\
\hline $\begin{array}{l}\text { PA Consolidation } \\
\text { index }\end{array}$ & PA Consolidation index & Conservation International \\
\hline $\begin{array}{l}\text { Qld Rapid } \\
\text { Assessment }\end{array}$ & Qld Rapid Assessment & $\begin{array}{l}\text { Queensland Parks and Wildlife } \\
\text { Service }\end{array}$ \\
\hline USA SOP & US State of Parks & NPCA \\
\hline WARPO & WARPO & $\begin{array}{l}\text { WWF West Africa Regional } \\
\text { Program Office }\end{array}$ \\
\hline $\begin{array}{l}\text { Wetland tracking } \\
\text { tool }\end{array}$ & Wetland tracking tool & WWF \\
\hline WWF Italy system & WWF Italy system & WWF Italy \\
\hline MPAME Indonesia & $\begin{array}{l}\text { Improving Marine Protected Area Management } \\
\text { Effectiveness in Indonesia }\end{array}$ & TNC Indonesia Marine Program \\
\hline
\end{tabular}

Fonte: http://www.wdpa.org/ME/tools.aspx (acesso em fevereiro de 2016) 


\section{Anexo 3 - Lista de Unidade de Conservação apoiadas pelo Programa Arpa}

\begin{tabular}{|c|c|c|c|c|c|c|}
\hline NOME DA UC & $\begin{array}{l}\text { TAMANHO } \\
\text { (HÁ) }\end{array}$ & CATEGORIA & $\mathbf{U F}$ & ESFERA & $\begin{array}{l}\text { ENTRADA } \\
\text { NO Arpa }\end{array}$ & $\begin{array}{c}\text { GRAU DE } \\
\text { CONSOLIDAÇÃO }\end{array}$ \\
\hline ESEC Terra do Meio & 3.373 .111 & Estação Ecológica & Pará & Federal & Fase I & 2 \\
\hline PARNA Anavilhanas & 350.018 & Parque & Amazonas & Federal & Fase I & 2 \\
\hline ESEC Jutaí Solimões & $288.187,38$ & Estação Ecológica & Amazonas & Federal & $\begin{array}{l}\text { Fase III } \\
(\text { Ago./15) }\end{array}$ & 1 \\
\hline ESEC Maracá & 101.312 & Estação Ecológica & Roraima & Federal & Fase I & 1 \\
\hline ESEC Maracá-Jipioca & 72.000 & Estação Ecológica & Amapá & Federal & $\begin{array}{c}\text { Fase II } \\
(\text { Nov./11) }\end{array}$ & 1 \\
\hline Esec Niquiá & 283.600 & Estação Ecológica & Roraima & Federal & $\begin{array}{c}\text { Fase II } \\
(\text { Nov./11) } \\
\end{array}$ & 1 \\
\hline ESEC Jari & 227.126 & Estação Ecológica & $\begin{array}{c}\text { Pará, } \\
\text { Amapá }\end{array}$ & Federal & $\begin{array}{c}\text { Fase II } \\
(\text { Nov./11) } \\
\end{array}$ & 1 \\
\hline ESEC Rio Acre & 77.500 & Estação Ecológica & Acre & Federal & $\begin{array}{c}\text { Fase II } \\
(\text { Nov./11) }\end{array}$ & 2 \\
\hline ESEC Juami Japurá & 572.650 & Estação Ecológica & Amazonas & Federal & Fase I & 2 \\
\hline PARNA Amazônia & 1.084 .896 & Parque & $\begin{array}{c}\text { Pará, } \\
\text { Amazonas } \\
\end{array}$ & Federal & $\begin{array}{c}\text { Fase III } \\
(\text { Mai./15) } \\
\end{array}$ & 1 \\
\hline PARNA Serra do Divisor & 842.736 & Parque & Acre & Federal & Fase I & 1 \\
\hline PARNA Serra do Pardo & 445.392 & Parque & Pará & Federal & Fase I & 2 \\
\hline PARNA Cabo Orange & 619.000 & Parque & Amapá & Federal & Fase I & 2 \\
\hline PARNA Jaú & 2.272 .000 & Parque & Amazonas & Federal & Fase I & 2 \\
\hline 15. PARNA Viruá & 227.011 & Parque & Roraima & Federal & Fase I & 2 \\
\hline $\begin{array}{l}\text { 16. PARNA Montanhas do } \\
\text { Tumucumaque }\end{array}$ & 3.867 .000 & Parque & Amapá & Federal & Fase I & 2 \\
\hline 17. PARNA Serra da Cutia & 283.612 & Parque & Rondônia & Federal & Fase I & 1 \\
\hline 18. PN Serra da Mocidade & 350.960 & Parque & $\begin{array}{c}\text { Amazonas, } \\
\text { Roraima }\end{array}$ & Federal & $\begin{array}{c}\text { Fase II } \\
(\text { Nov./11) }\end{array}$ & 1 \\
\hline REBIO Do Abufari & 288.000 & Reserva Biológica & Amazonas & Federal & $\begin{array}{c}\text { Fase III } \\
(\text { Mai./15) } \\
\end{array}$ & 1 \\
\hline Rebio Gurupi & 341.650 & Reserva Biológica & Maranhão & Federal & $\begin{array}{c}\text { Fase II } \\
(\text { Nov./11) } \\
\end{array}$ & 2 \\
\hline REBIO Jarú & 328.150 & Reserva Biológica & Rondônia & Federal & Fase I & 2 \\
\hline 22. $\quad$ REBIO Lago Piratuba & 357.000 & Reserva Biológica & Amapá & Federal & Fase I & 2 \\
\hline 23. REBIO Rio Trombetas & 385.000 & Reserva Biológica & Pará & Federal & Fase I & 2 \\
\hline 24. $\quad$ REBIO Tapirapé & 103.000 & Reserva Biológica & Pará & Federal & Fase I & 2 \\
\hline 25. $\quad$ REBIO Uatumã & 940.358 & Reserva Biológica & Amazonas & Federal & Fase I & 2 \\
\hline $\begin{array}{l}26 . \quad \text { REBIO Nascentes da Serra } \\
\text { do Cachimbo }\end{array}$ & 342.478 & Reserva Biológica & Pará & Federal & $\begin{array}{c}\text { Fase III } \\
(\text { Mai./15) } \\
\end{array}$ & 1 \\
\hline RDS Itatupã-Baquiá & 64.735 & $\begin{array}{c}\text { Reserva } \\
\text { Desenvolvimento } \\
\text { Sustentável } \\
\end{array}$ & Pará & Federal & Fase I & 1 \\
\hline 28. RESEX Auati-Paraná & 146.951 & $\begin{array}{c}\text { Reserva } \\
\text { Extrativista } \\
\end{array}$ & Amazonas & Federal & Fase I & 2 \\
\hline 29. RESEX Barreiro das Antas & 107.234 & $\begin{array}{c}\text { Reserva } \\
\text { Extrativista } \\
\end{array}$ & Rondônia & Federal & Fase I & 1 \\
\hline 30. RESEX Chico Mendes & 970.570 & $\begin{array}{c}\text { Reserva } \\
\text { Extrativista }\end{array}$ & Acre & Federal & $\begin{array}{c}\text { Fase II } \\
(\text { Nov./11) } \\
\end{array}$ & 2 \\
\hline
\end{tabular}




\begin{tabular}{|c|c|c|c|c|c|c|}
\hline $\begin{array}{l}\text { 31. RESEX Marinha Chocoaré- } \\
\text { Mato Grosso/Gestão integrada com } \\
\text { RESEX Maracanã; RESEX Mestre } \\
\text { Lucindo; RESEX Cuinarana }\end{array}$ & 2.785 & $\begin{array}{l}\text { Reserva } \\
\text { Extrativista }\end{array}$ & Pará & Federal & $\begin{array}{c}\text { Fase III } \\
(\text { Ago./15) }\end{array}$ & 1 \\
\hline $\begin{array}{l}32 . \quad \text { RESEX Maracanã/Gestão } \\
\text { integrada com RESEX Chocoaré- } \\
\text { Mato Grosso; RESEX Cuinarana; } \\
\text { RESEX Mestre Lucindo } \\
\end{array}$ & 30.019 & $\begin{array}{l}\text { Reserva } \\
\text { Extrativista }\end{array}$ & Pará & Federal & Fase I & 1 \\
\hline $\begin{array}{l}33 . \quad \text { RESEX São João da } \\
\text { Ponta/Gestão integrada com RESEX } \\
\text { Mãe Grande Curuça e RESEX } \\
\text { Marinha Mocapajuba } \\
\end{array}$ & 3.203 & $\begin{array}{l}\text { Reserva } \\
\text { Extrativista }\end{array}$ & Pará & Federal & $\begin{array}{l}\text { Fase III } \\
(\text { Ago./15) }\end{array}$ & 1 \\
\hline 34. RESEX Baixo Juruá & 187.982 & $\begin{array}{c}\text { Reserva } \\
\text { Extrativista } \\
\end{array}$ & Amazonas & Federal & Fase I & 2 \\
\hline 35. RESEX Cazumbá-Iracema & 750.795 & $\begin{array}{c}\text { Reserva } \\
\text { Extrativista } \\
\end{array}$ & Acre & Federal & Fase I & 2 \\
\hline 36. RESEX Médio Juruá & 286.932 & $\begin{array}{c}\text { Reserva } \\
\text { Extrativista } \\
\end{array}$ & Amazonas & Federal & $\begin{array}{c}\text { Fase II } \\
(\text { Nov./11) } \\
\end{array}$ & 1 \\
\hline 37. RESEX Rio Cautário & 73.817 & $\begin{array}{c}\text { Reserva } \\
\text { Extrativista }\end{array}$ & Rondônia & Federal & Fase I & 1 \\
\hline 38. RESEX Rio Jutaí & 275.533 & $\begin{array}{c}\text { Reserva } \\
\text { Extrativista } \\
\end{array}$ & Amazonas & Federal & Fase I & 1 \\
\hline 39. RESEX Ipaú-Anilzinho & 55.816 & $\begin{array}{c}\text { Reserva } \\
\text { Extrativista } \\
\end{array}$ & Pará & Federal & Fase I & 1 \\
\hline \begin{tabular}{|cc}
40. & RESEX Lago do Capanã \\
Grande & \\
\end{tabular} & 304.146 & $\begin{array}{c}\text { Reserva } \\
\text { Extrativista } \\
\end{array}$ & Amazonas & Federal & Fase I & 2 \\
\hline $\begin{array}{ll}41 . & \text { RESEX Mãe Grande } \\
\text { Curuça/Gestão integrada com } \\
\text { RESEX Marinha Mocapajuba e } \\
\text { RESEX São João da Ponta } \\
\end{array}$ & 37.062 & $\begin{array}{l}\text { Reserva } \\
\text { Extrativista }\end{array}$ & Pará & Federal & $\begin{array}{l}\text { Fase III } \\
\text { (Ago./15) }\end{array}$ & 1 \\
\hline 42. RESEX Mapuá & 94.464 & $\begin{array}{c}\text { Reserva } \\
\text { Extrativista } \\
\end{array}$ & Pará & Federal & Fase I & 1 \\
\hline 43. RESEX Rio Ouro Preto & 204.583 & $\begin{array}{c}\text { Reserva } \\
\text { Extrativista } \\
\end{array}$ & Rondônia & Federal & $\begin{array}{c}\text { Fase II } \\
\text { (Nov./11) } \\
\end{array}$ & 2 \\
\hline $\begin{array}{ll}44 . & \text { RESEX Riozinho da } \\
\text { Liberdade }\end{array}$ & 325.603 & $\begin{array}{c}\text { Reserva } \\
\text { Extrativista } \\
\end{array}$ & Acre & Federal & Fase I & 1 \\
\hline $\begin{array}{ll}45 . & \text { RESEX Riozinho do } \\
\text { Anfrísio } & \\
\end{array}$ & 736.341 & $\begin{array}{c}\text { Reserva } \\
\text { Extrativista } \\
\end{array}$ & Pará & Federal & Fase I & 2 \\
\hline $\begin{array}{l}46 . \quad \text { RESERVA } \\
\text { EXTRATIVISTA TAPAJÓS- } \\
\text { ARAPIUNS } \\
\end{array}$ & 647.611 & $\begin{array}{l}\text { Reserva } \\
\text { Extrativista }\end{array}$ & Pará & Federal & $\begin{array}{l}\text { Fase III } \\
\text { (Mai./15) }\end{array}$ & 1 \\
\hline 47. RESEX Verde para Sempre & 1.288 .717 & $\begin{array}{c}\text { Reserva } \\
\text { Extrativista } \\
\end{array}$ & Pará & Federal & Fase I & 2 \\
\hline 48. PARNA Rio Novo & 537.757 & Parque & Pará & Federal & Fase I & 1 \\
\hline 49. PN Jamanxim & 852.616 & Parque & Pará & Federal & $\begin{array}{c}\text { Fase II } \\
(\text { Nov./11) } \\
\end{array}$ & 2 \\
\hline 50. RESEX Arioca-Pruanã & 83.445 & $\begin{array}{c}\text { Reserva } \\
\text { Extrativista } \\
\end{array}$ & Pará & Federal & Fase I & 1 \\
\hline 51. RESEX Alto Tarauacá & 151.200 & $\begin{array}{c}\text { Reserva } \\
\text { Extrativista } \\
\end{array}$ & Acre & Federal & Fase I & 1 \\
\hline 52. RESEX Cururupu & 185.047 & $\begin{array}{c}\text { Reserva } \\
\text { Extrativista }\end{array}$ & Maranhão & Federal & $\begin{array}{c}\text { Fase II } \\
\text { (Nov./11) }\end{array}$ & 1 \\
\hline 53. RESEX Rio Iriri & 398.938 & $\begin{array}{c}\text { Reserva } \\
\text { Extrativista } \\
\end{array}$ & Pará & Federal & Fase I & 2 \\
\hline 54. PARNA Juruena & 1.957 .000 & Parque & $\begin{array}{c}\text { Mato } \\
\text { Grosso e } \\
\text { Amazonas } \\
\end{array}$ & Federal & Fase I & 1 \\
\hline
\end{tabular}




\begin{tabular}{|c|c|c|c|c|c|c|}
\hline $\begin{array}{l}\text { 55. RESEX Terra Grande- } \\
\text { Pracuúba }\end{array}$ & 194.695 & $\begin{array}{c}\text { Reserva } \\
\text { Extrativista } \\
\end{array}$ & Pará & Federal & Fase I & 1 \\
\hline 56. RESEX Rio Unini & 833.352 & $\begin{array}{c}\text { Reserva } \\
\text { Extrativista } \\
\end{array}$ & Amazonas & Federal & Fase I & 1 \\
\hline $\begin{array}{l}\text { 57. PARNA Campos } \\
\text { Amazônicos }\end{array}$ & 873.570 & Parque & $\begin{array}{c}\text { Amazonas, } \\
\text { Rondônia } \\
\text { e Mato } \\
\text { Grosso }\end{array}$ & Federal & Fase I & 2 \\
\hline 58. RESEX Arapixi & 133.637 & $\begin{array}{c}\text { Reserva } \\
\text { Extrativista } \\
\end{array}$ & Amazonas & Federal & Fase I & 1 \\
\hline 59. RESEX Rio Cajari & 481.650 & $\begin{array}{c}\text { Reserva } \\
\text { Extrativista } \\
\end{array}$ & Amapá & Federal & $\begin{array}{c}\text { Fase II } \\
(\text { Nov./11) } \\
\end{array}$ & 1 \\
\hline 60. RESEX Médio Purus & 604.209 & $\begin{array}{c}\text { Reserva } \\
\text { Extrativista } \\
\end{array}$ & Amazonas & Federal & Fase I & 1 \\
\hline 61. PN Nascentes do Lago Jari & 812.141 & Parque & Amazonas & Federal & $\begin{array}{c}\text { Fase II } \\
(\text { Nov./11) } \\
\end{array}$ & 1 \\
\hline 62. RESEX Ituxi & 766.940 & $\begin{array}{c}\text { Reserva } \\
\text { Extrativista } \\
\end{array}$ & Amazonas & Federal & Fase I & 1 \\
\hline 63. PARNA Mapinguari & 1.776 .914 & Parque & $\begin{array}{c}\text { Amazonas, } \\
\text { Roraima } \\
\end{array}$ & Federal & $\begin{array}{c}\text { Fase III } \\
(\text { Mai./15) } \\
\end{array}$ & 1 \\
\hline 64. RESEX Rio Xingu & 303.841 & $\begin{array}{c}\text { Reserva } \\
\text { Extrativista }\end{array}$ & Pará & Federal & Fase I & 1 \\
\hline 65. RESEX Renascer & 211.741 & $\begin{array}{c}\text { Reserva } \\
\text { Extrativista } \\
\end{array}$ & Pará & Federal & Fase I & 1 \\
\hline 66. ESEC Alto Maués & 668.160 & Estação Ecológica & Amazonas & Federal & $\begin{array}{c}\text { Fase III } \\
\text { (Mai./15) } \\
\end{array}$ & 1 \\
\hline $\begin{array}{l}67 . \quad \text { RESEX Marinha } \\
\text { Mocapajuba/Gestão integrada com } \\
\text { RESEX Mãe Grande Curuça e } \\
\text { RESEX São João da Ponta } \\
\end{array}$ & 21.029 & $\begin{array}{l}\text { Reserva } \\
\text { Extrativista }\end{array}$ & Pará & Federal & $\begin{array}{l}\text { Fase III } \\
(\text { Ago./15) }\end{array}$ & 1 \\
\hline $\begin{array}{l}\text { 68. RESEX Marinha Mestre } \\
\text { Lucindo/Gestão integrada com } \\
\text { RESEX Maracanã; RESEX } \\
\text { Chocoaré-Mato Grosso; RESEX } \\
\text { Cuinarana }\end{array}$ & 26.465 & $\begin{array}{l}\text { Reserva } \\
\text { Extrativista }\end{array}$ & Pará & Federal & $\begin{array}{l}\text { Fase III } \\
\text { (Ago./15) }\end{array}$ & 1 \\
\hline $\begin{array}{l}\text { 69. RESEX Marinha } \\
\text { Cuinarana/Gestão integrada com } \\
\text { RESEX Maracanã; RESEX } \\
\text { Chocoaré-Mato Grosso; RESEX } \\
\text { Mestre Lucindo }\end{array}$ & 11.037 & $\begin{array}{l}\text { Reserva } \\
\text { Extrativista }\end{array}$ & Pará & Federal & $\begin{array}{l}\text { Fase III } \\
\text { (Ago./15) }\end{array}$ & 1 \\
\hline ESEC Samuel & 71.061 & Estação Ecológica & Rondônia & Estadual & $\begin{array}{c}\text { Fase III } \\
\text { (Mai./15) } \\
\end{array}$ & 1 \\
\hline PE Guajará-Mirim & 203.178 & Parque & Rondônia & Estadual & Fase I & 2 \\
\hline ESEC Serra dos Três Irmãos & 89.101 & Estação Ecológica & Rondônia & Estadual & Fase I & 1 \\
\hline $\begin{array}{cc}73 . & \text { RESEX do Rio Pacaas } \\
\text { Novos }\end{array}$ & $342.903,50$ & $\begin{array}{c}\text { Reserva } \\
\text { Extrativista }\end{array}$ & Rondônia & Estadual & $\begin{array}{l}\text { Fase III } \\
(\text { Ago./15) }\end{array}$ & 1 \\
\hline 74. PE Serra dos Reis & 42.287 & Parque & Rondônia & Estadual & $\begin{array}{l}\text { Fase III } \\
\text { (Mai./15) } \\
\end{array}$ & 1 \\
\hline $\begin{array}{l}\text { 75. RESEX estadual Rio } \\
\text { Cautário }\end{array}$ & 146.400 & $\begin{array}{l}\text { Reserva } \\
\text { Extrativista }\end{array}$ & Rondônia & Estadual & $\begin{array}{l}\text { Fase II } \\
\text { (Nov./11) }\end{array}$ & 1 \\
\hline 76. RESEX Rio Preto Jacundá & 95.300 & $\begin{array}{c}\text { Reserva } \\
\text { Extrativista }\end{array}$ & Rondônia & Estadual & $\begin{array}{c}\text { Fase II } \\
(\text { Nov./11) }\end{array}$ & 1 \\
\hline 77. PE Corumbiara & 430.082 & Parque & Rondônia & Estadual & Fase I & 2 \\
\hline 78. PE Chandless & 693.975 & Parque & Acre & Estadual & Fase I & 2 \\
\hline
\end{tabular}




\begin{tabular}{|c|c|c|c|c|c|c|}
\hline 79. RDS Amanã & 2.313 .000 & $\begin{array}{c}\text { Reserva } \\
\text { Desenvolvimento } \\
\text { Sustentável } \\
\end{array}$ & Amazonas & Estadual & $\begin{array}{c}\text { Fase II } \\
(\text { Nov./11) }\end{array}$ & 1 \\
\hline $\begin{array}{l}\text { 80. } \\
\text { Apuí }\end{array}$ & 224.291 & $\begin{array}{c}\text { Reserva } \\
\text { Desenvolvimento } \\
\text { Sustentável } \\
\end{array}$ & Amazonas & Estadual & Fase I & 1 \\
\hline $\begin{array}{l}\text { 81. RDS Bararati/ Mosaico } \\
\text { Apuí }\end{array}$ & 113606 & $\begin{array}{c}\text { Reserva } \\
\text { Desenvolvimento } \\
\text { Sustentável } \\
\end{array}$ & Amazonas & Estadual & Fase I & 1 \\
\hline 82. RDS Cujubim & 2.450 .381 & $\begin{array}{c}\text { Reserva } \\
\text { Desenvolvimento } \\
\text { Sustentável } \\
\end{array}$ & Amazonas & Estadual & $\begin{array}{c}\text { Fase II } \\
(\text { Nov./11) }\end{array}$ & 2 \\
\hline 83. RDS Mamirauá & 1.124 .000 & $\begin{array}{c}\text { Reserva } \\
\text { Desenvolvimento } \\
\text { Sustentável } \\
\end{array}$ & Amazonas & Estadual & $\begin{array}{l}\text { Fase III } \\
\text { (Mai./15) }\end{array}$ & 1 \\
\hline 84. RDS Piagaçú-Purus & 1.005 .280 & $\begin{array}{c}\text { Reserva } \\
\text { Desenvolvimento } \\
\text { Sustentável } \\
\end{array}$ & Amazonas & Estadual & Fase I & 1 \\
\hline 85. RDS Rio Amapá & 214.133 & $\begin{array}{l}\text { Reserva } \\
\text { Desenvolvimento } \\
\text { Sustentável }\end{array}$ & Amazonas & Estadual & Fase I & 1 \\
\hline 86. RDS Uacari & 623.934 & $\begin{array}{c}\text { Reserva } \\
\text { Desenvolvimento } \\
\text { Sustentável } \\
\end{array}$ & Amazonas & Estadual & Fase I & 2 \\
\hline 87. RDS Uatumã & 424.430 & $\begin{array}{l}\text { Reserva } \\
\text { Desenvolvimento } \\
\text { Sustentável }\end{array}$ & Amazonas & Estadual & $\begin{array}{c}\text { Fase II } \\
(\text { Nov./11) }\end{array}$ & 1 \\
\hline 88. RESEX Catuá-Ipixuna & 215.416 & $\begin{array}{c}\text { Reserva } \\
\text { Extrativista } \\
\end{array}$ & Amazonas & Estadual & Fase I & 2 \\
\hline $\begin{array}{ll}89 . & \text { Resex do Guariba/Mosaico } \\
\text { Apuí }\end{array}$ & 150.465 & $\begin{array}{c}\text { Reserva } \\
\text { Extrativista } \\
\end{array}$ & Amazonas & Estadual & Fase I & 1 \\
\hline 90. $\quad$ PE Guariba/Mosaico Apuí & 72.296 & Parque & Amazonas & Estadual & Fase I & 1 \\
\hline $\begin{array}{l}91 . \quad \text { PE Rio Negro Setor } \\
\text { Sul/Gestao integrada com RDS } \\
\text { Puranga Conquista }\end{array}$ & 77.950 & Parque & Amazonas & Estadual & $\begin{array}{c}\text { Fase II } \\
(\text { Nov./11) }\end{array}$ & 1 \\
\hline \begin{tabular}{|ll} 
92. & PE Rio Negro Setor Norte \\
\end{tabular} & 148.634 & Parque & Amazonas & Estadual & Fase I & 2 \\
\hline $\begin{array}{ll}\begin{array}{c}\text { 93. } \\
\text { Apuí }\end{array} & \text { PE do Sucunduri/Mosaico } \\
\end{array}$ & 808.312 & Parque & Amazonas & Estadual & Fase I & 1 \\
\hline 94. RESEX Rio Gregório & 477.042 & $\begin{array}{c}\text { Reserva } \\
\text { Extrativista } \\
\end{array}$ & Amazonas & Estadual & Fase I & 1 \\
\hline 95. RDS do Juma & 589.611 & $\begin{array}{l}\text { Reserva } \\
\text { Desenvolvimento } \\
\text { Sustentável } \\
\end{array}$ & Amazonas & Estadual & $\begin{array}{c}\text { Fase II } \\
(\text { Nov./11) }\end{array}$ & 1 \\
\hline 96. RDS Rio Negro & 102.978 & $\begin{array}{l}\text { Reserva } \\
\text { Desenvolvimento } \\
\text { Sustentável } \\
\end{array}$ & Amazonas & Estadual & $\begin{array}{c}\text { Fase II } \\
(\text { Nov./11) }\end{array}$ & 1 \\
\hline 97. RDS Igapó-Açu & 397.557 & $\begin{array}{l}\text { Reserva } \\
\text { Desenvolvimento } \\
\text { Sustentável } \\
\end{array}$ & Amazonas & Estadual & $\begin{array}{c}\text { Fase II } \\
(\text { Nov./11) }\end{array}$ & 1 \\
\hline 98. Resex Canutama & 197.986 & $\begin{array}{c}\text { Reserva } \\
\text { Extrativista } \\
\end{array}$ & Amazonas & Estadual & $\begin{array}{c}\text { Fase II } \\
(\text { Nov./11) }\end{array}$ & 1 \\
\hline $\begin{array}{l}\text { 99. RDS Matupiri/Gestão } \\
\text { integrada com PE Matupiri }\end{array}$ & $179.083,50$ & $\begin{array}{c}\text { Reserva } \\
\text { Desenvolvimento } \\
\text { Sustentável } \\
\end{array}$ & Amazonas & Estadual & $\begin{array}{l}\text { Fase III } \\
\text { (Ago./15) }\end{array}$ & 1 \\
\hline $\begin{array}{l}100 . \quad \text { PE do Matupiri/Gestão } \\
\text { integrada com RDS Matupiri }\end{array}$ & 513.747 & Parque & Amazonas & Estadual & $\begin{array}{c}\text { Fase II } \\
(\text { Nov./11) }\end{array}$ & 1 \\
\hline
\end{tabular}




\begin{tabular}{|c|c|c|c|c|c|c|}
\hline 101. RDS do Rio Madeira & 283.117 & $\begin{array}{c}\text { Reserva } \\
\text { Desenvolvimento } \\
\text { Sustentável } \\
\end{array}$ & Amazonas & Estadual & $\begin{array}{c}\text { Fase II } \\
(\text { Nov./11) }\end{array}$ & 1 \\
\hline $\begin{array}{l}\text { 102. PE Serra dos } \\
\text { Martírios/Andorinhas }\end{array}$ & 24.897 & Parque & Pará & Estadual & $\begin{array}{c}\text { Fase II } \\
\text { (Nov./11) }\end{array}$ & 1 \\
\hline 103. REBIO Maicuru & 1.151 .760 & Reserva Biológica & Pará & Estadual & $\begin{array}{c}\text { Fase II } \\
(\text { Nov./11) } \\
\end{array}$ & 1 \\
\hline 104. ESEC Grão Pará & 4.245 .819 & Estação Ecológica & Pará & Estadual & $\begin{array}{c}\text { Fase II } \\
(\text { Nov./11) }\end{array}$ & 1 \\
\hline 105. RDS do Iratapuru & 860.184 & $\begin{array}{c}\text { Reserva } \\
\text { Desenvolvimento } \\
\text { Sustentável } \\
\end{array}$ & Amapá & Estadual & $\begin{array}{c}\text { Fase II } \\
(\text { Nov./11) }\end{array}$ & 1 \\
\hline 106. PE Cantão & 100.413 & Parque & Tocantins & Estadual & Fase I & 2 \\
\hline 107. PE Serra Ricardo Franco & 158.621 & Parque & $\begin{array}{c}\text { Mato } \\
\text { Grosso } \\
\end{array}$ & Estadual & $\begin{array}{c}\text { Fase II } \\
(\text { Nov./11) }\end{array}$ & 1 \\
\hline 108. ESEC Rio Ronuro & 102.671 & Estação Ecológica & $\begin{array}{c}\text { Mato } \\
\text { Grosso }\end{array}$ & Estadual & Fase I & 1 \\
\hline 109. PE Igarapés do Juruena & 223.888 & Parque & $\begin{array}{c}\text { Mato } \\
\text { Grosso } \\
\end{array}$ & Estadual & Fase I & 2 \\
\hline 110. Resex Guariba-Roosevelt & 138.092 & $\begin{array}{c}\text { Reserva } \\
\text { Extrativista }\end{array}$ & $\begin{array}{c}\text { Mato } \\
\text { Grosso }\end{array}$ & Estadual & $\begin{array}{c}\text { Fase II } \\
(\text { Nov./11) }\end{array}$ & 1 \\
\hline 111. PE Xingu & 95.024 & Parque & $\begin{array}{c}\text { Mato } \\
\text { Grosso }\end{array}$ & Estadual & Fase I & 1 \\
\hline 112. Esec do Rio Roosevelt & 80.915 & Estação Ecológica & $\begin{array}{c}\text { Mato } \\
\text { Grosso } \\
\end{array}$ & Estadual & $\begin{array}{c}\text { Fase II } \\
(\text { Nov./11) } \\
\end{array}$ & 1 \\
\hline 113. PE Cristalino I e II & 184.900 & Parque & $\begin{array}{c}\text { Mato } \\
\text { Grosso }\end{array}$ & Estadual & Fase I & 2 \\
\hline $\begin{array}{l}114 . \quad \text { RDS Puranga } \\
\text { Conquista/Gestão integrada com PE } \\
\text { Rio Negro Setor Sul }\end{array}$ & 86.233 & $\begin{array}{c}\text { Reserva } \\
\text { Desenvolvimento } \\
\text { Sustentável } \\
\end{array}$ & Amazonas & Estadual & $\begin{array}{c}\text { Fase II } \\
(\text { Dez./14) }\end{array}$ & 1 \\
\hline
\end{tabular}




\section{Anexo 4 - Decretos de criação do Programa Áreas Protegidas da Amazônia - Programa Arpa}

Decreto № 4.326, DE 8 DE AGOSTO DE 2002

\section{DECRETO No 4.326, DE 8 DE AGOSTO DE 2002}

Institui, no âmbito do Ministério do Meio Ambiente, o Programa Áreas Protegidas da Amazônia - ARPA, e dá outras providências.

O PRESIDENTE DA REPÚBLICA, no uso da atribuição que lhe confere o art. 84, inciso VI, alínea "a", da Constituição,

DECRETA:

Art. 1o Fica instituído, no âmbito do Ministério do Meio Ambiente, o Programa Áreas Protegidas da Amazônia - ARPA, a ser desenvolvido com recursos ordinários de programas daquele Ministério da mesma categoria de programação, com recursos oriundos de cooperação internacional internalizados pelo Programa Piloto para a Proteção de Florestas Tropicais do Brasil - PPG7, regulado pelo Decreto no 2.119, de 13 de janeiro de 1997, e com recursos de doação internacional e nacional.

Art. 2o O ARPA tem por finalidade expandir e consolidar a totalidade de áreas protegidas no bioma Amazônia, de modo a assegurar a conservação da biodiversidade na região e contribuir para o seu desenvolvimento sustentável de forma descentralizada e participativa.

Parágrafo único. O ARPA terá caráter estratégico e será executado em articulação com o PPG7.

Art. 3o São objetivos específicos do ARPA:

I - a criação de unidades de conservação de proteção integral e de uso sustentável na região amazônica;

II - a consolidação das unidades de conservação de proteção integral;

III - a manutenção das unidades de conservação de proteção integral e dos serviços de vigilância das unidades de conservação do uso sustentável (reservas extrativistas e reservas de uso sustentável); e

IV - a criação de mecanismos que garantam a sustentação financeira das unidades de conservação de proteção integral e de uso sustentável em longo prazo.

Art. 4o O ARPA será dirigido pelo Comitê do Programa, que terá como membros necessários:

I - o Secretário-Executivo do Ministério do Meio Ambiente, que o presidirá;

II - os Secretários de Coordenação da Amazônia e de Biodiversidade e Florestas do Ministério do III - o Presidente do Instituto Brasileiro do Meio Ambiente e dos Recursos Naturais Renováveis - IBAMA;

IV - um representante do Fórum Estadual de Secretários de Meio Ambiente da Amazônia;

V - um representante da região amazônica, designado pela Associação Nacional de Municípios e Meio Ambiente - ANAMMA;

VI - um representante dos doadores de recursos privados; e

VII - um representante do Fundo Nacional de Biodiversidade - FUNBIO. 
$\S 1$ 1o Na ausência do Secretário-Executivo do Ministério do Meio Ambiente, as reuniões do Comitê do Programa serão presididas pelo titular da Secretaria de Coordenação da Amazônia.

§ 2o O Ministro de Estado do Meio Ambiente poderá designar outros representantes da sociedade civil e do Governo Federal para integrar o Comitê do Programa, de modo a assegurar a paridade do colegiado.

$\S 30$ De acordo com a natureza dos assuntos em pauta, o Comitê do Programa poderá convidar outras pessoas de notável saber para participar das suas reuniões.

§ 4o A participação no Comitê do Programa não será remunerada, cabendo aos órgãos nele representados a prestação de apoio técnico e administrativo aos respectivos representantes.

Art. 5o Ao Comitê do Programa compete, prioritariamente:

I - deliberar sobre o planejamento estratégico do ARPA, estabelecendo procedimentos, diretrizes e critérios para a formalização de convênios e contratos nele previstos;

II - acompanhar e avaliar as atividades do ARPA;

III - articular a participação dos órgãos governamentais e dos governos estaduais da Amazônia no ARPA;

IV - analisar e emitir pareceres sobre os relatórios de desempenho técnico-financeiro;

V - analisar e aprovar o Plano Operativo Anual do ARPA.

Art. 6o O Comitê do Programa, nos noventa dias seguintes à publicação deste Decreto, adotará as providências necessárias para o seu funcionamento.

Art. 7o O Ministro de Estado do Meio Ambiente baixará as normas complementares para a implementação deste Decreto.

Art. 8o Este Decreto entra em vigor na data de sua publicação.

Brasília, 8 de agosto de 2002; 181o da Independência e 114o da República. Meio Ambiente

FERNANDO HENRIQUE CARDOSO

José Carlos Carvalho

Portaria MMA № 187, DE 22 DE MAIO DE 2014

\section{PORTARIA No 187, DE 22 DE MAIO DE 2014}

Institui a terceira Fase do Programa Áreas Protegidas da Amazônia-ARPA, criado pelo Decreto no 4.326, de 8 de agosto de 2002, e define mecanismo de aporte de recursos financeiros.

A MINISTRA DE ESTADO DO MEIO AMBIENTE, no uso de suas atribuições que lhe confere o art. 87 da Constituição da República Federativa de 1988, e tendo em vista o disposto no art. 50 da Lei no 9.985, de 19 de julho de 2000 e no Decreto no 4326, de 8 de agosto de 2002, resolve:

Art. 1o Instituir a terceira Fase do Programa Áreas Protegidas da Amazônia-ARPA, com prazo de duração de 25 anos.

Art. 2o O Programa ARPA, nesta fase, terá por meta consolidar 60 milhões de hectares de Unidades de Conservação no bioma Amazônia, nos âmbitos federal e estadual.

Art. 3o Para a consecução dos seus objetivos e metas, o Programa ARPA apoiará, técnica e financeiramente, o desenvolvimento de estudos à criação de Unidades de Conservação de proteção integral e de uso sustentável.

Art. 4o O Programa ARPA fará uso das seguintes fontes: 
I - recursos ordinários do Ministério do Meio Ambiente e de suas entidades vinculadas;

II - recursos ordinários, materiais e humanos aportados por Governos Estaduais, destinados à manutenção e consolidação de Unidades de Conservação sob sua gestão; e

III - recursos a serem alocados por doações privadas nacionais e internacionais.

$\S 1$ 1o Serão apoiadas, inicialmente, as seguintes categorias de Unidades de Conservação:

I - Estação Ecológica, Reserva Biológica;

II - Parque Nacional e Estadual;

III - Reserva Extrativista; e

IV - Reserva de Desenvolvimento Sustentável.

$\S 2$ o Os recursos provenientes de doação serão geridos conforme disposto em Manual Operacional aprovado pelo Comitê do Programa.

Art. 5o O Ministério do Meio Ambiente, os Parceiros do Programa ARPA e demais membros do Comitê do Programa deverão estabelecer mecanismos financeiros e planejar o aporte gradual de recursos para atender às necessidades de implementação das Unidades de Conservação, no decurso de tempo previsto no art. 1o desta Portaria.

Art. 6o Esta Portaria entra em vigor na data de sua publicação.

IZABELLA TEIXEIRA

Decreto № 8.505, DE 20 DE AGOSTO DE 2015

\section{DECRETO No 8.505, DE 20 DE AGOSTO DE 2015}

Dispõe sobre o Programa Áreas Protegidas da Amazônia, instituído no âmbito do Ministério do Meio Ambiente.

A PRESIDENTA DA REPÚBLICA, no uso da atribuição que lhe confere o art. 84, caput, incisos IV e VI, alínea "a", da Constituição, e tendo em vista o disposto no art. $5^{\circ}$, caput, inciso XI, da Lei $\mathrm{n}^{\circ}$ 9.985, de 18 de julho de 2000,

DECRETA:

Art. $1^{\circ}$ O Programa Áreas Protegidas da Amazônia - ARPA, instituído no âmbito do Ministério do Meio Ambiente, terá os seguintes objetivos:

I - apoiar a criação e a consolidação de unidades de conservação federais e estaduais de proteção integral e de uso sustentável na região amazônica que integram o Programa;

II - auxiliar a manutenção das unidades de conservação federais e estaduais de proteção integral e de uso sustentável na região amazônica que integram o Programa, conforme seus manuais e normas;

III - propor mecanismos que garantam a sustentação financeira das unidades de conservação de proteção integral e de uso sustentável em longo prazo; e

IV - promover a conservação da biodiversidade na região e contribuir para o seu desenvolvimento sustentável de forma descentralizada e participativa.

Art. $2^{\circ} \mathrm{O}$ ARPA terá duração de vinte e cinco anos e será executado mediante: 
I - o aporte de recursos financeiros, materiais e humanos para a manutenção e a consolidação de unidades de conservação;

II - a utilização de recursos ordinários do Ministério do Meio Ambiente e de suas entidades vinculadas, e de recursos recebidos por força de instrumentos celebrados com outros órgãos da administração pública federal direta ou indireta;

III - a captação de recursos de doação nacional e internacional; e

IV - o aporte de bens e serviços por parte de entidades públicas ou privadas.

Parágrafo único. A União desenvolverá mecanismos e planejará o aporte gradual de recursos para atender às necessidades de implementação das unidades de conservação federais integrantes do Programa, no decurso do prazo previsto no caput.

Art. $3^{\circ} \mathrm{O}$ ARPA será dirigido pelo Comitê do Programa, que terá como membros:

I - o Secretário-Executivo do Ministério do Meio Ambiente, que o presidirá;

II - dois representantes do Ministério do Meio Ambiente;

III - o Presidente do Instituto Chico Mendes de Conservação da Biodiversidade - Instituto Chico Mendes;

IV - um representante do Ministério do Planejamento, Orçamento e Gestão;

V - um representante do Ministério da Fazenda;

VI - um representante indicado pelos órgãos estaduais responsáveis pela gestão de unidades de conservação integrantes do Programa, em caráter rotativo;

VII - dois representantes da sociedade civil com relevância social e ambiental na região amazônica; e

VIII - três representantes dos doadores de recursos privados.

$\S 1^{\circ} \mathrm{Na}$ ausência do Secretário-Executivo, as reuniões do Comitê do Programa serão presididas por um dos representantes do Ministério do Meio Ambiente indicados pelo titular da Pasta.

$\S 2^{\circ}$ Os representantes referidos nos incisos IV e V do caput serão indicados pelo respectivo órgão e designados pelo Ministro de Estado do Meio Ambiente.

$\S 3^{\circ}$ Os representantes referidos no inciso VII do caput serão escolhidos por processo similar ao utilizado para a eleição dos representantes do Cadastro Nacional de Entidades Ambientalistas junto ao Conselho Nacional do Meio Ambiente e designados pelo Ministro de Estado do Meio Ambiente.

$\S 4^{\circ}$ Os representantes referidos no inciso VIII do caput serão indicados pelo conjunto de doadores privados, mediante procedimento a ser estabelecido pelo Ministério do Meio Ambiente.

$\S 5^{\circ} \mathrm{O}$ Ministro de Estado do Meio Ambiente poderá designar outros representantes da sociedade civil e do Governo federal para integrar o Comitê do Programa, de modo a assegurar a transparência e o controle social do Programa.

$\S 6^{\circ}$ A participação no Comitê do Programa não será remunerada, cabendo aos órgãos e entidades nele representados a prestação de apoio técnico e administrativo aos seus representantes, ressalvado o custeio de diárias e passagens para os representantes referidos no inciso VII do caput, que poderá correr à conta do Ministério do Meio Ambiente.

Art. $4^{\circ}$ Ao Comitê do Programa compete:

I - deliberar sobre o planejamento estratégico do ARPA e estabelecer procedimentos, diretrizes e critérios para a formalização de convênios e contratos nele previstos;

II - acompanhar e avaliar as atividades do ARPA; 
III - articular a participação dos órgãos da administração pública federal e dos governos estaduais no ARPA;

IV - analisar e emitir pareceres sobre os relatórios de desempenho técnico-financeiro para garantir o alcance das metas do Programa; e

$\mathrm{V}$ - analisar e aprovar o planejamento plurianual do ARPA.

Art. $5^{\circ} \mathrm{O}$ Ministro de Estado do Meio Ambiente editará normas complementares para garantir a execução do disposto neste Decreto.

Art. $6^{\circ}$ Este Decreto entra em vigor noventa dias após a data de sua publicação.

Art. $7^{\circ}$ Fica revogado o Decreto $n^{\circ} 4.326$, de 8 de agosto de 2002.

Brasília, 20 de agosto de 2015; $194^{\circ}$ da Independência e $127^{\circ}$ da República.

DILMA ROUSSEFF

Izabella Mônica Vieira Teixeira 


\section{Anexo 5 - Formulário aplicado ao estudo sobre os Benefícios Sociais das UCs do Programa Arpa e lista das UCs consultadas}

\section{FORMULARIO: \\ BENEFÍCIOS SOCIAIS DAS UCS DO PROGRAMA ArPa PARA AS POPULAÇÕES/COMUNIDADES LOCAIS}

O WWF em parceria com o MMA e ICMBio esta realizando um levantamento para identificar os benefícios sociais das UC para as populações/comunidades locais residentes DENTRO e/ou no ENTORNO destas áreas.

Segundo a constituição Brasileira em seu Art. $6^{\circ}$ :

"São direitos sociais a educação, a saúde, a alimentação, o trabalho, a moradia, o lazer, a segurança, a previdência social, a proteção à maternidade e à infância, a assistência aos desamparados, na forma desta Constituição”.

Neste contexto, esta entrevista tem a finalidade de identificar como as UC (sua criação e implementação/consolidação) contribuem para a o alcance ou manutenção dos direitos sociais de EDUCAÇÃO, SAÚDE, ALIMENTAÇÃO, TRABALHO, MORADIA, LAZER, SEGURANÇA.

\section{- Identificação}

Apta para Entrevista:

Nome da UC:

Área da UC (hectares):

Ano de Criação:

Grupo:

Categoria:

Bioma:

UF:

Municípios:

Entrevistador:

Entrevistado:

Vinculo: ( ) Sociedade Civil ( .) Administração pública

Especificar:

E-mail:

Telefones(s):

Data da entrevista:

Forma de contato: 


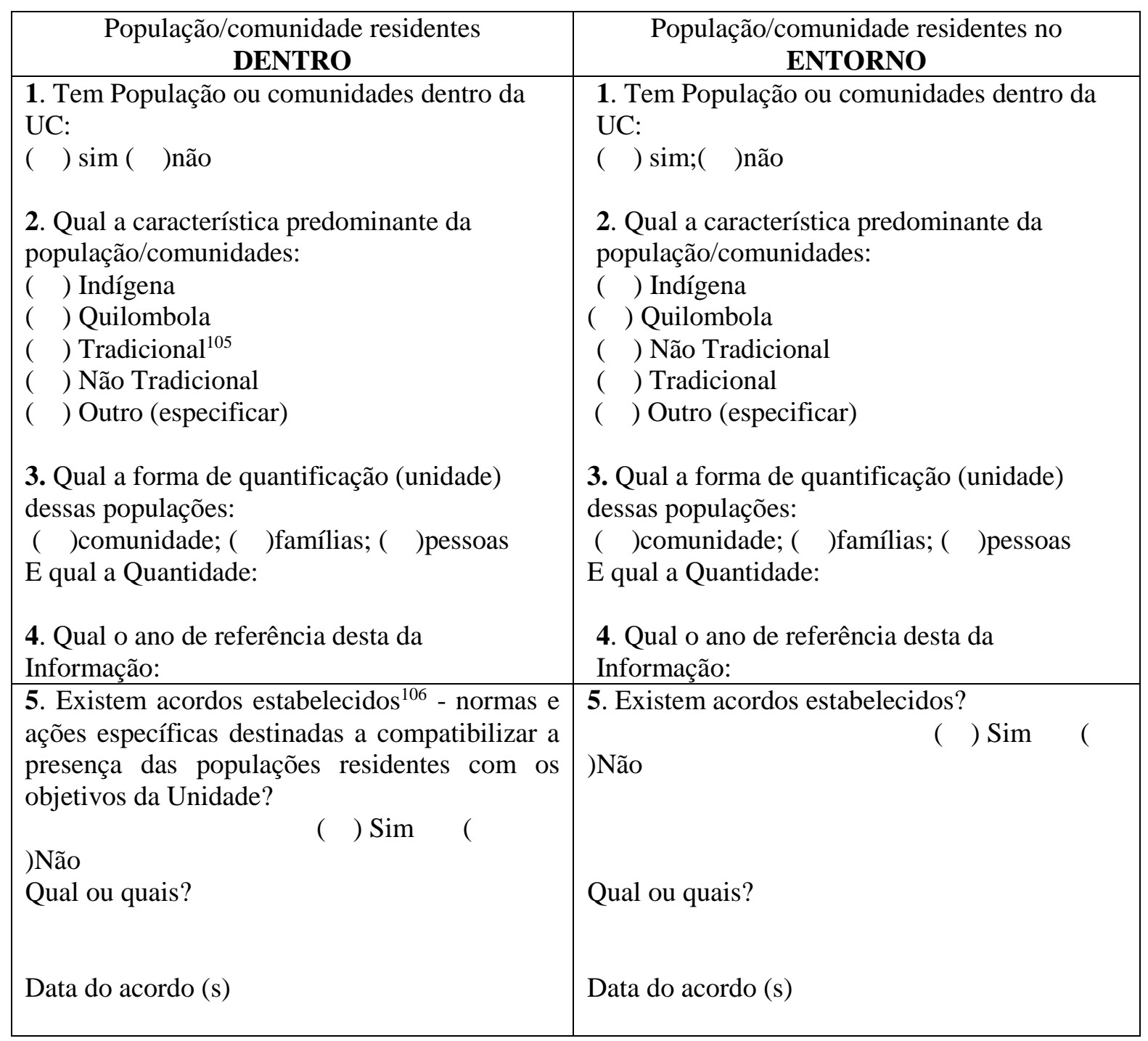

- Contexto de Gestão - as informações abaixo, correspondem a atual situação da UC (dados levantados no CNUC/ Observatório/Entrevista com gestores no período de setembro/2013 a fevereiro/2014).

\footnotetext{
105 Povos e Comunidades Tradicionais: grupos culturalmente diferenciados e que se reconhecem como tais, que possuem formas próprias de organização social, que ocupam e usam territórios e recursos naturais como condição para sua reprodução cultural, social, religiosa, ancestral e econômica, utilizando conhecimentos, inovações e práticas gerados e transmitidos pela tradição (Decreto 6040/2007 - que Institui a Política Nacional de Desenvolvimento Sustentável dos Povos e Comunidades Tradicionais)

${ }^{106}$ Normas e ações específicas destinadas a compatibilizar a presença das populações residentes com os objetivos da Unidade, sem prejuízo dos modos de vida, das fontes de subsistência e dos locais de moradia destas populações, assegurando se a sua participação na elaboração das referidas normas e ações. Tais como:

- Acordos de Gestão

- Termos de Compromisso - condições de permanência das populações tradicionais nas UCs de proteção integral - Decreto 4340/2002 Art. 39

- Concessão do Direito Real de Uso (CDRU) - documento com prazo determinado que legitima nas UC de uso sustentável o uso da terra, moradia e à utilização dos recursos conforme definidos no plano de manejo.
} 
Plano de Manejo:

Numero de funcionários:

Pressão Atual:

Situação fundiária:

Conflito Fundiário:

Contexto regional:
(Fonte: ICMBio/RAPPAM)

(Fonte: ICMBio/RAPPAM)

(Fonte: ICMBio/RAPPAM)

( ) Mosaico

( ) Corredor Ecológico

( ) Outro (especificar:

Desmatamento DENTRO da UC Percepção do Conselho: Percepção do Conselho:

$\begin{array}{llll}\text { ( ) Aumentou ( ) Estável } & (\quad) \text { Reduziu } \\ \text { ( }) \text { Aumentou } & (\text { ) Estável } & (\text { ) Reduziu }\end{array}$

- Qualidade de Vida

6. Qual o impacto da criação e da implementação da UC na qualidade de vida das pessoas que RESIDEM na unidade?

( ) Impacto negativo na qualidade de vida das comunidades residentes

( ) A UC não contribui para a qualidade de vida das comunidades residentes

( ) A UC não contribui para a qualidade de vida das comunidades residentes, mas tem potencial para contribuir

( ) A UC contribui pouco para a qualidade de vida das comunidades residentes

( ) A UC contribui significativamente para a qualidade de vida das comunidades residentes

7. E das pessoas do ENTORNO?

( ) Impacto negativo na qualidade de vida das comunidades residentes

( ) A UC não contribui para a qualidade de vida das comunidades residentes

( ) A UC não contribui para a qualidade de vida das comunidades residentes, mas tem potencial para contribuir

( ) A UC contribui pouco para a qualidade de vida das comunidades residentes

( ) A UC contribui significativamente para a qualidade de vida das comunidades residentes 
- Segurança Territorial - Os indicadores (questões) deste elemento devem dar subsídios para identificar o grau de permanência (direito de uso, moradia e utilização dos recursos) das comunidades/famílias na área da UC.

8. A criação da UC a gestão trouxe mais conflito ou solução em relação a segurança territorial da população residente e do entorno?

\begin{tabular}{|l|l|}
\hline População/comunidade residentes DENTRO & \multicolumn{1}{|c|}{$\begin{array}{c}\text { População/comunidade residentes no } \\
\text { ENTORNO }\end{array}$} \\
\hline ( ) Conflito ( ) Solução & \multicolumn{1}{c|}{ ( ) Conflito ( ) Solução } \\
\hline Se, conflito qual o grau de conflito? & Se, conflito qual o grau de conflito? \\
( ) Muito Alto & ( ) Muito Alto \\
( ) Mediano & $(\quad$ ) Mediano \\
( ) Baixo & ( Baixo \\
\hline
\end{tabular}

9. As negociações e mediações de conflitos são realizadas através do diálogo?

\begin{tabular}{|l|l|}
\hline População/comunidade residentes DENTRO & População/comunidade residentes no \\
ENTORNO
\end{tabular}

- Segurança Alimentar - Os indicadores (questões) deste elemento devem dar subsídios para identificar o grau de dependência das comunidades/famílias, no que diz respeito ao acesso a alimentos/recursos oriundos das UC.

10. Qual a base alimentar das famílias dentro e no entorno da UC? Lista abaixo:

\begin{tabular}{|l|c|}
\hline População/comunidade residentes DENTRO & $\begin{array}{c}\text { População/comunidade residentes no } \\
\text { ENTORNO }\end{array}$ \\
\hline & \\
\hline
\end{tabular}

11. As comunidades são dependentes dos recursos da UC para alimentação?

\begin{tabular}{|c|c|}
\hline População/comunidade residentes DENTRO & $\begin{array}{c}\text { População/comunidade residentes no } \\
\text { ENTORNO }\end{array}$ \\
\hline ( ) Sim ( ) Não & ( ) Sim ( ) Não \\
Se sim, Qual o grau de dependência? & Se sim, Quanto? \\
( ) $70-100 \%$ & ( ) $70-100 \%$ \\
( ) $50-70 \%$ & ( ) $50-70 \%$ \\
( ) $20-50 \%$ & ( ) até $20 \%$
\end{tabular}

12. A criação da UC a gestão trouxe mais conflito ou solução em relação à segurança alimentar da população residente e do entorno? 


\begin{tabular}{|l|l|}
\hline População/comunidade residentes DENTRO & \multicolumn{1}{|c|}{$\begin{array}{c}\text { População/comunidade residentes no } \\
\text { ENTORNO }\end{array}$} \\
\hline ( ) Conflito ( ) Solução & \multicolumn{1}{c|}{ ( ) Conflito ( ) Solução } \\
\hline $\begin{array}{l}\text { Se, conflito qual o grau de conflito? } \\
\text { ( ) Muito Alto }\end{array}$ & $\begin{array}{l}\text { Se, conflito qual o grau de conflito? } \\
\text { ( ) Muito Alto } \\
\text { ( ) Baixo }\end{array}$ \\
& ( ) Mediano \\
\hline
\end{tabular}

- Saúde - Os indicadores (questões) deste elemento devem dar subsídios para identificar os benefícios da UC para a saúde das populações residentes

13. A partir da criação da UC as comunidades DENTRO da UC tiveram maior acesso aos serviços de saúde?

( ) Sim ( ) Não

Como? Pq?

14. A gestão da UC auxilia o acesso das comunidades aos postos/centros de saúde?

( ) Sim ( ) Não

Como? Pq?

15. A UC é fonte direta de abastecimento de água para as comunidades residentes DENTRO e para as comunidades do ENTORNO?

\begin{tabular}{|c|c|}
\hline População/comunidade residentes DENTRO & $\begin{array}{c}\text { População/comunidade residentes no } \\
\text { ENTORNO }\end{array}$ \\
\hline ( ) Não & ( ) Sim \\
\hline
\end{tabular}


16. Você reconhece a UC como vetor (ou facilitador) para o acesso aos serviços de educação? ( ) $\operatorname{Sim}($ ) Não

17. A gestão da UC promove ações de educação ambiental e/ou interpretação ambiental para população residente no INTERIOR e no ENTORNO?

\begin{tabular}{|ll|ll|}
\hline População/comunidade residentes DENTRO & \multicolumn{2}{|c|}{$\begin{array}{c}\text { População/comunidade residentes no } \\
\text { ENTORNO }\end{array}$} \\
\hline ( ) $\quad$ Sim $\quad$ ( ) Não & $(\quad)$ & $\operatorname{Sim} \quad$ ( ) Não \\
\hline
\end{tabular}

18. Você, ou algum membro da sua instituição ou família, já participou de algum evento educacional realizado pela $\mathrm{UC}$ ?

( ) $\operatorname{Sim}($ ) Não

\section{- Postos de Trabalho}

19. Qual a principal fonte de renda de famílias DENTRO e ENTORNO?

\begin{tabular}{|l|c|}
\hline População/comunidade residentes DENTRO & $\begin{array}{c}\text { População/comunidade residentes no } \\
\text { ENTORNO }\end{array}$ \\
\hline & \\
& \\
\hline
\end{tabular}

20. Você, ou algum conhecido está envolvido em alguma atividade remunerada NA OU PELA UC?

( ) Sim ( ) Não

Qual (is) atividade(s)?

\begin{tabular}{|l|l|l|}
\hline Atividades & NA UC & PELA UC \\
\hline & & \\
\hline & & \\
\hline & & \\
\hline & & \\
\hline
\end{tabular}


21. Quanto da renda das famílias residentes e das famílias do ENTORNO depende das atividades realizadas na/pela UC

\begin{tabular}{|l|l|}
\hline População/comunidade residentes DENTRO & \multicolumn{1}{|c|}{$\begin{array}{c}\text { População/comunidade residentes no } \\
\text { ENTORNO }\end{array}$} \\
\hline ( ) $70-100 \%$ & ( $) 70-100 \%$ \\
( ) $50-70 \%$ & ( ) $50-70 \%$ \\
( ) $20-50 \%$ & ( ) $20-50 \%$ \\
( ) $0-20 \%$ & ( ) $0-20 \%$ \\
( ) Não tem conhecimento & ( ) Não tem conhecimento \\
\hline
\end{tabular}

22. Houve incremento da renda familiar com a criação da UC?

\section{( ) Sim ( ) Não}

23. A criação da UC e/ou a sua gestão/implementação facilita/media ações para acesso à politicas públicas de incentivo a geração/complementação de renda?

( ) Sim ( ) Não

Quais?

( ) PAA - Programa de Aquisição de Alimentos da Agricultura Familiar
( ) PAE Programa de Apoio à Comercialização de Produtos do Extrativismo
( ) ATER Assistência Técnica e Extensão Rural
( ) PRONAF Programa Nacional de Fortalecimento da Agricultura Familiar -
( ) PNAE Programa Nacional de Alimentação e Nutrição do Escolar/FNDE
( ) DAP Acesso a Declaração de Aptidão ao Pronaf - DAP ${ }^{107}$
( ) REB Cadastro na Relação de Extrativistas Beneficiários
( ) Outros:

- Lazer e Recreação - Os indicadores (questões) deste elemento devem dar subsídios para identificar se a UC é utilizada como espaço de recreação, lazer e turismo

24. A área da UC é utilizada pela população RESIDENTE e pela população do ENTORNO, como espaço de lazer e recreação?

\begin{tabular}{|l|l|l|}
\hline \multicolumn{2}{|l|}{ População/comunidade DENTRO } & \multicolumn{2}{|l|}{ População/comunidade ENTORNO } \\
\hline$(\quad) \quad \operatorname{Sim}($ ) Não & $($ Sim $\quad(\quad)$ Não \\
\hline
\end{tabular}

25. Os gestores da UC incentivam a comunidade local a realizar atividades de turismo e recreação dentro da UC?

( ) Sim ( ) Não

107 Conceitos Relevantes

DAP - Declaração de Aptidão ao Programa Nacional de Fortalecimento da Agricultura Familiar é o instrumento utilizado para identificar e qualificar as Unidades Familiares de Produção Rural e suas formas associativas organizadas em pessoas jurídicas.

Unidade Familiar de Produção Rural - é o conjunto composto pela família e agregados denominados, em seu conjunto, como "agricultores familiares", que exploram uma combinação de fatores de produção com a finalidade de atender à demanda interna por alimentos e outros bens que contribuem para o abastecimento da sociedade brasileira e na geração de divisas. 
- Segurança - Os indicadores (questões) deste elemento devem dar subsídios para identificar se a UC auxilia na proteção das comunidades locais e do entorno

26. A partir da criação da UC as comunidades DENTRO da UC tiveram maior acesso aos serviços de segurança e proteção?

( ) $\operatorname{Sim}($ ) Não

- Governança - Os indicadores (questões) deste elemento devem dar subsídios para identificar a contribuição da UC como vetor de implementação de politicas publica.

\section{Conselho Gestor:}

Ano de criação do Conselho:

Portaria:

Situação do conselho (ativo/inativo/em formação):

Número de reuniões (anuais):

Ano da ultima renovação:

Renovação com Portaria: ( )SIM ( )Não

27. Existe uma boa comunicação entre a equipe gestão da UC e a comunidade local?

$$
\text { ( ) Sim ( ) Não }
$$

28. As instancias de participação e gestão da UC (Conselho)contribuem para discussão e definição de encaminhamentos que possibilitem melhorias nas áreas de Saúde , Educação e Segurança Territorial (moradia), Alimentação, e Proteção?

( ) Sim ( ) Não

Para que áreas:

$$
\begin{aligned}
& \text { ( ) Saúde } \\
& \text { ( ) Educação } \\
& \text { ( ) Segurança Territorial } \\
& \text { ( ) Alimentação } \\
& \text { ( ) Proteção }
\end{aligned}
$$

